\title{
Who Wants to Run? \\ How the Devaluing of Political Office Drives Polarization
}

Book Manuscript

October 23, 2016

Andrew B. Hall

Stanford University

andrewbenjaminhall.com 


\section{Contents}

Introduction: Those Fittest for the Trust i

1 Ideological Divergence and the Rigidity of Candidate Positions 1

1.1 The Median Voter Theorem and Fluid Candidate Positions . . . . 5

1.2 Research Focuses on Voter-Driven Polarization . . . . . . . . . . 6

1.3 Why So Much Divergence? . . . . . . . . . . . . . . . . . . 11

1.4 Why Candidates May Be Ideologically Rigid . . . . . . . . . . . . 15

1.5 Measuring Candidate Ideology Using Contributions . . . . . . . . 20

1.6 U.S. House Candidates' Positions: Stable Over Time . . . . . . . 29

1.7 Long-Term Effects of Elections on Roll-Call Votes . . . . . . . . . 32

1.8 Incumbents Do Not Adjust Positions Based On Primary Challenges 34

1.9 Candidate Identity Linked to Candidate Positions . . . . . . . . . 37

1.10 When Do Candidates Change Positions? . . . . . . . . . . . . . . 40

2 Polarized Candidates and Constrained Voters 51

2.1 Studying the Links Between Ideology and Electoral Success . . . . 53

2.2 Voters Tend to Prefer Moderate Candidates . . . . . . . . . . . . 59

2.3 Moderates Not Running for Office . . . . . . . . . . . . . . . . 81

2.4 Who Runs in Broader Context . . . . . . . . . . . . . . . . 88

3 Who Wants to Run: A Theory 103

3.1 A Thought Experiment . . . . . . . . . . . . . . . . . . . . . 104

3.2 Who Wants to Run? . . . . . . . . . . . . . . . . . . . 113

3.3 A Theory of Who Runs . . . . . . . . . . . . . . . . . 119

3.4 The Interaction of Voters and Candidates . . . . . . . . . . . . . . 127

3.5 Primary Elections' Role in Polarization . . . . . . . . . . . . . . . 129

4 The Devaluing of Office and Polarization:

$\begin{array}{ll}\text { Empirical Evidence } & 143\end{array}$

4.1 How Costs Deter Moderates from Running . . . . . . . . . . . . . 148

4.2 How Benefits Encourage Moderates to Run . . . . . . . . . . . . . 155

4.3 The Rising Costs of Running for Office . . . . . . . . . . . . . . . 175

4.4 The Falling Benefits of Holding Office . . . . . . . . . . . . . . . . 182

4.5 Decreasing the Costs of Running for Office . . . . . . . . . . . . . 189 
CONTENTS

5 Conclusion: Good Government from Reflection and Choice 210

5.1 Ben Franklin's Dated Views on Legislative Salaries . . . . . . . . 219

5.2 Designing Institutions to Attract Effective Representatives . . . . 222

5.3 Who Will Run? Our Future Candidates . . . . . . . . . . . 226 


\section{List of Figures}

1.1 The Rigidity of Candidate Positions: Lack of Changes From Candidates' First to Second Campaigns. Plots estimates of first- and second-term candidate ideology based on dynamic CFScores for U.S. House Candidates, 1980-2012, who run for election at least twice. As the horizontal lines show, candidates' estimated positions rarely change. . . . . . . . . . . . . . .

1.2 The Rigidity of Candidate Positions: The Distribution of Changes From Candidates' First to Second Campaigns. Plots estimated change in candidate ideology based on dynamic CFScores for U.S. House Candidates, 1980-2012, who run for election at least twice. The vast majority of candidates display almost

1.3 The Rigidity of Candidate Positions: Evidence from Candidate Careers. Compares dynamic CFScores for a candidate in an election at time $t$ to her previous dynamic score at $t-1$, for U.S. House Candidates, 1980-2012. Previous ideology is an extremely strong predictor of current ideology. . . . . . . . . . . . . .

1.4 Incumbents Do Not Respond to Primary Challenger Positions. The plots present how much incumbents of each party in U.S. House races, 1980-2012, change their ideological positions in response to varying positions of their primary challengers. There appears to be no relationship between challenger position and changes in incumbent positions.

1.5 Candidate Ideology by Gender and Party. Among candidates for the U.S. House, 1980-2012, women hold more liberal positions than men of the same party, on average.

2.1 Studying Candidate Positions When Median Voter is Unobserved but Held Constant. . . . . . . . . . . . . . . . . . . 61

2.2 Studying Candidate Positions When Median Voter is Unobserved and Not Held Constant. . . . . . . . . . . . . . . 62

2.3 Studying Candidate Positions When Median Voter is Unobserved but Held Constant: the Midpoint Approach. . . 64 
2.4 The Electoral Success of Moderate Candidates, U.S. House, 1990-2012. Plots the proportion of U.S. House candidates who win election across binned averages of the estimated ideological distance between the candidate and her district, using CFScores. .

2.5 The Electoral Success of Moderate Candidates By Party, U.S. House, 1990-2012. Plots the proportion of U.S. House candidates by party who win election across binned averages of the estimated ideological distance between the candidate and her district, using CFScores. . . . . . . . . . . . . . . . .

2.6 The Electoral Success of Moderate Candidates In OpenSeat Races, U.S. House, 1990-2012. Plots the proportion of U.S. House candidates who win election in open-seat races across binned averages of the estimated ideological distance between the candidate and her district, using CFScores. . . . . . . . . . . .

2.7 Using Primaries to Study Candidate Selection Across Ideology. . . . . . . . . . . . . . . . . . . . . . . . 72

2.8 The Penalty to Nominating Extremists, U.S. House, 19802012. When extremists barely win competitive primaries (just to the right of the vertical line in the middle of the plot), their party does much worse in the general election than when they just barely lose and the more moderate candidate wins the nomination (just to the left of the vertical line). . . . . . . . . . . . . . .

2.9 The Growing Extremism of U.S. House Candidates, 19802010. In both parties, those running for the U.S. House have become more ideologically extreme over time. . . . . . . . . .

2.10 The Growing Polarization of U.S. House Incumbents and New Candidates, Respectively, 1980-2010. Each line is the absolute difference in average CFScores across the two parties for the relevant candidate group, by year. Incumbent polarization has grown in step with the candidate supply. . . . . . . . . . . . . the Least Extreme Candidates in U.S. House Districts, Across Eras. While already a polarized era, more districts had choices between ideologically similar candidates in the 1980s than they have in the 2000s. . . . . . . . . . . . . . . . .

2.12 Average Ideology of State Legislators Who Run for the U.S. House Candidates by Party, 1996-2010. There is a pronounced ideological divergence among state legislators who run for the U.S. House. . . . . . . . . . . . . . . . . . . . . 87 
2.13 State Legislator Extremism and the Propensity to Run for the House, 1996-2010. More extreme state legislators are more likely to run for the House than are more moderate state legislators. . . . . . . . . . . . . . . . . . . . . . 89

2.14 Who Runs for Office Over Time, U.S. Senate, 1980-2012. 90

2.15 Average Polarization of U.S. Senate Incumbents and New Candidates, Respectively, 1980-2012. . . . . . . . . . . 91

2.16 Who Runs for Office Over Time, U.S. State Legislatures, 1990-2012. . . . . . . . . . . . . . . . . . . 92

2.17 Who Runs for Office Over Time by State, U.S. State Legislatures, 1990-2012. . . . . . . . . . . . . . . . . 94

2.18 Who Runs for Office Over Time, U.S. Statewide Offices, 1990-2012 . . . . . . . . . . . . . . . . . . 95

3.1 Alice and Bob Each Decide Whether or Not to Run for Office.

3.2 Moderates, Extremists, and Running for Office. Moderates facing each other would rather drop out; extremists facing each other constitute an equilibrium. . . . . . . . . . . . . . . . . 124

3.3 Divergence in Two-Candidate Equilibria. . . . . . . . . . . 138

3.4 Divergence in Two-Candidate Equilibria with a Uniform Distribution of Voters. . . . . . . . . . . . . . . . 139

4.1 State Legislators Consider Costs When Choosing Whether to Run for the U.S. House, 1994-2012. Would-be candidates for the House are sensitive to the costs of running. State legislators are twice as likely to run for the House when they can do so without giving up their current seat. . . . . . . . . . . . . . . 150

4.2 Moderate State Legislators More Sensitive to Costs. The left panel plots the relationship between extremism and the propensity to run for the U.S. House for state legislators, 1994-2012, who have to give up their seat in order to run; the right panel plots the same relationship for state legislators who do not have to give up their seat. Extremists are more likely than moderates to run when costs are high (left panel), but this relationship goes away when costs decrease (right panel). . . . . . . . . . . . . . . . . . 152 


\section{LIST OF FIGURES}

4.3 Moderate State Legislators More Sensitive to Costs. The shaded gap between the two lines represents the difference in the probability of running for the House, 1994-2012, between state legislators who can run without giving up their seat and those who must give up their seat to run. This effect is large for moderate legislators (left part of the plot) but zeros out for extreme legislators (right part of the plot). Moderates are more sensitive to this

4.4 Lower Benefits Deter Moderates: Incumbency and the Ideology of Subsequent Candidates, U.S. House, 19802012. Both parties field more ideologically extreme candidates, on average, in seats they lost in the last election than in seats they Lower Benefits Deter Moderates: Incumbency and the Ideology of Subsequent Candidates, U.S. House, 19802012. The candidate pool is more extreme after elections in which the other party barely wins office (left of discontinuity) than after elections in which the party barely wins office (right of discontinuity). The figure uses the Democratic party as the reference party, but results are essentially identical focusing on the Republican party instead.

4.6 Meme Opposing Legislator Salary Raises, May 2014. . . . 160

4.7 Salaries in U.S. State Legislatures as of 2012. . . . . . . . . 164

4.8 Moderating Effect of Alaska's Increase in State Legislator Salaries. Plots the polarization of candidates running for the Alaskan state legislature, over time, compared to a synthetic control version of Alaska. Alaska's large salary increase, put into place in 2010, appears to have substantially reduced polarization in the candidate pool in 2012. . . . . . . . . . . . . . . . . . . . . 168

4.9 Legislator Salaries and Candidate Ideologies in State Legislatures, 1990-2012. When states increase legislator salaries, the candidate pool becomes less polarized. . . . . . . . . . . . 170

4.10 Legislator Salaries and Polarization in State Legislatures. When states increase legislator salaries, the legislature becomes less polarized. . . . . . . . . . . . . . . . . . 172

4.11 The Rising Costs of Campaigning. Candidates for the U.S. House are forced to raise more money from more donors than ever before.

4.12 U.S. House Salaries Over Time, Adjusted for Inflation. In real terms, members of the US. House are paid 33\% less today than in 1969. 
LIST OF FIGURES

4.13 Centrism and Primary Vote Share Across Media Information. Moderates are disadvantaged in low information districts, but this disadvantage is erased in higher-information districts. . . 195 


\section{List of Tables}

1.1 Incumbents Do Not Shift Positions in Response to Extremist Primary Challenges. . . . . . . . . . . . . . . 46

1.2 Incumbents Do Not Shift Positions in Response to Extremist Primary Challenges: Including Only Ideologically Distinct Challengers. . . . . . . . . . . . . . . . . . . . 48

1.3 Women Candidates Hold More Liberal Positions Than Male Candidates, On Average. . . . . . . . . . . . . . . 49

2.1 Comparing the Ideology of Winning and Losing Candidates, U.S. House, 1980-2012. . . . . . . . . . . . . . . . . 98

2.2 The Penalty to Nominating Extremists. . . . . . . . . . 100

2.3 The Penalty to Nominating Extremists: Evidence from State Legislatures. . . . . . . . . . . . . . . . . . . . . . . 101

2.4 State Legislator Extremism and the Propensity to Run for the House. . . . . . . . . . . . . . . . . . . . . . . . . 102

3.1 Alice's and Bob's Decision to Run Depends on Costs and Benefits. . . . . . . . . . . . . . . . . . . . . . 110

3.2 When Costs are High, Bob Runs but Alice Doesn't. . . . 111

3.3 When Costs are Low, Alice Runs and Wins. . . . . . . . . 112

4.1 Potential Candidates Are More Likely to Run When Costs Are Lower. . . . . . . . . . . . . . . . . . . . . 200

4.2 Moderates Are More Sensitive to Costs Than Are Extremists. . . . . . . . . . . . . . . . . . . 202

4.3 Effect of Party Incumbency on Ideological Composition of Out-Party Candidate Pool in Next Election Cycle. . . . . 204

4.4 Higher Salaries Decrease Polarization of Candidate Pool, U.S. State Legislatures, 1990-2012. . . . . . . . . . . . 206

4.5 Higher Salaries Decrease Polarization of Legislature. . . . 207

4.6 District-level Information and Voting for Primary Candidates. More informed districts support less extreme primary candidates. . . . . . . . . . . . . . . . . . . . . 209 


\section{Introduction: Those Fittest for the Trust}

And of what kind are the men that will strive for this profitable preeminence, through all the bustle of cabal, the heat of contention, the infinite mutual abuse of parties, tearing to pieces the best of characters? It will not be the wise and moderate, the lovers of peace and good order, the men fittest for the trust. ${ }^{1}$

$$
\begin{array}{r}
- \text { Benjamin Franklin, } \\
\text { Dangers of a Salaried Bureaucracy }
\end{array}
$$

You'd have to be crazy to run for Congress.

- Steven Latourette $(\mathrm{R}-\mathrm{OH})$, interviewed on "The Daily Show"

Imagine you're in charge of hiring people at a major company, a place like Google or Apple, let's say. To keep the company's business humming, you need to hire talented employees. How do you advertise job openings to attract talent? You'd probably start by stressing that the opportunity is an exciting one, with the chance to solve interesting problems quickly to make a valuable product. You'd probably say that yours is a great company to work for, with a bright future and a high regard for its employees. Most importantly, you'd probably offer competitive compensation to convince good candidates to join your team.

\footnotetext{
${ }^{1}$ Throughout the book, I will quote from some old texts in which politicians are, unfortunately, assumed to be men. Although I will leave these quotes unaltered for accuracy, in my own prose I will use the pronouns "she" and "her" to refer to generic candidates and politicians throughout.
} 
Here are a few things you probably wouldn't do. You wouldn't offer a salary substantially below the market rate for someone with the talent, training, and experience that you're looking for. You wouldn't create a policy of publicizing the embarrassing missteps that potential employees make during their job interviews. You wouldn't criticize applicants' family members as part of your interview process. And above all else, you would not make the job an irritating one, one that by its very nature prevents its possessor from getting anything done and that regularly makes him or her look like a buffoon to friends and colleagues. This should be obvious. Creating a job that pays below market rates, that offers fewer perks than competing jobs, and that promises a worse work experience with a worse work-life balance than your competitors, is a perfect formula for finding only the worst possible employees, the ones so woefully unqualified for the other, better jobs your competitors are offering that they're willing to take a stab even at your job. You're not looking for bad employees, so you don't offer a job like that.

Any job that seeks talented, highly trained employees who possess specialized skills, but that offers little to attract these individuals, is doomed to fail from the start. And yet, this is exactly the job we, the American people, have created for our politicians. We have created a job so full of humiliating obligations, so difficult to obtain and to hold, so underpaid relative to other opportunities for high-skilled individuals, and so generally horrible, undignified, and demeaning, that, in the words of one former member of Congress, "you'd have to be crazy" to take it. We've created this warped job. We've shaped it with the harrowing campaigning and fundraising structure we've endorsed, with the endless parade of media reports about candidates' personal lives and obvious misstatements that 
we consume with gusto, and with the below-market wage we insist on paying our legislators despite the specialized requirements of their job. And now that we've created a job that "you'd have to be crazy" to want, we complain that our legislature seems to have gone mad.

The point of this book is that if we want to understand how our legislatures have become so polarized and dysfunctional, we need to take a good, hard look at the job we're asking our legislators to perform. The more unpleasant we make the job description, the more we ensure that, by and large, only the ideologically extreme on both sides of the aisle will be willing to apply.

If we want more moderate legislators in office, we need to make them a better job offer.

\section{Running Harder for a Worse Job}

On November 16th, 2013, newly elected Democratic members of Congress sat down to view a presentation by the Democratic Congressional Campaign Committee (DCCC) on how they should allocate their time as first-term incumbents in the U.S. House. On a slide entitled "Model Daily Schedule," the presenter suggested that new members should plan to dedicate 4 hours per day to "Call Time," time set aside for making fundraising calls, and another 1 hour per day to "Strategic Outreach," other forms of in-person fundraising. This is a tremendous amount of time to devote to an activity that is almost uniformly regarded as abhorrent. Reacting to the slides, Congressman John Larson (D-CT) told the Huffington Post, "You might as well be putting bamboo shoots under my fin- 
gernails." ${ }^{2}$ Describing the off-site call centers that members of Congress use for these activities, Peter DeFazio (D-OR) told This American Life: "If you walked in there, you would say, boy, this is about the worst looking, most abusive call center situation I've seen in my life." ${ }^{3}$ Donna Edwards (D-MD) summed up the current state of legislative politics in an interview with Esquire: "It's a neverending hustle. You get elected to this august body to fix problems, and for the privilege, you find yourself on the phone in a cubicle, dialing for dollars." 4

Fundraising, that "disgusting, degrading, demeaning experience" as Hubert Humphrey once called it, ${ }^{5}$ is only one of the many burdens members of Congress must bear. Opportunities to legislate - ostensibly the job MCs are sent to Washington to do - are few and far between. The signs of this gridlock are everywhere. Not only are legislators getting less done, but they are acting more hostile towards one another, socializing with each other less, spending less time in Washington, and even polarizing in the language they use on the floor of Congress (Gentkow, Shapiro, and Taddy 2015). These facts weigh on the minds of our legislators. In explaining her decision to quit politics, moderate Senator Olympia Snowe (R-ME) pointed to the "dysfunction and political polarization" of Congress. ${ }^{6}$ Discussing the departures of moderate legislators, Senator Michael Bennett (D-

\footnotetext{
${ }^{2}$ http://www .huffingtonpost.com/2013/01/08/call-time-congressional-fundraising_ n_2427291.html, Accessed February 3, 2015. Note that Larson is a long-time member of Congress, not one of the first-year members there to view the presentation.

${ }^{3}$ http: //www.thisamericanlife.org/radio-archives/episode/461/transcript, Accessed February 3, 2015.

${ }^{4}$ http://www .esquire.com/news-politics/news/a23553/congress-living-hell-1114/, Accessed June 20, 2015.

${ }^{5}$ As quoted in Francia and Herrnson (2001).

${ }^{6}$ http: //www . washingtonpost . com/opinions/olympia-snowe-why-im-leaving-thesenate/2012/03/01/gIQApGYZlR_story.html, Accessed February 3, 2015.
} 
CO) lamented that "There are a number of folks who don't want to come here and participate in the dysfunction." 7

This dysfunction is not just frustrating but embarrassing to legislators. In approval surveys, Americans rank their legislators somewhere between venereal diseases and mosquitoes. These surveys are surely overblown, but the central point is clear: being a member of Congress is more often a source of embarrassment than of pride. Running for office today is seeking to gain the right to disappoint angry people on a regular basis.

Yet even to gain the right to bear these burdens, would-be members of Congress must first endure an often grueling campaign both for the nomination and for election to office. In addition to the daunting fundraising requirements of campaigning, these elections place tremendous scrutiny on candidates' lives - not only on their careers as politicians and public servants, but on the details of their personal lives and the minute wording of their every public utterance. Reflecting on the 1987 Gary Hart scandal in his recent book, Matt Bai wrote, in memorable prose, that the scandal was "the harbinger of an age when the threat of instant destruction would mute any thoughtful debate, and when even the perception of some personal imperfection could obliterate, or at least eclipse, whatever else had accumulated in the public record." With each passing campaign, as the internet and social media play a larger and larger role in politics, this age of "instant destruction" reaches new heights. For this reason, and for many others, too,

\footnotetext{
${ }^{7}$ http://www. washingtonpost.com/opinions/bennet-joins-flight-of-the-moderates/ 2012/02/29/gIQAqhKBjR_story.html, Accessed February 3, 2015.
} 
"electoral politics is a brutal, soul-sucking experience for a candidate" 8 as one unsuccessful candidate, Taylor Griffin, put it.

The profound costs of running for Congress, and of being in Congress, have not gone unnoticed. Almost daily, we hear further news about the historic unpopularity of Congress, the gridlock of Congress, and the difficulties of running for Congress. At least four major news outlets have run articles in the past two years with the headline "Why Would Anyone Run For Congress?" or an extremely similar variant. ${ }^{9}$

If we want to understand why our legislatures have become so polarized and what we can do about it, we must answer this question.

\section{Why Would Anyone Run For Congress?}

Why would anyone run for Congress? The question is obviously an important one, yet it has received short shrift in the broad academic literature on democratic governance. Democracy relies on individuals to stand up and represent their fellow citizens, and it depends on their quality for its success. But there is a pervading sense - among journalists, politicians, and political observers - that running for Congress has never been more difficult or more costly than it is today, that being in Congress has rarely, if ever, been so frustrating as it is today, and that, as a result, only a particular set of people with a particular set of beliefs are willing to stand for office today.

\footnotetext{
${ }^{8}$ http://www.realclearpolitics.com/articles/2013/10/24/why_would_anyone_run_ for_congress_these_days.html, Accessed February 3, 2015.

${ }^{9}$ These outlets are: RealClearPolitics, The Atlantic, The National Journal, and MSNBC. Found via Google search for the phrase "Why Would Anyone Run For Congress", Accessed February 3,2015 .
} 
Despite this sense, pre-eminent political science theories of the electoral process focus on the positions strategic candidates choose to take after entering the race, taking for granted that people want to run for office (Downs 1957). By stressing the fluidity of candidate positions - and demonstrating as a consequence of this fluidity an inexorable movement towards the views of the median voterthese theories need not speak of who the candidates are. Who runs for office is not important in the theoretical world in which anyone can adopt the median voter's views during a campaign - a hypothetical world in which candidates are generic.

This logic - which, to be clear, has been immensely helpful for studying many political topics - underpins the literature on legislative polarization in American politics, too. The growth of polarization in U.S. legislatures is well known (McCarty, Poole, and Rosenthal 2006), and many scholars have put forward plausible factors that contribute to it. Almost all of these factors are voter-centric; they study how voters' views have changed over time, or the ways that institutional rules translating voters' views through elections have changed. Implicitly, they argue that strategic politicians must follow their voters, and as a result must match their constituents' changing and polarizing views in order to win or maintain office. This strategic need, voter-centric theories imply, creates a causal link between the polarizing views of voters (the cause) and the polarization of the legislature (the effect). This link is plausible and important. I will not argue that we should dismiss it, but rather, that it is only part of the story.

Indeed, candidates do not match voters' views so readily. Real candidates in real elections cannot or will not adopt new positions so quickly or change old ones so easily. Building on a longstanding literature, I will show that candidate 
positions are more rigid than fluid, and as a result, I will focus not just on what voters want but on who runs. Candidates come to political campaigns with all manner of pre-existing ideological commitments. They have expressed views that they must now hold on to; they have pursued professions that may carry an ideological signal for elites and voters; they have, perhaps, participated in political campaigns, donated to political campaigns, or registered with a party in previous elections, all of which are matters of public record; and they have developed personal commitments to policy positions, commitments strong enough to compel them to run for office in the first place. What is more, voters may punish candidates for changing views, for "flip-flopping" or "waffling" as it's sometimes called. Even if candidates want to change positions, they may find themselves unable to do without facing severe electoral harm in many cases. In short, candidates have many reasons to stick to their views.

This is one reason why who runs matters. Candidates fundamentally constrain voters. Voters are free to choose any of the candidates who run for office, but they cannot elect someone who does not run. Although voters tend to prefer ideologically moderate politicians, a claim for which I offer new evidence in this book, if they are faced with a choice between only ideological extreme candidates, they cannot send a moderate representative to office and they cannot turn a more extreme candidate into a more moderate candidate. If only extremists want to run for office, then voters can only elect extremists.

So, who wants to run? People considering running for office make cost-benefit calculations. They enjoy benefits from holding office if they win, but they must pay costs to run. If these costs are too high, or if the benefits of holding office are too low, some will choose not to run. And because these costs and benefits 
do not affect all potential candidates equally, who chooses to run can create polarization. Following the logic of so-called citizen-candidate models, I will argue that more ideologically extreme citizens are generally more willing than moderate citizens to bear the costs of running, not necessarily because they place different psychological weights on the costs and benefits but rather because they differ more from their opponents, ideologically. More extreme people are more loathe to let an opponent from the other side of the ideological spectrum win office. As a consequence, more relatively ideologically extreme people - and fewer moderates, who are more ambivalent about the positions of the other party's candidateswill still be willing to run when costs are high or benefits are low. Voters, in turn, will be unable to elect more moderate representatives even if they would like to. The more we devalue political office, the more we will deter moderates from running.

Voters have no doubt contributed to polarization, but the devaluing of political office - the rising costs and falling benefits - also drives polarization. These changes have been well documented, as the earlier anecdotes and quotes suggested. Campaigning has become an increasingly arduous duty, consuming all of a candidate's waking hours. The ceaseless need to raise ever more money from ever more donors sucks up most of candidates' days. The media's ever-increasing scrutiny on seemingly inane details of candidates' personal lives, not just on their romantic dalliances but, for example, on the contents of college essays written twenty or thirty years ago, contributes all the more to this growing unpleasantness. And the moment a member of Congress wins election, she must turn immediately to the task of running for reelection. 
In return for these costs, what benefits do our legislators receive once in office? Fewer than you might think. The last forty years have witnessed a dramatic restructuring of our legislatures. Where once committees dominated, allowing individual members to participate in the policymaking process through service on particularized committees, party leadership now dominates. As one anonymous member of Congress puts it, "congressional committees are a waste of time." 10 He or she continues, "Why try to get on a good committee if you have already ceded authority to your unelected, unaccountable party leaders?" Indeed, major legislation no longer treads its familiar path from committees, then to chambers, and then to the conference committee. Instead, party leaders negotiate directly, "ping-ponging" legislation between the chambers and passing it in identical form with little chance for individual legislators to influence the bill's content. Serving in office today seems to be much more akin to being a foot soldier for the party. Changes for individual legislators to blaze their own trails are scant.

Making exactly this argument about the changing benefits of serving in the U.S. House, Thomsen (2016) shows that the set of state legislators running for the House have gotten more extreme over time, and that moderate House members are retiring at higher rates. Thomsen uses this evidence to argue that moderates are "Opting Out" of politics because they do not fit in well with our polarized legislatures. The House no longer offers moderate legislators the same chances to force a successful, rewarding career in politics.

At the same time, we now pay our legislators far less than we used to. I do not mean to heap pity on our sitting legislators; they are doing just fine, financially. But this is part of the problem. We pay our legislators so little, relative to the

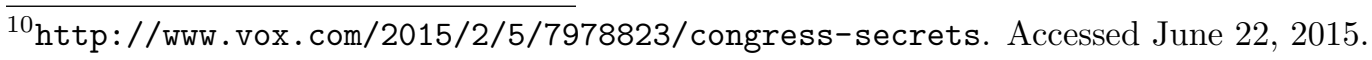


amount of training required to be a viable candidate for the job, that only the wealthy can afford to run. Who among the wealthy chooses to run? Most likely, it is the people who hold extreme views and see the job as an opportunity to push their ideological agenda in the legislature. The less we pay our legislators, I

argue, the more our candidate pool will consist of wealthy people who can afford to work for little pay in return for the opportunity to take ideological positions in the legislature.

Over the past fifty or so years, we have dramatically devalued political office. With one hand we have made it harder to obtain legislative office while, with the other, we have made winning office less valuable. The devaluing of office means that, by and large, only ideologically extreme candidates run. And because candidate positions are not nearly as fluid as theories might suppose, the fact that only these candidates run for office constrains the ideological options voters receive. The devaluing of office leaves voters, in many cases, to elect extremists even though they prefer moderates.

\section{Enhancing Political Office to Depolarize Legisla- tures}

Devaluing political office polarizes our legislatures by polarizing the candidate pool. By the same token, revaluing political office should depolarize our legislatures. How might we accomplish this?

A basic way to enhance office is to pay legislators more, even though I am well aware how politically unpopular this idea is. Paying future legislators more- 
distinct from giving pay-raises to our current legislators! - would have several benefits. It would encourage more moderate people to run for office, it would enhance the prestige of office, meaning that younger people might once more aspire to serving in government, and it would obviate the need to rely on wealthy people to be our candidates. Unlike other ways to enhance office, raising salaries is simple, constitutional, has historical precedent and, thanks to our state legislatures, lends itself to empirical scrutiny. Later in the book, I will introduce a new dataset on state legislative salaries that will allow me to estimate the effects of pay-raises on who runs for office. When states pay their legislators more, more moderate people tend to run for office, on average, and legislative polarization decreases.

Similarly, reforms to campaign finance can decrease the costs of running for office. Even cursory discussions with anyone involved in political campaigns confirm that the money chase dominates the life of a congressional candidate. From the moment they declare, candidates must raise money from a vast number of donors quickly. Whether or not this money has any corrupting influence on politics, it makes it much, much harder to be a candidate. Reducing the amount of time candidates are forced to spend fundraising would make running for office much more attractive for most people. There are nuances to this idea. There are many kinds of campaign finance reform - some that restrict fundraising, some that restrict spending (though constitutional interpretations make this difficult), some that rely on public funding, etc.- - and they may each have unique effects on the political process. The more such reforms make campaigning easy, rather than bring other changes - like altering the ideology of the donor base or skewing other 
types of incentives candidates have - the more we can rely on them to encourage more moderate people to run for office.

The book's policy reform proposals are somewhat unusual; most existing proposals center on altering how voters elect candidates. Reforms to the primary system, such as the move to the "top two" primary system in California, hinge on the idea that voters' and donors' preferences are responsible for polarization. Although reforms in this direction may well prove successful, we can also reduce polarization by altering the costs and benefits of running for office. These latter policy levers are often easier to change and more reliable than ones that depend on changing the way voters behave.

\section{Studying Polarization}

This book is about the ideology of our representatives in Congress, the ideology of those who seek the office, and whether or not voters would prefer different people with different positions to run for office. Like much of the literature on polarization, the implicit premise of the book is that we care about the ideology of our legislative representatives, and that we want more moderate people to hold office - or, at the very least, that we would like to learn about the factors that might produce more moderate representatives. Why do we care so much about having moderate representatives? How can we even define what it means to be moderate? And, more generally, how can we study something as complicated as candidate ideology? Before I go further, I need to lay out my views on why polarization matters and how we should and should not study ideology in the context of who runs for office. 


\section{Why Polarization Matters}

Anyone who reads the news or follows politics probably takes for granted that legislative polarization is an important issue in politics today. The political science literature clearly thinks so; a vast proliferation of articles and books studies the topic (I will review this literature in subsequent chapters). On the other hand, many claims the media makes are dubious, and journalists and scholars alike often have incentives to make issues that barely matter into crises worthy of panic. Should we really care about whether our legislature is polarized or not? Maybe it reflects the genuine, changing views of voters; if so, it may be neither a puzzle nor a normative concern, depending on one's views about the purposes of the political process. Not so long ago, in a time when legislative polarization was much lower, the American Political Science Association (1950) even issued a committee report decrying the lack of polarization! Clearly, our normative intuitions regarding polarization are complicated.

I believe there are two main reasons to study the electoral process in order to understand the factors that determine the ideology of our legislatures and that underlie today's legislative polarization.

The first reason is philosophical and concerns the choices of voters. As I will show later in this book, and as much previous literature has also documented, the aggregated electoral choices of general-election voters show that they generally prefer representatives who offer more moderate positions. I do not mean prefer in the sense that voters themselves espouse particular policy views that are moderate, or that they report preferring such views when asked, or even that it's the candidates positions per se that drive voters to support them-although all 
these things may well be true. Instead, I mean it in the precise sense that, when given the choice to elect candidates who have taken more moderate positions or to elect candidates who have taken more extreme positions, voters tend to elect the candidates who offer more moderate positions. Voters have therefore revealed a preference for these types of candidates. Extending this logic, if our legislature is nevertheless populated with candidates whose positions are more extreme than those of the candidates voters seem to prefer, then our political institutions have failed to translate the desires of voters into legislative activity efficiently. Put simply, it is likely that voters would be better off - in the sense that they would change who they elected to office - if more of the candidates who offer moderate platforms ran for office. ${ }^{11}$

The second reason to care about polarization concerns the legislative process more generally. Whatever one's views on government, our legislatures must conduct a minimal amount of necessary activity. Old policies must be adjusted in response to changes in economic and political conditions; new policies must be created in response to changing technology. A legislature polarized with regards to ideology may be unable to meet these needs. One scarcely needs to recount recent tales of extraordinary gridlock to make this point. Paralysis over issues like the debt ceiling and the appropriations process strongly suggest that polarization can hamper the effective functioning of our legislature. If polarization leads to gridlock, then the ideology of the legislature can spill over into non-ideological realms. If this is true, and I acknowledge it remains an open question, then un-

\footnotetext{
${ }^{11}$ This assumes that these hypothetical new moderate candidates would be similar to the moderates voters have already elected, the ones they have revealed their preference for, on all other attributes, too. I will discuss this issue in detail in Chapter 1.
} 
derstanding polarization's root causes is important for figuring out how we could encourage our legislature to function more effectively.

\section{Studying Elections and Legislative Polarization}

Even if we grant that polarization in our legislatures is a problem worthy of inquiry, actually studying it requires confronting difficult conceptual issues. Ideology is a tangled object resistant to easy scrutiny, especially when it comes to voters. In most political science research on the topic, scholars deploy surveys to measure voters' views on specific policy issues. The basic premise, which seems quite reasonable, is that we can learn about voters' ideologies by asking them. Typically, research in this vein concludes that most voters know little about politics, struggle to name their representatives, and can offer little in the way of consistent policy views (e.g., Campbell et al. 1960; Miller and Stokes 1963). Instead, this literature argues, voters form impressions based on feelings of group attachment and partisan identity (e.g., Achen and Bartels 2006; Bartels 2003; Green, Palmquist, and Schickler 2002), and are susceptible to a number of cognitive biases that frustrate any systematic, rational link between candidate ideology and vote choice (e.g., Bartels 2009; Healy and Malhotra 2009; Healy, Malhotra, and Mo 2010).

The strongest proponents of this view conclude, based on this evidence, that ideology is essentially meaningless, and has no bearing whatsoever on elections. For example, in a recent New York Times op-ed describing their research, Achens and Bartels declare that "Over time, engaged citizens may construct policy preferences and ideologies that rationalize their choices, but those issues are seldom 
fundamental." ${ }^{12}$ In a similar vein, Tausanovitch and Warshaw (2015) scale voters and legislators (though not challengers) using surveys and roll-call votes, finding little relationship between how close a legislator appears to be to a survey taker, ideologically, and who that survey taker reports supporting, electorally. And even if we were to grant that ideology has something to do with vote choice, whether it maps to polarization or not is unclear. Ahler and Broockman (2016), for example, ask survey respondents to choose between hypothetical candidates who do or do not match the respondents' stated views on a select set of issues. The authors conclude that voters do not seem to choose so-called moderate candidates and instead focus on issue-match on particular issues, even though their stances on these issues might be extreme.

The many survey-based studies of voter ideology - a literature the previous paragraph has barely even begun to scratch the surface of - are without a doubt important. Theoretical claims over how voters behave have clearly missed the mark on many important details. I do not quibble with the survey literature on this point, and I will not rely on any theoretical caricature of voters as hyperrational, hyper-informed calculators, nor as consistent moderates who prefer the moderate position on every issue. However, I will argue that these types of studies are not particularly relevant for studying the links between electoral outcomes and legislative polarization, which is not actually about voters' preferences on specific policies but about their preferences over candidates.

The issue is in many ways definitional. Survey-based approaches suppose that a voter's ideology is equivalent to some aggregate of the positions she says she

\footnotetext{
${ }^{12} \mathrm{http}$ ://www.nytimes.com/2016/05/23/opinion/campaign-stops/do-sanderssupporters-favor-his-policies.html, Accessed September 22, 2016.
} 
supports on a survey. Election-based approaches, like those that I will employ in this book, suppose instead that a voter's ideology is defined based on the choices she makes in actual elections when choosing between actual candidates. There is no guarantee these two ideas will be the same or even similar.

Indeed, even if voters honestly and correctly report their policy views on surveys, our government is not run by referendum; voters do not get to vote on policy issue by issue. Instead, voters determine the ideological composition of our legislature by voting for candidates, who represent whole bundles of issues and other attributes. This latter kind of ideology - that which is revealed by voters' choices in actual elections - is what we need to focus on to explain legislative polarization. It is by no means the only kind of ideology worth studying, but it is the particular kind appropriate for this book's mission.

Measuring voters' preferences for different candidates is itself challenging, of course. Much of the early analyses in this book will tackle these challenges, reviewing existing literature and offering new evidence on how candidates position themselves ideologically and how voters choose among these candidates. The conclusion is simply stated. Under a variety of strategies to study candidate ideology, voters in U.S. legislative elections strongly prefer the candidates who offer more moderate positions, on average. This may indicate that voters are more thoughtful than scholars like Achens and Bartels suggest, or it may simply suggest that moderate candidates do better for other reasons, like because they receive more support from elites, are better campaigners, or get more news coverage. The precise mechanisms for this advantage, though interesting, do not change the central fact that our legislatures are polarized despite the fact that voters tend to vote for more moderate candidates when given the opportunity. 


\section{Building Institutions To Attract Good People}

At a broader level, beyond legislator ideology, the point of this book is that our legislatures and our electoral system must be designed with a gimlet eye towards the people who will seek to serve in them. Too often in political science, we either study elections, or legislatures, but not both. Yet most would agree that the two are deeply interdependent. Elections depend on what the legislature has or has not accomplished, and legislators anticipate future elections when they cast votes, make amendments, and do all the other things that legislators do. How well the legislature functions, and what it allows its legislators to do, will influence which people step forward to serve in office in the future.

This is not a new idea. The notion that institutions can be better or worse at attracting quality members is an old one, sometimes called adverse selection. Consider a recent example from Abramitzky (2011). Abramitzky studies the Israeli kibbutz, which is like a commune. Members of the kibbutz share equally in the fruits of their labors, own no private property, and operate in a purely non-cash economy. Of course, the kibbutz does not exist in a vacuum; people can choose to join the kibbutz, or they might instead choose to live in another part of Israeli society (or in another country, for that matter). We might wonder about what types of people choose to join in this arrangement, in which they are guaranteed an equal share of all the kibbutz's product (food and other goods). We might worry that high productivity workers, anticipating that they will contribute more than they receive, won't want to join the kibbutz; lower productivity workers, on the other hand, will want to join, anticipating getting more out than they put into the arrangement. Abramitzky describes the problem thus: "low- 
ability individuals have an incentive to enter equal-sharing arrangements so that they can be subsidized by more-able individuals - so-called adverse selection."

The problem, thus stated, is much like the problem of our legislatures as I have described it. If individuals vary in their ability or quality, and they are presented with a job opportunity which seems disproportionately more attractive to one type than to the other - to extremists rather than moderates, in the case of the legislature, or to lower productivity people rather than higher productivity people, in the case of the kibbutz - we might suspect the members of the institution to be systematically of lower quality. This is as bad for the functioning of the legislature as it is for the functioning of the kibbutz.

How have the kibbutzim dealt with this problem? According to Abramitzky, the key is a rigorous screening process which only allows qualified, high-productivity members to join. He writes, "Since the mid-1980s, kibbutzim have had a special centralized organization that screens entrants, and they have not accepted individuals with especially low education or skills." The screening process is rigorous, and few people are accepted.

The potential solution in our legislatures is similar. Like the kibbutzim, voters screen our potential legislators quite carefully; our elections select for more moderate candidates quite aggressively. Also like the kibbutzim, this selectivity means that many more candidates are turned away than are accepted for office. But the fundamental problem for voters is the shortage of qualified candidates. As I will show, they simply do not receive many chances to vote for candidates with more moderate positions. Where the members of the kibbutz have found sufficient quality applicants to maintain their highly selective ways, voters in the 
U.S. have been forced to elect extremists to office even in cases where they would have preferred to elect moderates.

Making the situation all the more complicated, our legislators by and large choose the design of the legislature themselves - and they design it for their own benefit (Mayhew 1974). When they choose how to structure the committee system, how much power to imbue party leadership with, how to regulate their own campaign finance, and so on, they rarely consider how their choices will influence who runs for office in the future; or if they do do so, they focus mainly on scaring off potential challengers to their own seats. To think seriously about how we can redesign our legislatures and our elections to attract moderate candidates, we will have to account for these externalities, and we will have to think carefully about how we can design our legislatures and our elections ourselves, rather than leaving these decisions in the hands of our legislators.

\section{What This Book Does}

In a nutshell, this book accomplishes three things. First, it argues that candidates for U.S. legislatures tend to be ideologically rigid. This explains why "who wants to run?" is an important question. Candidates cannot bend themselves to the wills of voters so easily. Voters therefore depend on candidates they like to run for office. Second, the book documents that voters prefer more moderate candidates, but that moderates are running for office less and less often. Voters are limited by who runs for office; polarization in our legislatures in part results from polarization in the candidate pool. Third, it helps explain why voters are increasingly being constrained in this way. Through a variety of analyses, I show 
that when office is more difficult to obtain and less attractive to hold, the people who run for office become increasingly extreme. When we make office more attractive, more moderate people seek it out.

More specifically, the book is organized as follows. In Chapter 1, I review current thinking on elections and polarization, pointing out that most of the work in this area supposes that legislators are mirrors for their constituents' policy preferences. What I mean is that many studies observe the ideological positions of legislators and presume that these reflect the electoral demands of voters, or survey the opinions of voters and presume that these will be reflected in the legislature. Implicit in this logic is the idea that legislators can and do adopt the positions their voters want-an idea I call into question. First, I motivate the possibility that candidates are ideologically rigid by presenting a variety of evidence on the degree to which candidates of the two parties offer divergent ideological positions to the same sets of voters. Next, I connect this divergence to the rigidity of candidate positions. Using a variety of data on candidate positions, I show that candidates rarely seem to change positions over time, and I demonstrate that incumbents do not change their positions even when faced with primary challengers from their ideological flanks. I also show, instead, how candidate positions do seem to vary, systematically, with candidates' underlying identities. Even when running to represent the same sets of voters, men and women in the same party offer systematically different positions, on average. Again, this suggests that candidate positions are more deeply rooted and less strategic than the Downsian model supposes.

I do not conclude that candidates' positions need be fully rigid; in fact, I discuss evidence for particular contexts in which incumbents do change their po- 
sitions. Nevertheless, the overall empirical patterns show why who runs matters. The precise identities of candidates have a tremendous bearing on the ideological choices that voters are faced with. Unlike the Downsian view, candidates do not fluidly switch positions to pander to the electorate wholesale.

Motivated by these empirical patterns, in Chapter 2 I show how who runs constrains voters. First, I offer evidence that voters as a whole tend to prefer more moderate candidates. I begin by reflecting on the myriad challenges of studying the policy demands of voters, the ideological positions of candidates, and the outcomes of elections. Using a variety of different techniques, I show that candidates who offer a more moderate set of policy positions tend to do better electorally. Though many of these analyses rely on ideological scalings based on campaign finance, I also show that the same conclusions apply when studying state legislators' roll-call votes. There is consistent, wide-ranging evidence that voters prefer moderates. This evidence does not depend on any one approach or any one set of empirical assumptions. As I have already stressed, this does not mean that voters themselves have consistently moderate views or that they even know much about candidates' positions - it is purely a reflection of how actual elections proceed.

If voters vote for candidates who offer moderate positions, why do we see so much polarization? The second part of the chapter explores exactly how who runs has changed over time, and how this has constrained voters. The past 30odd years have seen a striking divergence in the ideology not just of our elected representatives, but of the full set of people standing for office - counting both primaries and the general election. The people running today are more extreme than they used to be, and voters have far fewer moderate options than they used 
to have. As I show, these changes are not just changes in the extremes of the candidate distribution - the minimum ideological distance between candidates of the two parties in a given district has risen dramatically. Because of this change, voters are simply not given many opportunities to elect moderates to office.

Much of the book focuses on the U.S. House because it lends itself so well to empirical study. The logic is not limited to the House, though. Before moving on to subsequent analyses, I offer descriptive evidence for how who runs constrains voters in many settings beyond just the House. Studying the Senate, state legislatures, and statewide offices, I show that candidates running for office are consistently polarized.

Why has the pool of candidates polarized? In Chapter 3, I offer a simple theory, based on the logic of so-called "citizen-candidate" models, to help explain why people across the ideological spectrum choose to run for office or choose to sit out. The theory highlights why more extreme individuals are more likely to run for office because of their fear of people who hold dramatically different beliefs from their own, all the way on the other side of the ideological spectrum. Ideological moderates are more ambivalent about their potential opponents, and thus more willing to sit out. When the costs of running are low, moderates may still choose to run - and enjoy a considerable electoral advantage if they do sobut when costs are high, they are more easily deterred than are more extreme people.

Does this simple theory seem to help explain reality? And if so, can policy reforms intended to make running for office easier, or to make holding office more valuable, depolarize our legislatures? In Chapter 4, I examine variation in the costs and benefits of running for office, offering empirical support for 
my theoretical arguments. When the costs of running for office are higher and when the expected benefits of holding office are lower, the people who run for office are more ideologically extreme. First, I compare the ideological positions of state legislators running for the U.S. House in cases when they have to give up their state legislative seat vs. in cases when they can run without risking their current seat. Ideologically moderate candidates are much more likely to run when they can do so without risk, while ideologically extreme candidates are equally likely to run regardless. Next, I look at the effects of incumbency on who runs. Incumbency status represents a downward shift in the expected benefits of holding office for a would-be candidate because it lowers the probability that she will win office if she runs. Consistent with expectations, the candidates who run for office are more ideologically extreme, on average, when an incumbent in the opposing holds office than when there is an open seat. Finally, I also examine the effects of pay-raises in state legislatures, and I show that these reforms encourage more moderate candidates to run for office, on average. Moreover, these pay raises also appear to reduce legislative polarization. Though we must be cautious in extending these results to other contexts, they suggest that offering more benefits to would-be politicians can indeed induce more moderate people to run.

These analyses show how the costs and benefits of running for office affect who runs. Is it true, as I have supposed, that the costs have gone up and the benefits down over the past forty years, as polarization has increased? Next, I show a variety of descriptive evidence that it has become much more costly to run for office, and to suggest that, at the same time, the benefits of holding office have likewise decreased. 
In the latter part of the chapter, I discuss possible ways to reduce the costs of being a candidate. Reforms to campaign finance that reduce the amount of time candidates have to spend raising money seem especially promising for reducing the costs of running for office, but these reforms are quite complicated. I review recent work on the effects of different kinds of campaign finance reform, showing how many have subtle and unexpected effects that go beyond just making campaigning easier. Although reforms that simply allow candidates to spend less time fundraising are likely to encourage moderates to run for office, reforms that simultaneously alter the types of voters and donors that candidates have to appeal to may instead encourage more extreme people to run.

In the final chapter, I conclude by discussing the implications of my argument for our electoral theories. Focusing on voters' demands in a Downsian framework has produced incredibly useful discoveries about American politics. But when we add to this the idea that candidates have fixed attributes and can constrain voters' choices, we uncover different and important implications for elections and representation. Thinking about who runs helps us understand a whole host of issues concerning how effective our legislatures function and how well voters are represented in government.

In addition to these academic implications, I also discuss broader ideas about how we induce people to run for office. Since the founding of our Republic, American thinkers have been uneasy that paying members of government might encourage those of venal interests to become our representatives. I am sensitive to this concern, but I believe many of those concerns were also the luxury of thinkers who were wealthy enough to avoid working, and who were philosophizing about a political system they assumed would in perpetuity be run only by those wealthy 
enough to not work. I think it is fair to say that most people no longer believe that is the system of government we want. And in a world where we want people who work "real jobs" to become legislators, when they possess the necessary expertise, skills, and motivations, we cannot shut our eyes and trust a vague sense of honor and pride to produce for us the ideal set of legislators. Whatever our political goals, whether we aspire to government big or small, limited or redistributive, we simply must have competent legislators who reflect the desires of their constituents, broadly construed. We cannot achieve this fundamental goal without confronting the reality that the people capable of achieving it are, by and large, not running for office today. 


\section{Chapter 1}

\section{Ideological Divergence and the Rigidity of Can- didate Positions}

...members of Congress have locked themselves into a slate of inflexible positions.

- Sen. Richard Lugar (R-IN), Remarks in the Congressional Record

As we get so divided, we get increasingly highly partisan and ideologically rigid. It makes it difficult to govern a nation as large and as broad and as diverse and as complicated as this Nation is...

—Sen. Ben Nelson (D-NE), Remarks in the Congressional Record

In one of the most infamous primary races of the 2012 election cycle, Indiana state treasurer Richard Mourdock shocked long-time incumbent Senator Richard "Dick" Lugar, winning the G.O.P. nomination for U.S. Senate by 20 percentage points. Lugar was seen as a relatively moderate Republican Senator, known for working across the aisle to craft the country's policies related to nuclear nonproliferation. Though he had deep and long-lasting ties to his party, he was considered a pragmatist and had even received praise from President Obama, a 
Democrat. The New Yorker, for example, called Lugar "Obama's Favorite Republican." ${ }^{1}$ Mourdock, on the other hand, styled himself an extreme anti-government candidate and drew strong support from the Tea Party. He staked out a number of far right-wing views, questioning the constitutionality of governmental support programs, supporting the forced removal of illegal immigrants, and, most infamously, declaring that pregnancies that resulted from rapes were "something that God intended to happen." ${ }^{2}$ Mourdock went on to lose the general election badly, even though the Republican party had been expected to win Indiana easily.

As observers of politics, the Lugar-Mourdock primary seems, at first blush, easy to explain. Lugar's track record as a moderate member of the "establishment" made him a ripe target for the Tea Party movement; Mourdock's underlying character flaws made it hard for him to avoid saying something severely damaging to his prospects in the general election. Hence, we get Mourdock's victory in the primary but defeat in the general. But the experiences of Lugar and Mourdock actually expose one of the central puzzles of elections, from an academic perspective. If primary voters were looking for someone to offer them Tea Party views, why didn't Lugar simply match Mourdock's positions in order to win the nomination? Likewise, if Mourdock's extreme positions and bizarre statements were harmful to his general-election prospects, why didn't he move to the middle and stop making such outrageous claims?

Before you conclude that it's obvious Mourdock was unable to do so because of his character, consider that popular political accounts are replete with anecdotes

\footnotetext{
${ }^{1}$ http://www.newyorker.com/news/news-desk/losing-obamas-favorite-republican, Accessed April 27, 2016.

${ }^{2}$ http://www.cbsnews.com/news/new-ad-slams-mourdock-for-extreme-positions/, Accessed April 27, 2016
} 
of politicians telling voters what they want to hear-shaking the "etch-a-sketch" to match their stated positions to those that seem most electorally valuable, as Mitt Romney's campaign advisor so memorably put it. Yet, at the same time that many espouse this belief about the dishonesty, or at least the flexibility, of politicians, they simultaneously complain about how ideologically rigid our candidates' positions seem to be. Moreover, congressional races often seem to be contests between candidates with contrasting platforms, offering starkly different ideological options to the same set of voters. Which of these two worlds - the one where candidates pander without principle, or the one where candidates stick to rigid and occasionally unpopular views - accurately describes congressional campaigns? And what does this tell us about polarization?

If politicians are truly etch-a-sketches, then the polarization in our legislatures must come from the policy demands of voters, themselves. That is, if the preferences of voters determine the ideology of representatives, then any activity representatives take in the legislature is purely the result of their voters' desires. As a consequence, who chooses to run is irrelevant for understanding polarization. On the other hand, if politicians are more than mirrors, then "who runs?" matters. The case of Lugar and Mourdock, and many others like it, tells us that candidates' identities matter. Dick Lugar and Richard Mourdock do not appear to be interchangeable, generic candidates pandering to the same set of voters in the same ways. Instead, they look like distinct individuals with radically different views about policy, views that they hold strongly even in the face of electoral demands that might pressure them to change.

Consistent with this latter view, in this chapter I review existing evidence and I present a variety of new empirical tests all of which suggest that candidates are 
far more than mirrors. Candidates rarely alter their overall ideological platforms, measured using either the publicly visible votes they cast in the legislature or the mix of campaign donations they receive. As a result, voters' role in the electoral process appears to be one of selection; they select candidates on the basis of pre-existing attributes but they seem less able to pressure candidates to change. This leaves voters at the mercy of those who choose to run for office.

Specifically, this chapter pursues three closely related goals. First, I review the way the American Politics literature has tended to think about elections, with a heavy focus on the Median Voter Theorem (hereafter MVT) - the idea that candidates will move to the middle in response to electoral competition. I argue that this compelling idea underlies the lion's share of our thinking about polarization, guiding us towards a focus on changes in public opinion. This has been a boon for many research questions, but one unintended consequence has been to obscure the ways in which who runs can affect our legislatures.

Second, I review existing research that suggests candidates may not be so fluid in their views as the MVT predicts. There are many reasons to suspect candidates to be relatively rigid, ideologically. Here my aim is not to offer a new theory of rigidity but rather to highlight existing work on the subject. I connect this research to a large literature on candidate divergence - the tendency for candidates of the two parties to offer distinct ideological platforms even when competing to win over the same electorate. This latter literature, too, casts doubts on the idea that candidates are ideological mirrors for their constituents.

Finally, I offer a series of new empirical analyses that support the rigidity hypothesis. Descriptively, candidates for the U.S. House rarely if ever seem to alter their overall ideological platforms. Even in situations where elections are 
thought to compel them to do so-like when they are challenged by partisans in their own primary - they seem to stand pat. Though there are no doubt situations in which candidates alter their views on specific policy issues, their overall ideological positioning only changes rarely. This is why the book's central question - "Who Wants to Run?" - is important for understanding the ideological composition of our legislatures. Who runs for office helps determine who serves in the legislature and how polarized they are.

\subsection{The Median Voter Theorem and Fluid Can- didate Positions}

In democratic elections, how do candidates choose the positions that they offer to voters? Understanding this question is at the root of understanding legislative polarization.

The predominant model of candidate positions in the study of American politics, one that provides the foundation for thinking about democratic elections, is found in Downs (1957). ${ }^{3}$ Cited more than 20,000 times, ${ }^{4}$ Downs's theory predicts that candidates will converge, offering the positions that the median voter prefers in order to secure a majority of votes. In its simplest form, the model considers two parties running to represent a constituency. The ideological preferences of each voter can be arrayed along a single line, and each party's candidate chooses

\footnotetext{
${ }^{3}$ Although we most frequently associate the logic of the MVT with Downs' seminal work, we should also give credit to the earlier research in social choice and economics on which his work was based, the work that fleshed out the MVT. This includes foundational work by Black (1948) and Hotelling (1929).

${ }^{4}$ This estimate comes from Google Scholar, accessed February 3rd, 2015.
} 
a platform that is represented as a point on this line. ${ }^{5}$ Voters support whichever candidate offers a platform closer to their own preferred point. Logically, the only inevitable position for candidates to offer is that of the median; if either candidate offers any other position, either to the left or to the right of the median, then the other candidate can offer the median position and win with certainty.

The expected outcome of this strategic process is a static one, with both candidates offering the views that the median voter desires. But the logical argument underpinning this result requires flexibility. Candidates are able to move to the middle. As a result it is a voter-centric model of the political process; the precise identities of candidates do not matter because any candidate can choose any position. This way of thinking about elections has guided a tremendous amount of research in American politics, and for good reason. It provides a clear set of assumptions that lay bare why candidates may have incentives to moderate. As I now explain, it has also helped lead to our historical focus on voters rather than candidates when considering why polarization has grown in our legislatures.

\subsection{Research Focuses on Voter-Driven Polariza- tion}

Like many other parts of political science, the extensive literature on legislative polarization in American politics takes its cue from the Downsian model. Most work seeking to explain the large and growing polarization of U.S. legislatures relies on demand-side factors: the changing preferences of voters; the changing

\footnotetext{
${ }^{5}$ Downs was careful to distinguish preferences over specific policies from ideology. The connection between ideology and issue positions, as well as the question of how coherent voters' ideologies are, will be taken up in a subsequent section.
} 
behavior of primary voters; and/or the changing distribution of voters across districts. My argument is not that these literatures are wrong or that these factors are unimportant in understanding polarization-far from it. Instead, I aim only to highlight that these accounts miss that part of polarization which is not voter-driven.

McCarty, Poole, and Rosenthal (2006) is perhaps the defining work on legislative polarization in America. The book presents roll-call based evidence for the sharp growth in legislative polarization since the 1970s. In conjunction with other academic work and with many political accounts, this research has spurred a large literature that seeks to explain why polarization has grown and where it will head in the future. After documenting the rise in polarization, the book links it to rising income inequality. The authors argue that the simultaneous rise in inequality and polarization is causal, with the wealthy increasingly opposing redistribution while the poor support it (they also suggest that polarization can produce policies that increase, or at least fail to slow, inequality). Subsequent work further suggests this causal link between inequality and polarization (Voorheis, McCarty, and Shor 2015).

A large body of other work enumerates changes in the preferences and behaviors of citizens that may also influence polarization. But even on the fundamental question of whether voters' views, themselves, have polarized, substantial disagreement remains. To pick perhaps the most famous of these disagreements, Fiorina, Abrams, and Pope (2005) and Fiorina and Abrams (2009) argue that only a small class of political elites has polarized over time, while voters, themselves, have not. Abramowitz (2011) strongly disagrees, arguing that voters of the two parties have sorted in their views on a range of issues and become more extreme. 
To date, the disagreement rages on. However voters' views have changed, or not changed, though, the debate is entirely voter-centric. Abramowitz (2011), for example, focuses on the differences in - and the changes over time of - voter engagement across the ideological spectrum to explain polarization. Bishop (2009) discusses the sorting of citizens across districts as another possible factor (though see Abrams and Fiorina (2012) for counterarguments). Levendusky (2009) studies a different kind of sorting - the sorting of liberals and conservatives into the Democratic and Republican parties, respectively, which he argues is responsible for the changing nature of polarized politics in the U.S. All of these are about voters.

Relatedly, a large literature points to the U.S. system of primary elections, beginning with a theoretical literature on two-stage elections (Aranson and Ordeshook 1972; Coleman 1971; Owen and Grofman 2006). Burden (2001) points to primaries to explain the failure of U.S. candidates to converge to the median voter. Brady, Han, and Pope (2007: abstract) likewise argues that "primaries pull candidates away from median district preferences." In perhaps the strongest version of these claims, Pildes (2011) proposes abolishing the primary system because of its hypothesized effects on polarization. On the other hand, Hirano et al. (2010) examines changes in polarization as states implemented primary elections and finds no evidence of a polarizing effect. McGhee et al. (2014) investigates the effects of changes in the type of primary election (open vs. closed) and again finds little relationship with polarization.

Finally, a separate literature focuses on redistricting as a causal factor, hypothesizing that the creation of more partisan districts, i.e., districts with a greater proportion of voters that support one party or the other, induces leg- 
islators to take more extreme positions. Carson et al. (2007: abstract) reports "modest" effects of redistricting on polarization and concludes that "redistricting is one among other factors that produce party polarization in the House." Theriault (2008) makes similar arguments, as do a number of journalistic accounts of the process (see for example Eilperin 2007). However, McCarty, Poole, and Rosenthal (2009) presents clear evidence against the hypothesis. ${ }^{6}$ First, as they point out, polarization appears to be just as high in the U.S. Senate as in the House, despite the fact that redistricting only occurs in House elections. Second, they also show that most of the polarization in the House actually comes from intradistrict polarization, the degree to which the two parties diverge within a given district, rather than from interdistrict polarization, as would be caused by gerrymandering.

These ongoing literatures all take a voter-centric view of politics. Whether focused on the preferences of the citizenry as a whole, like in the case of income inequality, or on a particular portion of the electorate, like in the case of primary elections, redistricting, or changes in participation, all of these studies investigate causes of polarization that lie with voters. Whether or not voters themselves have polarized over time (see Fiorina, Abrams, and Pope (2005) for arguments to the contrary), the preferences of voters need not be the only input into polarization. The behavior of candidates, separate from voters, can play its own role. Fiorina, Abrams, and Pope (2008) raise this point in their discussion of the literature, writing: "When statistical relationships change, students of voting behavior have a tendency to locate the source of the change in voter attitudes, but unchanging

\footnotetext{
${ }^{6}$ Also see Masket, Winburn, and Wright (2012).
} 
voters may simply be responding to changes in candidate strategy and behavior (556)."

By focusing on what voters want rather than on who runs, these literatures often also rely on an implied model of fluid candidate positions. This is especially true in work that is survey-based. Since most surveys only ask about voter preferences, justifying them as a means by which to understand legislative polarization presupposes that these preferences are successfully translated into the legislature's membership. But if candidates are unwilling or unable to change their positions, then shifts in the electorate's preferences will not necessarily appear in the legislature.

Likewise, work on how primaries may produce polarization depends on fluid candidate positions. Even if we grant for the moment that primary electorates are more ideologically extreme, for them to pull candidates away from the district median, candidates must be able to change their positions in response to primary voters' demands. Strategic incumbents may have reasons to want to ward off primary challenges by hewing closer to the party's stances, but doing so in practice requires deviating from one's chosen positions, with all the personal and strategic costs that that entails.

Finally, explanations that rest on changing voter support for differing candidate positions across districts and over time assume a steady supply of those positions amongst the candidate pool - either because such candidates are always willing to run or, more likely, because of an implicit model of fluid positions in which candidates can adapt to the needs of their electorate at any time.

The overall focus on voters is highly appropriate; the demands of voters are a key driving force in democratic politics. My point is only that they are one half 
the whole story. Since our system of government requires that representatives enact policy on behalf of voters, voters must find candidates willing and able to translate their views into public policy. If candidate positions are not fluid, and

if not all types of candidates are willing to run for office, then this constraint can become binding. To figure out whether "who runs?" matters for polarization, we must therefore first determine whether or not the Downsian view applies in practice. Do candidates actually move to the middle in real elections? I now review empirical literature that the suggests that the answer is no.

\subsection{Why So Much Divergence?}

Nearly anyone who has observed recent U.S. political elections probably agrees that the candidates of the two parties stand for very different things, generally speaking. Across a wide range of issues concerning the government's role in the economy, our nation's foreign policy, and a number of pressing social questions, Democratic and Republican candidates take widely different stances. This ideological gap is quite pronounced in the legislature, where we watch the two parties do battle on almost a daily basis, but it is also evident in electoral campaigns themselves. Even when a Democrat and Republican are running against each other, and thus are competing for the exact same set of voters, they continue to say and do noticeably different things, despite the Downsian model's predictions.

Scholarly work confirms this intuitive feeling. As discussed previously, legislative polarization in the U.S. is near all-time highs (McCarty, Poole, and Rosenthal 2006). The ideological positions of candidates for U.S. elections, whether measured based on the stances they take during campaigns or, for the winners, based 
on the positions they take as legislators, have become more ideologically extreme over time. There are many ways to study candidate positions and to investigate how candidates of the two parties diverge from one another, ideologically. No method is perfect, but taken as a whole, the literature shows overwhelmingly that the two parties diverge, and that this divergence drives polarization in the legislature.

McCarty, Poole, and Rosenthal (2009) examines the relative positions of Democratic and Republican candidates competing in U.S. House elections. The key finding, for our purposes, is "that congressional polarization is primarily a function of the differences in how Democrats and Republicans represent the same districts rather than a function of which districts each party represents or the distribution of constituency preferences" (abstract). The paper emphasizes that polarization is not merely the result of voters sorting into districts, with candidate selection proceeding efficiently within each district - that is, according the revealed preferences of voters - and producing polarization only in the aggregate. Instead, voters within a district are faced with systematically different choices across the two parties.

Many other papers explore similar issues of divergence. Examining the positions of U.S. House candidates over a long time period, Ansolabehere, Snyder, and Stewart (2001) find a marked gap in positions between Democrats and Republicans even when running for election in districts with the same underlying partisanship. The logic is as follows. If the median voter theorem holds, then whatever the median's views are, the Democratic and Republican candidates should converge to those views. As a result, even if we cannot directly observe the median voter's position, we can compare the positions of the two parties' can- 
didates; if these positions differ from each other, then we know that convergence has not occurred.

This approach requires measuring the positions of both candidates within a given race, which is difficult since only incumbents have had the opportunity to take formal positions within the legislature by casting roll-call votes. Ansolabehere, Snyder, and Stewart (2001) address this obstacle first by studying races in which candidates of both parties answered survey questions about their views on a range of ideological issues. They then supplement this analysis, which focuses only on the year 1996, with a broader historical one that scales a special set of challengers - future winners - on the basis of roll-call votes they will go on to cast in the legislature.

An alternative approach is to focus only on incumbents but imagine an experiment in which a district randomly receives either a Democratic or Republican representative. In this case, we cannot directly compare two candidates in a given race where the median voter's positions are held fixed, but we know that, across the districts in our experiment, the median voters' positions will be equal in expectation across the places that "randomly" get a Democrat and the places that "randomly" get a Republican. If we find a difference in how representatives in the districts where the Republican was assigned to office vote vs. how representatives in the districts where the Democrat was assigned to office vote, we can conclude again that there is ideological divergence.

Following this logic, Lee, Moretti, and Butler (2004) uses a regression discontinuity design to focus on districts where a Democratic or Republican candidate is "as-if" randomly assigned to hold office. Districts that quasi-randomly receive a Democrat see much more liberal roll-call voting from their representative than do 
the districts that receive the Republican incumbent, even though the underlying preferences of the two sets of districts are, on average, identical.

Fowler and Hall (N.d.) extends this design, investigating a larger set of races over a larger time period and emphasizing just how profound this ideological divergence is. One of the important additional conclusions of the paper is that "elected officials do not adapt their roll-call voting to their districts' preferences over time, and that voters do not systematically respond by replacing incumbents" (abstract). Ideological divergence in U.S. elections is persistent. The theory put forward in this book offers a new explanation for this persistence. Voters may not replace these incumbents because they have no viable alternative options. Even when incumbents do not match the district, ideologically, there is no guarantee a challenger will emerge offering a more fitting ideological platform. The constrained candidate supply is therefore an important potential factor to consider.

Fowler and Hall (2015) pushes this evidence further, exploring not overall ideological divergence but instead issue-specific divergence. The paper scales incumbent roll-call votes by issue area, rather than pooling roll-call votes across all issues, and then measures the degree of district-specific divergence for each issue area. That is, for each issue area, how far apart are Democratic and Republican incumbents even when representing the same median voter? The paper then compares the size of this divergence across levels of salience. Some districts care more about particular issues than others; for example, districts with more agricultural workers probably care more about roll-call votes on bills related to agriculture. Even if candidates fail to converge in general, the increased salience of particular issues might lead them to converge at least partially in some cases. Surprisingly, 
the paper finds no evidence that this prediction holds. Divergence remains just as large even in cases where districts care a great deal about a particular issue.

To sum up: a large empirical literature shows how Democratic and Republican candidates offer systematically different positions even when vying to represent the same voters. These results do not prove that individual candidates are rigid and unchanging in their positions, but it does suggest that, for one reason or another, candidates are not moving to the middle in response to electoral pressures. One possible explanation for these results is that candidates hold personal views which they either cannot or will not alter during the electoral process. If this is the case - and I will offer many kinds of evidence that it is - then polarization in our legislatures is not only a response to voters' own views, but to our candidates' own views, too.

\subsection{Why Candidates May Be Ideologically Rigid}

Candidates systematically fail to converge, ideologically. As a result they systematically fail to offer positions consistent with those of the median voter in their district. If candidates cannot easily change their positions, this rigidity may help explain the divergence we have reviewed in the previous section. I now turn to a variety of reasons why this rigidity hypothesis is plausible.

\section{Candidates Hold Strong Personal Views}

First, candidates may hold strong personal preferences over policy —indeed, this is likely part of why they are willing to run for office in the first place. Many theories allow for at least some room for personal preferences in candidate positions and 
behavior (e.g., Aldrich and Rohde 2001; Cox and McCubbins 2007; Wittman 1983). Articulating this view especially strongly, Wittman (1977: 180) writes: "candidates view winning as a means to policy."

Personal conversations with congressional staffers reaffirm this view; staffers I have spoken to are often struck by the deep commitment, or even obsession, their bosses have to particular policy issues. Though re-election concerns are never far from members' minds, neither are the specific policy goals that, in many cases, drove them to seek office. Formally interviewing a variety of congressional staff, Jacobs and Shapiro (1997: 3) concludes that "the policy positions of members were guided by their personal beliefs, ideology, and judgments." Certainly, politicians are likely to care about some issues more than others, and may therefore be more rigid in some cases than in others. But, in general, their personal investment in policy may make it less likely that they will alter positions frequently.

Caring about policy does not guarantee that candidates will not change their views. The need to gain election in order to implement policy may still force candidates to offer views to voters other than their own. But it makes it costly for them to do so. If these costs are high enough, candidates may not be willing, in all cases, to alter their views for strategic gains. This is especially true when candidates are uncertain about voter preferences. Probabilistic voting models-models that incorporate uncertainty about the location of the median voter-typically predict that candidates with personal preferences will move towards their own views and away from the middle (Calvert 1985; Wittman 1977). Empirically, we know that U.S. House candidates have little information to go on when determining positions. As Jacobs and Shapiro (1997: 3) reports, "one reason members do not rely on opinion polls is that they do not trust them." Possessing personal 
views, when combined with tremendous uncertainty about the most politically advantageous positions, provide a powerful incentive to candidates to offer positions similar to their personally favored ones, and to budge from these only grudgingly if at all.

\section{Voters Discourage Ideological Flexibility}

Second, voters may punish candidates for changing positions, forcing candidates to hold fixed positions over time even if they do not want to. Describing an overall sense of American elections, Fearon (1999: 63) muses: “'Waffling' is considered a bad thing, even if one waffles toward the median voter."

Tomz and Van Houweling (2015) presents experimental evidence that voters do not react favorably to "flip-flopping," interpreting changes in candidate positions to be a sign of weak character. After showing survey takers "policy histories" of hypothetical candidates, the authors asked respondents to rate them on the basis of five traits labeled "Honest," "Moral," "Strong Leader," "Knowledgeable," and "Open-Minded." When respondents saw candidates with varying policy histories, they rated them consistently lower on all four traits other than "Open-Minded." As the authors write in a detailed synopsis of the experiment, "In general...voters drew negative inferences about the character of candidates who changed positions over time." 7 The Tomz and Van Houweling (2015) results are experimental, but they are likely to translate into the world of real elections. Punishment for flip-flopping need not require voters to recall previous candidate

\footnotetext{
${ }^{7}$ http://web.stanford.edu/ tomz/working/TomzVanHouweling_ PoliticalRepositioning.pdf, p.7, Accessed February 6, 2015.
} 
positions; there is no shortage of interest groups, or opposing candidates, ready to point out such behavior when it occurs.

Focusing on senatorial elections - but with obvious applicability to House elections, too-DeBacker (2015) also shows how incumbents are hurt by flip-flopping. Investigating changes in senator roll-call positions over time, the paper estimates "significant costs of changing position" (109). Closely related to this book's arguments, DeBacker uses the results to discuss the possibility that incumbent rigidity is, at least partially, responsible for the observed failure of candidates to converge to the median voter.

These empirical results are consistent with a game-theoretic literature concerning ideological rigidity, too. Canes-Wrone and Shotts (2007) offers a model in which incumbents can, in certain cases, continue to offer a partisan position on an issue even when they've received knowledge that changing their position would create more effective policy. This rigidity results from incumbents' fear of being misunderstood by their constituents. Unlike the literature on flip-flopping, in this model voters punish incumbents who change positions not because position changing is viewed as a weakness per se, but rather because it is a signal of disloyalty. Voters and incumbents alike would be better off if the incumbent could switch to the better policy, but there is no way for incumbents to do this without giving voters the impression that they do not share their ideological views.

\section{Candidates' Commitment Conundrum}

Third, candidates may simply be unable to convince voters that they are being honest if they change positions - even if voters would not punish them for these 
changes if they could believe them. This is one example of a more general problem of commitment; candidates may wish to cater to the policy preferences of voters, but if voters know candidates' true policy goals, these promises will not be credible. This is the key challenge explored in Alesina (1988).

This problem of commitment is also at the heart of citizen-candidate models, a class of models that heavily inspires the theoretical arguments I lay out in Chapter 3. One way to rationalize the problem is that voters have external information about candidates' backgrounds, previous statements, previous political behavior, and more. Voters thus have little reason to believe a candidate if she claims to have a new position on an old issue, or if she offers a position on a novel issue that seems at odds with her established positions on similar, existing issues. Voters might know these things for themselves or, just as likely, might be helped along by opposing candidates and the media in uncovering these inconsistencies.

To explain this idea in a bit more detail, imagine a candidate with relatively extreme views running for office. In order to try to win, the candidate might pretend to hold more moderate views, under the hypothesis that these views will help her win office. But everyone knows that campaign promises are not binding. So, looking ahead, voters (and opposing candidates) may be skeptical when the candidate attempts to look moderate - especially if they have other information that suggests she is not. Realizing that these claims won't convince anyone, the candidate may not bother to look moderate in the first place.

For these and other reasons, candidate positions may be difficult to change, and candidates may change them only rarely. 


\subsection{Measuring Candidate Ideology Using Con- tributions}

Having offered my views on why we might expect candidates to be less than fluid in their ideological positions, I now offer empirical evidence in favor of the claim.

For much of the rest of the book, I will rely on measures of candidate ideology from Bonica (2014), called CFScores, downloaded online from the Database on Ideology, Money in Politics, and Elections (DIME). CFScores extract an indication of candidate ideology using the mix of campaign contributions that candidates, both winners but also losers, receive from donors. To understand the idea, think about a new candidate running for office. We don't know much about her ideological positions because she has yet to serve in the legislature. But she has started to make speeches, to offer issue positions, and, most importantly, to raise money for her campaign. If we see that she receives most of her donations from donors that typically support, say, far left-wing candidates, then we have good reason to think that she, too, is probably a left-wing candidate. In principle, we could extract all of her position statements from her speeches, conversations, and so forth to measure her overall ideological positions directly, but this is not practical. The sheer amount of data would require decades of collection, processing, and interpretation. Instead, CFScores let the donors do that work for us; they are a useful indication of what the candidate's positions are, precisely because donors pay special attention to the political process, tend to know something about the candidates they donate to, and tend to care about candidates' positions. 
The contribution-based scalings, in contrast to roll-call based scalings, allow for the study of both winners and losers - not just incumbents who cast roll-call votes. Inevitably, contribution-based estimates are limited to the set of candidates who raise sufficient money to be scaled. Candidates who never raise any money obviously cannot be scaled on the basis of campaign contributions. However, as a practical matter, my resulting focus on "viable" candidates will not limit the study significantly. Most any candidate with any chance of winning electoral office receives sufficient contributions to receive a scaling.

One major concern with this focus on viable candidates would be if moderates are finding it increasingly hard to raise those first, initial donations. If that were the case, the reason we don't see more moderates running for office might not be that they don't want to run, as I am arguing, but instead that they try to run but can't find enough support among donors, dropping out of the race before they can receive a CFScore. There are two reasons to think this is not a major issue for my analyses. First, candidates who receiver fewer donations appear to be substantially more extreme, not more moderate (Hall and Snyder 2014). Although more extreme candidates may have an advantage in primary races, and this advantage may bleed into fundraising as well as election outcomes, this advantage is not so large as to render moderates incapable of raising money — and the threshold to receive a CFScore is very low. Second, for many of the main analyses throughout the book, I will look at parallel results using state legislators, whom we can scale using their roll-call votes instead of contributions, ensuring that the conclusions are not driven by unique features of the campaign finance landscape. All that said, it is entirely possible that the extreme demands that campaign finance has come to place on candidates is an important reason why 
moderates are not running - in fact, I suspect campaign finance is an important part of why moderates are not running for office, as I will discuss throughout the book. The key is to distinguish, on the one hand, the idea that moderates do not want to run, in part because of campaign finance, from, on the other hand, a purely statistical mistake that would occur if moderates do want to run, but we fail to observe them because of the nature of CFScores.

The main contribution-based estimate that DIME makes available is the regular CFScore, which pools all of the contributions candidates receive in their entire careers, producing the most precise possible estimate of their ideology. The CFScore ranges from roughly -5 to +5 for U.S. House candidates, with smaller (more negative) numbers indicating liberal positions and larger (more positive) numbers indicating conservative positions. I utilize this measure in cases where I am not studying dynamic parts of the electoral process. In order to investigate possible changes in candidate positions over time, however, I rely on dynamic CFScoresthe contribution-based estimates of ideology made available in DIME that are estimated separately for each election cycle.

\subsubsection{What Is Ideology?}

Before I discuss whether CFScores accurately measure candidate ideology or not, I need to define what I mean when I say "candidate ideology." Following the majority of work in empirical political science, and in the spirit of Downs (1957), I will think of candidate ideology as the aggregated representation of a candidate's many issue positions. Though candidates are free to take any position on any issue, ideology is conceived of as an underlying dimension that predicts a candi- 
date's position on most issues. As Downs conceived ideology, it is not merely a summary of a candidate's underlying positions but in fact a solution to voters' lack of information. Rather than studying each policy in isolation, voters can look to ideology to learn about candidates. Downs writes: "[A] voter finds party ideologies useful because they remove the necessity of his relating every issue to his own philosophy...With this shortcut a voter can save himself the cost of being informed upon a wider range of issues" (98).

Ideology is a complicated object. There are an infinity of possible issues on which to take positions, and not all candidates will take positions on all issues. What's more, candidates may be vague about their views on some issues, or

might not disclose their personal views honestly. And, inevitably, collapsing candidates' positions onto a single dimension called ideology will always obscure much interesting variation. No doubt, many candidates hold packages of views that do not necessarily map onto this single dimension perfectly. But, as a whole body of literature has concluded, we still get a clear overall sense of where candidates lie based on a unidimensional measure. Any empirical measure of ideology is necessarily only a crude abstraction from candidates' actual views, but that does not mean the measure is not useful. Even if crude and noisy, an unbiased measure of candidate ideology allows us to make meaningful comparisons among candidates that we would not be able to make otherwise.

\subsubsection{Do CFScores Measure Ideology Well?}

The first and most basic criterion by which to evaluate the use of CFScores for the purpose of this study is: do they seem to measure actual candidate ideology? 
In brief, the answer is yes. I will not dwell on this issue only because it has been dealt with in extreme detail in the original paper laying out the technique and the resulting measure (Bonica 2013). The paper shows a variety of facts, including:

1. CFScores correlate highly with roll-call based measures of ideology for sitting incumbents, even within party.

2. CFScores accurately classify incumbents' roll-call votes without conditioning on their roll-call based measures of ideology.

3. CFScores appear to extract a meaningful indicator of ideology even for cases where the correlation with roll-call based measures is weaker.

Overall, CFScores do a good job of reflecting candidate ideology. Not only are the scores relatively accurate, but they apply to a vast number of candidates. This is a big deal. No other measurement is available for the vast majority of these candidates - most never serve in office and thus never cast roll-call votes. There is simply no option but CFScores to study the ideology of these candidates.

The main criticism leveled at CFScores is that money is often given strategically. We have ample evidence, both statistical and qualitative, that interest groups donate to incumbents in exchange for political access (e.g., Fouirnaies and Hall 2014; Grimmer and Powell 2014; Snyder 1992). Donations given in this manner will not reveal ideology. Moreover, because interest groups who are strategic will likely seek access to members of both parties, these donors may appear "moderate" when in fact they are simply non-ideological. There is no doubt that this kind of contribution behavior occurs. However, it does not raise nearly as large a problem for the money-based scalings as one might think, because the 
reality is that such interest groups comprise a relatively small amount of the entire donor pool. More than $50 \%$ of all contributions in federal elections are made by individuals (Ansolabehere, de Figueiredo, and Snyder 2003; Barber, CanesWrone, and Thrower N.d.). Individuals, unlike groups, are generally thought to be non-strategic in their contributions, so that their money credibly reveals what candidates they align with. Barber, Canes-Wrone, and Thrower (N.d.), for a recent example, shows that individual donors tend to support candidates who agree with them ideologically. This is the main reason the scalings seem to work so well. Indeed, money-based scalings that throw out interest-group contributions and use only individual contributions are extremely highly correlated with those that use all donations. ${ }^{8}$

Another potential issue with CFScores is that they do not correlate well with DW-NOMINATE, the predominant approach to measuring incumbent ideology based on roll-call votes, when making within-party comparisons for nonincumbent candidates. In the worst case of all, Bonica (2013) shows that, among Democratic candidates challenging Republican incumbents in the U.S. House, the correlation between CFScores and DW-NOMINATE scores (for the set of open-seat Democratic candidates who go on to serve in the legislature) is only 0.2. The correlation is better for Republican challengers facing Democratic incumbents (0.49), and for open-seat candidates of both parties (0.4), but still relatively weak. How should we think about this important issue?

There are two points worth making. First: how will measurement error affect the inferences I draw in this book? In almost every single case throughout this and the subsequent chapters, this error will bias against my arguments. Con-

${ }^{8}$ Personal correspondence with Adam Bonica, May 21, 2016. 
sider the present chapter. The goal here is to establish that candidates seem to have relatively rigid positions which they do not change, much, over time. Pure measurement error, in which simple noise is added to a candidates' estimated ideology, will cause candidate positions to appear to change frequently. Later cases will follow a similar logic, and I will take care to spell this out when I consider each subsequent analysis in turn. At the end of the day, it is far better to have a noisy measure of challenger ideology than to have no measure at all.

And second, as Bonica (2013) discusses, there is no sense in which DWNOMINATE is the "ground truth." One of the reasons the within-party correlations are weaker than the overall correlations is that DW-NOMINATE, itself, doesn't do a very good job of distinguishing the ideology of co-partisan legislators. In fact, in many cases it may be that CFScores are actually extracting more meaningful comparisons among co-partisans than are roll-call votes. This could be in part because many roll-call votes are strategic battles between the parties, with the more moderate members of each party compelled to go along with their more extreme colleagues. Consistent with this idea, Bonica (2013: Fig. $4,304)$ shows that the biggest difference in predictions for DW-NOMINATE vs. CFScores occurs for candidates considered "moderate" when scaled on the basis of their contributions. This in turn may suggest that, within each party, more moderate legislators appear less moderate than they truly are when they cast rollcall votes because of issues of agenda and party influence. CFscores potentially circumvent this issue, and that difference may help explain the weak within-party correlations between the two measures. (If this concern is true, DW-NOMINATE may overstate the degree of polarization in Congress. But a variety of alternative techniques, including CFScores, all show big rises in polarization, too.) 
A final concern with the money-based scalings is that, even if they do capture overall ideology well, they may be ill-suited to detect changes in ideology. As I have already laid out, the present chapter will show evidence that candidates are relatively rigid, ideologically. Although I will draw on other kinds of data, the main evidence for this claim will rely on CFScores. What if CFScores are artificially rigid? We may have theoretical reasons to expect this. Accounts of political campaigns often stress how candidates, their staff, and their consultants start looking for contributions by going back to old donors. Even if a candidate changes her views, old donors may continue to donate out of habit, especially if they are contacted regularly by the campaign. This behavior, if common, could produce an artificial stability in the dynamic CFScores.

It is impossible to rule this possibility out completely without another indicator of candidate positions to use as a comparison. One somewhat reassuring fact is that habitual donating of this form is quite rare. The modal total number of donations a donor makes over his or her entire lifetime is one. The majority of candidates' contributions in any given electoral cycle come from new donors. ${ }^{9}$ Although CFScores will necessarily depend on more frequent donors (donors who only ever make one donation can't give us any ideological information), the point is only that habitual donation is not necessarily as common as one might expect. So long as we think these frequent donors give in a manner that reveals something about candidate ideology - and the various validation exercises I have discussed suggest that they do - the dynamic scores will help examine how candidates do or do not change their ideological positions over time. But we should not consider

\footnotetext{
${ }^{9}$ These facts are computed directly from the FEC's data. Again, I acknowledge personal correspondence with Adam Bonica.
} 
these analyses the end of the story. I will discuss a variety of other, more indirect evidence that likewise suggests candidates are relatively ideologically rigid. No one analysis is, or ever could be, a "slam dunk" for making this argument. Instead we must consider the evidence as a whole.

Beyond these issues, there is one main drawback to using CFScores: they only provide meaningful measures of ideology for the set of candidates who raise enough money to be scaled. As a result, whenever I talk about the ideology of "the candidate pool" or "those who run for office," I'll implicitly be talking about "those who run for office and raise enough money to have an estimated ideology."

This is only a drawback in the absolute sense of the word; it would be better if we had a measure that applied to all candidates. It is not a drawback relative to other options because there simply are no other options available that have nearly the coverage that CFScores do. As Key (1966: 12) put it, describing a similar problem using ANES data, such data "have their shortcomings...but they have the incontestable virtue of being available - and of being the only information covering so long a period." Only a small fraction of all candidates go on to serve in office, so roll-call based measures of ideology do not get us very far into the candidate pool. Though CFScores may not be perfect, they offer us an unprecedented opportunity to study candidate ideology on a wide scale. 


\subsection{U.S. House Candidates' Positions: Stable Over Time}

Perhaps the best existing statistical evidence for the candidate rigidity hypothesis comes from Poole and Rosenthal (2000). The authors use the entire set of roll-call votes in Congress to scale legislators from liberal to conservative. The resulting scalings offer a sense of which legislators tend to vote in which directs on bills that come up for consideration on the floor of the House and/or Senate. Most, but not all, members serve for more than one term. As such, the authors can assess whether members' ideologies seem to change over time, using a couple of handy statistical tricks. They conclude: "we find remarkable and increasing stability...Members of Congress come to Washington with a staked-out position on the continuum, and then, largely die "with their ideological boots on"' (8).

Another piece of suggestive evidence comes from Grimmer (2013). In the book, Grimmer studies the representational styles of members of Congress. Among many other things, he analyzes the way Senators alter, or do not alter, these styles over the lifecycle of a six-year term. Grimmer concludes " that there is a great deal of stability in legislators' presentational styles - suggestive evidence that senators articulate similar priorities throughout their electoral cycle."

Most of the existing evidence considers incumbents only. While suggestive, it is possible that the stability they detect is an artifact of the manner in which legislators, and especially the majority party, control the roll-call voting agenda. In addition, regardless of these agenda effects, the results only speak to incum- 
bents, and thus do not indicate whether the entire candidate supply-including challengers as well as open-seat candidates - displays the same ideological rigidity.

First, I use CFScores to examine how U.S. House candidates position themselves in their first and second election attempts, respectively (regardless of whether they win office or not). Figure 1.1 plots, for each candidate in the dataset who runs in at least two elections, their positions in their first two campaigns. Perfectly horizontal lines connecting each candidates' two datapoints indicate no change in position. As the figure shows, the vast majority of lines are perfectly horizontal. Though there are some changes - reflected in the scattered non-horizontal lines in the plot-they are few and far between.

Figure 1.2 examines this another way. Here, I calculate the change in position between the first and second campaign for every candidate that runs at least twice in the U.S. House. I then plot the distribution of those changes. A huge amount of the mass of the distribution is placed in the immediate vicinity of zero; most candidates simply do not change their positions.

Figure 1.3 presents the data another way, comparing a candidate's estimated position in one election to her position in the previous election. The black points present raw data, comparing each candidate's position in the previous election (on the horizontal axis) to the candidate's position in the current election (on the vertical axis). The red line overlaid on the plot presents the regression estimate. As can be seen in the plot, there is an extremely high association between lagged candidate positions and current candidate positions. Again, we see that candidates do not appear to change their positions over time. 
Figure 1.1 - The Rigidity of Candidate Positions: Lack of Changes From Candidates' First to Second Campaigns. Plots estimates of first- and second-term candidate ideology based on dynamic CFScores for U.S. House Candidates, 1980-2012, who run for election at least twice. As the horizontal lines show, candidates' estimated positions rarely change.

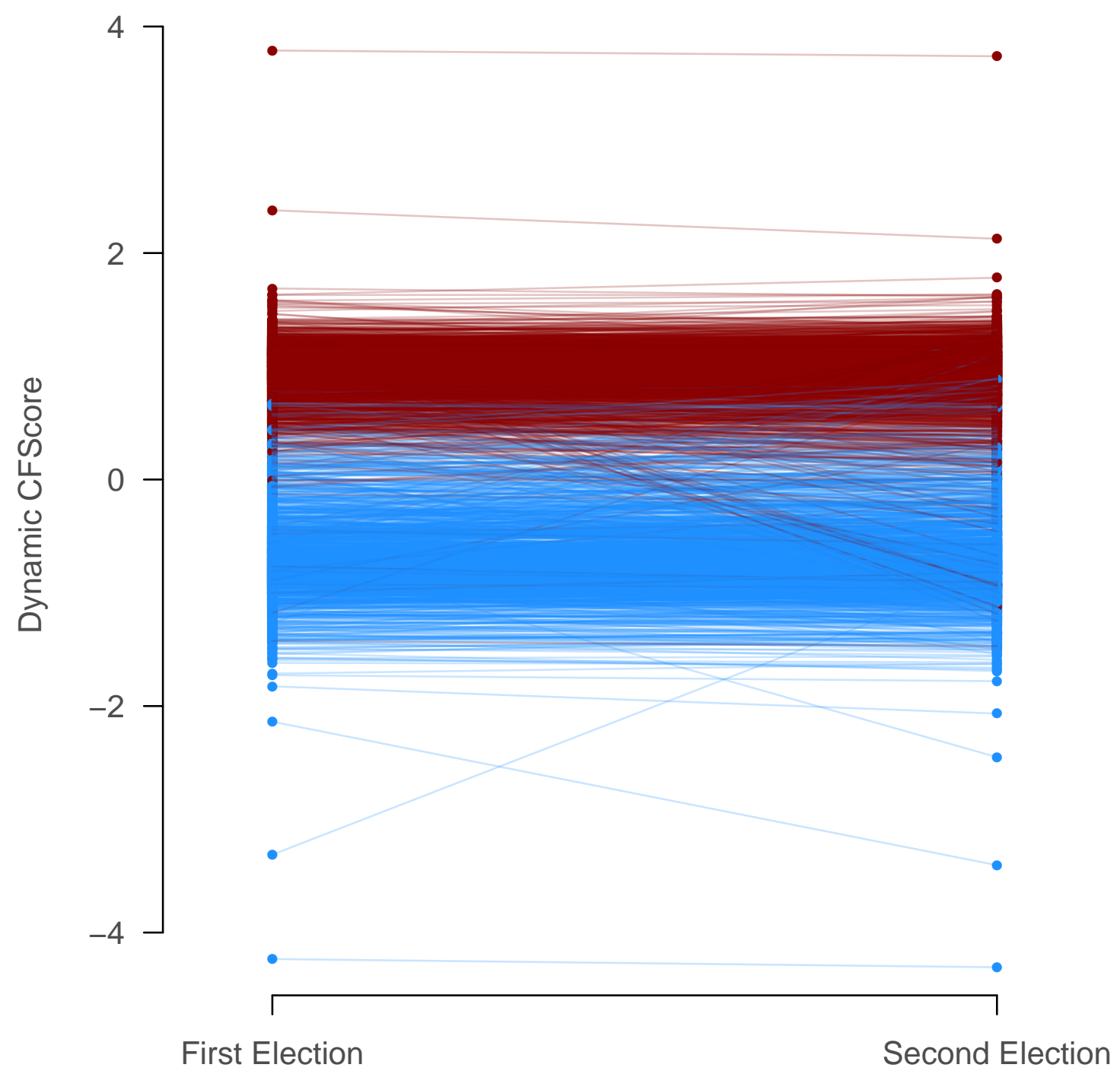


Figure 1.2 - The Rigidity of Candidate Positions: The Distribution of Changes From Candidates' First to Second Campaigns. Plots estimated change in candidate ideology based on dynamic CFScores for U.S. House Candidates, 19802012, who run for election at least twice. The vast majority of candidates display almost no change in their ideology.

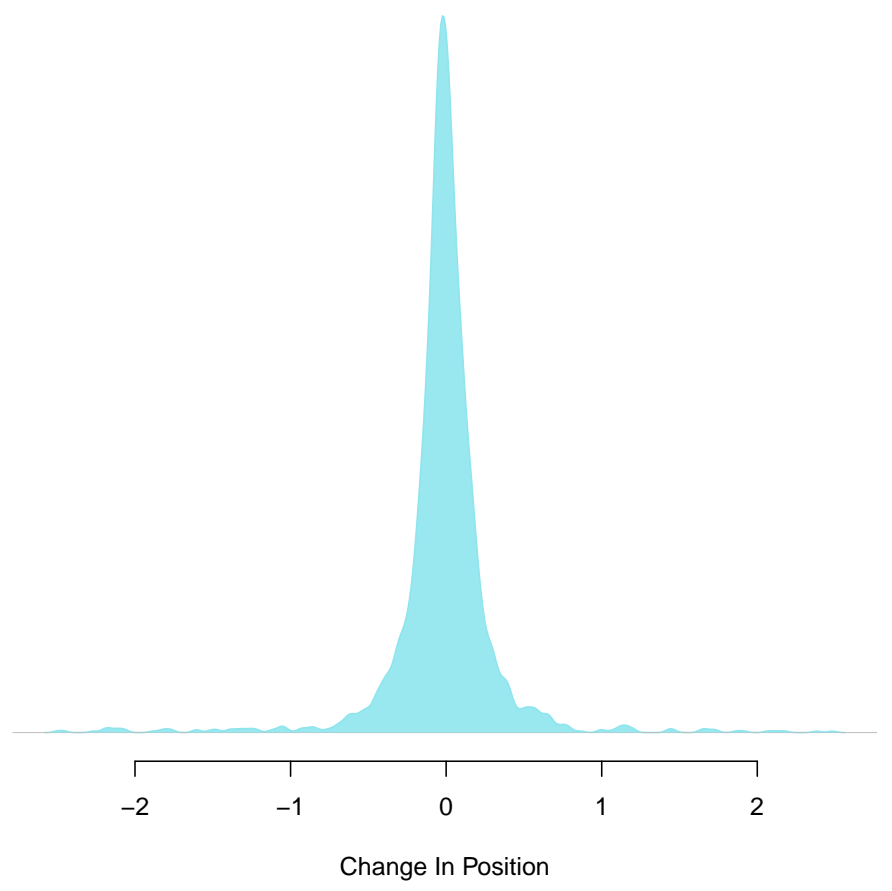

\subsection{Long-Term Effects of Elections on Roll-Call}

\section{Votes}

Another way to explore how rigid candidate positions are is to look at the longterm effects of election results. As I mentioned previously, Fowler and Hall (N.d.) examines how the "as-if" random assignment of a Democratic or Republican candidate to represent a district today affects the downstream roll-call voting cast on behalf of the district in the future, showing evidence of a profound divergence between the two parties, even when representing the same hypothetical set of 
Figure 1.3 - The Rigidity of Candidate Positions: Evidence from Candidate Careers. Compares dynamic CFScores for a candidate in an election at time $t$ to her previous dynamic score at $t-1$, for U.S. House Candidates, 1980-2012. Previous ideology is an extremely strong predictor of current ideology.

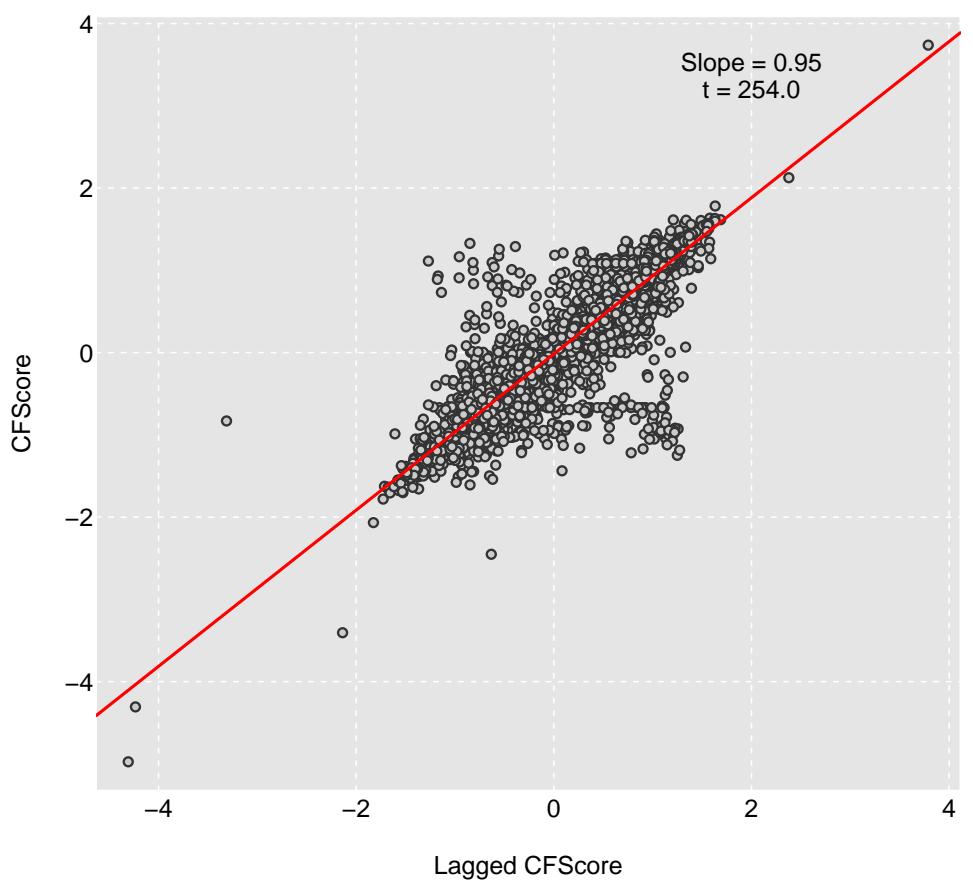

voters. Alone, this divergence does not necessarily imply rigidity; there are many reasons members of the two parties might diverge. However, Fowler and Hall (N.d.) goes further and investigates how long into the future the roll-call voting cast on behalf of a given district displays divergence, and how long into the future the district still keeps the same representative.

Essentially, the paper finds that the effects of an election outcome on future elections - that is, on the chance the party who won the election at a given time continues to win elections in the future, decays in close proportion with the effects on future roll-call voting. As the paper explains, "The long-term consequences 
of election results for partisan representation and roll-call representation decay in almost exact proportion to one another, suggesting that legislators do not, on average, improve over time. Even when a legislator fails to closely match her district, and even when the district continues to re-elect her over the course of many terms, the legislator continues to cast roll-call votes in the same way without moderating to the positions of the district" (16).

\subsection{Incumbents Do Not Adjust Positions Based On Primary Challenges}

Thus far I have presented descriptive evidence that candidate positions do not appear to move much, if at all, over the course of candidates' careers. In this section, I focus on a particular factor thought to affect incumbents quite profoundly: primary challenges. An important body of work discusses the possible consequences of primary challenges for incumbents, especially when members of Congress "get primaried," i.e., get challenged by more ideologically extreme candidates from their own party (Boatright 2013).

An obvious prediction is that incumbents should respond to such challenges by moving farther away from the median voter in the district, and closer instead to the median primary voter. Here I test this particular prediction by examining how incumbents respond, ideologically, to the emergence of more extreme primary challengers. Consistent with the descriptive evidence above, I again find that incumbents hold remarkably rigid positions. When challenged by more ideologically extreme primary candidates, incumbents on average make 
no alterations to their ideological platforms. Though this analysis does not test theories that predict that incumbents pre-emptively take non-median views in order to dissuade primary challenges, the results certainly suggest that incumbents' positions - however chosen - do not respond to the ideological positions of opponents.

Obtaining empirical leverage on this question is difficult. First, we must identify extremist primary challengers. Then, we must find a way to assess the effects these challengers have on incumbent positions. Simply comparing average incumbent positions when there is or is not an extremist challenger will not accomplish this goal; incumbents who get challenged may differ, systematically, from those who are not challenged, and so, too, may the districts in which the two types serve. If we focus on how individual incumbents change their positions when faced with an extremist challenger vs. when faced with a moderate challenger vs. when faced with no challenger, we can attempt to address this source of bias, because we hold fix both the underlying type of the candidate and the district.

However, this within-incumbent design still has problems. Most obviously, changes in an incumbent's platform over time may not be due only to whether or not an extremist challenger is present. We can address this type of dynamic problem by performing a difference-in-differences in which we examine the differential way in which incumbents challenged by extremists change their positions relative to incumbents who are not challenged. The difference-in-differences is an improvement over the simple within-incumbent design, addressing the problems of selection bias inherent in making comparisons across incumbents and districts and across time periods. As a result it offers a plausible look at how incumbents react to extremist challengers. 
The formal results are presented in the appendix to this chapter. In both parties, incumbents exhibit no discernible ideological shift in response to primary challenges from their ideological flanks. Democratic incumbents who enjoy uncontested primaries have an average dynamic CFScore of -0.478 ; those with an extremist challenge have, on average, a dynamic CFScore 0.003 points less - a minuscule difference, and one we cannot statistically differentiate from the null hypothesis of no difference. Results are similar for Republican incumbents. Pooling across both parties by taking the absolute value of CFScores (so that positive scores indicate more extreme candidates, more or less), incumbents have on average a score of 0.713 ; those with extremist challengers shift their positions by an estimated 0.003 points, i.e., they do not change at all.

Figure 1.4 offers these results in a different way. Each of the two plots compares challengers' dynamic CFScores to the change in incumbent dynamic CFScores from the previous election to this one. The overlaid red lines represent simple OLS estimates. For both parties the lines are remarkably flat. Incumbents appear not to change their positions at all regardless of where their challengers lie, ideologically.

If candidates possess fluid ideological positions, we should expect them in many cases to alter these positions in response to the positions of challengers. This logic is at the heart of models that predict that incumbents should address primary challenges by moving their positions. If, on the other hand, candidates have rigid positions, then such challenges should have no effect on incumbent positions. The evidence supports this second hypothesis. Incumbents do not respond to moderate or extreme challengers by moving at all. The easiest way to explain this behavior, in conjunction with the previous sections' results on 
Figure 1.4 - Incumbents Do Not Respond to Primary Challenger Positions. The plots present how much incumbents of each party in U.S. House races, 1980-2012, change their ideological positions in response to varying positions of their primary challengers. There appears to be no relationship between challenger position and changes in incumbent positions.

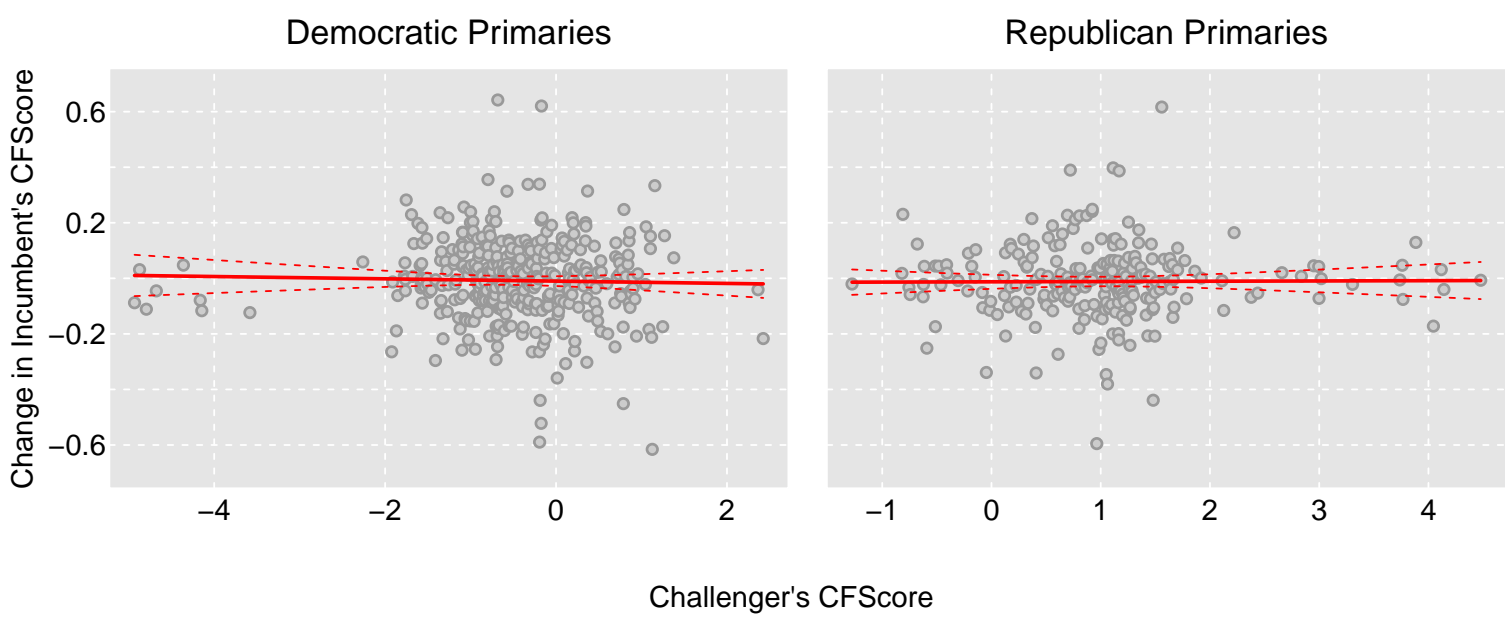

Note: Red lines are OLS fits to data. Dashed lines are $95 \%$ confidence intervals. CFScores are dynamic scores.

candidate positions over time, is that candidate positions are at least partially rigid.

\subsection{Candidate Identity Linked to Candidate Po- sitions}

If, as I argue, candidates come pre-committed to certain ideological positions, we might expect to observe systematic differences in candidate positions across salient aspects of candidate identity. Downsian theories predict that all candidates - regardless of backgrounds, identities, etc. - move to the middle. If this 
is true, we should observe no systematic differences candidate positions across candidate identities, for a set of candidates running to represent the same voters. This last caveat is crucial. We might observe systematic differences in, for example, men and women candidates across the pooled dataset. But these differences could indicate that men and women candidates arise in different areas, where voter preferences are different, and thus would not necessarily run counter to Downsian predictions. But if candidates offering to represent the same median voter offer systematically different positions based on observable demographic characteristics, then we might conclude there is more to candidates' positions than the location of their districts' median voters.

To examine this hypothesis, I focus on a single demographic trait which is readily observable in the data: candidate gender. An existing literature studies differences in ideology by gender, both for candidates and for elected legislators (see for example McCarty, Poole, and Rosenthal 2006; McDermott 1997; Welch 1985); I simply reinforce the findings in this literature using a larger dataset containing the full universe of U.S. House candidates. I use the Bonica (2014) dataset, which includes an estimate of each candidate's gender based on first names. In Figure 1.5, I plot the distribution of candidate ideology for men and women by party. By splitting by party I ensure that observed differences between men and women candidates do not simply reflect an imbalance in their prevalence across parties - e.g., since women are more frequently Democratic candidates (Thomsen N.d.), finding that women on average have more liberal positions than men might only reflect differences across the parties and not across men and women candidates in other ways. As the densities show, women offer on average 
Figure 1.5 - Candidate Ideology by Gender and Party. Among candidates for the U.S. House, 1980-2012, women hold more liberal positions than men of the same party, on average.

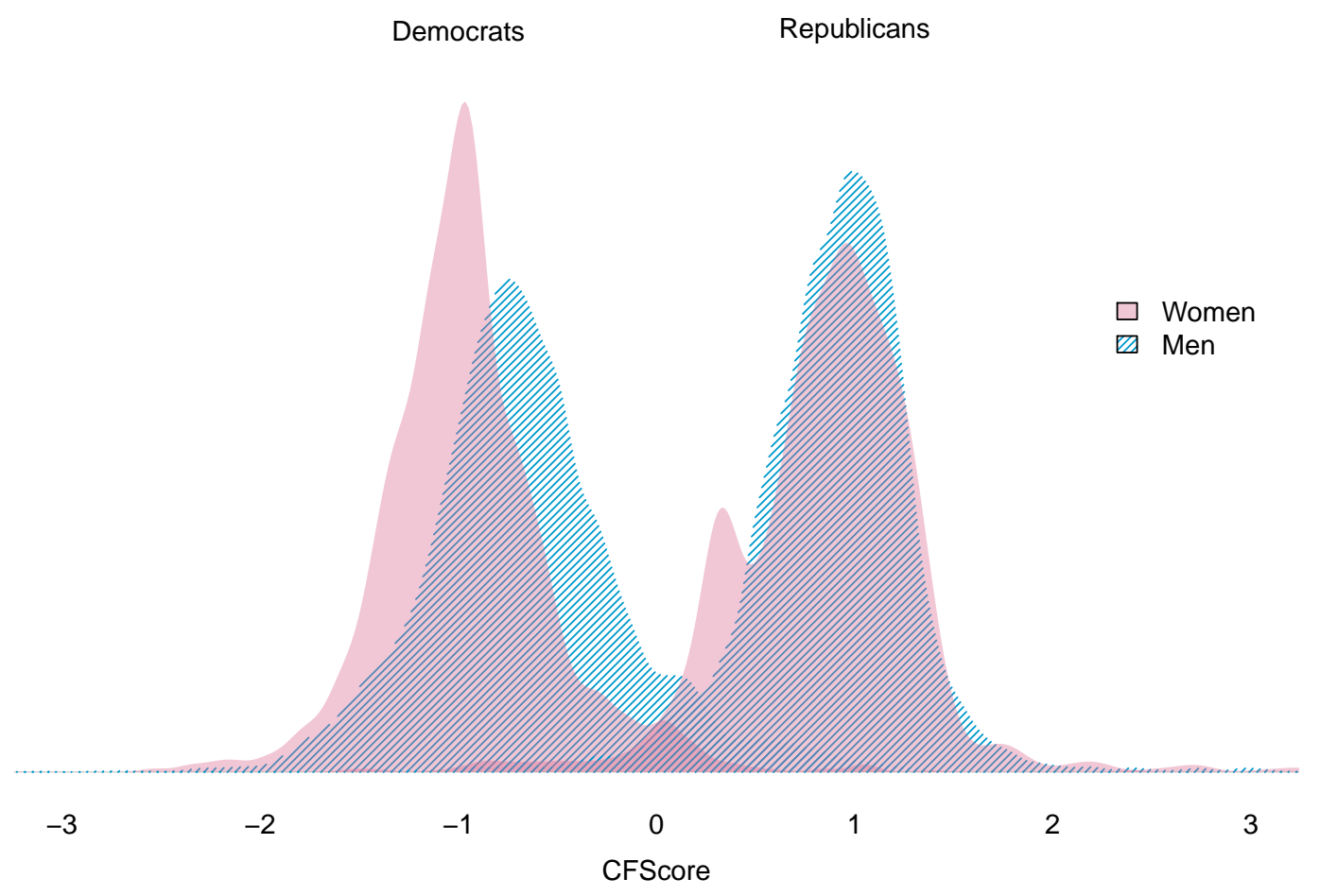

more liberal positions. This difference is especially marked in the Democratic party but present in both parties.

What if women and men run for office in systematically different districts, so that these observed differences confuse electoral context with candidate identity? Or, alternatively, what if women candidates are simply more common in recent time periods, during which time positions have shifted for everyone? In the appendix to this chapter, I run more formal regression analyses in which I account for unobserved differences across districts and across time. I continue to find the same kinds of systematic differences in positions. 
There are many possible reasons for this relationship, and understanding it is far beyond the scope of this study. But the documented pattern has important implications for this book's argument. Candidates are not just strategic, blankslate agents seeking out the median voter in their district. They come to elections with pre-existing views that arise, in part, from pre-existing traits, like identities and experiences. They do not change these views on a whim. As a result, who is willing to run for office is a crucial factor in determining the positions voters have the opportunity to choose between.

\subsection{When Do Candidates Change Positions?}

From a bird's eye view, candidate positions appear to be largely unchanging. But that does not mean that candidates have no room to maneuver. The results presented here have all been "on average" findings, averaging over candidates, eras and, most importantly, issues. In the big picture, candidates rarely change their positions, but we should not conclude that candidates never change positions on any issues. To do so would be to caricature a much more nuanced process.

For example, several recent papers explore conditions under which incumbents change their positions. Feigenbaum and Hall (2015) shows how localized, negative shocks from trade cause U.S. House incumbents to vote more protectionist on trade bills while leaving their positions on other issue areas unchanged - especially when they are more threatened, electorally. Clinton and Enamorado (2014) documents how MCs change their roll-call records in response to the roll-out of Fox News in their districts. Both papers uncover unusually salient situations in which incumbents will change their positions, but because effect sizes are relatively mod- 
est, it is unsurprising that such changes do not alter the larger picture of rigid positions much.

Another way in which incumbents can alter their overall platform is by taking action on specific issues. Sulkin (2005) argues that incumbents "take up" issues that their challengers prioritize in unsuccessful bids to unseat them. This represents an important dimension of flexibility for incumbents, but it is distinct from changing ideological positions. It focuses on specific policy actions rather than incumbents' overall ideological portfolio, and it depends on action rather than position.

Finally, it may be the case that candidates for other, non-legislative offices may enjoy more ideological flexibility. Many of our intuitions about how flexible candidates can be, along with the "etch-a-sketch" moment I mentioned before, come from presidential elections. Presidential candidates seem both to change their positions between the primary and the general election, and also to choose many of their positions based not on personal belief but on political expediency. The evidence and arguments in this chapter say absolutely nothing about this possibility. Executive elections are fundamentally different than legislative ones. Voters judge candidates by different standards, and ideology may be far less important than other factors given the range of personal responsibilities executives have. Moreover, the types of candidates may vary from those in the legislature, too. Many presidents, like Clinton and Reagan, were governors but not legislators. I am wary of extending any of the claims made here about legislators to other elections like those for president or governor.

Legislative candidates have many reasons to alter their positions, both for strategic gain - if they can do so while escaping punishment for "flip-flopping" - 
and due to changing personal preferences. The claim I develop in this chapter does not rule out such changes, but it does argue that they should be the exception, rather than the rule. The more common these changes are, the less binding a constraint who runs is likely to be. The more malleable candidates are, i.e., the more voters can pressure them to cater to their demands, the less it matters, from an ideological perspective, who runs for office. But, as the empirical analyses in this chapter have shown, such changes are in fact exceedingly rare. Candidates positions appear to be quite rigid, and voters are thus left to select candidates with pre-existing positions rather than to pressure candidates into catering to their preferred ones.

\section{Summary: Voters as Selectors}

A vast literature in American politics is based on a theoretical view of fluid candidate positions. This view implies that voters must drive polarization, since candidates simply reflect voters' preferences in this theoretical world. How fluid are candidate positions, empirically? In this chapter I have reviewed existing evidence and offered a new series of analyses that suggest that candidates' overall slates of positions rarely change. Within their careers, candidates rarely, if ever, display any marked shifts in their ideology. This rigidity persists even in the face of primary challenges from incumbents' ideological flanks - often thought to contribute to polarization. Incumbents display no change in their positions, on average, in response to challenges by extremist primary challengers. As I made clear before presenting these analyses, no one strategy or piece of evidence can prove, beyond a shadow of a doubt, that candidates are entirely rigid. CFScores 
may overstate the stability of candidate positions. In addition to offering some arguments for why this bias may not be too much of a problem, I have also offered additional pieces of evidence - by reviewing a variety of work on incumbent roll-call votes, and by looking at how positions do vary along with candidate attributes - all of which point to the idea that candidates are relatively rigid in their positions.

The inflexibility of candidates' positions is consistent with the simple idea that candidates have underlying traits, including their ideology, that spring from longstanding, personal characteristics and experiences. In accord with this idea, the latter part of this chapter echoes previous literature in showing how candidate ideology varies, systematically, with an important component of candidate identity, gender. Women candidates in both parties offer systematically more liberal positions. This is true even when making comparisons among candidates running in the same district, thus highlighting the role of identity, rather than only generic strategic concerns, in determining the positions that candidates offer to voters.

In general, we think of voters having two tools with which to influence ideological representation: they can select for candidates of particular ideological bents, and/or they can pressure candidates into changing their positions. Or, in the language of Fearon (1999), voters can select for ideologically congruent candidates, and/or they can sanction candidates for taking actions in office that are contrary to voters' wishes. As Fearon (1999: 76) sums up, "a number of empirical observations suggest that voters think about elections more in terms of selection than as sanctioning mechanisms to influence future incumbents." Lee, Moretti, and Butler (2004: 849-9) concludes likewise, writing, “...voters do not influence 
policy choices as much as they are presented with choices." Voters' main chance to influence ideology is therefore to select candidates.

The evidence in this chapter - that candidate positions are rigid - further supports these views. When it comes to ideology, elections are largely about selecting candidates rather than sanctioning them. In turn, this implies that who runs is an important factor to consider in explaining polarization. If the candidates who run for office are systematically out of step with voters, ideologically, then who runs becomes a binding constraint on voters. On the other hand, if voters are faced with plenty of candidates whose views match their own, then it is not a binding constraint. As such, this chapter has set the stage for the questions we must now consider: who actually runs for office? And who would voters like to have run for office? These are the next questions we must answer to understand how who runs can drive legislative polarization. 


\section{Appendix}

\section{Primary Challenges and Incumbent Positions}

To implement the difference-in-differences, I estimate equations of the form

$$
\begin{array}{r}
\text { Dynamic CFSCore }_{i t}=\beta_{0}+\beta_{1} \text { Extremist Challenger }_{i t} \\
+ \text { Moderate Challenger }_{i t}+\gamma_{i}+\delta_{t}+\epsilon_{i t},
\end{array}
$$

where Extremist Challenger ${ }_{i t}$ is an indicator variable for the presence of an extremist challenger to incumbent $i$ in the primary at time $t$. Finally, $\gamma_{i}$ and $\delta_{t}$ represent incumbent and year fixed effects, respectively.

Extremist challengers are identified as follows. For Democratic incumbents, a challenger is coded as "extreme" if her estimated dynamic CFScore is farther to the left (more negative) than the incumbent's dynamic CFScore in the previous electoral cycle. For Republican incumbents, a challenger is coded as extreme if her estimated dynamic CFScore is farther to the right (more positive) than the incumbent's dynamic CFScore in the previous electoral cycle. Moderate challengers are constructed analogously, except for candidates farther to the right than the incumbent's previous position, in Democratic primaries, and farther to the left in Republican primaries.

Table 1.1 presents the estimated results. The first row presents the coefficient estimates on Extremist Challenger. In both parties, incumbents exhibit no discernible ideological shift in response to primary challenges from their ideological flanks. Consider the estimate in the first column, for Democrats. Democratic 
Table 1.1 - Incumbents Do Not Shift Positions in Response to Extremist Primary Challenges.

\begin{tabular}{lccc}
\hline \hline & $\begin{array}{c}\text { Democrats } \\
\text { CFScore }\end{array}$ & $\begin{array}{c}\text { Republicans } \\
\text { CFScore }\end{array}$ & $\begin{array}{c}\text { Both Parties } \\
\text { Abs CFScore }\end{array}$ \\
\hline Extremist Challenger & -0.003 & -0.015 & 0.003 \\
& $(0.013)$ & $(0.014)$ & $(0.010)$ \\
Moderate Challenger & -0.029 & 0.008 & 0.020 \\
& $(0.013)$ & $(0.013)$ & $(0.010)$ \\
No Challenger & -0.478 & 0.969 & 0.713 \\
& $(0.017)$ & $(0.023)$ & $(0.015)$ \\
$\mathrm{N}$ & 3,481 & 2,778 & 6,259 \\
\hline Year Fixed Effects & Yes & Yes & Yes \\
Incumbent Fixed Effects & Yes & Yes & Yes \\
\hline \hline
\end{tabular}

Robust standard errors clustered by incumbent in parentheses. CFSCores are dynamic scores.

incumbents who enjoy uncontested primaries have an average dynamic CFScore of -0.478; those with an extremist challenge have, on average, a dynamic CFScore 0.003 points less - a minuscule difference, and one we cannot statistically differentiate from the null hypothesis of no difference. (Note that because of the fixed effects, the "No Challenger" row requires some additional explanation. This coefficient is the intercept reported from areg in Stata. It is reported as the value that makes the sum of the OLS residuals zero when all $\mathrm{X}$ variables are set to their means. It can thus be interpreted as the average no-challenger incumbent position for the "average" observation in the sample. The choice to present the results this way is purely for simplicity; it does not (and cannot) change the interpretation of the differences in any meaningful way.) 
The second column shows similar results for Republican incumbents. Again, the smallest of differences is seen between uncontested incumbents and those facing an extremist challenger. The third row combines the results from the first two columns by taking the absolute value of the dynamic CFScores. Across both parties, incumbents have on average a score of 0.713 ; those with extremist challengers shift their positions by an estimated 0.003 points, i.e., they do not change at all.

The second row presents the analogous estimates for the case of moderate challengers. Again we find no meaningful changes. Although we can reject the null hypothesis in the first and third columns, the estimated effects are substantively negligible. Consider the point estimate on "Moderate Challenger" in the first column, for example. The intercept in the first column tells us that an uncontested Democratic incumbent has, on average, a dynamic CFScore of -0.478 , while those challenged by a more moderate candidate change their position, on average, to a dynamic CFScore of -0.507 , a change of -0.029 points. The average distance between the parties' uncontested incumbents, for comparison, is 1.447. This change is thus only $2 \%$ the size of the distance between the parties.

The method of identifying extremist or moderate candidates that I have used in these analyses has two potential, related problems. First, some challengers may have ideological positions very much like those of the incumbent. For these races, we might expect the incumbent to move less, if at all, due to the proximity. Second, since these positions are estimated with noise, challengers close to incumbents will be more likely to be mis-classified as "moderate" challengers when they are in fact extremist challengers, or vice-versa. To address this issue, I follow the technique of Hall (2015). Next, I re-estimate the same regressions 
only using the subset of data in which the distance between the incumbent and her challenger is at or above the median such distance across all races. This ensures that I only perform the analysis on incumbents and challengers with quite distinct positions. I continue to find exactly the same pattern of evidence.

Table 1.2 - Incumbents Do Not Shift Positions in Response to Extremist Primary Challenges: Including Only Ideologically Distinct Challengers.

\begin{tabular}{lccc}
\hline \hline & $\begin{array}{c}\text { Democrats } \\
\text { CFScore }\end{array}$ & $\begin{array}{c}\text { Republicans } \\
\text { CFScore }\end{array}$ & $\begin{array}{c}\text { Both Parties } \\
\text { Abs CFScore }\end{array}$ \\
\hline Extremist Challenger & 0.022 & -0.044 & -0.020 \\
Moderate Challenger & $(0.017)$ & $(0.017)$ & $(0.014)$ \\
& -0.064 & 0.027 & 0.039 \\
No Challenger & $(0.016)$ & $(0.019)$ & $(0.014)$ \\
& -0.477 & 0.965 & 0.713 \\
$\mathrm{~N}$ & $(0.018)$ & $(0.024)$ & $(0.015)$ \\
& 3,280 & 2,644 & 5,924 \\
\hline Year Fixed Effects & Yes & Yes & Yes \\
Incumbent Fixed Effects & Yes & Yes & Yes \\
\hline \hline
\end{tabular}

Robust standard errors clustered by incumbent in parentheses. CFSCores are dynamic scores.

\section{Positions of Men Vs. Women Candidates}

In this chapter, I showed that, on average, women in both parties offer systematically different positions than men. It is still possible that the observed difference reflects a difference in context; within party, women may run for office in different types of districts than do men, which would again prevent us from concluding that we are detecting a demographic difference. Accordingly, I estimate regression 
Table 1.3 - Women Candidates Hold More Liberal Positions Than Male Candidates, On Average.

\begin{tabular}{lcccc}
\hline \hline & CFScore & CFScore & CFScore & CFScore \\
\hline Woman & -0.20 & -0.17 & -0.16 & -0.16 \\
& $(0.02)$ & $(0.02)$ & $(0.02)$ & $(0.02)$ \\
Democrat & -1.62 & -1.75 & -1.65 & -1.76 \\
& $(0.02)$ & $(0.02)$ & $(0.02)$ & $(0.02)$ \\
$\mathrm{N}$ & 21,178 & 14,545 & 21,178 & 14,545 \\
\hline Year Fixed Effects & No & No & Yes & Yes \\
District Fixed Effects & No & No & Yes & Yes \\
Controls & No & Yes & No & Yes \\
\hline \hline
\end{tabular}

Robust standard errors clustered by district in parentheses. Controls in columns 2 and 4 are average donor CFScore by district and district's previous Democratic presidential vote share.

equations of the form

$$
\text { CFScore }_{i j t}=\beta_{0}+\beta_{1} \text { Woman }_{i j t}+\beta_{2} \text { Dem }_{i j t}+X_{j t}+\epsilon_{i j t},
$$

where $W_{o m a n}$ ijt is an indicator variable for candidate $i$ in district $j$ in the election at time $t$ being a woman and Dem is the corresponding indicator variable for party. The variable $X_{i j t}$ stands in for a vector of district-level control variables to address the possibility of differences across the set of districts that see women candidates more often.

Table 1.3 presents the results using four different specifications. In the first column, I include no additional controls - thus computing the simple average difference in ideology across men and women candidates within party. In the second column, I add district-level controls for the average donor ideology and 
the district's previous Democratic vote share for president. In the third and fourth columns I repeat this exercise but with the addition of district and year fixed effects. Across all four columns we see a steady difference; women candidates are consistently estimated to be, on average, more liberal than male candidates. 


\section{Chapter 2}

\section{Polarized Candidates and Constrained Voters}

If the people can choose only from among rascals, they are certain to choose a rascal.

- V.O. Key,

The Responsible Electorate

Many of our theories of elections, and even many popular accounts of the way politics works, think about legislative campaigns as if they are contested by ideologically fluid candidates seeking only to mirror their voters' views. In these accounts, politicians are abstract campaigners without principles or beliefs, choosing whatever set of views seem electorally convenient and saying whatever they think will help them win office. The point is not that this is an unrealistic depiction of politicians; theories are intentionally unrealistic, but still useful for thinking through the strategic dynamics of many political settings. The key question is whether thinking this way misses something important when we attempt to explain why our legislatures are polarized.

In the last chapter, we saw that candidates rarely change their ideological positions. This suggests that candidates are more than just mirrors for their voters' desires. As a result, who runs can affect the choices voters are able to make. If voters are faced with choices among only ideologically extreme candidates, and if 
they cannot induce these candidates to change their positions, then polarization may be in part the result of this constraint. The rise in polarization is in part the result of the changing nature of who runs. We miss this component, that part driven by the ideology of the people willing to run for office, when we think of candidates as mirrors. In this chapter, I lay out the basic empirical evidence in favor of this claim.

Contrary to the reasoning of the Median Voter Theorem, if elections are primarily about selecting candidates of particular ideological positions, and not about inducing candidates to adopt positions seen as electorally desirable, then who runs for office is crucial. But the results in the previous chapter only established the possibility that who runs affects voters' choices in the U.S. House. To determine whether who runs actually matters, ideologically, and in particular to see if it helps explain why our legislatures have become more polarized, we need to show that (a) voters tend to prefer more moderate candidates, and (b) those running for office have become more ideologically extreme, over time. These are the twin goals of this chapter.

To tackle the first goal, I investigate the choices voters make at the ballot box in a variety of ways. I review existing work on the electoral advantages of more moderate candidates and I present new evidence that general-election voters prefer more moderate candidates. In doing so, I am careful to distinguish this revealed preference from the underlying ideology and views of voters. Voters may themselves be moderate, extreme, or incoherent; all that matters for my argument is that, in the aggregate, they tend to choose more moderate candidates when given the opportunity. The mechanism by which they do so-be it ideology, or be it some other factor that moderate candidates tend to offer (e.g., quality) - does 
not change the central fact that they send more moderate candidates to office when presented with the chance to do so. It is this consequence, rather than the underlying mechanisms, that informs us about candidate-driven polarization.

For the second goal, I explore the changing composition of the candidate pool for the U.S. House. I confirm that those who run for office, not just those sent to the general election but all those who even enter primary elections, have become more ideologically extreme over time, on average. This phenomenon is common to both parties. Moreover, this shift is not the result of outlier candidates; looking within congressional districts, even the most moderate candidates available to voters have moved farther away from the middle. Voters systematically receive fewer opportunities to elect moderates in today's legislative elections than they did forty years ago. Not surprisingly, this trend in the ideology of the candidate pool tracks legislative polarization tightly. Both have risen in lock-step over the past several decades.

In combination, the results strongly suggest that voters are actively constrained by who runs. If more moderate candidates were to run, voters would likely elect them to office.

\subsection{Studying the Links Between Ideology and Electoral Success}

A long and sometimes fraught literature seeks to link the ideological positions of candidates to their electoral performance. Scholars vary in the techniques they employ, the data they use, and the conclusions they draw. Do moderate 
candidates do better, electorally, or not? I will explore this question below, but first, I must draw important distinctions among this literature. Because the literature has often been vague about the actual goals of studying candidate ideology, it is difficult to make meaningful comparisons across studies. I try to be as clear as possible about the goals of my analyses, and in so doing, I (hopefully) help reconcile some of the differences amongst previous works.

\subsubsection{Defining Research Goals}

Why do we study ideology and electoral results? And why is the literature so inconsistent in how it approaches this topic and in the conclusions it draws? In part, the disagreements in this literature stem from a failure to make explicit what the research goals are. Is the point to identify the "causal effect" of a candidate changing her platform on voting outcomes, or is the point to understand how the ideological composition of our legislature is determined? These are two very different goals which require different kinds of evidence, but the literature has rarely, if ever, separated them clearly.

Consider the following two explicit statements, each of which offers a goal for empirical research studying candidate positions and electoral outcomes:

1. Examine which candidates offering which ideological platforms tend to win office, in order to understand how our elections determine the ideological composition of our legislatures.

2. Identify the causal effect of a candidate changing her ideological platform on vote outcomes in order to understand the ideology of voters and the incentives of strategic candidates. 
The first goal concerns understanding our legislatures. Why have our legislature become more polarized? Answering this question requires, in part, evaluating what types of candidates are being elected to office. Are more moderate or more extreme candidates winning elections at a higher rate? Why?

Answering this question could have little, or nothing, to do with the causal effect of a candidate changing her positions and choosing to make them more moderate or more extreme, in contrast to goal (2). Suppose - as an extreme hypothetical! - that all moderate candidates are short and all extreme candidates are tall, and that voters know nothing about candidate positions and vote purely based on height, preferring taller candidates to shorter ones. Now let's suppose that we as researchers ask the question: do moderate candidates make it into office? In this hypothetical, the answer will be "no," not because taking more moderate positions causes a candidate to do worse, but rather because moderate candidates are short and voters only vote for tall candidates.

In answering this question, we will learn something about polarization: more extreme candidates are winning races and making it into the legislature. We will not necessarily observe the mechanism by which they win races (in this case, their height), but we will observe the ideological consequences. That is, elections have ideological consequences for the legislature even if the mechanism by which voters choose whom to vote for is not ideological. This example can also be pushed forward to thinking about who runs. Suppose we find that tall people are more willing to run for office, and that as a result, the candidate pool is disproportionately extreme, ideologically (and vertically!). This fact helps us understand polarization even if the decision to run has nothing to do with ideology, and even if voters do not vote on the basis of ideology. 
This is not to say that the causal effect of candidate positioning is not also interesting - of course it is, as a matter of theory, not to mention as an input into any candidate's strategic thinking. But if we want to understand polarization, these ideological consequences, rather than mechanisms, must be our primary focus. These consequences may be entirely separate from, or even opposite, the causal effects of candidate positioning.

This does not mean that observing these consequences is always straightforward, however. Although there may not be issues of causality, there are clear issues of measurement and omitted variables. We must somehow assess which candidates are more extreme and which are more moderate, relative to the districts in which they run. This is no simple task. While we have access to somewhat reliable estimates of candidate ideology, we know little about the ideological preferences of the voters in each congressional district. Since candidates can only be "moderate" or "extreme" in relation to their voters, this makes the problem difficult.

The literature has used a variety of strategies to get around this fundamental issue. In some cases, papers attempt to hold the unobserved position of the median voter, and the distance between candidates, constant in order to evaluate the association between shifts in the candidates' ideological midpoint and electoral outcomes (Ansolabehere, Snyder, and Stewart 2001). Others examine the absolute value of candidates' ideological positions (when measure as negative for liberal and positive for conservative), under the assumption that being farther from zero (i.e., greater in absolute value) will at least generally indicate distance from the unobserved median (Canes-Wrone, Brady, and Cogan 2002). 
I will present two kinds of analyses - one in keeping with these traditions, and the other to attempt a new approach. In both cases I will again find that elections overwhelmingly filter for moderate candidates. This conclusion holds whether we use campaign finance or roll-call votes to measure ideology. Though candidates of the two parties diverge quite dramatically, voters typically select the more moderate options from among this polarized pool. Whether are not these choices are driven by ideology, directly, or whether voters are in fact only selection for some other correlate of candidate ideology, the conclusion is that voters tend to prefer the types of candidates who offer more moderate positions.

\subsubsection{Defining Ideological Extremism}

Separate from the issue of defining research goals, the literature is not always clear about what it means for a candidate to be "extreme," though this concept is vital to interpreting any empirical results about our elections and our legislatures.

Consider all candidates running in a given year for the U.S. House of Representatives. Who is extreme, and who is moderate? There are two obvious options for answering this question. The first option, which I will call legislative extremism, is to compare candidates to the legislature. This exercise could be done using all candidates, when we possess a measure of ideology that applies to incumbents and non-incumbents alike, or it could be done only for the set of incumbents for whom we have roll-call based measures of ideology.

Legislative Extremism. Under this definition, a candidate's extremism is measured in terms of the ideological distance between herself and the median of the legislature (or potentially the median 
legislator of her party). Candidates especially far from the median legislator are more extreme; those closer to the median legislator are more moderate.

The second option, which I will call district extremism, is to compare candidates to their districts.

District Extremism. Under this definition, a candidate's extremism is measured in terms of ideological distance between herself and the median voter in her district. Candidates farther from the median voter in the district are more extreme; those closer to the median voter are more moderate.

Clearly, these two choices will lead to quite different classifications. Someone who is extreme relative to the median legislator might be a perfect fit for her district; think for example of left-wing representatives that come from extremely liberal cities, or right-wing representatives that come from extremely conservative rural areas. They may be extreme relative to their colleagues in the legislature but it is possible their views are quite similar to those who have sent them to Washington. Conversely, someone who appears moderate in the legislature could just as easily be extreme relative to her the median voter in her district. As such, the two definitions produce distinct classifications of incumbents. Which is to be preferred?

The answer, naturally, varies depending on the research questions we wish to study. In the realm of polarization, each definition plays a valuable role. When we think of overall legislative polarization, we may well simply mean that some 
legislators have very different views than others, and that this might lead to gridlock. In this case, the first definition, legislative extremism, makes sense. But this definition cannot disentangle the potential ways that elections drive underlying polarization. Because legislators come from different constituencies, legislative polarization itself could be consistent with a world in which the median voter in each district elects a candidate with precisely her views. Or it could be consistent with a world in which only extreme candidates run for office. Alone, legislative polarization thus does not tell us about election-level divergence. As a result, it is the second definition - district extremism - that fits best for the present purpose. The point is that voters are being faced with increasingly unpalatable options at the ballot box. This is only true if district extremism is increasing; it may or may not be true when legislative extremism is increasing, because the latter can be the result of sorting across districts rather than only district-level divergence.

Accordingly, whenever I use the terms "moderate" or "extreme" from here on out, I will be implicitly referring to district ideology - that is, I will be defining candidates as relatively moderate or extreme relative to their districts. In cases where I depart from this definition, I will explicitly say so.

\subsection{Voters Tend to Prefer Moderate Candidates}

\subsubsection{Considering the Existing Evidence}

Probably the best known evidence that voters prefer more moderate candidates, on average, comes from Canes-Wrone, Brady, and Cogan (2002). The authors compare incumbents who compile differing roll-call records and link their ideology 
to their electoral performance. In particular, the paper defines a variable called Roll-Call Ideological Extremism, which takes on higher values for members of the legislature whose roll-call record indicates they are farther into the wings of their respective parties.

The key obstacle to using measures of this form is that it does not immediately imply that a candidate is extreme for her district. Imagine two Democratic incumbents, one from a very liberal district in Massachusetts, the other from a more centrist district in Texas. The Massachusetts incumbent is likely to have a much more "extreme" roll-call record than her Texas colleague, but we cannot conclude from this evidence alone which one is farther from her district's median voter. It is entirely possible it is the Texas incumbent who is farther away.

To tackle this issue, Canes-Wrone, Brady, and Cogan (2002) controls for a proxy of district ideology - presidential vote share. Instead of making a raw comparison across members with more or less "extreme" roll-call records, they make these comparisons only among districts that showed similar support for the Democratic presidential candidate. The hope is that such districts have similar median voters and, therefore, that increases in roll-call extremism imply an increase in the distance from the district's median.

Figure 2.1 helps make the setup clear. The figure shows two hypothetical districts with the same unobserved median voter. In the first district, the Republican incumbent is further to the right; in the second, the Republican incumbent is closer to the median. This is an ideal case. As long as the unobserved median is to the "correct" side - that is, to the left of Republican incumbents and to the right of Democratic ones - shifts in roll-call ideological extremism will accord with the Downsian notion of extremism perfectly. 


\section{Figure 2.1 - Studying Candidate Positions When Me- dian Voter is Unobserved but Held Constant.}

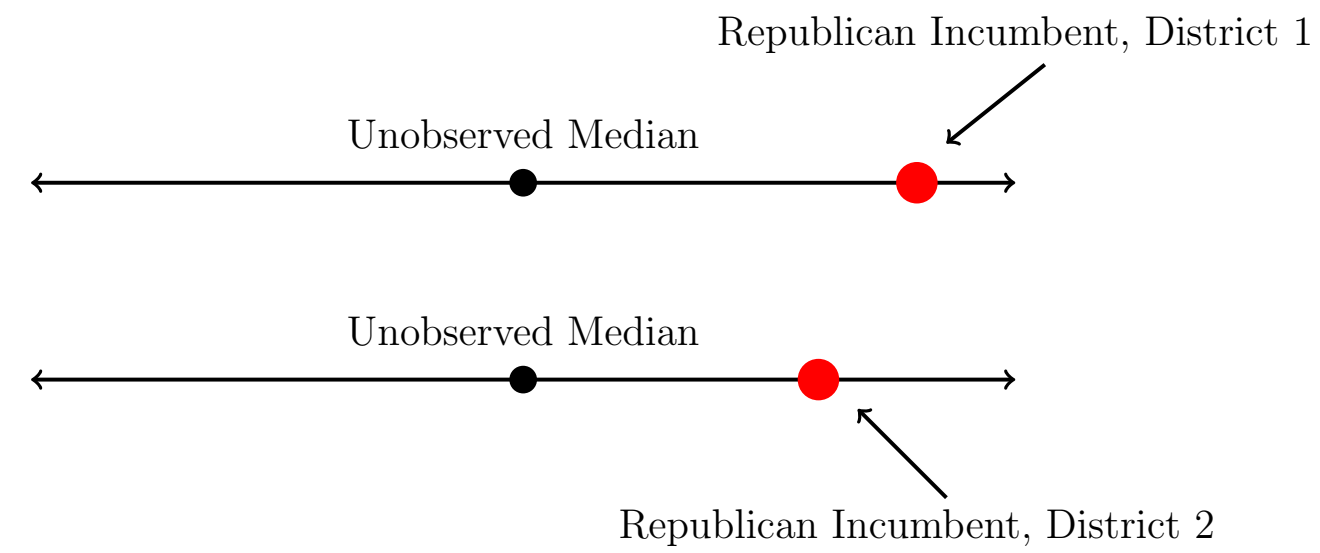

The approach therefore requires two key assumptions. First, presidential vote share must be an effective means for holding fixed the unobserved median voter; and second, the unobserved median voter must be to the proper side of the incumbents being studied. These are reasonable though not innocuous assumptions, and all studies will have to do something similar in order to make progress, empirically. How would the design be affected if these assumptions are violated?

A violation of the presidential vote share assumption could cause serious problems. Consider the situation presented in Figure 2.2. Again, we compare Republican incumbents in two districts; this time, however, the unobserved median varies. Suppose that, despite this, the presidential vote share in the two districts is equal (perhaps because voters vote differently in presidential races, or because the median has changed in between a previous presidential election and the current Congressional election, or for some other reason). The design is now biased. 


\section{Figure 2.2 - Studying Candidate Positions When Me- dian Voter is Unobserved and Not Held Constant.}

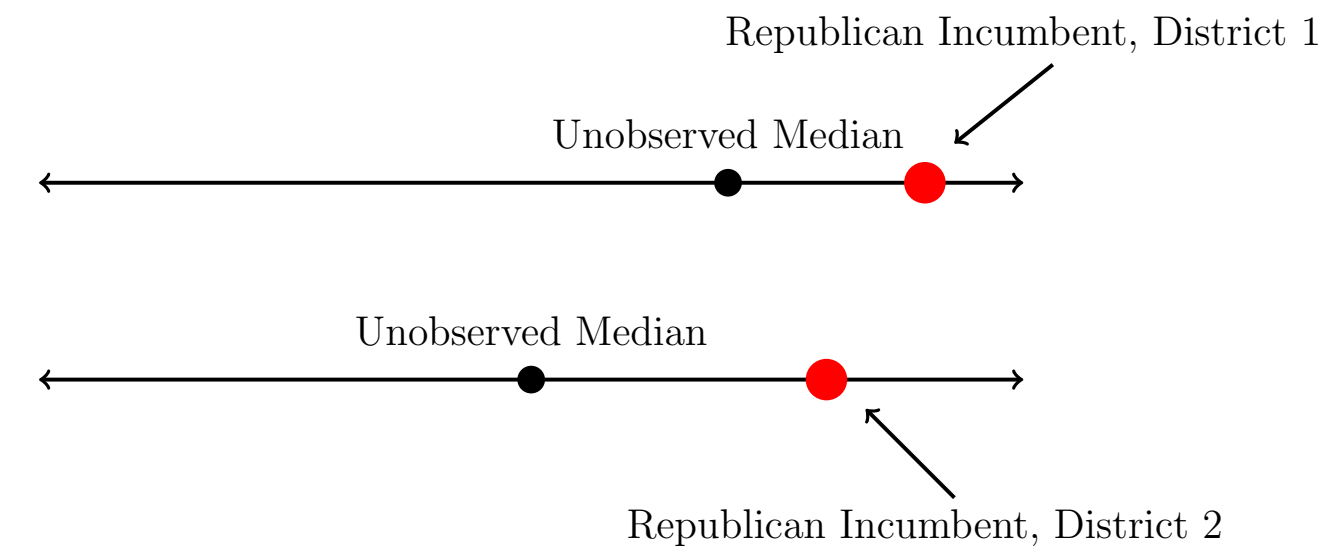

The incumbent in district 1 is considered more "extreme" based on her roll-call record even though she is actually closer to the median voter in her district than is the incumbent in district 2. Most likely, a problem like this would attenuate the association between moderation and electoral success, but it is possible that the bias could go in any direction.

Violations of the second assumption cause similar problems. In cases where the median is on the other side of the incumbent - in this case, further to the right than the Republican - the definition of "extreme" again breaks down. Again, though, this adds error which should in general bias against finding an advantage for moderate candidates.

Ansolabehere, Snyder, and Stewart (2001) offers further evidence for the advantage of moderate candidates, using information about both candidatesincumbents and challengers, as well as open-seat candidates in some cases. The 
Appendix to the paper lays out the precise conditions under which we can link changes in ideological positions to proximity to the median voter. First, they hold fixed the district's ideology using presidential vote share, just like in CanesWrone, Brady, and Cogan (2002). Next, they also hold fixed the ideological distance between the Democratic and Republican candidates. In this framework, shifts in the midpoint between the two candidates have an unambiguous interpretation. A shift right in this midpoint must imply that the Republican candidate is worse off, spatially. Likewise, shifts left in the midpoint must imply that the Democratic candidate is worse off, spatially.

Figure 2.3 lays out this logic visually. In the first district, the Democratic candidate is closer to the unobserved median voter than the Republican candidate is. In the second district, the candidates have shifted left but the distance between them has stayed the same, and the unobserved median has not moved. This shift is unequivocally good for the Republican candidate in the spatial model. Regardless of whether the median voter is to the left of the Democratic candidate, in between them (as pictured), or to the right of the Republican, the shift left can only hurt the Democratic candidate relative to the Republican.

The authors link observed shifts of this form to electoral outcomes, and they find that more moderate candidates possess a significant electoral advantage. In performing these analyses, they obviate the need to assume that the median voter is located in between the Democratic and Republican candidates, because of the midpoint technique. However, they still must assume that presidential vote share can hold the location of the unobserved median voter constant. Though I will not discuss them in detail, several other well-cited papers employ similar evidence and come to similar conclusions (Burden 2004; Erikson 1971; Erikson and Wright 


\section{Figure 2.3 - Studying Candidate Positions When Me- dian Voter is Unobserved but Held Constant: the Mid- point Approach.}

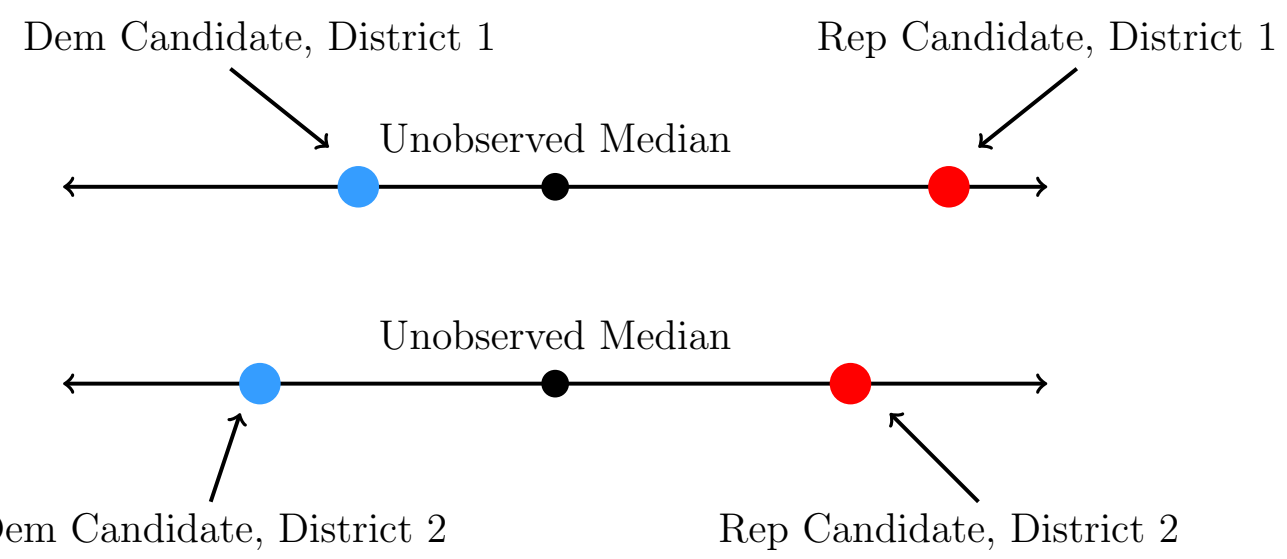

2000). Taken together, the literature strongly suggests that more moderate candidates perform better in U.S. House elections. Nonetheless, concerns may still linger. To test these questions in more detail, in the next section I offer several additional approaches, all of which point to a significant advantage for moderate candidates.

In the previous paragraphs I have summarized what I would call the electionsbased literature on candidate ideology and electoral success. This literature relies on studying the interplay of candidates and voters in actual elections, avoiding the need to survey voters in order to assess the role of ideology in elections. It therefore focuses on what I called voters' "election-based" ideology in the introduction. I believe it is fair to say that the evidence in this literature, when considering this kind of ideology, overwhelmingly supports the notion that more moderate candidates do better. As I have made clear, this does not mean that 
moderation causes an increase in electoral performance, and it does not mean that voters are consistent moderates with clear policy views. But it makes clear that more moderate candidates are those from among the candidate pool most likely to make it into office.

A separate but related literature studies ideology and voting using surveys. As I explained in the introduction to this book, I will not dwell on this literature because it generally does not directly speak to voter preferences over candidates, focusing instead on policy-specific attitudes. That said, a few papers in the very broad survey literature do link to voter choices over candidates, rather than issues, more directly. Doing so is of course challenging. The main obstacle is that individual voter ideologies estimated from survey questions will contain large amounts of measurement error. This noise biases observed associations between ideological proximity and vote choice towards zero. In addition, the set of voters willing to answer such surveys may differ systematically from the electorate as a whole. Perhaps because of these issues - as well as because of the limited samples provided by available surveys - the findings in this literature vary considerably. Stone and Simas (2010: abstract), for example, uses voter positions from the 2006 CCES combined with expert evaluations of candidate positions and argues that "challengers can reap electoral rewards by taking more extreme positions relative to their districts." Studying the same 2006 survey, and using the same expert evaluations, Joesten and Stone (2014: abstract) concludes instead that "proximity voting is common" - that is, they find that candidates whose ideological positions are closer to the self-reported positions of voters do better, electorally. Tausanovitch and Warshaw (2015), mentioned previously, finds little association between proximity and vote choice, but does not account 
for challenger positions. Other papers in this literature, using a variety of different datasets, are similarly divided.

\subsubsection{Further Evidence That Voters Prefer Moderates}

Taking advantage of the large dataset of CFScores, I can extend and confirm the results of the previous literature that studies voters' choices over candidates. A basic and answerable question is: are the candidates who win election to the U.S. House more moderate, on average, than the losers?

Using the contribution-based ideology data, I can pursue several alternative empirical approaches. Each will relax or alter the assumptions from the previous work in some way. In particular, rather than use presidential vote share to hold fixed the unobserved median voter, we can proxy for the median voter using data on the contribution behavior of individuals in each congressional district (this particular data is available for 1990-2012). Is this behavior perfectly indicative of the district's ideology? Of course not. The median donor in a district is likely to be more engaged, wealthier, and have stronger political views than the median voter. That said, the lion's share of congressional contributions come from individuals, and their donations are highly partisan. As such, the aggregated contribution behavior of individuals gives us a good signal about the ideology of districts. The measure is not perfect, but, if we can a series of alternative techniques and continue to find the same patterns of results, we can be increasingly confident that moderate candidates possess an electoral advantage.

I start with graphical evidence. Figure 2.4 presents simple descriptive evidence that moderate candidates out-perform more extreme candidates systematically 
Figure 2.4 - The Electoral Success of Moderate Candidates, U.S. House, 1990-2012. Plots the proportion of U.S. House candidates who win election across binned averages of the estimated ideological distance between the candidate and her district, using CFScores.

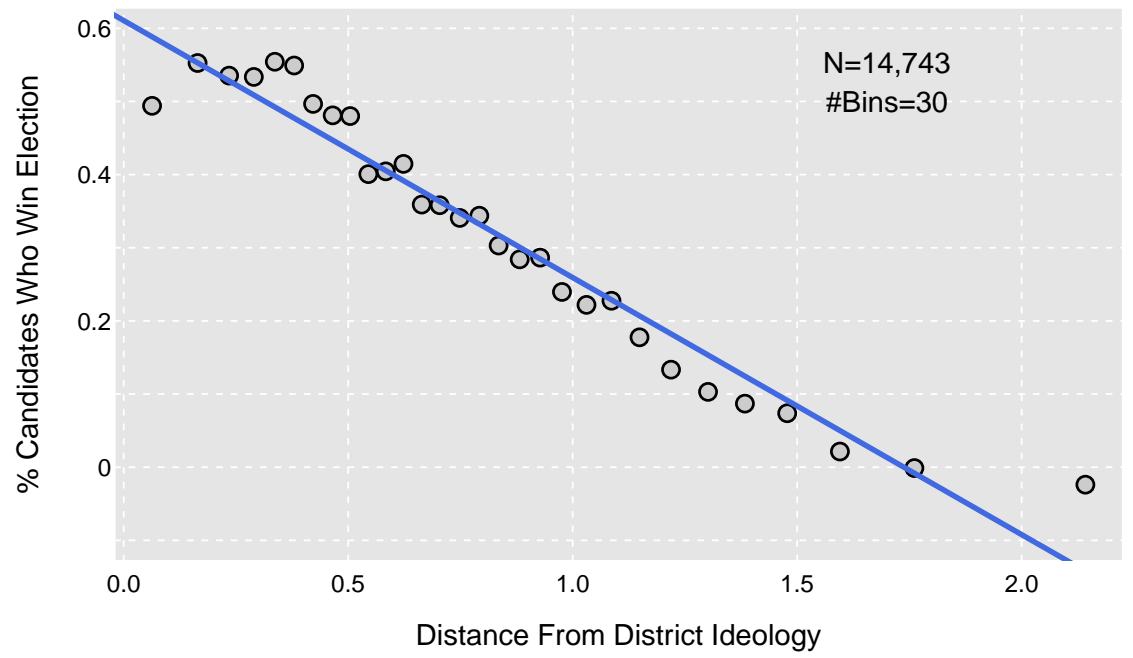

Note: Points are averages in equal-sample-sized bins of the distance from district ideology variable, generated using Stata's binscatter package. Points are first residualized by the number of candidates to adjust for the correlation between district competitiveness, the number of candidates, and average win rates.

in House elections. Using the roughly 23,000 candidate-election observations in the DIME dataset, including all candidates in the primary and general elections, I first calculate the distance (in absolute value) between each candidate, based on her CFScore, and the average donor CFScore in her district, as a crude proxy for ideological congruence. I then compute binned averages which reflect, within equal-sample-sized bins of the distance from the district's ideology, the proportion of candidates who win election.

The results are quite clear. Candidates with smaller distances - that is, whose ideological positions are estimated to be closer to those of the district's average 
Figure 2.5 - The Electoral Success of Moderate Candidates By Party, U.S. House, 1990-2012. Plots the proportion of U.S. House candidates by party who win election across binned averages of the estimated ideological distance between the candidate and her district, using CFScores.

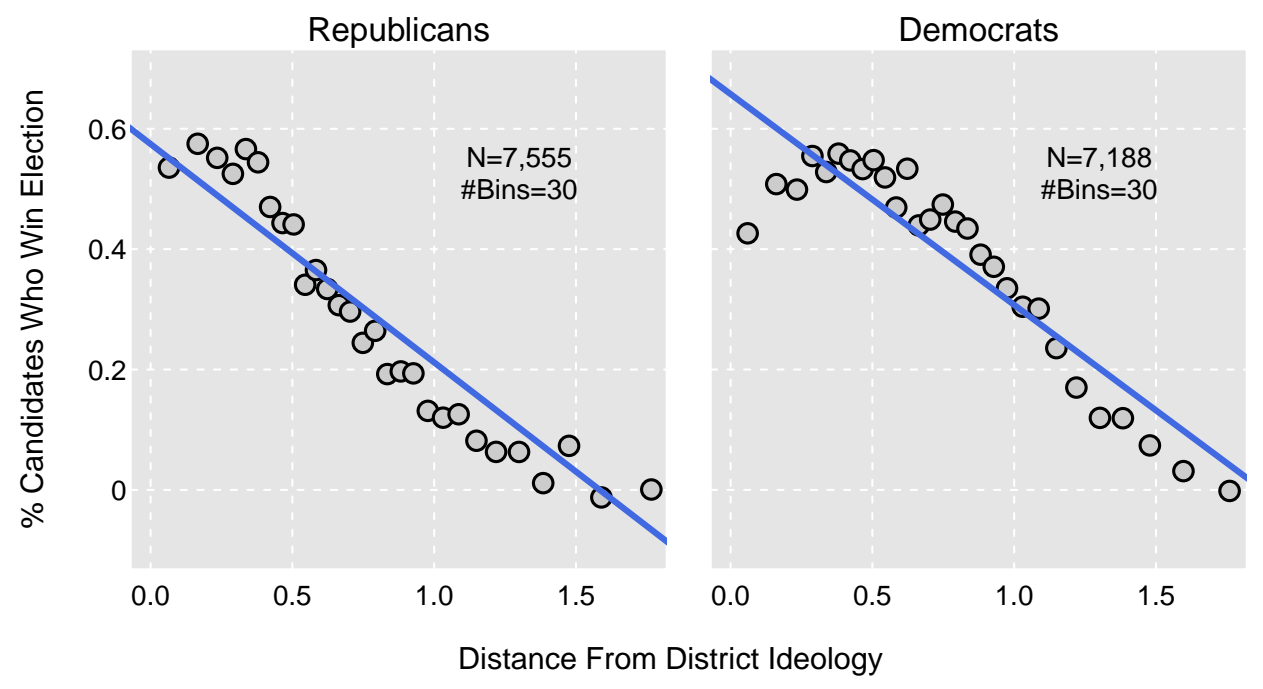

Note: Points are averages in equal-sample-sized bins of the distance from district ideology variable, generated using Stata's binscatter package. Points are first residualized by the number of candidates to adjust for the correlation between district competitiveness, the number of candidates, and average win rates.

ideology score - win election at a much higher rate. At larger and larger values of this distance variable, fewer and fewer candidates win election. In the Appendix to this chapter, I present formal regression results that reinforce this conclusion. Winning candidates are systematically more moderate than losing candidates.

In Figure 2.5, I perform the same analysis but splitting by party. The phenomenon is consistent across both parties, as the plots show. Among Republicans and Democrats, candidates whose estimated positions are closer to those of the average donor win elections at a higher rate. 
Figure 2.6 - The Electoral Success of Moderate Candidates In Open-Seat Races, U.S. House, 1990-2012. Plots the proportion of U.S. House candidates who win election in open-seat races across binned averages of the estimated ideological distance between the candidate and her district, using CFScores.

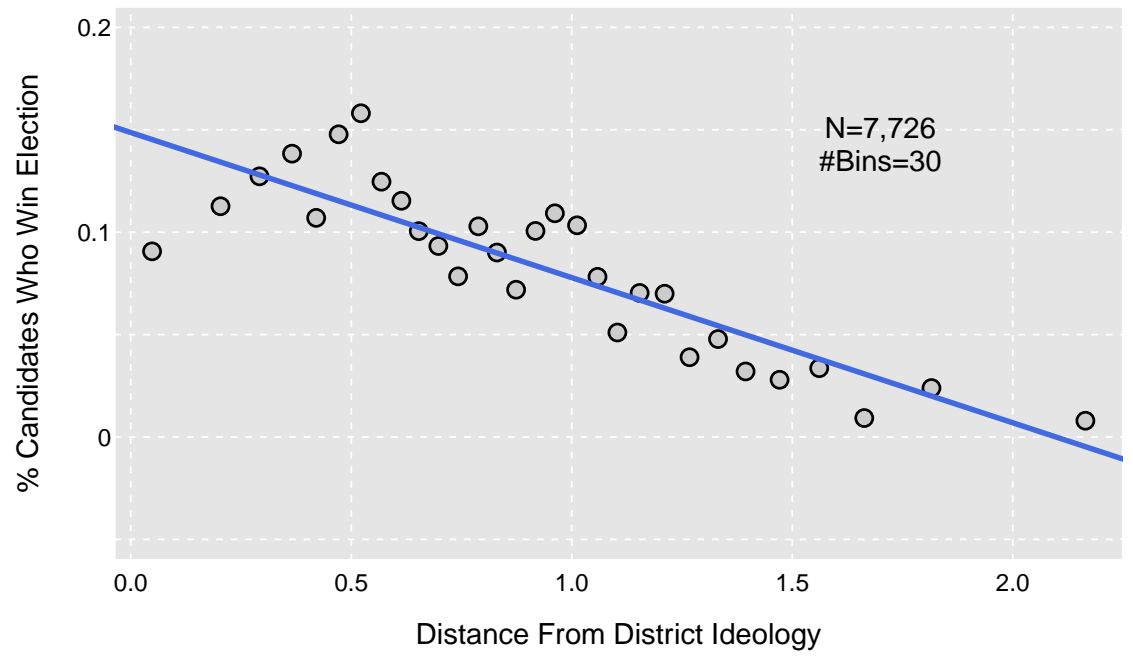

Note: Points are averages in equal-sample-sized bins of the distance from district ideology variable, generated using Stata's binscatter package. Points are first residualized by the number of candidates to adjust for the correlation between district competitiveness, the number of candidates, and average win rates.

Could these patterns simply reflect differences between incumbents and nonincumbents? For one, we might suspect that incumbents look more "moderate" in their campaign contributions because they receive more money from accessoriented donors (Fouirnaies and Hall 2014). To evaluate this quickly, Figure 2.6 presents the same kind of analysis, but only for open-seat races where no incumbent is present in either party. We continue to see the exact same kind of relationship. (The overall percent of candidates who win elections is lower in open-seat races, as the reader may notice looking at the vertical axis, because 
open-seat races tend to attract a large number of primary candidates, increasing the denominator of the outcome variable).

These simple plots do not address a variety of issues that confound the link between candidate attributes, like ideology, and electoral success. I now turn to more formal evidence which attempts to hold these factors constant, again finding that candidates who take more extreme positions do much worse, electorally.

\subsubsection{The Penalty to Nominating Extremists}

Note: This section presents an updated version of the analysis in Hall (2015). All analyses contained herein are new; however, a small amount of language is retained from the paper.

Thus far, I have extended previous analyses of candidate ideology and electoral outcomes, and I have also relaxed (though not removed) assumptions concerning how we measure and define "extremism." In this section, I pursue quite a different approach to confirm these findings further. Instead of using an observable proxy for district ideology, here I use the quasi-random outcomes of primary elections to approximate an experiment in which candidates of differing ideology are "randomly" assigned to stand for office in the general election. Because this is like an experiment, this means that districts that get candidates with varying ideologies will be otherwise alike, on average -including, crucially, in the positions of their respective median voters. This approach is thus another way to attempt to hold fixed the unobserved median voter. The results are highly consistent with those found above; when more extreme candidates beat out more moderate candidates to win the nomination, they do much worse in the general election. 


\section{Laying Out the Research Design}

The design starts by defining moderate vs. extremist candidates based on their positions relative to one another. That is, without observing the district's median, I compare candidates competing with one another in a primary election. I focus on the two candidates in each contested primary races who receive the two highest vote totals. For Democrats, the farther left candidate is called "extreme," and the farther right candidate is considered the "moderate," and vice-versa for Republicans.

Figure 2.7 helps spell out the research design. The top two diagrams show a hypothetical district holding two primary elections, one for the Democrats (on the left) and one for the Republicans (on the right). In each case we focus on the ideological positioning of the top two vote-getting primary candidates; hence, four candidates in total are shown. Focus first on the Democratic candidates in the top diagram. The left-most candidate is defined to be the "extremist" in this election because she is further to the left than her opponent, who we call the "moderate" (even though even this candidate is quite removed from the median voter's position). Now consider the second diagram, focusing on the Republican candidates in the same district at the same time. Here, the definitions are reversed, in the sense that it is the right-most candidate who is called the "extremist" and the left-most candidate who is called the "moderate." Again, these definitions are entirely relative to the district.

This is the ideal case for the research design, similar to the way in which Canes-Wrone, Brady, and Cogan (2002) hopes for candidates to be on the correct side of the median voter in the district. Here, the key is that a party's primary 
Figure 2.7 - Using Primaries to Study Candidate Selection Across Ideology.

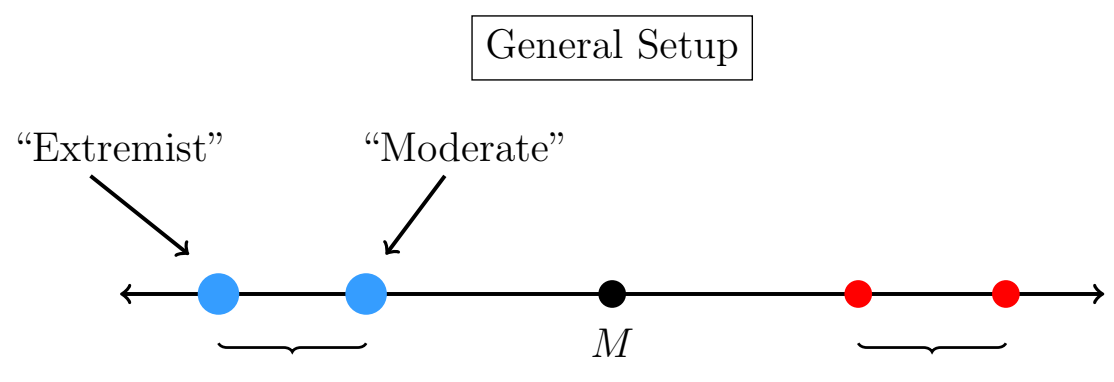

Dem Primary

Rep Primary

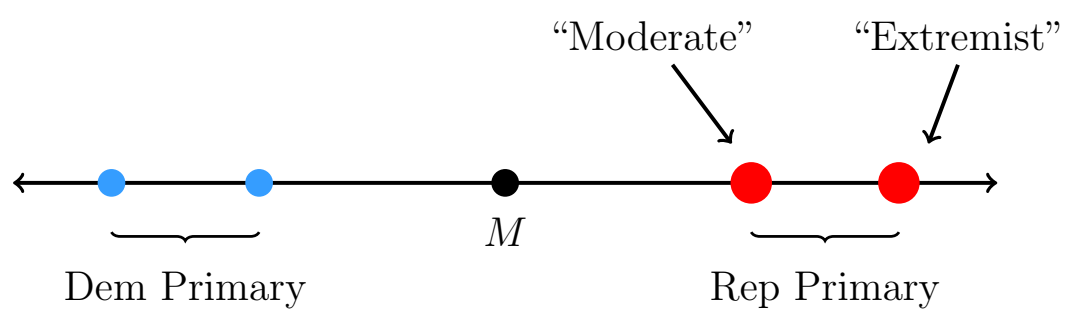

Problem 1: Candidates Too Close Together to Classify

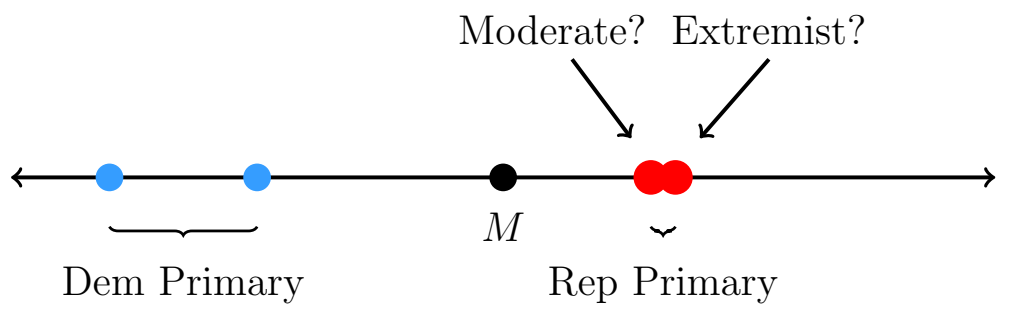

Problem 2: Candidates Not on Same Side of Median Voter

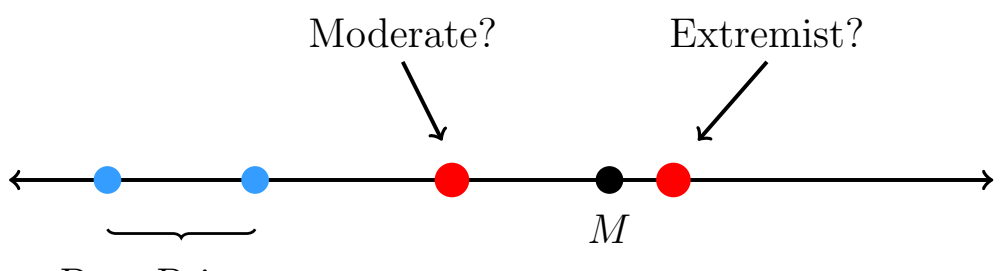

Dem Primary

Rep Primary 
candidates are arrayed all to the correct side of the median, allowing for coherent definitions of extremists vs. moderates.

How can this go awry? There are two major potential obstacles. The first, shown in the third diagram ("Problem 1"), is that the candidates can be too close together. Here, the candidates are still to the correct side of the median, but they are estimated to have very similar ideological positions. Which one is truly the "moderate", then? This is a difficult question in two ways: first, it's hard to believe such small ideological differences could matter much, and second, since candidate positions are in fact measured with error, we cannot be very confident we have even rank ordered the two candidates correctly in a case like this.

To address the first issue, I focus (preliminarily) on races where the distance between the top two candidates is quite large. Specifically, in primary races with two major candidates, the race is tentatively identified as being between an extremist and a relatively moderate candidate if the difference between their estimated ideological positions using CFScores is at or above the median in the distribution of ideological distances between the top two candidates in all contested primary elections. These are therefore races between candidates who offer meaningfully different platforms within the umbrella of their party. Using a strong cutoff like this has two potential advantages. First, it may reduce the number of incorrect moderate/extreme labels caused by measurement error in the donor scores. Second, it ensures that we are focusing on strong comparisons in which the two primary candidates are starkly different.

The second issue, like in Canes-Wrone, Brady, and Cogan (2002), is that there may be cases in which the party's candidates are not on the correct side of the median. Consider the fourth and final diagram in Figure 2.7 ("Problem 2"). In 
this case, the left-most Republican candidate is actually to the left of the median voter, while the right-most Republican candidate is to the right of the median voter but closer to her. The procedure will still label the left-most Republican candidate the "moderate" even though she is farther away from the district's median. There is no obvious way to tackle this issue directly in the empirical design. Instead, we must think substantively about how likely we think it is to occur and, if it does occur, about how it will affect the results.

The first thing to say is that such a violation seems unlikely, in most cases. As the discussion in Chapter 2 made clear, we know that candidates of the two parties tend to diverge, profoundly, even when running to serve the same voters. It would be difficult (though perhaps not impossible) to produce such a consistent divergence without the median voter located in between the two parties' candidates. This, in turn, would suggest that the two parties tend to "straddle" the median voter. Survey evidence also suggests that this may be the case, though the typical difficulties with scaling voters based on surveys always apply. Bafumi and Herron (2010) jointly scales voters and candidates and concludes that American politics features exactly this kind of "leapfrog" democracy in which representation alternates between Democratic and Republican candidates to either side of the median voter.

Second, and perhaps more importantly, such violations would bias us away from finding a penalty to nominating more extreme candidates. The more often we incorrectly label a moderate candidate extreme, and vice-versa, the more noise we add to our treatment variable, and the more we thus attenuate the estimated effect of nominating an extremist. 
How might the design incorrectly conclude that there is a penalty to extremists, then?

One possibility is the presence of "non-standard" measurement error. Could a particular kind of measurement error produce a spurious advantage for moderate nominees? Perhaps the cases where the party's candidates are not on the assumed side of the median voter-i.e., cases where we have misclassified extremists vs. moderates, potentially - also tend to be cases where, for other reasons, the party is expected to do better in the general election. Could this produce a bias in favor of moderate nominees? No. The key is that, even among these cases, we still compare the (roughly) half of cases where the moderate wins the primary to the other (roughly) half of cases where the extremist wins. Thus, issues like this will be differenced out.

A real problem is a different kind of measurement error. What if the scaling of candidates does not actually reflect their ideology, but rather something else about their profiles? In particular, what if the scaling confuses electability for ideology? The candidates we call "moderates" could in fact be the set of candidates that donors think are going to do better in the general. This would invalidate the design entirely if the donors' expectations are not based on the candidate's underlying ideology. There are several reasons to think that this is not a major issue in the data, though. First, we know that the contribution-based scores predict roll-call voting fairly well. Second, the bulk of the contributions come from individual donors, who do not generally seem to be particularly strategically inclined in whom they give to, making this "expectations" theory perhaps unlikely. Third, and most importantly, we can replicate the analysis using state 
legislators who have cast roll-call votes, who we can thus scale without using campaign finance. We again find large penalties to nominating extremists.

Finally, it is possible that the candidates scaled as moderates are in fact moderates, but are also different from extremist candidates in other ways. How do we know these other factors aren't driving the observed penalty? We don't! This is why it was important to lay out the precise research goals earlier in the chapter. The goal is not to isolate the causal effect of ideology, itself. Instead, we want to consider the actual choices that voters face. When voters in the general election receive the option to elect a more moderate candidate, they seize it. Whether or not this result is driven by ideology, itself, it tells us that moderates who stand for office in the general election tend to make it into office. Legislative polarization is thus unlikely to be driven by the electoral choices of general-election voters, directly.

\section{An Example: Arkansas District 2, 2010}

Before the 2010 elections, Vic Snyder, the Democratic incumbent member of Congress for Arkansas' 2nd district, announced his retirement. The 2nd district contained Little Rock and had historically been represented by Democrats, but amid the rise of Tea Party candidates and the backlash against Obama's victory in 2008, it was expected to be competitive in the general election.

A number of candidates entered the open-seat race in both parties. On the Democratic side, two front-runners emerged: Joyce Elliott, a veteran state legislator who was Majority Whip in the state senate at the time, and Robbie Wills, also a veteran state legislator and Speaker of the House in the Arkansas state house. When neither candidate secured a majority in the primary election, they 
entered a highly contentious runoff primary where they competed head-to-head for the Democratic nomination.

Elliott offered a platform of what might be called national Democratic policies. Most contentiously, she strongly supported increased gun control, even though she was running for an office in Arkansas, a state not known for its widespread support for gun control. Based on the mix of campaign contributions she received, Elliott's overall ideological positioning is roughly consistent with Nancy Pelosi's. Consistent with these facts, MoveOn.org, a leftwing advocacy group, endorsed Elliott in the primary. ${ }^{1}$

Wills, on the other hand, was a prominent businessman who opposed gun control and, surprisingly for a member of the Democratic party, Obamacare. With a gimlet eye on the general election and the conservative tilt of the 2010 elections, Wills repeatedly labeled Elliott an "extremist," sending out a controversial mailer that declared Elliott "unelectable" due to her far-left views. ${ }^{2}$

Comparing Elliott's and Wills' positions helps make clear the research strategy. For our purposes, Elliott is more "extreme" than Wills, not because we are making any judgment on whose views are "extreme" in any absolute sense, but purely based on their position in relation to each other. All facts-data based on campaign contributions, patterns of endorsements, newspaper accounts, and even the rhetoric of the candidates themselves - point to Elliott being further to the left than Wills. As such, for this research purpose, we label her the more extreme candidate.

\footnotetext{
${ }_{1}$ http://archives.arkansasnews.com/2010/09/28/joyce-elliott-endorsed-by-moveonorg-2/, Accessed April 27, 2016.

${ }^{2}$ http://archives.arkansasnews.com/category/blogs/the-tolbert-report/page/203/, Accessed April 27, 2016.
} 
How did the election turn out? In a nod to the results we will find below, Elliott, the "extremist," eked out a close victory over Wills in the runoff primary, and then went on to lose the general election by 14 percentage points.

\section{Empirical Results}

Data on U.S. House primary and general elections is compiled from primary sources by Ansolabehere et al. (2010) and updated by those authors to include subsequent years. I focus on elections in the years 1980-2012 to match the data on candidate positions. I keep all primary elections in which at least two candidates have donor scores. Among these elections, I analyze the two candidates with the top-two vote totals, and I calculate each candidate's share of the top-two vote total..$^{3}$

Figure 2.8 shows the main result. The horizontal axis reflects the vote-share winning margin of the extremist candidate in the primary election. When this variable is negative, the moderate wins nomination; when it is positive, the extremist does. The vertical axis reflects the frequency with which parties win the general election after extremists or moderates are nominated in their primary elections. To depict things simply, each point on the graph is a binned average that represents the proportion of cases within a 0.1 percentage-point bin of the extremist vote-share winning margin that the nominee's party won in the general election.

The RD estimate is the instantaneous fall in the rate of winning that occurs when parties go from just barely nominating the moderate to just barely moderate

\footnotetext{
${ }^{3}$ For the few cases of runoff primaries, I include the candidates and vote shares of the twocandidate runoff election.
} 
Figure 2.8 - The Penalty to Nominating Extremists, U.S. House, 1980-2012. When extremists barely win competitive primaries (just to the right of the vertical line in the middle of the plot), their party does much worse in the general election than when they just barely lose and the more moderate candidate wins the nomination (just to the left of the vertical line).

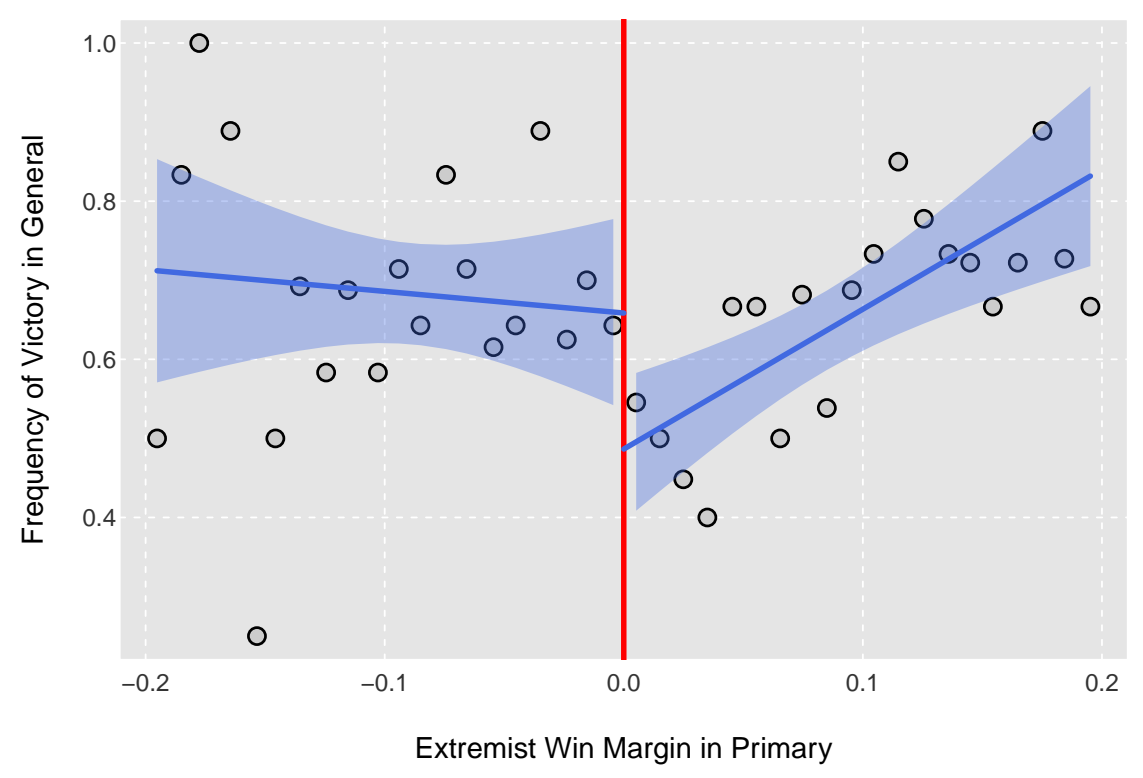

Note: Points are averages in 1 percentage-point bins of extremist win margin. Lines are from OLS estimated to the raw data (not the bins), estimated separately for each side of the discontinuity. Shaded areas represent $95 \%$ confidence intervals.

the extremist. As we can see in the figure, this drop is quite sharp. With the moderate nominee "randomly" winning the primary, parties win almost $70 \%$ of the races in the sample. But when the extremist instead "randomly" wins the nomination, the party wins about $50 \%$ of races - a 20 percentage-point penalty in terms of victory probability. This is a very large penalty.

In the Appendix, I present more formal econometric results. These results are consistent with the graph. Regardless of what specification I use, or whether we 
look at vote share or victory, there is a tremendously large penalty to nominating more extreme candidates. As I have hastened to stress, these estimates do not isolate the causal effect of candidate positions; instead, they indicate generalelection voters' marked preference for the types of candidates who offer more moderate positions.

\section{Replicating the Results with State Legislators}

It is always important to ensure that results are not driven by the particular scaling strategy used. In particular, as I have discussed in other parts of the book, we might be worried that candidates who are scaled as "moderate" based on their campaign contributions are not actually moderate at all. I have already given theoretical reasons why we should not be overly worried about this issue; because strategic campaign contributing is a small portion of all donations, we are unlikely to conflate moderate candidates with those predicted to do well, electorally. Nevertheless, empirical ways to address this issue are obviously valuable. Here, I replicate the $\mathrm{RD}$ estimates of the effect of extremist nominations without using CFScores. To do so, I focus on primary elections for the House that take place between two state legislators. For these cases, I can evaluate their ideology based on their roll-call votes in state legislatures, identifying moderates and extremists without looking at their campaign contributions.

Table 2.3 in the Appendix presents the results. Using this completely different scaling strategy, we again find large penalties to nominating extremists. 


\subsection{Moderates Not Running for Office}

As all the analyses above showed, when given the opportunity, voters tend to support more moderate candidates (on average). Yet, at the same time, we know that incumbents - those candidates elected to office - have been offering increasingly extreme positions to voters over time. How do we square these two facts?

Voters may prefer moderate candidates, but they can only elect such candidates if they run for office; this builds on the logic from Chapter 1, where we saw that voters select candidates rather than sanction them. They are at the mercy of the types of candidates willing to run. If, over time, fewer and fewer candidates with moderate views are running for office, then voters are fundamentally constrained by who runs. In this section, I show that this is indeed the case. The sharp growth in polarization in the U.S. House over the past forty years is closely associated with a similar rise in the polarization of the set of people running for office - considering both winners and losers at all stages of the process.

To establish this, I examine the ideology of the entire supply of candidates, again using the CFScore scalings based on the mix of campaign contributions candidates received. ${ }^{4}$ Specifically, for the 22,727 Democratic and Republican U.S. House candidates in the dataset, I first regress their CFScores on a set of dummies for each congressional district, in order to account for differences in positions across districts. I then take the average of the residualized candidate positions for each year by party. I plot these averages in Figure 2.9.

\footnotetext{
${ }^{4}$ For a discussion of this measure and its validity, refer back to Chapter 1.
} 
Figure 2.9 - The Growing Extremism of U.S. House Candidates, 1980-2010. In both parties, those running for the U.S. House have become more ideologically extreme over time.

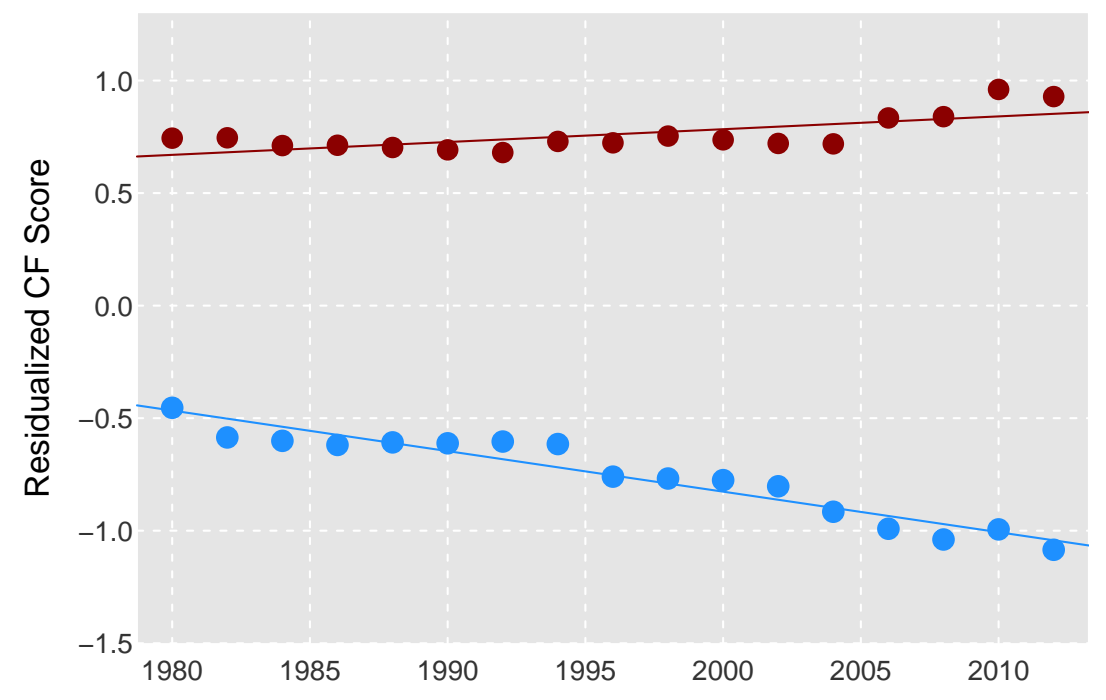

Note: Points represent yearly averages by party; lines are OLS fits to raw data. Candidate ideology measured by static CFScores residualized by congressional district. Standard error lines omitted because they are too small to discern.

The figure reveals two important patterns about who runs for the House. First, as the points at the far left show, for the year 1980, the two parties' candidates have always diverged significantly, ideologically. Second, the degree to which those who run for the House from each party diverge has grown, markedly, over time. Indeed, the average distance between the candidates of the two parties has grown from 1.2 points on the CFScore scale, in 1980, to just over 2.0 points in 2010. The ideological divergence between the two parties' candidate pools has thus almost doubled in a 30-year period.

Both of these patterns are consistent with the measures of legislative polarization based on incumbent roll-call voting, which also reveal a pronounced and 
Figure 2.10 - The Growing Polarization of U.S. House Incumbents and New Candidates, Respectively, 19802010. Each line is the absolute difference in average CFScores across the two parties for the relevant candidate group, by year. Incumbent polarization has grown in step with the candidate supply.

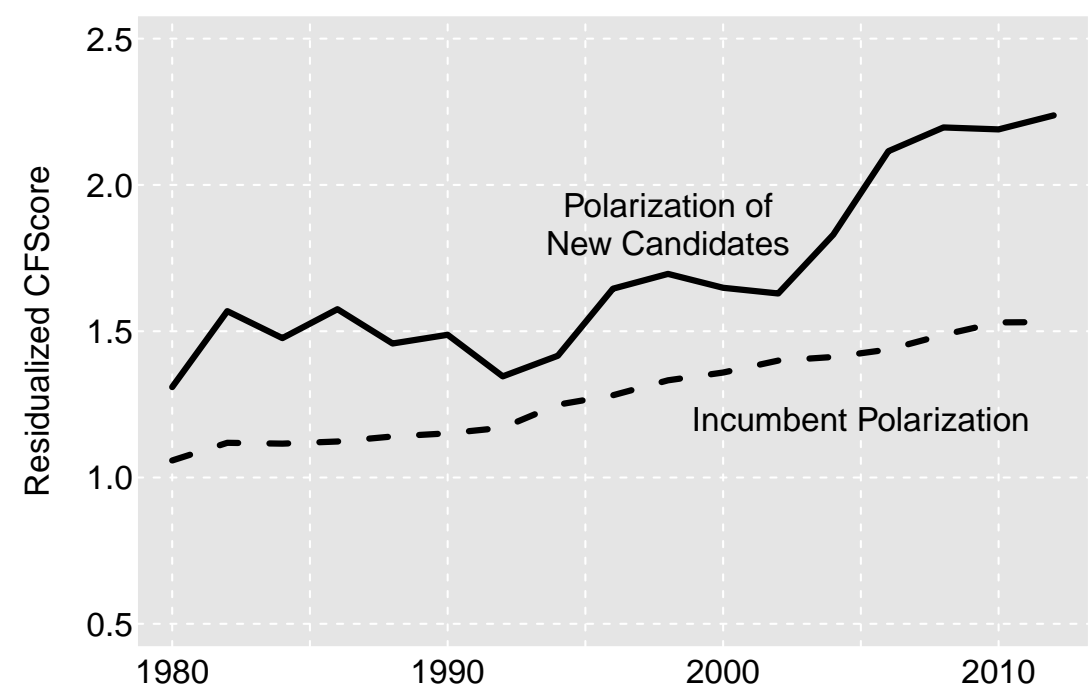

Note: Candidate ideology measured by static CFScores residualized by congressional district.

growing divergence over this time period (see McCarty, Poole, and Rosenthal 2006). Figure 2.10 illustrates this dynamic. The plot shows the absolute distance between the average ideological position of each party for each year, separately for two groups of candidates: incumbents and challengers/open-seat candidates, whom I call "new" candidates. Like before, candidate ideologies are first residualized by district so that the resulting calculations reveal candidate divergence and not sorting across districts.

The two lines track each other well $(r=0.9)$. As incumbent polarization has risen so, too, has the ideological polarization of new candidates for the House. 
Incumbent polarization is also consistently below that of new candidate polarization. The results in section 4.1 provide the likely explanation for this fact. Voters select for more moderate candidates from among the pool - thus producing Democratic and Republican candidates who are closer together, on average, than the overall candidate pools. Nonetheless, incumbent polarization remains quite high. The candidate supply does not give voters the opportunity to shrink the difference between the candidates of the two parties further.

Correlating two time series is hardly a way to establish a causal relationship, but the fact that candidate positions are rigid, as Chapter 1 established, permits us to interpret these relationships to some degree. Voters can only elect those who run for office, and those who run cannot, according to the theory, adjust their positions to respond to voter demand. Thus, if those who run become more polarized, then the ideological composition of the legislature is forced to polarize as a result.

The descriptive analyses above reflect average ideologies. Although they use candidate ideologies that are residualized by district, there is still the possibility that average candidate ideologies are changing mostly due to extreme outliers. Even though there may be fewer moderates, and even though those who run might be on average more ideologically extreme, it is still possible that a sufficient number of moderates remain such that voters are not constrained and can still elect moderates for office.

To address this possibility, I now examine differences between Democratic and Republican candidates by district. Specifically, for each district, I calculate the distance between the right-most Democrat, i.e., the most moderate Democrat, and the left-most Republican, i.e., the most moderate Republican, who enters the 
Figure 2.11 - Fewer Moderates Running: The Growing Gap Between the Least Extreme Candidates in U.S. House Districts, Across Eras. While already a polarized era, more districts had choices between ideologically similar candidates in the 1980s than they have in the 2000s.

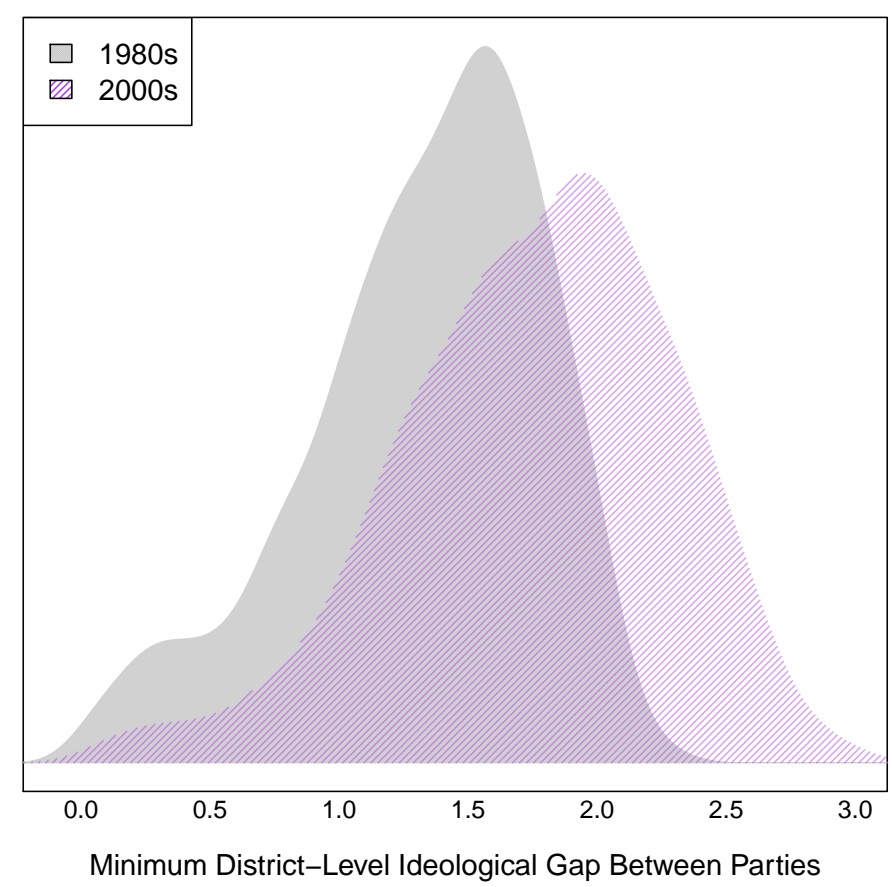

race. This includes primary-election winners and losers, since I am investigating the entire candidate supply.

Figure 2.11 plots the resulting distribution of district-level distances between the most moderate Republican and Democrat, for all races in which at least one Democrat and at least one Republican entered their respective primaries and raised enough money to obtain a CFScore. The gray density represents the distribution of these distances in the 1980s. Although the 1980s were already an era of polarization - as we see reflected by the fact that the majority of districts see significant differences in ideology between their most moderate Republican and 
most moderate Democratic candidates - there are still a small group of districts who have the option of similarly located Democratic and Republican candidates, as reflected by the positive density towards the left of the plot.

The purple distribution overlaid on the 1980s density depicts the same data for the 2000s. Here, almost no districts ever have the chance to choose between similarly located Republican and Democratic candidates. Very little density is located anywhere near the lefthand side of the plot. Instead, the entire density has shifted markedly to the right, indicating higher average distances between even the most moderate Republican and Democrat in each race. The plot thus reflects the degree to which the candidate supply constrains voters. Opportunities to choose moderate candidates from either party are few and far between.

\subsubsection{Who Runs From State Legislatures?}

Thus far, we have studied who runs using donation-based estimates of candidate ideology. In this section, I use state legislators as a separate opportunity to study who runs without using CFScores. Like members of our federal legislatures, our state legislators cast large numbers of roll-call votes. Shor and McCarty (2011) collected many of these roll-call records and used them to scale state legislators. The resulting scalings are known as NP-scores. In this section, I use NP-scores to study the set of state legislators who choose to run for the U.S. House, and to compare these individuals to their colleagues who choose not to run for the U.S. House.

Doing so will be valuable for making sure the results are not dependent on using contribution-based measures of ideology, and for scrutinizing one of the 
Figure 2.12 - Average Ideology of State Legislators Who Run for the U.S. House Candidates by Party, 19962010. There is a pronounced ideological divergence among state legislators who run for the U.S. House.

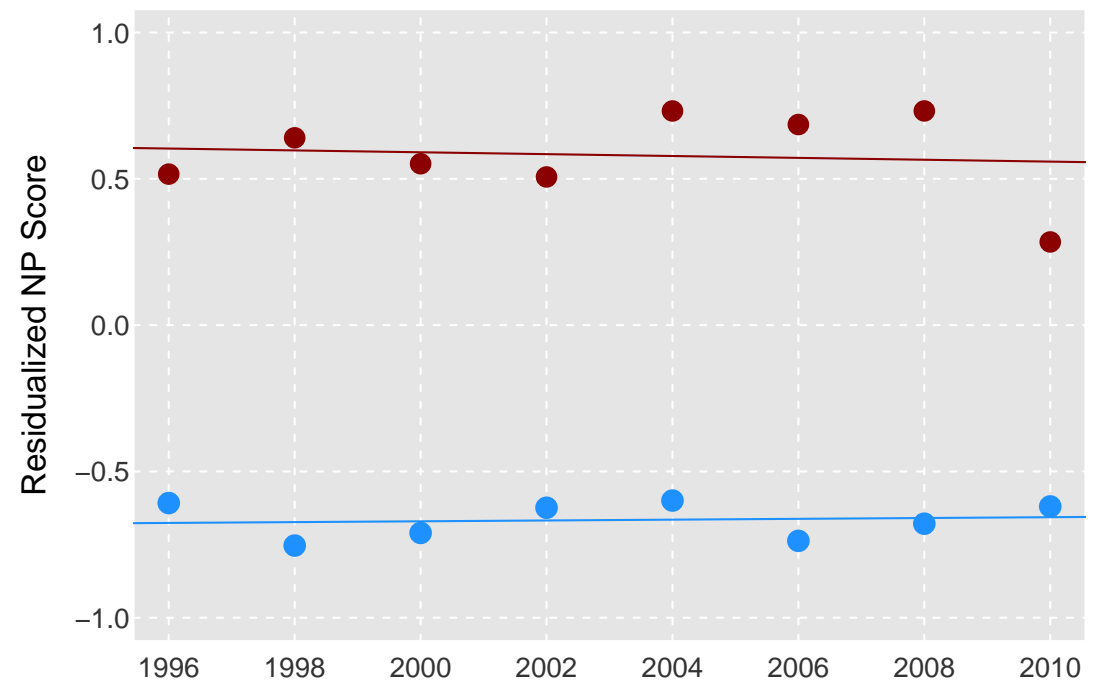

most important sets of potential candidates. State legislators are among the largest and most successful group of U.S. House candidates. What types of state legislators are likely to try to move up to the House?

Figure 2.12, mirroring a previous figure, shows the average NP-score by party and year. Although the time period is much shorter than when we used CFScores before - unfortunately the state roll-call records that have been digitized are not as extensive as the contribution records - a similar pattern is evident. Clearly, the state legislators of the two parties' who choose to run for the House are quite polarized, ideologically.

In a remarkable paper, Thomsen (2014) explores the differential propensity for different types of state legislators to run for the House. Studying Congres- 
sional elections from 2000-2010, and using CFScores, the author shows that more moderate state legislators are less likely to run for the U.S. House than are their more extreme colleagues. Here, I replicate this finding using the roll-call based measure of ideology instead of CFScores. As Figure 2.13 shows, I find the exact same pattern of results.

In particular, the plot shows binned averages comparing how far state legislators are from the median of their party, ideologically, and how frequently they run for the House. Candidates included in the averages to the left of the plot

are especially moderate - they are to the right of their party median, if they are Democrats, and to the left if they are Republicans. Candidates like these run for office roughly $1 \%$ of the time. To the right of the plot, candidates are out into the ideological flanks of their parties. These candidates run for the House more than $1.5 \%$ of the time, a $50 \%$ increase relative to their more moderate colleagues.

\subsection{Who Runs in Broader Context}

Because many of the arguments I will make throughout the book are most easily tested in the House, where data is plentiful, I have focused in this chapter on who runs for the House. Clearly, though, these arguments readily apply to other U.S. elections. In this section, I examine data on the ideology of those who run for office across a variety of other U.S. contexts: the U.S. Senate, U.S. state legislatures, both in the aggregate and disaggregated by state, and U.S. statewide offices. In all cases, I show how who runs continues to present voters with choices between divergent positions. 
Figure 2.13 - State Legislator Extremism and the Propensity to Run for the House, 1996-2010. More extreme state legislators are more likely to run for the House than are more moderate state legislators.

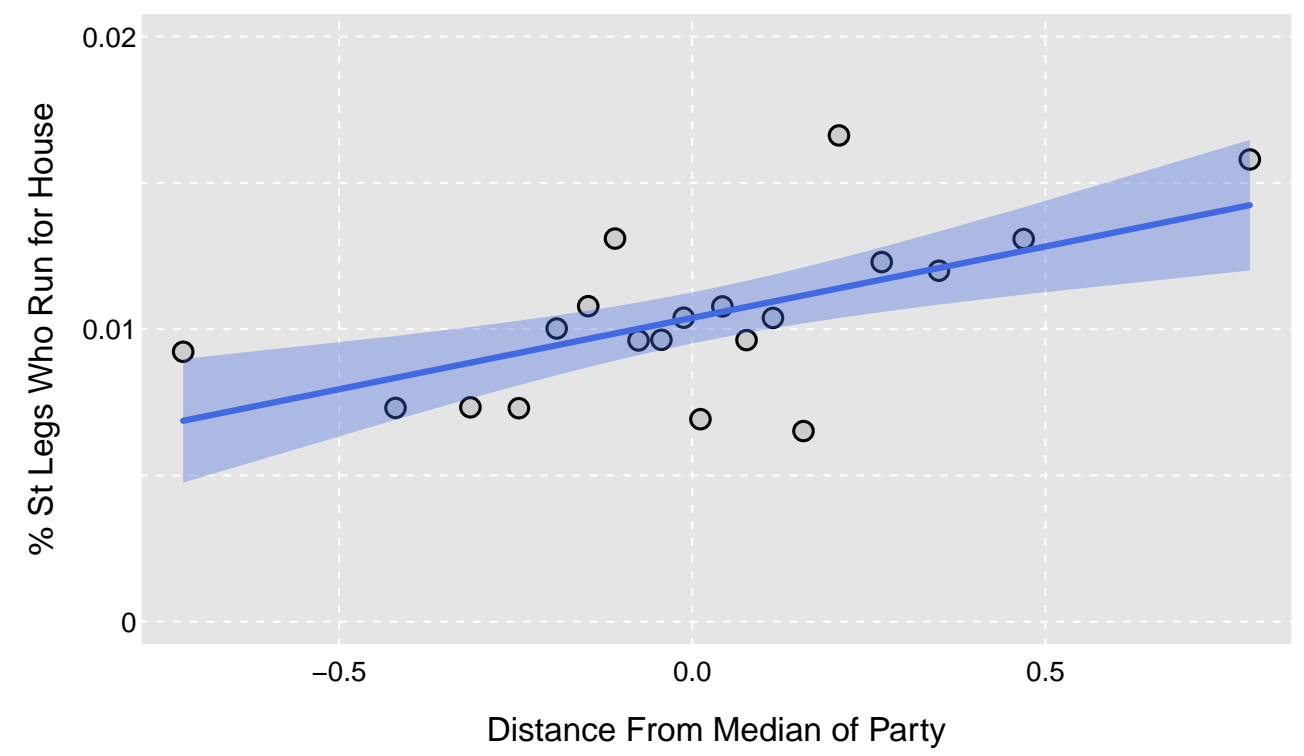

\subsubsection{U.S. Senate}

First, I investigate the U.S. Senate, which has many parallels with the House. Many of the factors that contribute to the costs and benefits of running for office are similar, or even more exacerbated, in the Senate. Elections for the Senate are much greater spectacles than are House races, subjecting candidates to far greater personal scrutiny. Running an effective senatorial campaign requires far more fundraising from more people over a larger area, taking up more of a candidate's time. It is probably fair to say that senatorial elections are the most salient American elections other than those for president, with the possible exception of certain gubernatorial contests. 
Figure 2.14 - Who Runs for Office Over Time, U.S. Senate, 1980-2012.

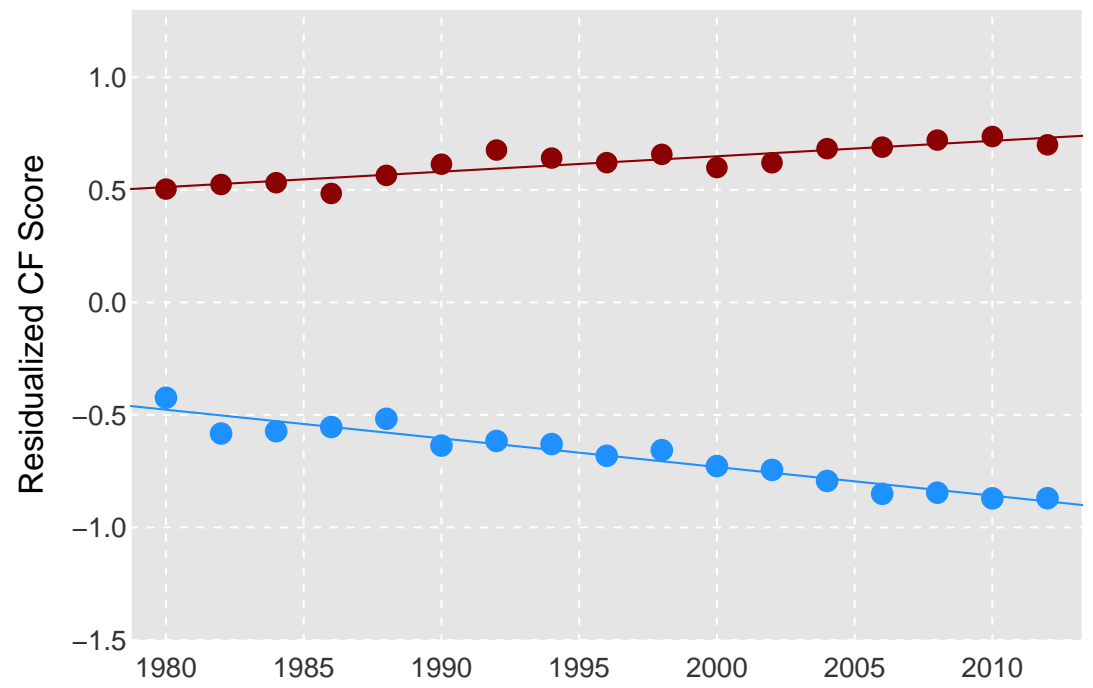

On the other hand, other factors are more favorable in the Senate. The internal organization of the Senate is arguably less partisan in nature, offering individuals more opportunities to influence the political process. There are fewer senators, too, making each individual more visible and giving each more opportunities to craft policy. The benefits of holding a Senate seat are also clearly higher since the time horizon is longer, thanks purely to the fact that senatorial terms are three times as long as terms in the House.

Finally, whatever the Senate's own characteristics are, it is fundamentally beholden to the House because many senatorial candidates serve, first, in the House. Since these candidates are filtered, first, by the House, constraints in who runs for the House may naturally become constraints on who runs for the Senate.

As it turns out, who runs seems to pose just as much of a constraint in the Senate as in the House. Figure 2.14 presents the same average ideology by 
Figure 2.15 - Average Polarization of U.S. Senate Incumbents and New Candidates, Respectively, 19802012.

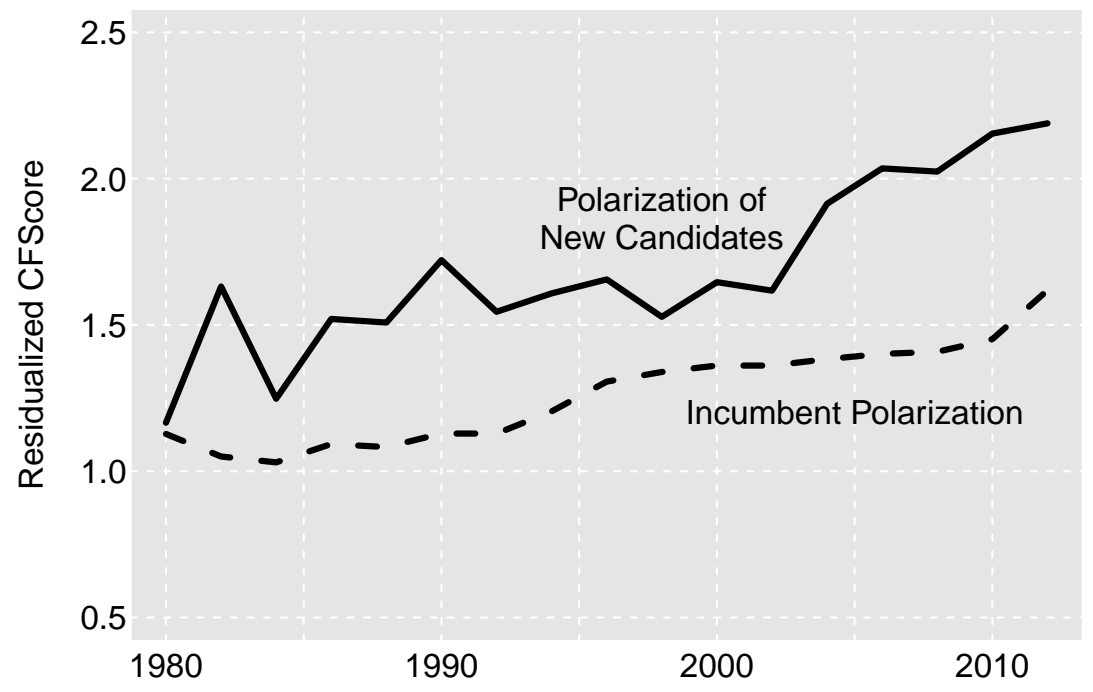

party as did Figure 2.9 in Chapter 2. The pattern is extremely similar. A large ideological gap is seen between the two parties' senatorial candidates across the entire time period. Just as in the U.S. House, voters are left to choose their senators from among a polarized pool of options.

Figure 2.15 considers how the set of new candidates compare to sitting candidates in terms of ideology. Just like we saw for the House in Chapter 2, the set of new people running for office polarizes at roughly the same rate as the legislature itself polarizes.

\subsubsection{State Legislatures}

Next, I investigate who runs for U.S. state legislatures. To start, I consider all state legislatures at once, residualizing candidate positions by state and district 
Figure 2.16 - Who Runs for Office Over Time, U.S. State Legislatures, 1990-2012.

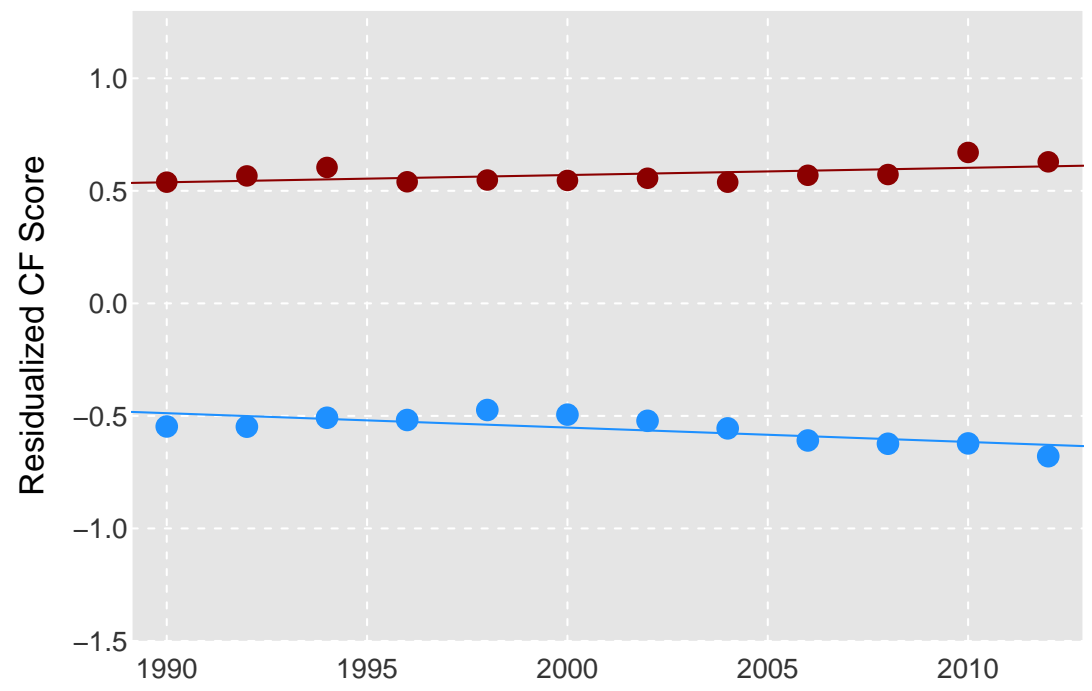

as before. Figure 2.16 presents the data. As the figure shows, we again see a large ideological gap between the two parties' candidates, across all state legislatures. Whether this gap has grown over time, averaging across all states, is less clear.

The state legislatures vary in a vast number of ways, and so, too, may who runs across states and time. Accordingly, Figure 2.17 plots the ideology of the two parties' candidates for state legislatures by state and year.

Several things are apparent in the figure. First, all of the states see some level of divergence, and far more have seen growth in this divergence than have seen it fall. It is tempting to investigate the associations between states that see more growth and changes in state-level costs and benefits of running for office. Although I will not do this directly - it is unclear how to create reliable crossstate comparisons that do not suffer from obvious sources of selection bias-I 
will conduct a variety of tests taking advantage of the state legislatures to probe who runs in more detail. In particular, in Chapter 4 I will investigate how more extreme vs. more moderate state legislators choose to run for office, showing that moderates are more sensitive to the costs of running than are extremists. And in Chapter 5, I estimate the effects of salary increases on who runs for office, using state legislative data again. I find that more moderate people run for state legislatures when legislative salaries are higher.

\subsubsection{Statewide Offices}

Finally, I also look at who runs for statewide offices. This includes races for Governor, District Attorney, and a variety of lesser state offices. Figure 2.18 presents the data. Again, we see a large ideological gap between the parties' candidates. The polarization of those who run for office does not appear to be limited to legislative offices.

\section{Summary}

In this chapter, I have established two related facts about American elections. First, U.S. House voters regularly select the candidates who offer more moderate positions. Though defining and measuring moderation perfectly and without error is impossible, the stability of the results across so many different measurement strategies points to this inescapable conclusion. And second, the candidates running for office have become increasingly ideologically extreme over time, constraining the choices of voters. 
Figure 2.17 - Who Runs for Office Over Time by State, U.S. State Legislatures, 1990-2012.

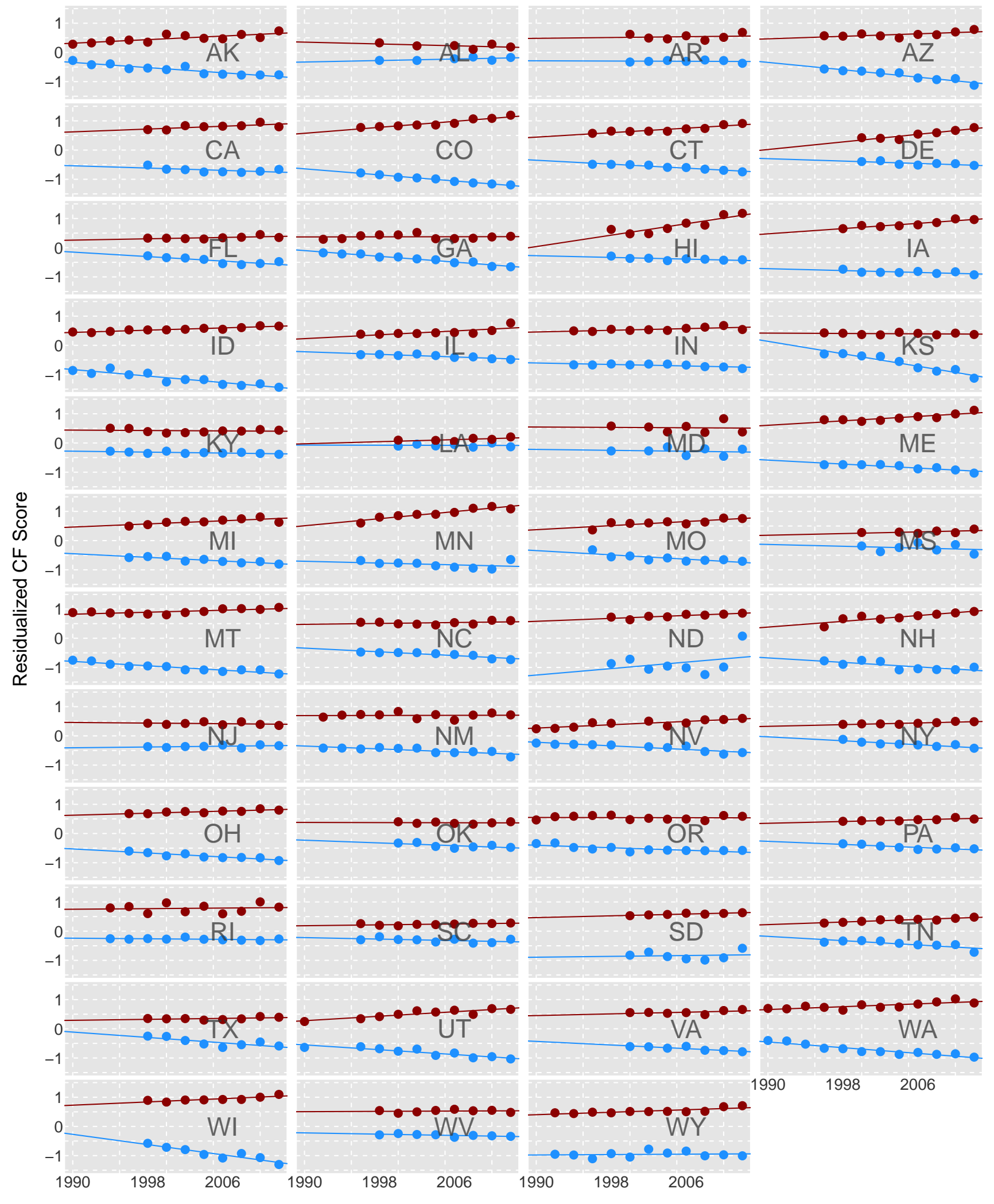


Figure 2.18 - Who Runs for Office Over Time, U.S. Statewide Offices, 1990-2012

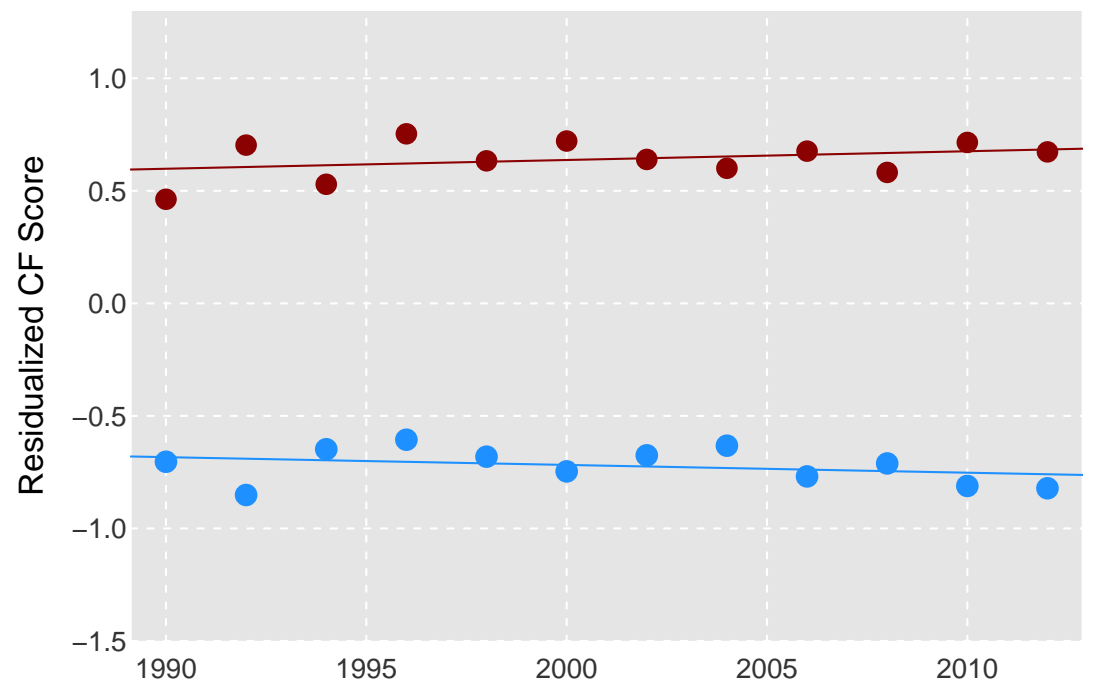

In going through these empirical exercises, we have examined what I would call the revealed preferences of voters, in the aggregate. Voters are faced with a variety of candidates but can send only one at a time to Washington. Under this constraint, voters on average prefer candidates who have offered more moderate positions. As I have strained to make clear, this does not imply that taking more moderate positions causes a candidate to perform better, electorally, nor does it imply that voters themselves have "moderate" views, or that they are hyper-informed and hyper-rational. It means that among the menu of candidates of varying positions, who may vary from each other in many other ways, voters tend to select the ones with more moderate positions. Leaving the mechanisms for these choices to one side, this implies that polarization is not the result of voters preferring candidates with more extreme positions. In conjunction with the results from Chapter 2-namely, that candidates rarely alter their positions, 
so that voters are stuck selecting pre-existing platforms from among the candidate pool - this tells us that we should look to who runs to understand how ideologically constrained voters may be at the voting booth.

This is exactly what I do in the second part of the chapter. As it turns out, fewer and fewer moderate candidates are running for office in recent decades. Indeed, the polarization of the candidate pool closely tracks the growing polarization of the U.S. House. When we look more closely at the district level, we see not only that candidates of the two parties diverge more, in terms of ideology, than they used to, but we also see that the most moderate options voters see are less moderate than they used to be. Moreover, we see evidence for this same polarization when we look just as state legislators who have compiled an ideological record in their home legislatures. The propensity to run for the House is not even across state legislators; instead, more extreme state legislators are more likely to run for the House than are their more moderate colleagues.

Putting these facts together, we can conclude that who runs matters for polarization. The evidence strongly suggests that voters would elect more moderates, and polarization would be lower, if more moderate candidates presented themselves to voters on the ballot.

Why aren't more moderates running for office, then? So far we have merely diagnosed a factor - who runs - that seems to lead to polarization. We have yet to explain it. In the next chapter, I lay out a simple theory about the costs and benefits of running for office, and I use it to try to explain why fewer and fewer moderates are willing to run for office in recent decades. 


\section{Appendix}

\section{Estimating the Advantage of Moderates}

To examine whether winning candidates appear to be more moderate than losing candidates, I run regressions of the form

$$
\text { Extremism }_{i j t}=\beta_{1} \text { Winner }_{i j t}+\gamma_{i}+\delta_{t}+\epsilon_{i j t},
$$

where Extremism $_{i j t}$ is one of two measures of a candidate's extremism. The first, following Canes-Wrone, Brady, and Cogan (2002), is simply the absolute value of the candidate's CFScore. As we discussed in detail above, we cannot know that an increase in this variable necessarily denotes extremism; it depends on where the district's median voter is located, ideologically. However, with the addition of district fixed effects, it is more likely that larger values mean more extreme candidates. The second outcome variable is the distance between the candidate's CFScore and the mean district CFScore - that is, the average donors' CFScore in the district, as used in the graph above. Finally, the variable Winner $_{i j t}$ indicates whether candidate $j$ won the election or not, and $\gamma_{i}$ and $\delta_{t}$ represent district and year fixed effects, respectively.

Table 2.1 presents the results. No matter the specification or the ideology variable employed, it is clear that winners are systematically more moderate than losers. Recall that, because both ideology measures reflect distance, lower values indicate more moderate positions. In all columns, winners have smaller - that is, ideologically less extreme - ideology scores than do losers, on average. Moreover, 
Table 2.1 - Comparing the Ideology of Winning and Losing Candidates, U.S. House, 1980-2012.

\begin{tabular}{lcccc}
\hline \hline & Abs CFScore & Distance & Abs CFScore & Distance \\
\hline Winners & -0.20 & -0.38 & -0.20 & -0.39 \\
& $(0.01)$ & $(0.02)$ & $(0.01)$ & $(0.02)$ \\
$\mathrm{N}$ & 22,723 & 15,626 & 22,723 & 15,626 \\
District Fixed Effects & Yes & Yes & Yes & Yes \\
Year Fixed Effects & Yes & Yes & Yes & Yes \\
District Time Trends & No & No & Yes & Yes \\
\hline \hline
\end{tabular}

Robust standard errors clustered by district in parentheses.

the differences are substantively large. Consider the results in the second column. A difference of roughly 0.4 on the CFScore scale is about the same as the distance between Nancy Pelosi and Steny Hoyer, the two leaders of the Democratic party in Congress. As the Washington Post has put it, Hoyer has long been considered the "practical moderate" in contrast to Pelosi's "liberal idealism." 5 Across all districts in the sample, winners are roughly as much more moderate than losers as Hoyer is than Pelosi. Another comparison is Jim Oberstar, another well-known moderate in the legislature whose views differ from Pelosi's quite markedly (for example, Oberstar is pro-life while Pelosi is pro-choice).

\section{RD Estimates of the Effects of Extremist Nominations}

I estimate models of the form

$$
\text { Win } \text { General }_{i t}=\beta_{0}+\beta_{1} \text { Extremist Primary } \text { Win }_{i t}+f\left(V_{i t}\right)+\epsilon_{i t} \text {, }
$$

\footnotetext{
${ }^{5}$ http : / www . washingtonpost . com/wp-dyn/content/article/2006/11/16/ AR2006111601524.html, Accessed June 1, 2016.
} 
where Extremist Primary Win $_{i t}$ is an indicator variable for the extremist winning the primary in district $i$ at time $t$. Thus $\beta_{1}$ is the quantity of interest, the RD estimator for causal effects from the "as-if" random assignment of an extremist in the general election. The variable Win General $i t$ is an indicator for whether the nominee in district $i$ wins the general election at time $t$.

The term $f\left(V_{i t}\right)$ represents a flexible function of the running variable, the extremist candidate's vote-share winning margin, i.e., the extremist candidate's share of the top two candidates' vote less 0.5 , which determines treatment status. There are many choices of specification and bandwidth for estimating the RD. I follow recent practices in using the automated technique from Calonico, Cattaneo, and Titiunik (2014), which uses a local kernel combined with an optimal bandwidth procedure, as implemented in the rdrobust package in Stata.

Finally, to address the issue that some primary races are between ideologically distinct candidates while others or not, I restrict the sample to only the set of races where the ideological distance between the top two candidates is at or above the median distance between the top two candidates across all races in the sample. This is in keeping with the method from Hall (2015).

Table 2.2 presents the results, for both the probability of winning the general election and for general-election vote share. We estimate very large penalties for nominating extremists. Consistent with the plot presented in the body of the chapter, nominating the extremist appears to cause a 20 percentage-point decrease in the probability the extremist's party wins the general election. As the second column shows, this same nomination appears to cause roughly an 8 percentage-point decrease in the general-election vote share. Although this latter estimate is not quite "statistically significant," it is substantively quite large. 
Table 2.2 - The Penalty to Nominating Extremists.

\begin{tabular}{lcc}
\hline \hline & Victory in General & Vote Share in General \\
\hline Extremist Win & -0.20 & -0.08 \\
& $(0.10)$ & $(0.06)$ \\
$\mathrm{N}$ & 383 & 356 \\
Bandwidth & 0.12 & 0.11 \\
\hline Specification & $\mathrm{CCT}$ & $\mathrm{CCT}$ \\
\hline \hline
\end{tabular}

Estimates from rdrobust package.

The key identifying assumption for this RD to extract causal effects of nominating more extreme candidates is that candidates close to the discontinuity cannot "sort" into winning or losing. Papers have shown some evidence that this assumption is violated in U.S. House general-election races, where barely winning candidates appear to be disproportionately likely to be incumbents, relative to barely losing candidates (Grimmer et al. 2012; Caughey and Sekhon 2011; Snyder 2005). Hall (2015) tests for the validity of the primary RD design and finds no evidence of sorting. Because the paper uses almost exactly the same sample of elections as this analysis, I do not repeat these exercises here-but to sum up, in brief, primaries in which the extremist barely won look no different from those in which the more moderate candidate barely won on a variety of pre-treatment traits including, most importantly, their previous general-election vote shares for one party or the other.

Separate from the RD's identifying assumption, we might worry that the results are somehow driven by the choice to scale candidates based on campaign contributions. To make sure this is not an issue, I replicate the previous analysis using the state legislative data, as I explained in the body of the chapter. Table 
Table 2.3 - The Penalty to Nominating Extremists: Evidence from State Legislatures.

\begin{tabular}{lcc}
\hline \hline & Victory in General & Vote Share in General \\
\hline Extremist Win & -0.68 & -0.24 \\
& $(0.33)$ & $(0.13)$ \\
$\mathrm{N}$ & 41 & 41 \\
Bandwidth & 10.14 & 10.48 \\
\hline Specification & $\mathrm{CCT}$ & $\mathrm{CCT}$ \\
\hline \hline
\end{tabular}

Estimates from rdrobust package.

2.3 presents the results, in the same format as the previous table. We again find very large penalties to nominating extremists. Sample sizes at the optimal bandwidth are quite small, so I would not place too much stock in the exact estimates, which are probably too large, but the pattern is striking. Even when we completely avoid using campaign contributions to scale candidates, we continue to find large penalties to extremist nominees in the general election.

\section{State Legislators Running for the House}

For the purposes of evaluating state legislators running for the House, I measure "legislative extremism" as the difference between a state legislator's NP-score and the median of her party in her chamber. I then run simple regressions using this variable to predict a binary variable indicating that a state legislator chooses to run for the House. Table 2.4 presents the results. As the first row shows, increases in legislative extremism predict a higher propensity to run for the House. Consider the intercept term in the first column; here we see that the party's median (averaging over the Democratic and Republican parties) runs for 
Table 2.4 - State Legislator Extremism and the Propensity to Run for the House.

\begin{tabular}{lccc}
\hline \hline & Run for House & Run for House & Run for House \\
\hline Legislative Extremism & 0.005 & 0.005 & 0.005 \\
& $(0.002)$ & $(0.002)$ & $(0.002)$ \\
Intercept & 0.010 & - & - \\
$\#$ Obs & 51,945 & 51,945 & 51,945 \\
State Fixed Effects & No & No & Yes \\
Year Fixed Effects & No & Yes & Yes \\
\hline \hline
\end{tabular}

Robust standard errors clustered by state in parentheses.

the House $1 \%$ of the time. A legislator whose NP-score is one unit more extreme than the median of her party (that is, one unit to the left for the Democrats, and one unit to the right for the Republicans) runs for the House $1.5 \%$ of the time - a substantial increase. In proportional terms, this represents a $50 \%$ increase in the probability of running for the House. The next two columns establish that this pattern is robust to specification. Taken together, there is clear evidence that more extreme state legislators are more likely to run for the House than are their more moderate colleagues. 


\section{Chapter 3}

\section{Who Wants to Run: A Theory}

The major problem - one of the major problems, for there are several - one of the many major problems with governing people is that of whom you get to do it; or rather of who manages to get people to let them do it to them. To summarize: it is a well-known fact that those people who must want to rule people are, ipso facto, those least suited to do it.

-Douglas Adams, The Restaurant at the End of the Universe

It will be the bold and the violent, the men of strong passions and indefatigable activity in their selfish pursuits. These will thrust themselves into your government and be your rulers. And these, too, will be mistaken in the expected happiness of their situation, for their vanquished competitors, of the same spirit, and from the same motives, will perpetually be endeavoring to distress their administration, thwart their measures, and render them odious to the people.

\section{-Benjamin Franklin, Dangers of a Salaried Bureaucracy}

In the previous chapters, I offered evidence that who runs is an important question when considering ideology and polarization in U.S. legislatures. Because candidates come to elections with pre-existing positions which they are unlikely to alter, as we saw in Chapter 1, voters choosing representatives are constrained by the identities of those who choose to run. And as we saw in Chapter 2, the people choosing to run are becoming increasingly ideologically extreme over time. 
Why is this the case? In this chapter, I construct a simple theoretical argument based on the costs and benefits of running for office to help explain when the set of people willing to run for office polarizes. Once I've developed this theory, in Chapter 4 I test it empirically in a number of ways.

\subsection{A Thought Experiment}

The theory is best introduced via a thought experiment. Imagine two citizens, Alice and Bob, considering running for the U.S. House. For concreteness, let's suppose Alice and Bob are registered Republicans, though this is not important for conveying any of the ideas. And let's suppose the Democratic candidate in their district is already well known (there is going to be an uncontested primary for the Democrats, let's say).

Alice is a "moderate" Republican, by which I mean that her views are not so far right wing as Bob's are relative to her potential constituents. A business executive, Alice supports what might generally be called "free-market" principles. This includes broad support for policies that reduce tariffs and generally encourage free trade, as well as support for lowering corporate and individual income taxes. To accomplish these goals, Alice is willing to have the country run a deficit, which she believes to be sound policy. Alice opposes raises in the minimum wage and does not believe the government should be involved in dictating employer decisions related to, for example, unequal pay for men vs. women. On the other hand, she differs from some of her fellow Republicans in holding what might be called socially liberal views on things like abortion (she is pro choice) and gay marriage (which she supports). Though she is ambivalent about gen- 
eral immigration policy, as a hirer of people with advanced degrees, she strongly supports the expansion of H1-B visas for high-skilled workers.

Bob, a small-business owner, is a hardcore member of the Tea Party. He opposes most government spending; he believes that President Obama should be impeached for overreaching the limits of the executive. Bob agrees with Alice on many of her free-market oriented policies, but he believes that the debt ceiling should never be raised under any circumstance. He believes that the government should use military force to remove illegal immigrants from America, and he believes that a significant military presence should be deployed along the U.S.Mexico border to deter future illegal immigrants.

Alice's and Bob's potential Democratic opponent—let's call her Claudiaholds relatively mainstream Democratic views on all these issues. This means broader support for redistributive programs, often at odds with "free-market" principles (though not necessarily free trade), strong support for gay marriage and for pro-choice policy, and strong support for immigration amnesty and a variety of pro-immigration policies.

Alice and Bob each sit down with their respective families to discuss the decision to run for office. First, they consider the personal aspects of the decision. How will their families navigate the scrutiny and stress of a round-the-clock campaign? Running for office is no picnic, they know. They each mull over their pasts. Is there anything an opponent could seize on and, fairly or unfairly, use against them?

They worry, too, about the toll the long hours of a campaign will take on their respective families. Running for office will mean long days of making endless phone calls to potential donors, attending bland breakfast events, making 
repetitive speeches, shaking hands, giving interviews, and worrying constantly about how any tiny misstatement might balloon into controversy. Somewhere in between these duties, Alice and Bob are expected to find times to (hopefully) study at least some of the policy issues they're expected to hold forth on, not to mention do research on each other's campaigns, the state of the economy, current events, the President's schedule and activities, and more. It is a 24-hour a day job. Alice and Bob will essentially not see their families until the campaign is over.

They also consider something more prosaic: their financial situations. Can they and their families afford to run for office? Doing so requires quitting, or at least taking a long leave of absence from, their respective jobs. If they win office, they must neglect their former jobs for even longer; if they lose, they may each be able to return to their jobs, but with a six-month backlog of work and ill will to make up for. In the meantime, debts will pile up, not just related to the campaign itself but simply because their families' expenses will continue unabated while they campaign for office.

Next, they and their families each discuss the feasibility of their respective campaigns. Will they be taken seriously, or will they embarrass themselves? Can they raise enough money quickly enough to be viable candidates? Will they get support from local party members, politically active business members, and the other local elites who involve themselves in the primary? Of course, they are not making these choices in a vacuum, and each has been contacted by various recruiters, but Alice and Bob are not sure how much these recruiters can deliver them electorally. 
Then, they discuss the pluses and minuses of actually being a member of Congress. On the one hand, representing their district in Congress sounds like an honor, a prize worth fighting for. More selfishly, both Alice and Bob suspect that it could be a helpful springboard for their respective careers, since former members of Congress must get at least some benefit in terms of name recognition, opportunities to work as lobbyists, and so forth. On the other hand, they are both realistic about what a job in the House entails. Gridlock and polarization means that they will have almost no opportunities to actually legislate. The party-oriented structure of the House means that they will be beholden at all turns to their party's leader, the Speaker. They will be expected to spend most of their time dialing for dollars, and they will have to fly back and forth to Washington every week. For all of these burdens, both Alice and Bob - as highly accomplished business people - will be taking more than a 50\% pay cut to work in the House.

Finally, they talk about what their candidacies might mean for the country. Bob is forceful. Claudia cannot be allowed to represent their district. Her views are anathema to Bob and, in his view, borderline treasonous. If he does not run, Bob realizes, he may have to endure two years - and probably many more, given the incumbency advantage the winner will receive - of Claudia's leftwing representation. The thought is unbearable. Not surprisingly, taking it all in, Bob decides he has no choice but to run for office.

Though no fan of Claudia's platform, Alice is far more ambivalent than Bob. True, she finds Claudia's economic policies unwise and downright damaging to her business prospects. But others of Claudia's positions are not so far from her own. Although on net she might marginally prefer Bob to Claudia, neither seems 
particularly close or far from her own ideals. Given this ambivalence, and the daunting prospect of running a full-bore campaign, Alice decides to stay out.

It is this final difference - the way Alice and Bob, respectively, consider the ideological gains and losses of holding vs. not holding office - that separate them. They face the same costs of running. In this story, they must raise the same amounts of money, make the same amounts of phone calls to the same amounts of people, endure the same levels of scrutiny, all for the same potential office- but they do not face the same ideological costs from not running. If Bob does not run, he might get stuck with Claudia, whom he finds completely, utterly objectionable. But if Alice stays out, she is merely displeased, not apoplectic, about the winner's platform. Alice's location towards the middle of the ideological spectrum makes her fear the specter of sitting out less.

Notice, too, that I have said nothing explicitly psychological about either Bob or Alice. It is not that Bob holds the views he holds stronger than Alice's holds hers (though I can easily imagine that would be the case). It is not that Bob enjoys the soap-box that candidacy will give him more than would Alice (though I can easily imagine that would be the case, too). The only difference as I have told the story is that Bob is much farther from Claudia, ideologically, than Alice is from Claudia.

Imagine, now, that we took away many of the things that make running so hard. Imagine Alice and Bob could run without having to fundraise for 6 hours a day and without worrying about having to explain the contents of an irrelevant college essay written 25 years ago. What would change? From Bob's perspective, while he would be happy to forego these burdens, it would not change his decision. He had already decided to run even when things were harder; he 


\section{Figure 3.1 - Alice and Bob Each Decide Whether or Not to Run for Office.}

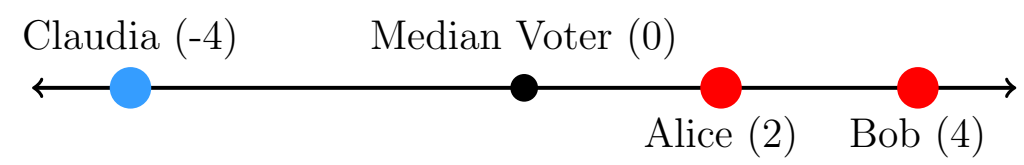

is likely to continue to do so now that it's easier. But Alice might well switch from not running to running. Before, she chose not to run because not running was not so bad for her, ideologically, which made running not worth the modest benefits. But if running is easy, those more modest benefits might become worth it.

\subsubsection{Formalizing the Thought Experiment}

Now that I have laid out the thought experiment in words, I can formalize it a bit to clarify how it works. Figure 3.1 depicts the setup, as I described it above. Each potential candidate is marked based on their ideological positions, using a single dimension of ideology. We take Claudia, the Democratic candidate, as given. She is shown to the left of the plot. Alice is the more moderate of the two possible Republican candidates, located relatively close to the median voter; Bob is farther out to the right.

Let's suppose that Alice and Bob simultaneously make the decision to run or not to run. If Alice runs and Bob does not, she wins office for sure in this model, because she is the most moderate of the three candidates. We will assume that Bob wins office only if he runs and Alice does not (in the graph above, Bob and 


\section{Table 3.1 - Alice's and Bob's Decision to Run Depends} on Costs and Benefits.

\begin{tabular}{c|c|c|c|}
\multicolumn{2}{c}{} & \multicolumn{2}{c}{ Alice } \\
\cline { 2 - 4 } \multicolumn{1}{c|}{} & Run & Don’t Run \\
\cline { 2 - 4 } Bob Run & $(-2-c, b-c)$ & $(b-c,-2)$ \\
\cline { 2 - 4 } & Don't Run & $(-2, b-c)$ & $(-8,-6)$ \\
\cline { 2 - 4 } & &
\end{tabular}

Claudia are equally distant from the median, so we will assume for now that ties are resolved in favor of the right-wing candidate in this hypothetical district). For simplicity, we will also assume for now that if both Alice and Bob run, so that there are three candidates in the race, Alice wins office (if you prefer more specifics, suppose either that the Republican primary voters are strategic, and so nominate Alice because she will win the general, or that there's a three-candidate general-election race in which Alice captures the most votes). And let's further suppose that Alice's and Bob's payoffs depend on:

- The ideological distance between themselves and the winner;

- The value, $b$, of winning office;

- The cost, $c$, of running for office.

To keep things as simple as possible, let's suppose that their overall payoffs are simply the sum of these factors (where $c$ comes in as a negative number). Table 3.1 presents the payoffs for each possible scenario, considering whether Alice or Bob each choose to run or not run for office. Consider the top left entry of the table. Here, both Alice and Bob choose to run. Since Alice is more moderate, she wins office over Bob and Claudia in this hypothetical race. The numbers in parentheses indicate that Bob receives a payoff of $-2-c$; the ideological distance between the winner (Alice) and his own ideal point is 2, and he further pays the 
Table 3.2 - When Costs are High, Bob Runs but Alice Doesn't.

\begin{tabular}{c|c|c|c|}
\multicolumn{2}{c}{} & \multicolumn{2}{c}{ Alice } \\
\cline { 2 - 4 } \multicolumn{1}{c|}{} & Run & Don't Run \\
\cline { 2 - 4 } Bob Run & $(-9,-7)$ & $(-7,-2)$ \\
\cline { 2 - 4 } & Don't Run & $(-2,-7)$ & $(-8,-6)$ \\
\cline { 2 - 4 } & &
\end{tabular}

cost, $c$, of running for office. Alice receives a payoff of $b-c$; she wins office, and so captures the benefits $b$, and she gets to implement her preferred policy, so she has no ideological loss - but she also pays the costs of running. The other cells' payoffs are computed using the same logic.

Clearly, what Alice and Bob decide will matter on the precise values for $b$ and $c$; that is, on the net benefits of winning office. Rather than look through the algebra from this generic table, we can explore this relationship through a few specific examples. In Table 3.2, we first suppose that $b=0$ and $c=-7$, so that the net benefits of office are equal to -7 . In this scenario, running for office is very costly. What do Alice and Bob decide?

First, let's examine the decision from Alice's perspective. If Bob runs, Alice can either run, in which case she wins office and obtains a payoff of -7 , or she can sit the race out, in which case she receives a payoff of -2 . Because the net benefits of office are so low in this hypothetical, if Bob runs, Alice clearly will not. Although Alice disagrees with Bob, her payoff when he is in office is only -2 - that is, the cost she pays for the ideological dissonance between herself and Bob isn't so much that it makes her want to bear the high costs of running. If Bob doesn't run, Alice now faces the risk of Claudia, who's further from her than Bob is, winning office instead. Even in this case, though, the costs of running are so high that she would rather sit out and let Claudia win, preferring the -6 
Table 3.3 - When Costs are Low, Alice Runs and Wins.

\begin{tabular}{c|c|c|c|}
\multicolumn{1}{c}{} & \multicolumn{2}{c}{ Alice } \\
\cline { 2 - 4 } \multicolumn{1}{c}{} & Run & Don't Run \\
\cline { 2 - 4 } Bob Run & $(-3,-1)$ & $(-1,-2)$ \\
\cline { 2 - 4 } & Don't Run & $(-2,-1)$ & $(-8,-6)$ \\
\cline { 2 - 4 } & &
\end{tabular}

payoff from the ideological distance between her and Claudia, the winner, to the -7 payoff from running and winning but paying the costs of running.

Since the payoffs are setup such that Alice always chooses not to run, we can now examine Bob's decision, fixing Alice's choice as Don't Run. The decision is different for Bob than for Alice. If he runs, he has to pay the high cost to be a candidate, but he also wins and gets to implement his preferred ideological position. If he doesn't run, he suffers a massive cost from the fact that he is so far, ideologically, from Claudia. The extra distance between Bob and Claudia, versus between Alice and Claudia, makes all the difference. Unlike Alice, Bob chooses to run in this hypothetical. The high costs of running deter Alice but not Bob because Bob's extreme views make him more reluctant to accept Claudia as his representative.

Now suppose that we raise the benefits of office, or equivalently, lower the costs of running - so that the net benefits of office go up. In particular, let's suppose that $c=-1$ and $b=0$, so that $b-c=-1$ instead of -7 like before. Table 3.3 shows the resulting payoffs. The situation changes. Now, Alice has a dominant strategy of running, rather than not running. No matter what Bob decides, Alice always gets a higher payoff by running and holding office than by sitting out. This is because the net benefits, at -1 , are now greater than the ideological cost of letting Bob win, which is a cost of -2 . When the costs of 
running are low enough, or the benefits are high enough, Alice, the moderate, will run for office.

This is a highly stylized story. Reality is much more complicated. Even in a simple, highly abstract game theoretic setup, the precise manner in which the above story holds will be more complex. Nonetheless, the basic lesson will remain the same. The fact that people whose views are closer to the middle have less to lose by sitting out if they think more extreme people are going to run will drive the ideological divergence of those who run in each party. And this phenomenon becomes all the stronger as running for office becomes harder or holding office become less attractive.

\subsection{Who Wants to Run?}

Who wants to run? The very commonness of this question suggests that running for office may be costly, and that not everyone is necessarily willing to do it. Yet, when I pose this question to people, I am often struck by their insistence that political ambition is a constant, unchanging fact of human nature. The retort I often hear is that there is surely no shortage of individuals ready and eager to seize political power, not necessarily out of a sense of honor and duty but rather for personal gain. Perhaps tellingly, none of the people who express this sentiment to me have themselves ever chosen to run for office.

While it is true that it is rare to find a Congressional election without any candidate willing to run, that alone does not establish that there are not many potentially more attractive candidates deterred by the process. One simple fact that suggests this is that many elections are uncontested. As Fowler (1993: 9) 
points out, "many districts appear to have lost the capacity to generate candidates in one of the major parties." Admittedly, this could as much to do with expectations about electoral outcomes than about the difficulty of running, but it seems clear that more people would run in general if it were easier to do so.

Indeed, the nature of Congress today forces the parties to exert a tremendous amount of effort attempting to recruit individuals to run for Congress. The headline of a 2013 article in The Atlantic sums up the situation:

\section{"Why Would Anyone Ever Want to Run for Congress? How Demo- cratic and Republican officials cajole potential candidates into signing on for constant stress, ceaseless fundraising, and the danger of losing your job every two years."1}

It is hard to believe candidate recruitment would be such an important activity if lots of qualified people constantly wanted to run for Congress.

Aware of this obstacle, countless generations of political thinkers have proposed that those who are willing to run for office may differ from the general populace in a variety of ways. One important set of differences, which won't be the focus of my inquiry, concerns means. Many people we might think would be good candidates lack the means to do so, whether because of limited economic resources, anticipated biases in our system of campaigns, or other reasons. For example, lower-income individuals rarely become candidates for office (Carnes 2013); women and minorities, too, are chronically underrepresented in the candidate pool (Fowler 1993; Lawless and Fox 2005). Because I am focused on the specific question of polarization, I will set aside this important literature (al-

\footnotetext{
${ }^{1}$ http://www . theatlantic.com/politics/archive/2013/04/why-would-anyone-everwant-to-run-for-congress/275135/, Accessed 8 February, 2016.
} 
though I will revisit it later in the book when I discuss how paying legislators more might encourage more diversity in our candidate pool) and instead focus on the phenomenon of ideological self-selection even among the set of likely candidates for office. Among this set, those who choose to run for office - i.e., those willing to undergo the costs of being a candidate, and those willing to forego whatever private sector opportunities they might otherwise have - will likely differ from those who choose not to run.

In the world of economics, such phenomena fall into the category of adverse selection. Intuitively, we know that some individuals have more career opportunities than others, in part because of differences in underlying skills, training and education. This means that some people have more attractive options outside of politics than others do. If running for office is difficult and unpleasant, and/or if holding office is not a particularly attractive opportunity, then we might worry that the set of people who choose to do it are not, on average at least, those who are more qualified for other, more lucrative professions. In such a case, the very fact that someone chooses to run for office could be an indication that they possess fewer of the skills that, at the very least, are valued in other professions.

In a classic exploration of these issues, Barber (1965) considered the factors that lead individuals to seek office. The stakes could not be higher, according to Barber: "...excellence in American government - the rationality of its decisions, the quality of justice it dispenses, the timeliness of its actions - these things depend profoundly on the character of those we elect" (1). But surprisingly, our system of government was not set up to ensure that people of good character would seek it out. "To turn these potentialities into political realities," as Barber puts it, "we have relied on the spur of ambition." That is, we have assumed "that 
the desire for public office is widespread, strong, and deep" (1). This assumption is unlikely to be met in practice. As Barber concludes, "We cannot rely upon a ready supply of excellent candidates...Those we find participating...are those who happen to find that this particular political opportunity serves certain needs for them" (10). In an equally classic exploration of political ambition, Schlesinger (1966: 1) begins with the declaration: "Ambition lies at the heart of politics. Politics thrive on the hope of preferment and the drive for office." The author continues, "A political system unable to kindle ambitions for office is as much in danger of breaking down as one unable to restrain ambitions" (2).

How do people decide to run for Congress? Are we sufficiently "kindling" their ambitions? No doubt, for some the choice is idiosyncratic and seemingly random. In such cases, the propensity to become a candidate will not affect overall legislative ideology; those attracted to office will be no different, in terms of average ideology, than those who choose not to run. But, more generally, might there be a link between the willingness to run for office and the ideological positions that one holds? If there were such a connection, it would help explain the results from Chapter 3, where we saw that the set of people in each party who run for office are ideologically extreme, on average.

Here, I outline a simple theory, somewhat more nuanced than the thought experiment from earlier, that predicts precisely this connection. Following the example above, I start with a decision-theoretic approach. I consider a hypothetical world in which citizens of all different ideological positions decide whether to run for office or not. Though these hypothetical citizens vary in their ideologies, they face the same non-ideological costs and benefits of running for office; they all must pay the same price for running for office, calling up donors for hours every 
day, for having their personal lives picked over, and so on, and they all get the gains of being a member of Congress if they win office. In line with the evidence I showed in Chapter 2, moreover, among the set of candidates who choose to run in the model, the candidate closest to the middle, ideologically, wins office.

Even though they all view the non-ideological costs and benefits in the same way, in this hypothetical, if they care about the ideological position of their representative no matter whether they win (in which case they are the representative), lose, or don't run, then their varying ideologies will alter their propensity to run.

The theory is based extremely closely on a set of models from formal theory that, collectively, are known as the "citizen-candidate model" (Besley and Coate 1997; Osborne and Slivinski 1996).

In particular, under certain conditions that I explore, some citizens with more extreme ideologies will be more likely to run for office than citizens with more moderate ideologies. Moreover, as the costs of running for office rise, and/or as the benefits of holding office fall - that is, as the net benefits of office decreasethe set of citizens willing to run for office will become increasingly ideologically extreme.

The model's premise tightly follows the empirical results of the previous two chapters. Consistent with the results from before, I will treat candidates' ideological platforms as fixed and pre-existing. At the time they choose to run, they already know what their platform will be and they will not change it based on electoral pressures. Voters in the model prefer to elect more moderate candidates, but, because candidate positions are fixed, they are limited to electing a representative from only the set of citizens who choose to become candidates. The key strategic conflict occurs between citizens considering whether to become 
candidates. Because running is costly, citizens will generally prefer someone else to stand up and run, but because citizens care about the ideology of their elected representative, each will have an incentive to run, themselves, if the alternative is to elect someone whose views are quite different from his or her own. This is the key dynamic that drives polarization in the model. While all citizens value the non-ideological benefits of holding office equally, and pay equal costs if they run for office, they face differing levels of "fear" for not running. A citizen with extreme views will find the specter of a citizen on the opposite side of the ideological spectrum winning office much more unpalatable than will a citizen near the middle of the ideological spectrum. This fear will disproportionately drive more extreme citizens to run against each other for office. Moreover, the harder it is to run for office, the less willing will be moderate citizens to run, which in turn creates a cascade that drives only more and more extreme citizens to become candidates.

The theory is not intended to capture every factor that influences the decision to run, nor is it intended to be a perfect depiction of reality. Rather, the goal is to isolate how ideology can help drive the decision to run, and to establish that the candidate pool can become increasingly polarized even under the minimal condition that the costs of running increase for everyone - not just for more moderate candidates.

Let me state briefly what this theory is not. It is not a theory of candidate psychology; it does not rest on the premise that citizens who hold more extreme views also hold these views more strongly, and are therefore more willing to run. This may well be true but it would be difficult to establish empirically. Instead, the argument will be built up on the assumption that everyone cares equally about 
ideology, but differs in their ideological views. This gap alone will be sufficient to establish the prediction that those with more extreme views will be more willing to run; layering on further inducements for more extreme individuals would only sharpen these predictions, but is not necessary for the overall conclusion.

Perhaps more importantly, the theory is also not about executive offices - it is an explicitly legislative theory. Perhaps in the future it could be extended to races for executive offices, but for now, it should suffice to say that elections for these latter offices are much different. Unlike in the legislature, executives possess significant unilateral authority, and many of their duties are non-ideological in nature. As a result, both the personal preferences of candidates and the views of voters may be less tied to ideology, and the choices voters make in executive elections may map only irregularly into ideological policies.

\subsection{A Theory of Who Runs}

\subsubsection{The Setup}

Each citizen possesses an ideal point along a unidimensional scale of ideology. Citizens run for office, and their electoral fortunes are determined by their position in the ideological space; that is, the candidate whose views are most preferred by a plurality of the other citizens wins office. The winning candidate takes office, and every citizen's ideological payoff depends on the ideological position of the winning candidate. 


\subsubsection{What Do Candidates Care About?}

To be more specific, in citizen-candidate models, potential candidates' utility depends on three separate factors (just like in the thought experiment form before):

1. The ideological distance between their personal ideal point and the ideal point of the elected representative;

2. The non-ideological benefits of holding office, if they win the election;

3. The non-ideological costs of running for office, if they run.

\section{Ideological Distance}

The first factor is how far the ideological position of the winning candidate is from the potential candidate's personally preferred position. If the candidate herself enters and wins, this distance is of course zero. If, on the other hand, the candidate enters and loses, or if she does not run at all, then her utility is influenced by how far away the winner's views are from her own.

There are many ways to interpret this theoretical feature. One possibility is to imagine the winning candidate implementing, or helping to implement policy, with citizens caring about the ideological content of policy and therefore caring about the ideological positioning of the winning candidate. This is probably a somewhat unsatisfying interpretation since any individual legislator only has a small amount of influence on policies determined by the legislature as a whole.

A more plausible way to think about it may be in terms of position-taking. Citizens may care about the positions their legislators take, even if they understand 
that a single legislator's vote rarely makes the difference between a bill passing or not passing. What is more, while the positions a legislator takes publicly may not usually affect policy, they may be a useful proxy for the other, less observable things a legislator is doing behind the scenes, things like amending bills, striking deals, and performing constituency services that have an ideological bent to them.

Is it plausible that, one way or another, potential candidates consider the disutility from having someone else, with differing positions, serve in their stead? Real people considering running for U.S. legislative elections consider many factors, of course, but the possible ideology of the winning candidate is one potentially important one. The winning candidate's positions matter; they contribute to the policies that the legislature produces, they lead the winning candidate to take certain positions, to introduce certain bills, and to conduct political business on the district's behalf in a particular manner. Most people invested enough to considering a run for office must surely weigh how their own ideology would contribute to this process vs. how an opponent's would in their stead.

This logic has a long tradition in politics. Plato mused that "the heaviest penalty for declining to rule is to be ruled by someone inferior to yourself." More recently, Matt Salmon (R, AZ), for example, returned to Congress after a long absence citing a "concern for future generations." He told RealClearPolitics that he "came back out of fear." ${ }^{2}$ Describing the mindset of many potential candidates dismayed at the current state of policy, the article concludes: "the fundamental

\footnotetext{
${ }^{2}$ http://www.realclearpolitics.com/articles/2013/10/24/why_would_anyone_run_ for_congress_these_days-2.html, Accessed February 9, 2015.
} 
way out of the current condition remains a straightforward one: grab the reins yourself."

\section{Non-Ideological Costs and Benefits}

The second two factors that potential candidates care about in the citizencandidate model together comprise the net benefit—non-ideologically speakingof running for office (the expected benefits of winning minus the sure costs of running). Though any candidate can choose to enter, she must pay a cost for doing so. If a candidate wins election, she receives a fixed, non-ideological benefit in addition to the opportunity to implement her preferred policies. Again, these are factors real people considering real elections are likely to consider. Some of the reasons candidates espouse for running are ideological — caring about certain policies, believing in one party or the other's vision for the country, etc.- - but others are not. Candidates of course value the prestige of office, the chance to possess some degree of power and influence, and the opportunity to perform constituent services while in office. At the same time, the non-ideological costs of running for, and of holding, office are patently obvious. Running for office is extremely difficult and time-consuming, requiring enormous amounts of effort. Maintaining office, too, especially in an environment where the next election is always right around the corner, is no picnic either.

\section{Choosing to Run}

Overall, the decision to enter thus depends on: the size of the benefit for winning; the probability of winning the election; the size of the cost for running; and, crucially, a citizen's views relative to those of her potential opponents. If she 
sees that a candidate with similar views to her own is running, then she may be willing to sit out and avoid paying the cost of running, "free-riding" off the candidacy of her like-minded fellow citizen.

Figure 3.2 helps explain this logic and why we don't see equilibria where two moderate candidates run against each other in the model. The blue and red dots to the extremes of the spectrum represent an equilibrium in which two relatively extreme candidates, one on either side of the median, run against each other. Consider the plight of the left extremist. If she decides to drop out of the race, the right extremist wins and she suffers a major disutility from seeing the right extremist's ideology in the legislature. The right extremist foresees the same cost if he, instead, drops out. It is this mutual dislike of each other's positions that preserves the two-candidate equilibrium.

There is a further important to detail needed to sustain this equilibrium. If the two extremists are too far from each other, someone in the middle of the ideological spectrum can enter and win outright-this can happen if the two extremists are far enough apart that more than $1 / 3$ of the electorate is closest to the median rather than to either extremist. This threat from the middle of the spectrum constrains how far apart the two candidates can be from one another, but the distance can still be quite large. The Appendix to this chapter lays this out in more detail.

Now imagine instead that two more moderate candidates are running against each other, as denoted by the vertical arrows pointing to the spectrum on the graph. This equilibrium cannot be sustained; if each of these candidates ran against each other, each would want to drop out and let the other win. The reason is that, by virtue of their being relatively moderate, their views are not as 
Figure 3.2 - Moderates, Extremists, and Running for

Office. Moderates facing each other would rather drop out; extremists facing each other constitute an equilibrium.

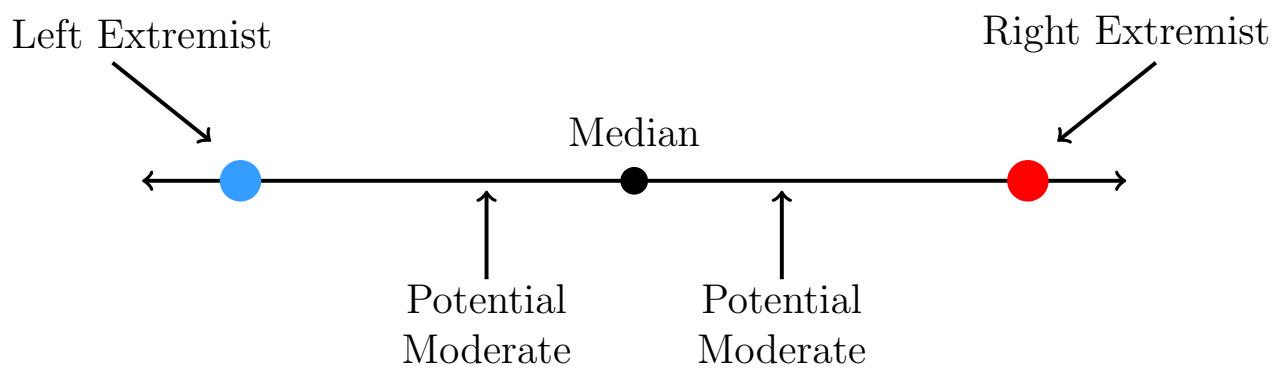

unpalatable to each other. As a result, the model never predicts any equilibrium in which two relatively moderate candidates run against each other.

The citizen-candidate model is highly abstract, and I do not claim that it fits reality perfectly. Among the important factors it excludes are: primary elections, which affect entry decisions; candidate attributes other than ideology, which affect electoral outcomes; and differential costs and benefits across candidates, which will affect equilibrium decisions and outcomes. Nevertheless, it isolates a key feature of the U.S. electoral process. The decision to run for office is a costly one, and one that is surely made with a gimlet eye towards the available benefits should one win election. These decisions, and the factors that go into them, are not fixed across the ideological spectrum. Candidates farther from the center have more to gain from the opportunity to implement their preferred policies, and more to lose from foregoing the opportunity to do so, than do candidates whose views are near the center.

In focusing on the potential costs and benefits of running for office, I follow a longstanding literature on "candidate ambition," stemming from Schlesinger 
(1966) and Black (1972). In these works, would-be candidates are thought to make similar cost-benefit analyses when deciding whether (and when) to run. A closely related body of work, building off of these works, examines how incumbents "scare off" quality challengers (Cox and Katz 1996; Jacobson 1989; Levitt and Wolfram 1997). These literatures have focused primarily on other attributes of potential candidates - like quality or sex - but the logic applies with equal force to ideology.

Separate from the ambition literature, the idea is also motivated by evidence presented in Thomsen (2014), which establishes that more extreme Democratic and Republican state legislators are more likely to run for the U.S. House than are their more moderate colleagues. Thomsen (2014) and Thomsen (N.d.) focus on how would-be candidates consider their degree of "party fit" in the legislature before deciding whether to run. Party fit is a possible benefit (or cost) of holding office. As Thomsen (N.d.: 6) explains: "The central claim is that candidate ideology - and more specifically, the congruence between a candidate's ideology and the ideological reputation of her party-influences the decision to run for office." Though I do not test the party-fit hypothesis directly —I focus instead on other sources of variation in the costs and benefits of office - it is likely to play an important role in determining the costs and benefits of running for and holding office.

\subsubsection{When Who Runs Polarizes the Legislature}

This theory yields two main testable hypotheses which tell us how who runs can polarize the legislature. 
First, as the costs of running for office increase, the people who run for office should become more extreme. As running becomes more costly, citizens towards the middle of the spectrum become increasingly unwilling to run. ${ }^{3}$ Relative to moderate citizens, more extreme ones are more willing to keep running because they fear the outcome if they do not run more. Put another way, moderates should be more sensitive to the costs of running for office.

The logic is as follows. Think of the possible pairs of candidates, one left and one right, that constitute an equilibrium in the model - that is, pairs where the two candidates are far enough apart from each other that they are don't want to drop out and let their opponent win. They are willing to stay in because of how much they dislike each other's positions, and because the net benefits of office are high enough to keep them in the race. If we now lower the benefits of making it into office, some pairs of candidates who were previously willing to stay in against each other will now drop out instead. Imagine, for example, the pair of candidates who were just indifferent between staying in against each other or dropping out. They were indifferent because the net benefits of holding office exactly offset the disutility of suffering their opponent's representation if they dropped out. Now when the benefits of holding office go down, they are no longer indifferent - now they strictly prefer dropping out. This is why lower the benefits of office is predicted to increase candidate divergence in the model.

Second, by the same logic, moderates should also be more sensitive to the benefits of holding office. In particular, as the expected benefits of office increase, the set of people who run for office should include more moderates. The argu-

\footnotetext{
${ }^{3}$ In citizen-candidate models, it is possible for costs to be so high that no one runs for office. I do not consider this situation since, empirically, we always observe at least one candidate running for U.S. House seats.
} 
ment is identical to that above. When office is relatively unattractive, moderate candidates facing one another will be more eager to drop out and let their opponent win; when office becomes more attractive, moderate candidates become more willing to keep running.

Although this logic is straightforward, the actual empirical predictions are a bit more nuanced. Technically, the model (see Appendix to this chapter) only makes predictions about how equilibria change as the costs and benefits change. It is harder to extend these predictions about equilibria to the behavior of individual citizens, but this is where we can test the idea with data. As such, we must make something of a logical leap. The intuition of the model should, hopefully, extend to the far more complex world in which actual individuals decide whether or not to run for office. If we think it is plausible that people consider the ideology of their opponents when they run for office, and if we think they are more averse to letting opponents who are farther away from them, ideologically, win office, then the fundamental idea of the model is sound. As I will show in subsequent chapters, the central predictions of the model appear plausible in data. Using a variety of different empirical strategies, I find consistent evidence that higher costs and lower benefits produce more extreme candidate pools. Raising legislative salaries, in contrast, encourages more moderates to run for office.

\subsection{The Interaction of Voters and Candidates}

So far, this chapter has studied the decisions of candidates as the costs and benefits of seeking office rise or fall, treating voters' as unchanging and supposing that candidates know where voters stand (so that the candidates know whether 
they'll win office if they run). Although I will not go into detail, we can also think about improving the theory to consider (a) how things change when voters, themselves, become more polarized and (b) what happens when candidates are uncertain about how voters will vote. Adding these two features would bring the idea more in line with existing models of probabilistic voting (e.g., Calvert 1985; Wittman 1983), which predict that candidates of the two parties will diverge, ideologically, when they hold non-median preferences and they are unsure what set of ideological positions would make them most appealing to voters.

A first gain to extending the model in this way is that we would alter the citizen-candidate model's unrealistic prediction that all elections should (in equilibrium) be tied. Adding in uncertainty allows candidates to make mistakes, entering races and winning or losing them badly. This brings the theory more in line with the empirical results from Chapter 2. In that chapter, we compared candidates who took different positions, and showed that those who chose more moderate positions tended to do better, electorally. This finding is consistent with the in-the-background assumption of the citizen-candidate model—namely, that more moderate candidates do better - but it is actually at odds with the equilibrium predictions of the model. This is not necessarily a problem, since these models are intentionally simplified versions of reality, but it is nice to think carefully about aligning the empirical analyses with the theory.

In this alternate setup, we can also think about how candidates change as voters change. As I discussed earlier in the book, some survey scholars believe that voters have themselves polarized over time. Polarized voters reduce the electoral advantage to moderate candidates in the probabilistic voting model (see for example McCarty et al. 2015). Candidates who are more extreme then 
have a better chance of winning office, and are correspondingly more likely to run for office, too. Polarizing voters could therefore exacerbate the polarizing effects of who runs. Imagine that first, voters start to polarize for external reasons (like changes in the structure of the economy). More extreme candidates start running for, and sometimes winning, office. As they alter the legislature and the way our campaigns are run, moderates become increasingly loathe to run, leading to an even more polarized candidate pool.

In summary, the root causes of polarization are complex, and likely depend on the interplay of voters and candidates, and not just on who wants to run for office. My purpose is to focus on the part of polarization that comes from candidates, themselves, but we should not lose sight of the bigger picture. Candidates choosing to run for office will surely consider the positions of their potential constituents. How these constituents' views have changed over time, and how uncertain candidates are about these views, play a crucial role in polarization.

\subsection{Primary Elections' Role in Polarization}

So far, I have also ignored many additional factors about who runs and why our legislatures are polarized. This is by design; a parsimonious theory lets us focus on a particular factor we think might be important. But could some of these omissions, rather than the strategic forces described in the model, be the reason why more extreme people are running for office, as we saw in Chapter 2?

Primary elections are perhaps the most obvious factor left out of the model. There is a widespread view that the tiny sliver of Americans who vote in primary elections are especially ideologically extreme. Recent work estimating the 
policy preferences of primary voters supports this view (Hill and Tausanovitch 2016). As a consequence of this fact, pundits and scholars argue, primary elections advantage more extreme candidates. Some go so far as to say that primary elections, themselves, are the main cause of our polarized legislatures (e.g., Pildes 2011). Despite these strong claims, it is surprisingly difficult to zero in on evidence for primary elections' role. McGhee et al. (2014) examines whether making primary elections open instead of closed - a reform thought to make the primary electorate less extreme - leads to lower polarization, finding instead that the type of primary election has no effects. Ansolabehere et al. (2010) examines the rolling out of primary elections, themselves, to test the hypothesis that primary voters drive polarization. Again, they find null results. To the extent we can measure it, primaries do not seem to be the cause of legislative polarization.

Another way primaries might affect polarization relates to the strategic behavior of candidates. If moderate candidates anticipate that the primary election won't be favorable to them, they may not run in the first place. The theoretical model I've just introduced, by ignoring primaries, may miss the fact that moderates wouldn't actually win elections because they wouldn't survive the primary.

Although it appears true that primary electorates do support more extreme candidates (Brady, Han, and Pope 2007), the strength of this relationship seems to be overstated in most people's minds. Comparing winning and losing candidates for congressional primaries, Hall and Snyder (2014) does find that more extreme candidates outperform more moderate candidates, but the size of the association is relatively small. A one-standard deviation increase in "centrism" - a variable defined to be the ideological distance between a given candidate and the most moderate candidate in the primary - is associated with a 2.5 to 6 percentage- 
point decrease in the probability of winning the primary. This relationship is thus detectable, but not particularly large.

Boatright (2013) explores primaries in detail, focusing on cases in which incumbents are challenged. Although the book does profile interesting cases in which incumbents have lost out to more ideologically extreme challengers - and since the book's publication, several more have fallen victim to such challengers, too - a central point of the book is that these cases are quite rare. The popular media's view of the primary electorate may therefore be overblown.

One reason why these claims may be overblown is that ideology may be relatively unimportant in primary elections. Bawn et al. (2015), for example, presents in-depth field research on a number of open-seat primary elections for the U.S. House. The paper describes how such contests often boil down to contests among "champions" supported by various core interest groups situated within the district. Unlike in general elections, where ideology either matters directly for electoral outcomes or is correlated with things that do-see Chapter 2 for an in-depth treatment of these issues - it may be that in primary elections the success of these candidates is relatively unrelated to their ideology, so that extremists do not have nearly the advantage that people might think.

Perhaps the strongest available evidence that primary elections do not simply advantage extreme candidates comes from Hirano and Snyder (2014). The authors measure primary candidates' non-ideological strengths using three measures: newspaper endorsements, previous office-holder experience, and published candidate ratings. For all three measures, competitive open-seat primary elections for the advantaged party (that is, for the party that historically does well in a given district), primary elections on average select the "best" candidate from 
among those running. For the set of primary races that truly matter, those where the nominee is quite likely to make it into office, extremists do not appear to be advantaged, and moderate candidates could do quite well if they were to run.

A final point to make is that the current turnout and voting behavior we observe in primaries is an equilibrium phenomenon. That is, it is the result not just of who has chosen to turnout but of whom primary voters are choosing among. If different candidates were to run, we might well observe different people turning out and voting differently in the primary, too. The 2016 state legislative primary cycle in Kansas perfectly conveys this idea. Past election cycles have seen the Kansas state legislature, and the governor's office, become increasingly ideological extreme. Led by Governor Sam Brownback, the state has slashed the size of government across the board. As The New York Times describes it, "deep cuts to taxes, a centerpiece of the Brownback agenda, have left the state short on revenue and led to cuts to government services." 4 These changes were championed by a bevy of tea-party like members of the legislature, and a simplistic view of primary elections as an engine driving these extremists would predict these members to win their primaries easily. But in 2016, local discontent about the state budget, and especially about the lack of funding for local schools, led to a widespread rebellion against these extreme incumbents. Six far-right state senators, as well as a number of far-right state house members, lost their primaries to more moderate opponents. ${ }^{5}$ This sudden shift reflects a sharp change in the primary equilibrium. Where in past races, extreme candidates had run and been supported by extreme primary voters, the widespread discontent in 2016 led

\footnotetext{
${ }^{4}$ http://www .nytimes.com/2016/08/04/us/kansas-republicans-reject-govbrownbacks-conservatives-in-primary.html, Accessed October 22, 2016.

${ }^{5}$ See the New York Times article from the previous footnote.
} 
a number of more moderate candidates to enter primaries and, consequently, to find support among more moderate primary voters.

Primary electorates have on more than one occasion nominated truly extreme people for office, even at the expense of relatively moderate, established incumbents. These anecdotes have created an impression that primary elections overwhelmingly favor extremists and may be responsible for the rise in polarization. But large-scale empirical analyses, like the ones I have reviewed in this section, cast considerable doubt on this claim. Neither changes to the type of primary election nor the rolling out of primary elections, themselves, appear to have driven the rise in polarization, and on average primary elections only mildly favor more extreme candidates. What is more, primary electorates in districts where primary elections are most consequential appear to favor more qualified candidates, separate from ideology. Taken together, the literature suggests a far more nuanced view of primary elections. This is important for our purposes because it reinforces the view that if we can get more moderate, more qualified people to run for office, they stand a good chance of winning election.

\section{Summary}

To understand how our legislatures have polarized, we need to understand why some people run for office and why others do not. Although many factors influence the decision to run, ideology can be an important motivator. In many cases, I have argued, people with relatively extreme ideological views have good reason to run against each other. When two relatively moderate people consider running against each other for office, they are more ambivalent about each other's views, 
and more willing to avoid the difficulties of running for office. When two more extreme people make this same calculus, they are more likely to stay in the race. Unlike the more moderate potential candidates, the more extreme candidates find the opposing party's views more unpalatable. Who runs can thus create polarization in our legislatures, even though voters would prefer to elect more moderate candidates.

Who runs for office is thus one important explanation for the presence of polarization, but can it explain why it has grown over time? If the costs of running for office have grown over time, and/or if the benefits of office have decreased over time, then the theory developed in this chapter predicts that the set of people who run for office will become more extreme. The more we devalue political office, the more polarized the people who run for office will be. In the subsequent chapters, I turn to empirical evidence that supports this theoretical prediction. 


\section{Appendix to Chapter 3: A Formal Model of Who}

\section{Runs}

\section{Basic Citizen-Candidate Model}

I start by laying out the simple citizen-candidate model from Osborne and Slivinski (1996) (with very minor modifications). To be clear, this is not a model of my creating. In fact, much of my analysis comes from an undergraduate problem set question in Osborne and Rubinstein (1994)! But by going through it in detail I can explain and defend my claim that increasing costs can lead to candidate divergence, which is not a focus of the original papers on the subject. Once I have done that, I can also modify the model to explore the consequences if moderates pay higher costs to run for office (or, similarly, if they face lower benefits of holding office).

Citizen $i$ holds a unidimensional ideological position $x_{i}$. There is a continuum of citizens, and citizens are distributed across ideology according to the CDF $F$ (where $F$ is symmetric around the median). Citizens pay a cost $c$ for sure if they choose to run; if citizen $i$ wins office, she receives benefit $b$ and implements policy $x^{*}=x_{i}$ for sure (consistent with the rigidity hypothesis from Chapter 2). Citizen

$j$ who does not hold office receives payoff $-\left|x_{j}-x^{*}\right|$. The median citizen has 
position $x_{m}$. To be clear, the utility for citizen $i$ is

$$
U_{i}\left(x^{*}\right)= \begin{cases}b-c & \text { if run and win } \\ -\left|x_{i}-x^{*}\right|-c & \text { if run and lose } \\ -\left|x_{i}-x^{*}\right| & \text { if don't run }\end{cases}
$$

where $x^{*}$ is the ideal point of the winning candidate (so $x_{i}=x^{*}$ if $i$ runs and wins). The game proceeds as follows. In the first stage, citizens simultaneously decide whether to run for office or not. Next, all citizens vote sincerely for the candidate closest to their ideal point. Finally, a candidate is selected as the winner and her favored policy is implemented. Electoral ties are resolved by a fair coin flip, so if $k$ candidates tie in an election, each has a $\frac{1}{k}$ chance of winning office.

Consider a proposed equilibrium in which two candidates, 1 and 2, holding positions $x_{m}-\epsilon$ and $x_{m}+\epsilon$, run. Two main conditions must hold for this to be an equilibrium. ${ }^{6}$

Condition 1: Given that 1 and 2 run, the median citizen cannot run and win. For this to be true, it must be the case that the median citizen would receive fewer than $1 / 3$ of the votes if she ran. Since the candidates must be arrayed symmetrically, this means that the leftmost candidates must be getting more

\footnotetext{
${ }^{6}$ Here I am glossing over a few extra technicalities. One is that we must also establish that there aren't other candidates who'd like to run even if they would lose, in order to alter the identity of the winner. This can be ruled out for the two-candidate case easily as shown in Osborne and Slivinski (1996).
} 
than $1 / 3$ of the votes. So, we must have

$$
\begin{aligned}
F\left(x_{m}-\frac{\epsilon}{2}\right) & \geq \frac{1}{3} \\
x_{m}-\frac{\epsilon}{2} & \geq F^{-1}\left(\frac{1}{3}\right) \\
\epsilon & \leq 2\left(F^{-1}\left(\frac{1}{2}\right)-F^{-1}\left(\frac{1}{3}\right)\right) .
\end{aligned}
$$

Condition 2: Neither 1 nor 2 can have incentive to drop out, given that other is running.

$$
\begin{aligned}
E U_{1} \mid \text { Run } & =\frac{1}{2}(b-c)+\frac{1}{2}(-c-2 \epsilon) \\
E U_{1} \mid \text { NoRun } & =-2 \epsilon \\
\frac{1}{2}(b-c)+\frac{1}{2}(-c-2 \epsilon) & >-2 \epsilon \\
\frac{1}{2} b-c & >-\epsilon \\
\epsilon & >c-\frac{b}{2} .
\end{aligned}
$$

Putting these together, we find the feasible range of $\epsilon$ such that we get a divergent, two-candidate equilibrium:

$$
c-\frac{b}{2}<\epsilon<2\left(F^{-1}\left(\frac{1}{2}\right)-F^{-1}\left(\frac{1}{3}\right)\right) .
$$

Figure 3.3 depicts this equilibrium graphically. 
Figure 3.3 - Divergence in Two-Candidate Equilibria.

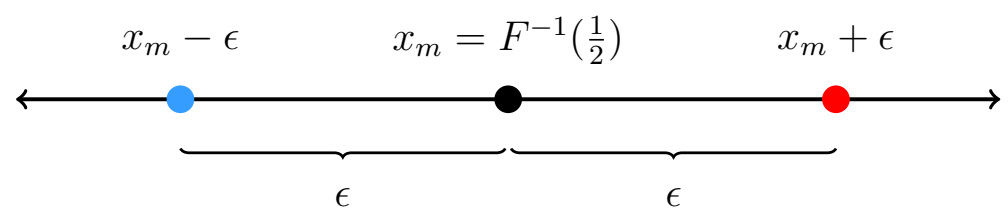

\section{Example with Uniform Distribution of Voters}

Suppose $F \sim \operatorname{Unif}(0,1)$, so that $x_{m}=\frac{1}{2}$. Using the above, we now have the following bounds on $\epsilon$ :

$$
c-\frac{b}{2}<\epsilon<\frac{1}{3}
$$

This means that the distance between each of the candidates and the median could be as much as one-third, which in turn would mean that fully two-thirds of all voters would be in between the positions of the two candidates. Graphically, we have the situation shown in Figure 3.4. The middle point again shows the median. In the range just around the median, marked by the center curly bracket labeled "Cands Drop Out," there is no two-candidate equilibrium. In this region, $\epsilon<c-\frac{b}{2}$, so that neither 1 nor 2 has an incentive to stay in the race given that the other is running.

Outside of this region, the next regions (one to each side) are those where twocandidate equilibria are possible. The blue and red points represent the positions 1 and 2 take in the maximally divergent equilibrium. In the uniform case, this divergence is quite large. 


\section{Figure 3.4 - Divergence in Two-Candidate Equilibria} with a Uniform Distribution of Voters.

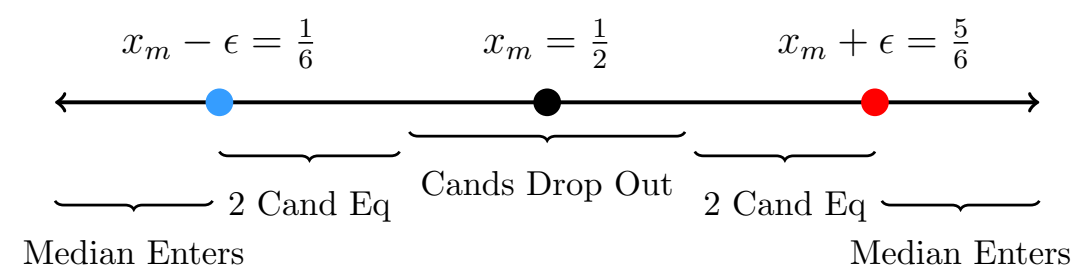

The final region to each side of the spectrum again covers a case with no two-candidate equilibrium. Beyond $\frac{1}{6}$ and $\frac{5}{6}$, the positions become so extreme that the median can enter and win outright, which she prefers to do.

\section{How Divergence Increases With Costs}

Having fleshed out the basic model, we can now discuss how things change as costs, $c$, increases. What's tricky, however, is that these are not "comparative statics" in the normal sense that most non-theorists (myself included) might be accustomed to. Here we are dealing with a multitude of two-candidate equilibria defined by a range of feasible values $\epsilon$ can take on. As we increase $c$ we restrict this range. In particular, as we increase $c$, we rule out lower-divergence equilibria. If we refer back to equation 4.2, we can see why. Increases in $c$ or decreases in $b$ increase the lower bound that defines the set of values $\epsilon$ can take on in a twocandidate equilibrium. That is, the minimum distance away from the median citizen necessary to sustain a two-candidate equilibrium becomes larger when $c$ increases or $b$ decreases.

Why is this the case? The lower bound, $c-\frac{b}{2}$, reflects the willingness of the two candidates to pay the cost to run to avoid the ideological cost of dropping out and letting the opponent win and implement her policy. When we increase 
$c$ or decrease $b$, we raise the costs of staying in the race while holding the ideological cost of dropping out and seeing your opponent implement her policy constant. Dropping out thus becomes increasingly attractive - in turn, the set of two-candidate equilibria contains only candidates who are farther away from the middle, far enough that they still fear the ideological cost of dropping out enough to stay in the race.

The claim that increases in $c$ (or decreases in $b$ ) lead to greater divergence is therefore nuanced. It is not a traditional comparative static in the sense of saying "as we change this parameter, the equilibrium level of divergence changes as follows." Instead, the idea is that only increasingly divergent equilibria (which are themselves unchanging) can be sustained as $c$ increases or $b$ decreases. The important part is the intuition, though - I would not claim this model accurately reflects reality. But it captures the important point that, as it becomes more costly to run for office, and/or as it becomes less compelling to hold office, races between two candidates become more divergent because more moderate candidates aren't afraid enough of the ideological positions of their potential opponents to be willing to pay the cost to run.

We can also do a more traditional comparative static if we focus on the least divergent equilibrium, across values for $c$ (or, equivalently, across values of $b$ ). The smallest $\epsilon$ that sustains a two-candidate equilibrium is always $c-\frac{b}{2}$. Thus, as $c$ increases, the least divergent two-candidate equilibrium becomes more divergent.

Here's a formal way of stating that. Consider the set of two-candidate equilibria, $\mathcal{E}=\left\{\left(\frac{1}{2}-\epsilon, \frac{1}{2}+\epsilon\right): \quad c-\frac{b}{2} \leq \epsilon \leq \frac{1}{3}\right\}$. For all $\epsilon \in \mathcal{E}$, define our measure of divergence as $\Delta(\epsilon)=2 \epsilon$. Finally, define our measure of polarization to be $\mathcal{M}:=\min _{\epsilon \in \mathcal{E}} \Delta(\epsilon)=2 c-b$. Clearly, $\mathcal{M}$ is increasing in $c$ (and increasing in $-b$ ). 


\section{Higher Costs for Moderate Candidates}

The analysis of changes in costs and benefits is remarkable in that it predicts increasing divergence even though candidates of all ideological stripes face the same non-ideological costs and benefits. The argument for why increasing costs drives polarization thus does not depend on arguing that more moderate candidates have a harder time running for office or find the legislature less profitable. Nevertheless, it is interesting to consider this addition to the model. What happens if moderates face higher costs (or, equivalently, lower benefits)?

The most immediate way to see what will happen is to focus on the most divergent equilibrium. The maximum amount of divergence possible is controlled by the fact that any more divergence will allow the median to enter and gain enough votes to win the race. With fixed costs and benefits, it must be the case that the median will prefer to do this. How do we know this? Consider the entry

decision of the median in the case that she can win for sure, leaving $b$ and $c$ constant across ideology. If the median sits out, her expected utility is

$$
E U_{m}\left|N o R u n=\frac{1}{2}-\right| x_{m}-\left(x_{m}-\epsilon\right)\left|+\frac{1}{2}-\right| x_{m}-\left(x_{m}+\epsilon\right) \mid=-\epsilon .
$$

On the other hand, if she enters, she wins for sure, so she receives

$$
E U_{m} \mid R u n=b-c .
$$


Thus, to sustain a divergent two-candidate equilibrium in which the median could run and win but chooses not to, we would need

$$
b-c<-\epsilon,
$$

or,

$$
c-b>\epsilon \text {. }
$$

But we already saw before that to sustain a two-candidate equilibrium we needed

$$
c-\frac{b}{2}<\epsilon
$$

These two conditions cannot be simultaneously met. Thus, in any divergent twocandidate equilibrium, if the two candidates are so far apart that the median can enter and win, she will choose to do so.

But what if the costs of running are decreasing in ideological extremity, so that the median citizen (as well as other relatively moderate citizens) face higher costs than those who are more extreme? The logic above should make clear that now we can increase the most divergent equilibrium; while before this would induce the median to enter and win, if now the median's costs are sufficiently high, she will choose to forego running and tolerate the disutility of having an extremist on one side or the other represent her. 


\section{Chapter 4}

\section{The Devaluing of Office and Polarization: Empirical Evidence}

A political system unable to kindle ambitions for office is as much in danger of breaking down as one unable to restrain ambitions.

- Joseph A. Schlesinger, Ambition and Politics

The best people don't run for Congress. Smart people figured this out years ago and decided to pursue careers other than running for Congress. The thought of living in a fishbowl with 30-second attack ads has made Congress repulsive to spouses and families. The idea of spending half your life begging rich people you don't know for money turns off all reasonable, self-respecting people. That, plus lower pay than a first-year graduate of a top law school, means that Congress, like most federal agencies, is not attracting the best and the brightest in America.

- Anonymous member of Congress, Confessions of a Congressman, vox.com

In 2002, Alice Kerr was a state senator serving Kentucky's 12th state senatorial district, a job she had held since 1998. In her time in the state senate, Kerr, a Republican, had amassed a moderate but right-wing policy portfolio, when considered in relation to her peers in the legislature. Based on her roll-call votes in the Shor and McCarty database, Kerr was markedly left of the Republican party's median legislator, though to the right of the legislature's median. Given 
her experience and visibility in the state senate, one might suspect that Kerr had her eye on Kentucky's 6th Congressional district, her home district, but as of 2004 Kerr had never chosen to make a bid for federal government. No doubt, there are many possible reasons Kerr had not yet tried for the House, including the fact that the 6th was at that time held by physician and popular politician Ernie Fletcher. But it may have also entered Kerr's mind that to run would entail special risks for her. Like in most states, in Kentucky candidates cannot run for a new office while simultaneously seeking reelection for their current office. ${ }^{1}$ If she were to run for the House, Kerr, like most other state legislators, would have to make the difficult decision to surrender her current political office. If her campaign were unsuccessful, she would be left without either job.

Then, fortune struck. In December of 2002, Ernie Fletcher announced that he would run for governor. In Kentucky, gubernatorial elections occur separately from legislative elections - meaning that when Fletcher went on to win the governorship, there was a special election, held at its own special time, to replace his seat in the House. Kerr could seek out this seat without surrendering her current office. Only then did Kerr enter the race for U.S. House; she went on to win the primary but lose the general election, returning to her state senate seat which she still holds to this day. Just recently, in March of 2016, Kerr joined four other state senate Republicans in crossing party lines to vote against Kentucky's controversial SB 180, a bill concerning whether or not business owners could legally refuse to serve gay customers. ${ }^{2}$ In the years since her failed House

\footnotetext{
${ }^{1}$ Keen observers of politics may recall that Rand Paul, a Kentucky Senator, successfully circumvented this rule while attempting to run for both President and the Senate in 2016.

${ }^{2}$ http://www.kansascity.com/news/politics-government/article66270867.html, Accessed May 1, 2016.
} 
bid, Kerr has continued to compile a reliably moderate record as she has risen through the ranks of the state senate.

The electoral story of Alice Kerr is a relatively common one in American politics. Lyndon Johnson famously made his first attempt for the U.S. Senate in a special election which allowed him to run without having to give up his current office - a good thing for Johnson, since he narrowly lost the election to W.L. "Pappy" O'Daniel, the popular radio host and political firebrand. Johnson was able to lick his political wounds from the comfort of his office in the House, and he went on to win a Senate seat on his next try (though not without controversy). As I will document below, politicians are, perhaps not surprisingly, sensitive to the cost of giving up a certain job for the uncertain prospect of a different one. But what is perhaps more surprising - but consistent with the theoretical argument I have outlined - is that this sensitivity varies across the ideological spectrum.

Consider now the case of current U.S. Congressman Tom McClintock, who represents California's 4th district. A Republican, McClintock ranked as one of the most far right-wing state legislators ever to serve in any state legislature when he was in the California state legislature, according to the Shor and McCarty data. McClintock gave up his seat in the state legislature not once but twice in order to run for the House - first, in 1992 when he was a member of the State Assembly, and then again in 2008 when he was a state senator. In the interim, he ran for - and sometimes, but not usually, won-a dizzying array of offices. After ten years in the State Assembly, followed by an unsuccessful bid for the U.S. House, McClintock ran for State Controller twice (both times without success), for Governor twice (both times without success), and for state senate (successfully). When he finally made it to the House after giving up his 
state senate seat in 2008, McClintock joined the so-called "Freedom Caucus," the Tea-Party affiliated group that famously opposed Speaker Boehner and generally represented the Republican party's farthest right flank.

Needless to say, Alice Kerr and Tom McClintock are just two anecdotes pulled from the vast sea of people who have seen fit to run for Congress. But, as the analyses below will show, their stories are telling. While more moderate individuals are more careful about running for office, and are more sensitive to the many costs of candidacy, more ideologically extreme individuals are far more likely to commit to running whatever the costs. This differential willingness to run may always be present, but because of the way it varies, it becomes exacerbated when running is more difficult. The harder we make it to run for office, and the worse we making holding office, the more we will see moderate people choose not to run.

In Chapter 2 of this book, I showed how voters in recent history in the U.S. House prefer more moderate candidates but often lack the opportunity to support them. Over the past several decades, the people who run for office are becoming increasingly ideologically extreme, leaving voters with fewer and fewer moderate options. Why has this happened? In Chapter 3, I argued that when the job of politician is worse - when seeking out office becomes harder and more unpleasant, and/or when holding office becomes a less attractive proposition-fewer moderate people will choose to become candidates.

Now, I use data to show that this idea really does help explain why our legislatures have polarized. First, I present analyses that suggest that would-be candidates really do make cost-benefit analyses when choosing whether to run, and I show that more moderate would-be candidates are more sensitive to these 
costs than are more extreme ones. In particular, I study state legislators, like Alice Kerr or Tom McClintock, weighing the decision to run for the House. Overall, state legislators are much more likely to run for the House in situations where they can do so without paying the cost of giving up their state legislative seat. Moreover, the more moderate state legislators are more sensitive to this cost, while more extreme legislators place less weight on the need to give up their current seat when considering running for the House. Moderates are disproportionately deterred by the costs of running for office.

Second, I study the other side of the coin: changes in the expected benefits of holding office. I show that when the other party takes control of a House seat, which sharply reduces the chance that the other party can win the seat the next time around, and thus sharply reduces the expected benefits of running for office, the set of people who choose to run become more extreme, on average.

Going further, I also consider a simple policy lever that can directly alter the benefits of office: legislative salary. Studying state legislatures, I show that pay raises appear to encourage more moderates to run for office and, because they win at a higher rate, these pay raises also appear to depolarize the legislature. Together, the analyses strongly support the theory laid out in Chapter 3.

Perhaps these tests suggest the theory is plausible in real elections; but does the theory help explain why Congress has polarized over time? In order for the theory to apply to trends in Congress, we must examine whether the costs and benefits of office have truly changed over the past several decades. Have we really devalued political office, polarizing our legislatures as a result?

In the second part of the chapter, I argue that the answer is a resounding yes. Running for office has become unequivocally harder, consistent with every 
anecdote we hear in the news. Candidates must now raise more money from more people than ever before. Perhaps this difficulty reflects that political office is even more valuable than ever before, though, in which case it would not alone explain why only more extreme people are running for office. Instead, I argue that, actually, political office is less valuable than in any other recent era. The reorganization of the House in the 1970s has left individual legislators with fewer and fewer opportunities to craft individual accomplishments. At the same time, fundraising expectations in anticipation of reelection have become crushing. Media scrutiny has only increased, too. Yet, over the same time period, salaries for members of the House have decreased, sharply, in real terms. Because salaries are not adjusted for inflation, and because pay raises are political kryptonite, legislators have seen their pay steadily decrease. The result of all these changes is that being a member of Congress is, quite simply, a loathsome proposition for most of the people with the qualifications we would expect legislators to possess.

\subsection{How Costs Deter Moderates from Running}

In this section, I show that more moderate potential candidates are more sensitive to increasing costs of running for office than are more extreme potential candidates. Establishing this requires identifying an observable dimension of the costs of running for office as well as isolating quasi-random variation in this dimension of cost. In general this is not an easy task. Though we can observe things like the total amount of money raised in campaigns over time, or the amount of time spent campaigning over time, changes in such variables will not be exogenous, 
and correlating them with the ideology of the candidate supply will not produce meaningful tests of the theory's hypothesis.

To perform a more meaningful test, I first focus on one specific source of costs: giving up one's state legislative seat in order to run for the U.S. House. State legislators represent an important swath of the overall candidate supply. Candidates with state legislative experience outperform inexperienced candidates in U.S. House elections (e.g., Jacobson 1989), and roughly $28 \%$ of all U.S. House candidates, 1980-2010, are previously state legislators. ${ }^{3}$ As a result, while focusing on state legislators for this test inevitably narrows its applicability, the results of the test speak directly to some of the most viable members of the candidate supply and likely generalize to others, too. The idea to investigate the candidate pool by looking at state legislators is not novel, and has been fruitfully executed in the past. Maestas et al. (2006: 196) reports that state legislators "have provided the dominant path to the U.S. House." Using novel survey data, the authors argue that state legislators follow a two-step process in determining their future political careers, first choosing whether to run, and then, conditional on this decision, choosing when to run. More recently, and more closely related to this analysis, Thomsen (2014) documents that more ideologically extreme state legislators are more likely to run for office than are more moderate state legislators.

Here, I investigate whether state legislators are more likely to make the leap to the U.S. House when they can run without surrendering their state legislative

\footnotetext{
${ }^{3}$ This number $(28 \%)$ is calculated using the primary- and general-election dataset from Hirano et al. (2010), which builds off of Gary Jacobson's dataset on previous officeholder experience. Using this data, I simply calculate the proportion of all candidates and all races who are listed as having held either a state senate or state house seat at any time in the past. Candidates who run for office more than once (including incumbents) are thus counted once each time they run.
} 
Figure 4.1 - State Legislators Consider Costs When Choosing Whether to Run for the U.S. House, 19942012. Would-be candidates for the House are sensitive to the costs of running. State legislators are twice as likely to run for the House when they can do so without giving up their current seat.

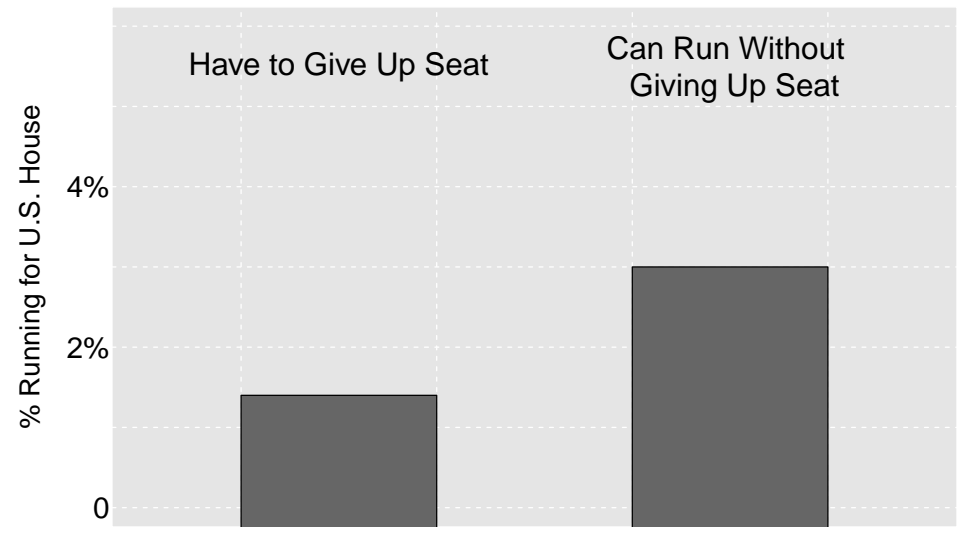

seat. In most cases, running for the House requires surrendering one's state legislative seat because the elections occur simultaneously and most states do not allow candidates to be listed on the ballot for multiple offices at the same time. However, state legislators whose terms are longer than two years - most often state senators - have opportunities to run for the House in a year in which they do not have to defend their seat, allowing them to run without risking their current seat. Occasional special elections for the House, like the one in Kentucky I discussed at the beginning of the chapter, which do not occur simultaneous with state legislative elections, offer a further source of riskless opportunities.

First, I verify that state legislative candidates are, in general, responsive to the costs of running for office. Figure 4.1 presents a simple comparison between state legislators in most times and places, who must give up their seat to run, and 
those lucky few who have a chance to run without giving up their seat. Roughly $1.5 \%$ of state legislators run for the House when they have to give up their seat to do so; but roughly 3\% - almost exactly twice as high a rate - run when they can do so without giving up their seat. In the appendix to this chapter, I confirm these differences in a more formal regression analysis.

Although state legislators are, by and large, unlikely to run for the House, they are much more likely - almost twice as likely - to do so when the costs of doing so are lower. Candidates thus appear sensitive to the costs of running for office. Does this relationship vary with ideology, as my theory predicts?

To test this, I use data on state legislators' ideology as estimated based on their roll-call voting records (Shor and McCarty 2011). These NP scores range from negative, indicating liberal roll-call voting records, to positive, indicating conservative roll-call voting records. The scalings are fixed over the lifetime of each legislator. I calculate a measure of state legislator extremism as

$$
\text { Extremism }_{i t}=\mid N P \text { Score }_{t}-m_{i t} \mid,
$$

where $m_{i t}$ is the NP Score of the median legislator in state $i$ at time $t$. Higher values of Extremismit indicate legislators who, at time $t$ are farther, ideologically, from the most centrist legislator. For interpretability, I standardize the Extremism variable, so that it has mean 0 and standard deviation 1.

Figure 4.2 presents the relationship between roll-call extremism and the propensity to run for the House, separately for the set of legislators who can run but have to surrender their seat to do so (left panel), and for the set who can run without doing so (right panel). In the left panel, when the costs of running are 
Figure 4.2 - Moderate State Legislators More Sensitive to Costs. The left panel plots the relationship between extremism and the propensity to run for the U.S. House for state legislators, 1994-2012, who have to give up their seat in order to run; the right panel plots the same relationship for state legislators who do not have to give up their seat. Extremists are more likely than moderates to run when costs are high (left panel), but this relationship goes away when costs decrease (right panel).

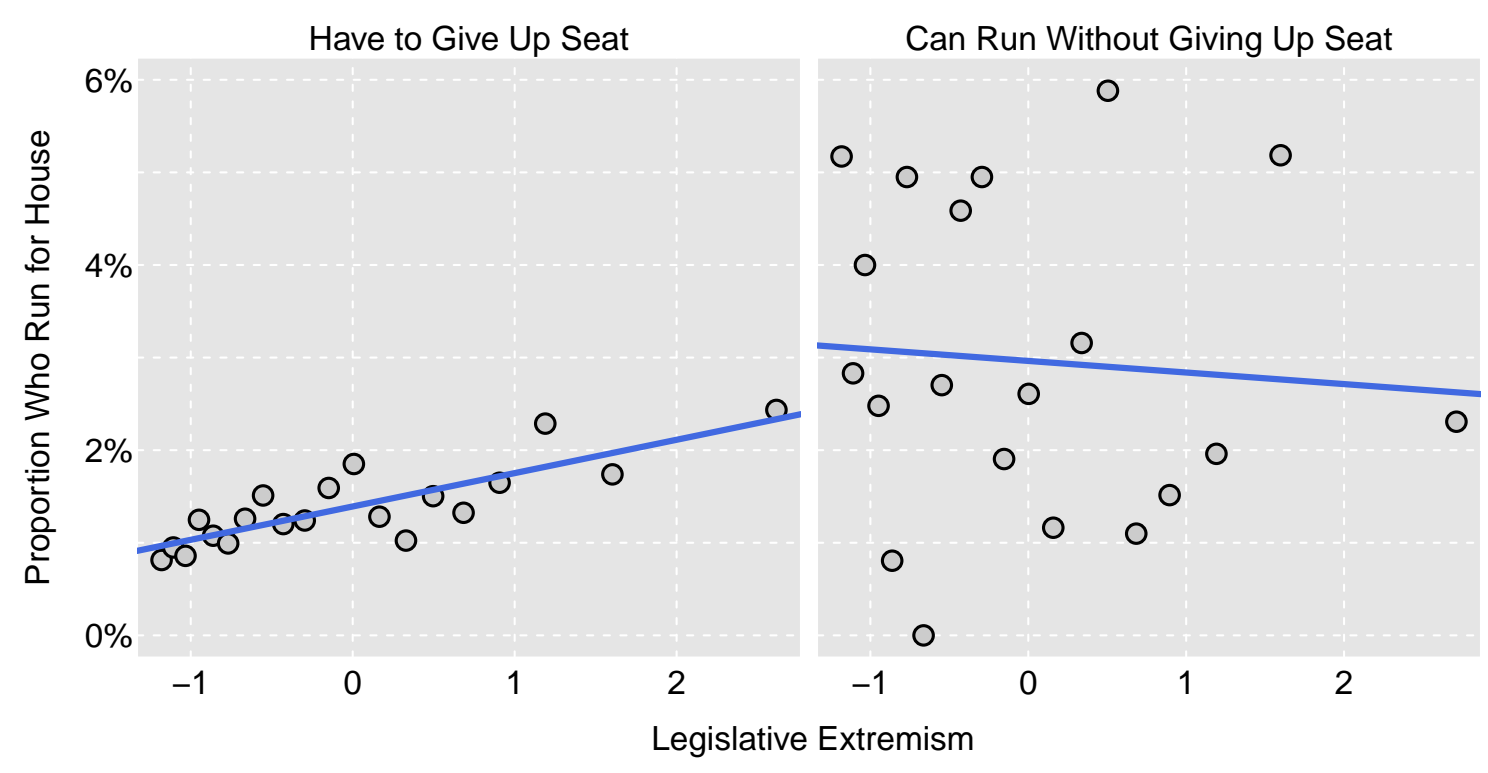

thus high, we see a clear relationship. More extreme state legislators are much more likely than more moderate state legislators to run when they have to give up their seats to do so. This relationship disappears in the right panel. Here, when costs are lower, moderate legislators are just as likely as more extreme legislators to run.

Figure 4.3 presents these results another way. The top line in the plot represents the estimated relationship between legislative extremism and the propensity to run for the House for state legislators who can do so without giving up their 
Figure 4.3 - Moderate State Legislators More Sensitive to Costs. The shaded gap between the two lines represents the difference in the probability of running for the House, 19942012, between state legislators who can run without giving up their seat and those who must give up their seat to run. This effect is large for moderate legislators (left part of the plot) but zeros out for extreme legislators (right part of the plot). Moderates are more sensitive to this cost of running than are extremists.

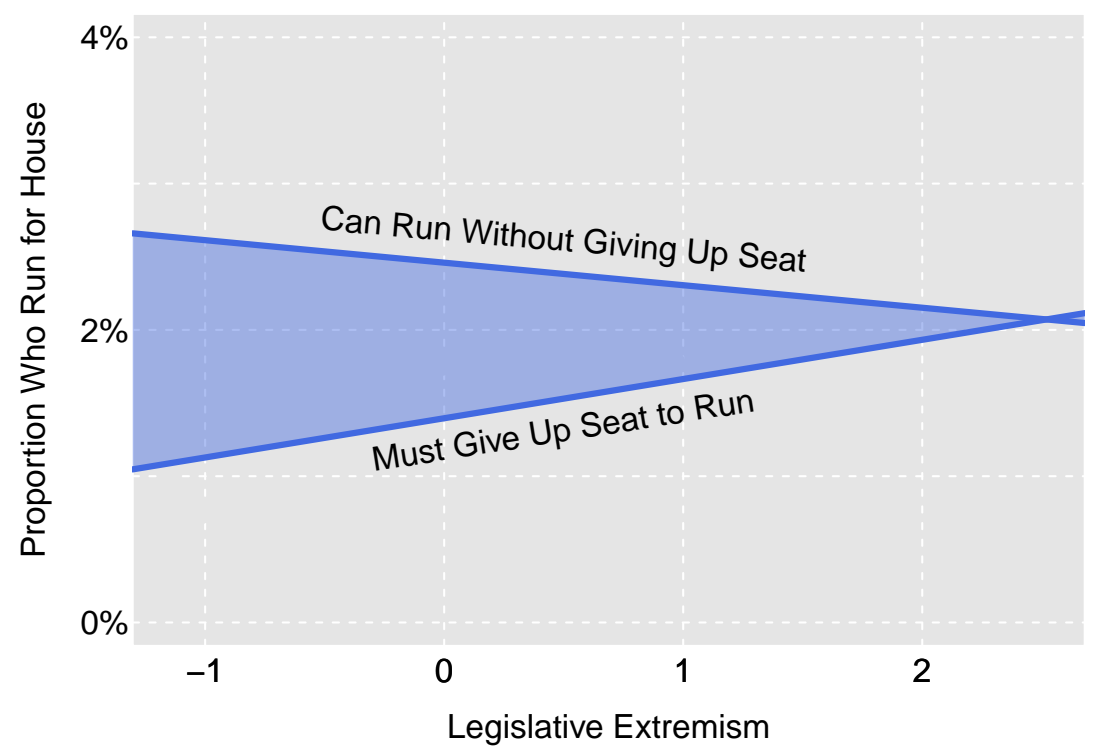

seat. The bottom line represents this relationship for those legislators who must give up their seat to run for the House. These are the same two lines from the previous figure, but now overlaid on the same plot. At any value of legislative extremism on the horizontal axis, the gap between the two lines represents how much more likely a legislator with that ideology is to run when she can do so risklessly vs. when she has to give up her seat to do so.

To the left of the plot, we see that moderate state legislators are very sensitive to this cost. The gap between the top line and the bottom line is large, indicating that moderate state legislators are much more likely to run when they can do 
so without giving up their seat. As we follow the plot to the right, so that we consider more and more extreme state legislators, this gap shrinks, and eventually disappears. Extreme state legislators do not care whether or not they have to give up their seat when they are deciding whether or not to run for the House. In the Appendix to this chapter, I examine this more formally, finding precisely the same pattern of results.

This section has established two important facts about how candidates decide to run for office. First, they are, on average, sensitive to the costs of running. When state legislators can run for the House without giving up their current seat, they are more than twice as likely to do so. Not surprisingly, would-be candidates are sensitive to how costly it is to run. Second, this sensitivity to costs is not constant across the ideological spectrum. As predicted, more moderate potential candidates are more sensitive to the costs of running - i.e., they are more easily deterred by higher costs - than are more ideologically extreme wouldbe candidates. In times when the costs of running for office are high, voters are thus forced to choose between increasingly extreme candidates, candidates who, because their positions are relatively rigid, will not cater to the ideological preferences of the median voters in their respective districts.

Would this finding extend to other kinds of costs besides giving up one's current job - costs like the difficulties of fundraising and the scrutiny of the media? The evidence does not say directly, but it is plausible. It is true that the cost of giving up your current job is unusually high, making these results harder to generalize. But on the other hand, the analysis also focused on a population unusually likely to want to run-namely, people who have already run for at least one office. Other candidates considering lower (but still high) costs, but not 
necessarily holding such a strong desire to run in the first place, might well be deterred from running if they are moderate.

\subsection{How Benefits Encourage Moderates to Run}

The theory's second prediction is that more moderate candidates should arise as the expected benefits of office rise - or conversely, that moderate candidates should be disproportionately deterred as the expected benefits of office fall.

\subsubsection{Moderate State Legislators Encouraged When Ex- pected Benefits Increase}

Like the costs of running, the benefits of holding office take many forms. Some, like prestige or power cannot be easily measured. Others, like salaries or policy opportunities, are measurable but do not often vary in an exogenous fashion that we could use to isolate the effects of changes in benefits. Quasi-random variation in party control of U.S. House seats offers an opportunity to look at changes in the expected benefits, though, because incumbents possess a tremendous electoral advantage that renders other potential candidates in the same district less likely to win office - and thus, less likely to enjoy the benefits of office.

Accordingly, I focus on changes in incumbent party control of U.S. House seats, investigating how much the average ideology of a party's candidate supply changes when it is the incumbent party in the district vs. when the other party is the incumbent party. Figure 4.4 offers a first look at the data. The figure plots the average ideological extremism (that is, the absolute value of candidate CFScores) for each of the two parties, separately for candidates running after 
Figure 4.4 - Lower Benefits Deter Moderates: Incumbency and the Ideology of Subsequent Candidates, U.S.

House, 1980-2012. Both parties field more ideologically extreme candidates, on average, in seats they lost in the last election than in seats they won in the last election.

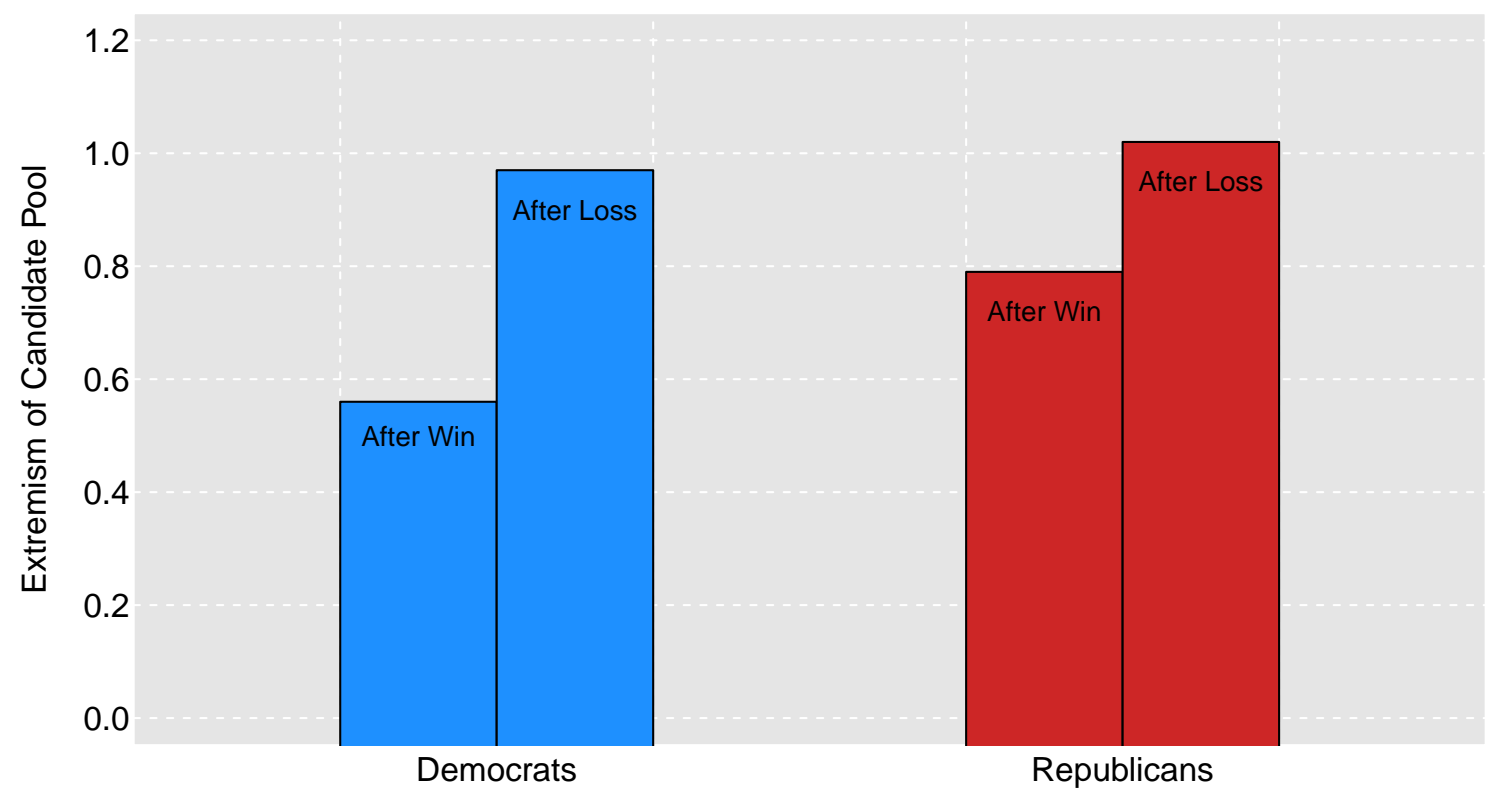

their party has won the seat in the previous election vs. for candidates running after their party has lost the seat in the previous election.

Consider the leftmost bar, which plots the average extremism of all U.S. House candidates in the Democratic party who are running for seats currently held by Democrats in the previous session of Congress (that is, won by Democrats in the previous election cycle). Many of these races have only one Democratic candidate - the current incumbent. Now consider the next bar to the right. This plots the average extremism of all U.S. House candidates in the Democratic party who are running for seats held by Republicans in the previous session of Congress. This second set of races are those where Democratic fortunes are likely to be 
poor. Perhaps because of this - because the expected chance of winning office is much lower - this latter set of candidates is much more extreme, ideologically, on average.

We see the same pattern for Republican candidates. The set of candidates running in races the Republicans won the previous time are more moderate, on average, than the set running in races the Republicans lost the previous time. Across both parties, those running for office are generally more extreme in cases where they are less likely to win office.

This initial analysis is simple, and as such, it leaves room for possible biases. In particular, the districts in which the Democratic party won last time will differ, systematically, from the districts in which the Republican party won last time. Most obviously, these districts will tend to be more liberal, but they will also vary in many other geographical and demographic traits. In the Appendix to this chapter, I present two strategies to attempt to address these issues. I find consistent evidence that incumbency in a congressional district scares off moderates in the other party in the next election.

Figure 4.5 shows the results of one of these analyses graphically. The horizontal axis reflects the winning margin, in terms of vote share, for Democratic candidates in elections at time $t$, while the vertical axis reflects the average ideological extremism of the Democratic party's subsequent candidate pool - that is, all candidates who enter the primary election - at time $t+1$. Points are averages in $1 \%$ bins of the Democratic win margin. I then fit a simple OLS line to each side of the discontinuity. As the plot shows, there is a substantial "jump" at the discontinuity between districts where the Democratic candidate barely loses, so that its subsequent candidate pool reflects a mix of candidates challenging the 
Figure 4.5 - Lower Benefits Deter Moderates: Incumbency and the Ideology of Subsequent Candidates, U.S.

House, 1980-2012. The candidate pool is more extreme after elections in which the other party barely wins office (left of discontinuity) than after elections in which the party barely wins office (right of discontinuity). The figure uses the Democratic party as the reference party, but results are essentially identical focusing on the Republican party instead.

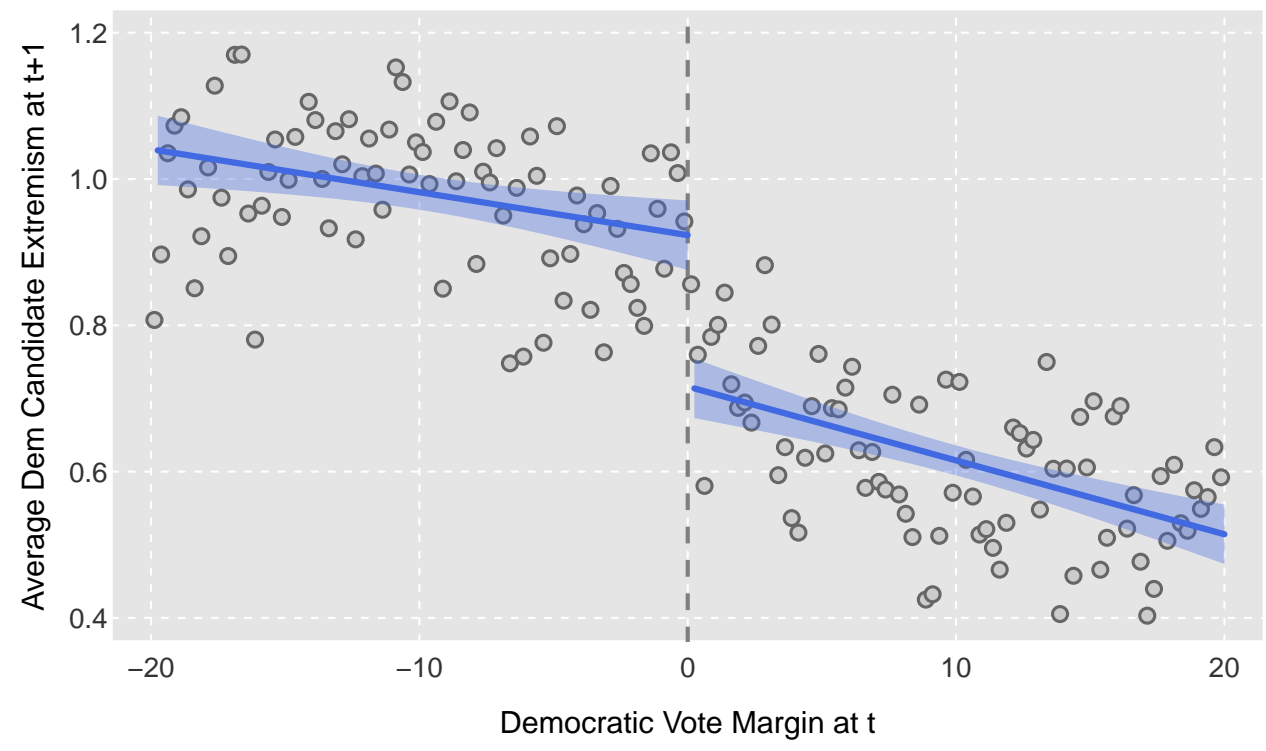

Republican incumbent at $t+1$ or running for an open seat at $t+1$, and districts where the Democratic candidate barely wins (and so is likely the incumbent at $t+1$ and is likely uncontested in the primary, though not always). In districts where the Democratic candidate barely wins, the subsequent candidate pool is far more moderate than in districts where the Democratic candidate barely loses. Again, lowering the expected chance of winning office appears to deter moderate candidates from running.

Might these estimates reflect a scare-off of quality candidates, if quality and candidate positions are correlated? This is certainly a possibility. However, for the very same set of races - close elections in the U.S. House-Hall and Snyder 
(N.d.) find that there is almost no scare-off of candidates with previous officeholder experience. Thus the effects observed here are likely to be driven, at least largely, by ideology.

Challenging an incumbent of the other party is an uphill battle in the U.S. House. While it may or may not require higher costs than does running in an open seat, it almost certainly represents, on average, a decrease in expected benefits for would-be candidates. In this section, I have explored this effect to learn about how changes in the expected benefits of office affect who runs for office. When a coin flip gives one party control of a U.S. House seat, the other party's subsequent candidates in that district becomes more ideologically extreme than in the counterfactual where it won the seat instead. Consistent with the predictions of the theory I laid out in Chapter 3, the set of people who run is more moderate when expected benefits are higher, and is more extreme when they are lower.

\subsubsection{Higher Legislative Salaries Encourage Moderates}

In May of 2014, a popular meme made the rounds on Facebook. Bright white letters on a blood red background declared: "Every single one of the 41 Republican senators who just blocked a raise in the minimum wage will receive a $\$ 2800$ cost-of-living adjustment on January 1, 2015." The meme is pictured in Figure 4.6. Such memes make the rounds frequently, whipping up popular outrage about the notion that our legislators get to set their own salaries - and thus, presumably, grant themselves frequent pay-raises at the taxpayer's expense. Though this particular meme was targeted at Republican senators, and was probably made 
Figure 4.6 - Meme Opposing Legislator Salary Raises, May 2014.

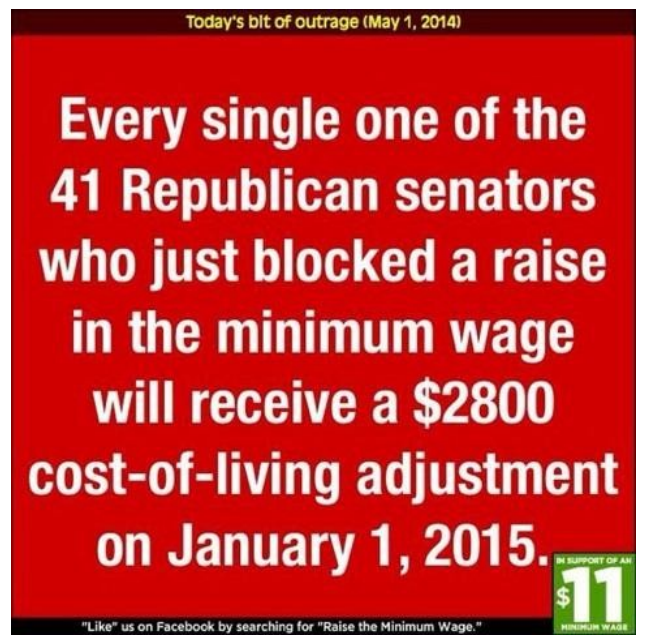

Source: politifact.com

by people with left-wing views, many others like it come from non-partisan or right-wing sources, too.

Perhaps not surprisingly, the meme is false, or at least not entirely accurate. It is true that members of the House and Senate are scheduled for small yearly payraises, mainly to keep up with inflation. But almost every year, legislators pass a bill declining these raises. ${ }^{4}$ Other than these regular salaries, our legislatures have not, in the modern era, voted any other raises for themselves. Instead, as I previously documented, pay for our legislators has declined in real terms over the past 50 years.

Separate from the factual matter of whether or not our legislators have given themselves raises, the meme speaks to Americans' consistent distaste for compensating our legislators. The fact that our legislators set their own salaries is

\footnotetext{
${ }^{4}$ See for example discussion on politifact: http://www.politifact.com/truth-ometer/statements/2014/may/06/facebook-posts/social-media-meme-says-lawmakerswill-get-2800-rai/, Accessed May 8, 2016.
} 
naturally discomforting. But one senses that even if legislator salaries were independently set, most voters would support only low, low salaries. Given the historically low approval ratings of our legislators - and the general notion that they have failed to do their job in recent years - there is absolutely no support for paying legislators more, and much support for paying them less.

I don't argue with this logic. If our legislators are doing a bad job, they should not be well-paid, no more than any employee working in any job should be lavishly compensated for doing a bad job. My point is only that setting higher salaries for future legislators could change who runs for office in important ways, separate from rewarding our current legislators. In Chapter 3, I laid out a simple theory to explain why fewer moderates are running for office. The theory predicts that more moderate people will run for office if the benefits of holding office increase. When office is more attractive, moderates choosing to run for office is an equilibrium; that is, given that relatively moderate people are facing each other, they won't drop out and let their opponents win if the value of winning the seat is sufficiently high.

As a simple way to increase the benefits of office, salaries seem like a logical lever by which to encourage moderates to run for office. Salary is the most basic benefit of office, though likely not the primary motivator for office-seekers. Raising legislative pay might alter who runs for office for several reasons.

First, higher salaries would help cancel out the opportunity costs of running for office. Like in any labor market, would-be candidates can be thought of as having a reservation wage for political office. They will not seek out a political job that pays under this amount. We can think of this reservation wage as tied to the compensation they expect to receive outside of political office. Of course, 
the value of office is manifold; would-be candidates may consider salary, but they are also thinking about future career benefits (both in terms of seeking higher offices after the House, as well as in seeking non-political offices for which prior experience in the House is beneficial), as well as political prestige, the chance to earn monetary compensation in other ways because of holding office (e.g., speaking events, corporate board membership, etc). Nevertheless, higher salaries make running for office increasingly attractive, holding all these other factors constant. This is especially true for lower-earning individuals, ones for whom the current $\$ 174,000$ salary would constitute a large increase yet not one large enough to offset all of the risk and burdens of candidacy (including taking time off of work for those currently employed).

In addition to this direct effect on who runs through monetary value, itself, raising salaries might help boost the prestige of office - currently at what seems like an all-time low. This is unlikely to help current, sitting incumbents, but higher pay for future incumbents could enhance the visibility of office by encouraging more and different types of people to run in the first place.

While increasing legislator salaries may have clear effects on who runs it does not come without costs. Most obviously, it requires tax payers to spend more money. Although increasing the pay of 435 employees would be an almost invisible fraction of the total U.S. budget, it would not be a popular policy recommendation, especially when one considers that legislators are already making far more than the median American.

Studying salaries is empirically beneficial, too, because they represent the primary observable value of holding office. This does not mean studying the effects of legislative salaries is straightforward, though. There is little variation in 
salaries at the federal level, and what variation there is was hardly "randomly" determined. To address this issue, I look at salary reforms in U.S. state legislatures. The state legislatures provide a promising avenue by which to study our federal legislatures because many candidates for the U.S. House first serve in state legislatures. Salary reforms are relatively frequent in state legislatures, and by making comparisons within states over time, we can address many of the most basic concerns about omitted variables and reverse causation that would normally make it difficult to estimate the effects of changes in legislative salaries.

To evaluate whether higher salaries encourage more moderate candidates to run for office, I collected a new dataset on salaries for legislators in the fifty states. The data comes from the Book of the States and covers the years 1992-2012 once merged with the campaign finance data.

Salaries vary widely across the states, not only in their magnitude but also in their form. Most states offer a fixed salary to legislators with, perhaps, modest pay-raises for those holding leadership positions. These salaries are typically set equal for state senators and members of the state house. Some states instead pay legislators per day the legislature is in session. For these latter states, we compare them to salaried state legislatures by multiplying this daily wage by the average number of days the legislature is in session (another piece of data available in the Book of the States).

Figure 4.7 presents the salaries of the state legislatures as of 2012. As the plot shows, there is tremendous variation. California leads the pack, paying legislators an annual salary of almost $\$ 100,000$. Michigan, New York, and Pennsylvania are not far behind. In contrast, at the very bottom of the plot, Alabama and New Hampshire pay their legislators almost nothing. New Mexico, to pick the 
Figure 4.7 - Salaries in U.S. State Legislatures as of 2012.

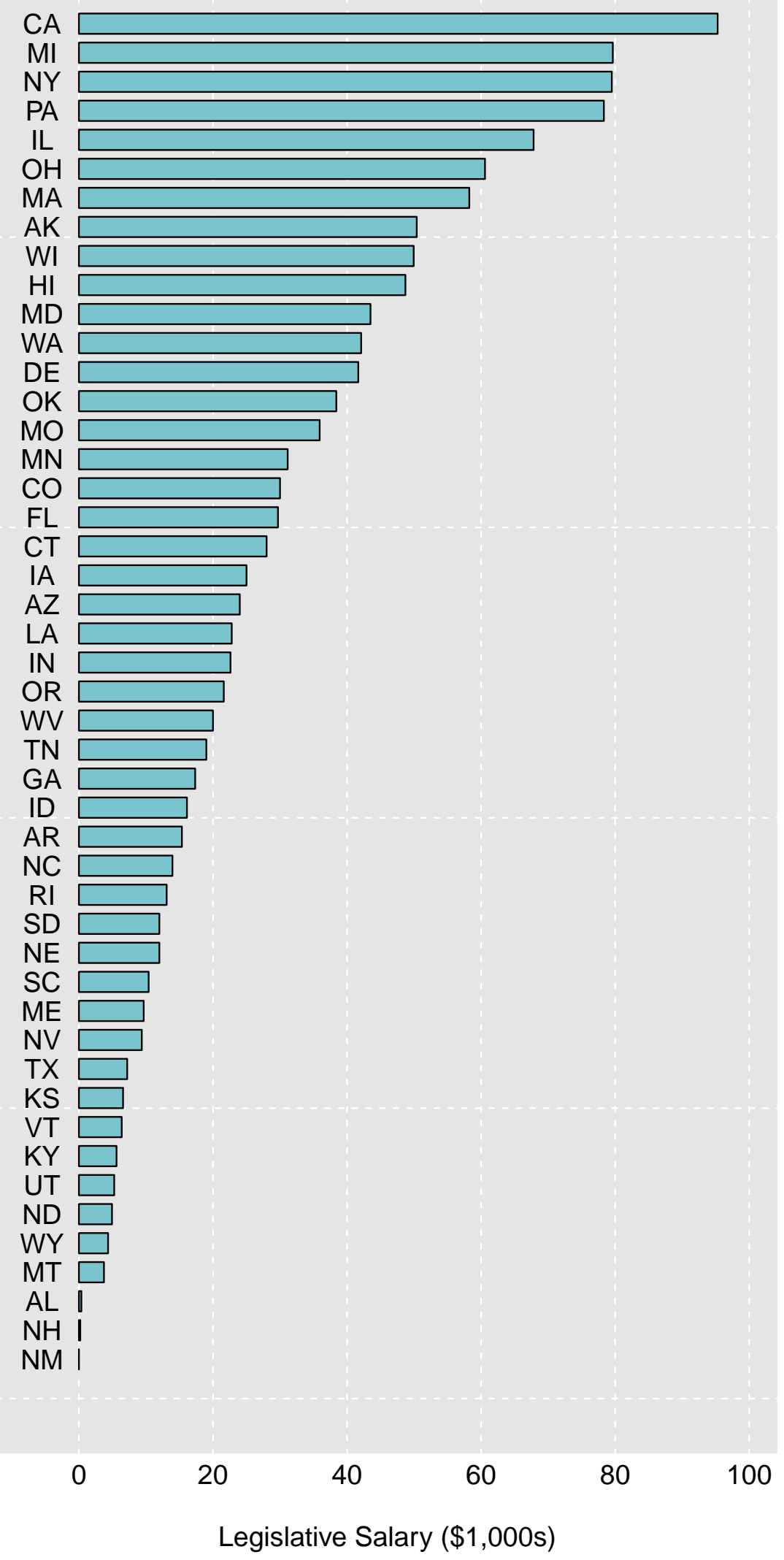


most extreme example, literally pays their legislators nothing. New Mexican state legislators are only entitled to a per diem intended to reimburse expenses incurred in the course of their political duties.

Despite this variation, making a raw comparison of the ideology of those who run for office when salaries are high vs. when salaries are low would not tell us much about whether raising salaries induces moderates to run. Obvious forms of selection bias lurk. Wealthier states with more active business communities, for example, might have more moderate candidates and pay legislators more, producing a spurious correlation between the two variables. To deal with this issue, I again turn to a difference-in-differences design. I compare changes in the ideology of the candidate pool before and after states change how much they pay their legislators to changes in other states with no salary reforms over the same time period.

How, when, and why do states change the salaries of their legislators? States have various mechanisms by which they can change these salaries, but most commonly the legislature either passes a bill to change its own pay, or an independent commission chooses a new salary level for members of government. Since 1990, when our data starts, we observe 49 distinct salary reforms. These reforms range in size from a roughly $\$ 300$ annual increase, in Wyoming in 1992 , to a $\$ 27,000$ annual increase passed in Michigan in 2002. From the research perspective, the main concern is whether these changes occur strategically. If they do, even the difference-in-differences design may attribute effects of these strategically timed reforms improperly. However, as I show below, standard validity checks suggest this strategic aspect is not a problem. This is probably because salary changes most often are imposed on the legislature externally. 
For example, the largest salary increases in recent times took place in Alaska in 2010. The state of Alaska appointed an independent commission to review salaries for government officials, recognizing that it was politically infeasible for elected officials to set their own salaries in the current political climate. The commission weighed many of the same issues I have discussed in this book. Speaking generally, the commission's report read:

Public service has non-monetary compensation. For some commissioners, public service represents a form of repayment to society for the opportunities it has provided them to achieve success and prosperity. For some it has the rewards of shaping public policies about which they have strong feelings. But along with its rewards, public service also entails costs, such as the loss of privacy, exposure to public criticism, possible relocation to the capital, and interruption of a career. It many also involve financial loss, both because of a lower salary and because of conflict-of-interest regulations that require divestiture of certain assets. To make cabinet posts as attractive as possible, salary levels have to be commensurate with the heavy responsibilities of office and also reasonably competitive with private-sector employment. Members of the commission believe it is necessary to increase the salaries of department heads to make service in the governor's cabinet as attractive and feasible for as many people as possible. ${ }^{5}$

Later, the commission turns specifically to the issue of legislator salaries. The report continues:

When a generally low and ambiguous system of compensation is combined with the large commitment of time required by legislative service, the disruption of careers and family life that it often entails, the increasing use of special sessions called at all times of the year, the general decline of remunerative seasonal employment, and the increasingly stringent ethics regulations that foreclose many business

\footnotetext{
${ }^{5}$ http://doa.alaska.gov/dop/fileadmin/socc/pdf/bkgrnd_socc24.pdf, Accessed May 19, 2016.
} 
opportunities for self-employed attorneys and other professional people, legislative service is not an attractive or even realistic prospect for many people. Consequently, the legislature does not represent a cross section of the Alaska public in terms of age, gender, and socioeconomic characteristics. It is heavily weighted with older, retired individuals, and those who are financially independent or without family obligations.

Legislators have the responsibility for decisions of momentous importance for Alaska and its citizens. The Alaska Legislature is a branch of government co-equal with the executive and judiciary, and it deserves all of the dignity and respect properly due the other branches. The current system of compensating Alaskans who serve in the legislature is unworthy of the farreaching duties and responsibilities inherent in the institution of the legislature.

Based on this logic, the commission doubled the salaries of Alaskan legislators, from roughly $\$ 24,000$ to just over $\$ 50,000$. How do these increases affect who runs for office?

To measure the polarization of the candidate pool, I calculate the estimated ideological difference between each candidate and the median candidate across both parties running for the same office at the same time. For example, for a candidate running for state senate in Alaska in 2012, I calculate the distance between her dynamic CFScore and the median CFScore for all candidates running for Alaska's state senate in 2012. I then take the average distance - that is, averaging over all candidates' distances - as the measure of candidate pool polarization for Alaska's state senate in 2012. The resulting measure therefore directly measures legislative, rather than district-level, extremism - this is the best we can do because for state legislatures we have no measure of district ideology like we do at the House and Senate level. If salaries encourage more moderates to run for office, we should see both district and legislative extremism decrease, so this still represents a useful test. 
Figure 4.8 - Moderating Effect of Alaska's Increase in State Legislator Salaries. Plots the polarization of candidates running for the Alaskan state legislature, over time, compared to a synthetic control version of Alaska. Alaska's large salary increase, put into place in 2010, appears to have substantially reduced polarization in the candidate pool in 2012 .

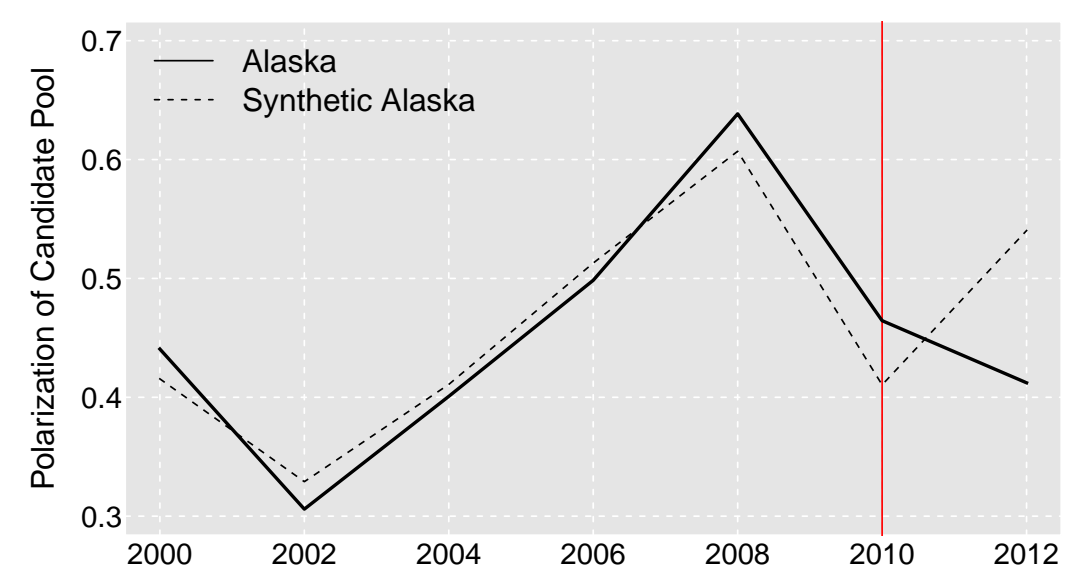

To start, I perform a simple case study of Alaska's change, using the technique of synthetic control (Abadie, Diamond, and Hainmueller 2010) to find a hypothetical control state that looks just like Alaska, in terms of its candidate polarization in the years before Alaska's salary reform, but that does not initiate a salary reform. As I mentioned above, Alaska instituted the largest salary increase in the dataset, and so is a logical choice for this case study. In addition, because the reform was relatively recent, Alaska offers a good number of pre-intervention years, which is necessary to find an effective synthetic control. Figure 4.8 shows the time trends for Alaska vs. its control, before and after the 2010 reform.

As the figure shows, the synthetic version of Alaska looks quite like it, in terms of candidate pool polarization, before the reform in 2010. After the salary increase, though, Alaska's candidate pool appears to become significantly less 
polarized. In 2012, the average distance from the median candidate, in terms of CFScores, is roughly 0.12 points lower in Alaska than it is in the hypothetical version of Alaska without the salary increase. Though it is hard to interpret the size of this effect substantively, it is almost exactly half a standard deviation in the candidate pool polarization measure, across all states, and it is slightly larger than the within-state standard deviation in this measure (0.09). I will discuss other ways to interpret the estimated effect below. Generally speaking, the effects of large salary increases seem to be meaningful and detectable.

Even when performing an analysis that focuses on within-state variation in salaries, we might worry that other differences besides changing salaries are driving the results. In particular, within states, a main driver of salary changes is inflation. That is, if we measure salaries in real dollars, then most of the changes from year-to-year in legislator salaries come from changes in the value of a dollar, rather than from actual reforms to how much they are paid. This variation is unlikely to be helpful since such changes are occurring simultaneously in any of the other jobs would-be legislators might take instead. To deal with this, I instead perform the analysis using nominal dollars. This way, the only time legislator salaries change in the data is when a state actually chooses to change legislator salaries.

Figure 4.9 presents the main result. The plot compares the polarization of the candidate pool to the logged salaries state legislators receive across states and time. Points in the plot are binned averages of candidate-pool polarization, where the size of the bins are chosen to make the sample size in each bin equal. Points are also first residualized by state and year so that the graph reflects the differencein-differences design; the reader can think about the resulting relationship being 
Figure 4.9 - Legislator Salaries and Candidate Ideologies in State Legislatures, 1990-2012. When states increase legislator salaries, the candidate pool becomes less polarized.

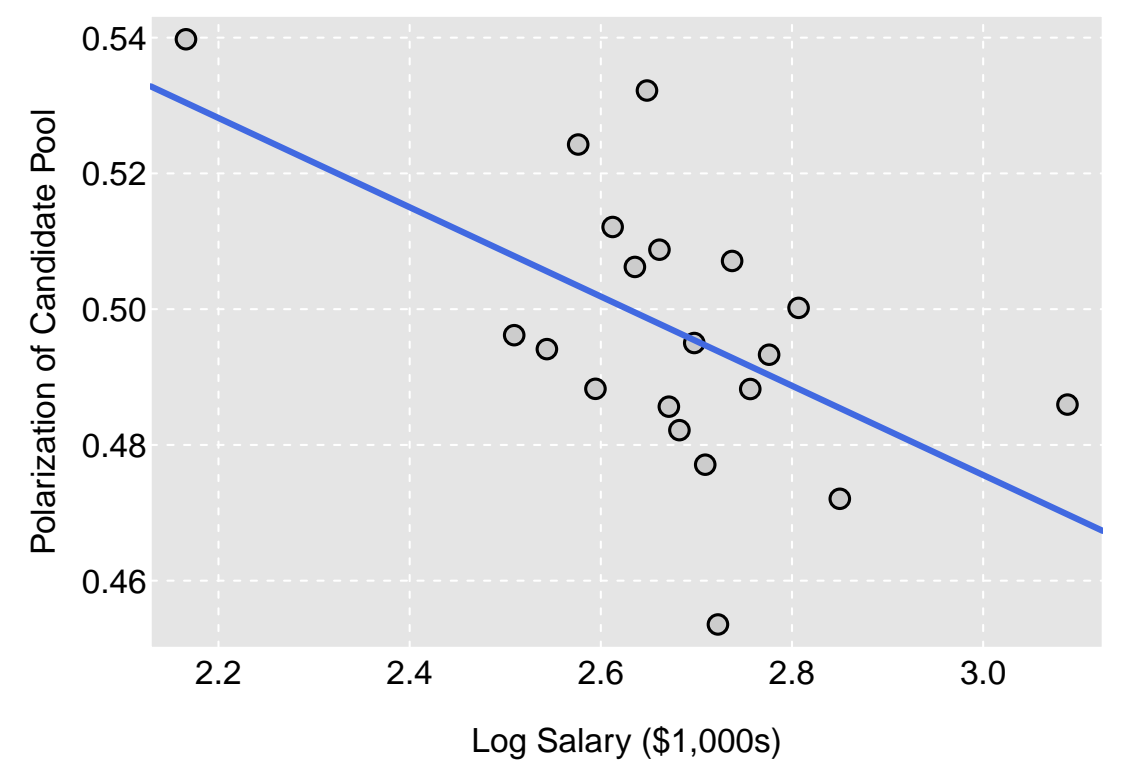

Note: Polarization is measured as the average absolute distance in CFScore ideology between each candidate and the median candidate for a given office. Points on graph are averages in equal-sample-sized bins of the log salary variable. Points are residualized by state and year to reflect difference-in-differences design.

causal, so long as the key assumption from the difference-in-differences design is met - that is, that the states that do not have salary changes provide a useful counterfactual for how the pool of candidates in a state that did change its salary would have changed over time if it hadn't changed its salary.

As the figure shows, when states increase legislator salaries, the candidate pool becomes noticeably less polarized. Consider first the leftmost point on the plot. This point is an average of all the years in all states where the annual salary in nominal dollars was around $\$ 10,000$ (so that logged thousands of dollars is around 
2.2). For these cases, as we see, the candidate pool is most polarized, with the average distance between candidates and the median competitor at roughly 0.54 on the CFScore scale. As we follow the plot to the right, as salaries increase, we see observations containing races with increasingly less polarized candidate pools. Though these cases are still quite polarized, the decrease is quite apparent.

As the accompanying table shows (see Appendix to this chapter), a 10\% increase in salary is estimated to produce a -0.004 point reduction in the polarization of the candidate pool-or, to put this in a more interpretable way, an increase from the smallest to the largest observed salary is estimated to reduce the polarization of the candidate pool by 0.25 points on the CFScore scale.

Is this a substantively meaningful decrease? One way to think about this is to compare candidates who are 0.25 points away in the CFScore measure from each other, to get a sense for what kind of gap this is. Nancy Pelosi, the well-known Democratic leader considered to be quite far to the left, is about 0.25 points away from John Larson, the veteran Connecticut Congressman. No doubt, Larson is still quite a liberal member of Congress, but he is thought to be significantly closer to the middle than Pelosi. In the 112th Congress, based on their roll-call votes as scaled using DW-NOMINATE, Pelosi was the 43rd most liberal member while Larson was only the 99th. The ideological gap between them seems quite large for co-partisans, which in turn suggests that the effect of increasing salaries on the ideology of the candidate pool is also meaningful. A big increase in salary, like those enacted in Alaska and Michigan, could shrink the average gap between any given candidate and the median candidate running for office by as much as the distance between these two quite distinct legislators. 
Figure 4.10 - Legislator Salaries and Polarization in State Legislatures. When states increase legislator salaries, the legislature becomes less polarized.

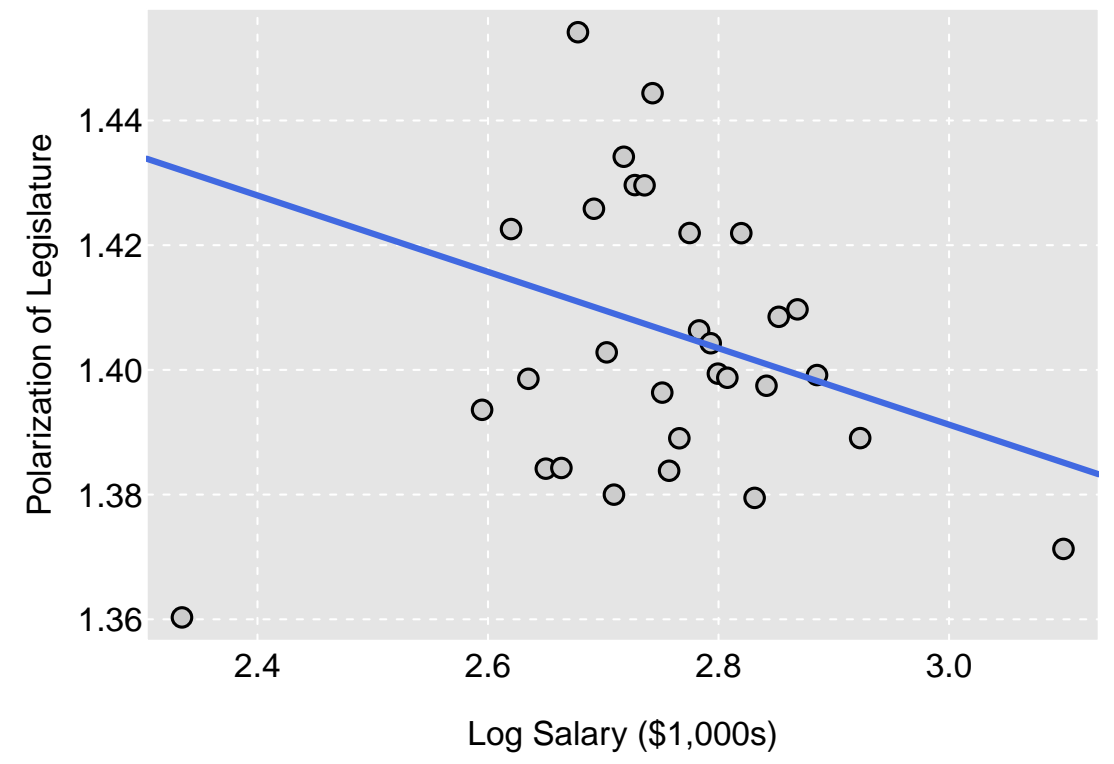

Note: Polarization is measured as the average absolute distance between the party medians in the legislature. Points on graph are averages in equal-sample-sized bins of the log salary variable. Points are residualized by state and year to reflect difference-in-differences design.

Another way to figure out if this change is meaningful is to consider its downstream effects on the polarization of sitting legislators. If the candidate pool becomes more moderate after salaries increase, and if voters prefer more moderate candidates, then we should see the legislature become less polarized.

Figure 4.10 presents the same analysis now using the polarization of the legislature, measured using the Shor and McCarty NP-Scores based on state legislative roll-call votes. We see a similar decrease. As predicted, when states raise legislative salaries, legislative polarization goes down. It is important to highlight that these results are not as statistically precise as those estimated on the candidate 
pool (see the Appendix to this chapter for more details). Nevertheless, the pattern is consistent with the results on the candidate pool and with the theoretical predictions.

To assess the impact of this effect, we can again consider the effect if we go from the lowest to the highest salary. This is estimated to decrease legislative polarization by roughly 0.3 on the NP-Score scale. It is difficult to know what this means, but given that the within-state standard deviation in NP-Score polarization is 0.13 , this represents more than a 2 -standard deviation decrease in polarization - which suggests that it is a large effect.

To sum up, looking at state legislatures, we have seen evidence that higher salaries induce more moderate candidates to run for office. In turn, higher salaries thereby reduce the amount of polarization in the legislature itself. This is further evidence that the theory laid out in Chapter 3 holds water, empirically. Just as the tests in Chapter 4 showed, here we see again that raising the benefits of holding office encourages moderates to run for office. But these results also have direct policy implications, unlike the tests in Chapter 4. If we want more moderates to run for office at the federal level, we should consider raising their salaries.

\subsubsection{Raising Benefits Alone May Be Insufficient}

Despite the salary results, in some cases raising the benefits of office alone may not make moderates run for office. Without a cap on the costliness of campaigns, higher benefits may dissipate as more people run for office and elections become more competitive. Imagine a sudden increase in the benefits of holding office. 
Seeing this increase, many new candidates may start thinking about running. Strategic and informed candidates may then realize that the new benefits of office will induce more people to consider running; in turn, they may realize that campaigns will become more difficult and time-consuming, precisely because the end prize is larger. Depending on how much more difficult the campaign becomes relative to this new prize, who runs in the end may not change as much as one would expect. Therefore, to encourage moderates, we must decrease the costs of running at the same time. If we hold the costs of running fixed and increase the benefits, alone, then it is seems more likely that more moderates will run for office.

\section{Summary: Increasing the Benefits of Office}

In this and the previous sections, I have used U.S. House and state legislative data to study the determinants of who runs for office, showing how the costs and benefits of running for office affect the ideology of those who run. These findings hold general implications for our theories of elections, and they also have direct implications for the literature on polarization. Now I turn to descriptive efforts in order to understand what the theory implies for modern-era U.S. elections. I argue that the costs of running for office have indeed risen over the past 30 years, at the same time as the benefits of holding office have decreased. The costs and benefits of running for office are therefore an important part of the rise in polarization in our legislatures. 


\subsection{The Rising Costs of Running for Office}

We know that legislative polarization has risen dramatically since the 1970s. My argument suggests that rising costs of running for office might help explain this rise. The more difficult it is to run for office, the theory predicts, the more extreme will be the people willing to do so. How have costs changed since the 1970s?

It is impossible to quantify in any precise manner the full costs of running for office. Certainly, some are numeric, like the amounts a candidate must raise, the number of hours a candidate is expected to spend campaigning, and the amount of salary a candidate foregoes while running. Others, like the stress a campaign

places on a candidate's family, the personal distaste and shame that comes along with the incessant public pandering candidates must do, and the sheer boredom of the endless banquets that candidates must attend, are harder to quantify. At the end of the day, the claim that running for office has become harder than it used to be is supported first and foremost by our own sense of politics and an appeal to a number of descriptive facts. That said, in an attempt to add rigor to the claim, I will focus on two of the most salient: fundraising needs and media coverage. There is little doubt that both have made running for office an extremely unpleasant task today.

\subsubsection{Fundraising: A Growing Burden}

The changing manner in which candidates pursue their campaigns is among the most salient and growing costs of seeking office. As the discussion at the very 
beginning of this book's introduction suggested, fundraising has come to dominate campaigns. Whether because campaign spending translates into votes, or because fundraising is a way to signal quality, or simply because candidates believe they must do it, every single viable candidate in an even vaguely competitive race for the U.S. House engages in a vast amount of fundraising activity.

This fundraising is, by and large, costly for candidates because it is difficult, time consuming, and unpleasant. Hubert Humphrey, to pick one such example among many, called fundraising a "disgusting, degrading, demeaning experience" (as quoted in Francia and Herrnson 2001). Speaking at a 2009 congressional hearing about a bill to implement a program for federal funding of congressional campaigns, at-the-time Congressman Dan Lungren (R, CA) captured the feelings of many congressional candidates:

I am going to put it on the record: I hate raising money for campaigns. The only two people I know who enjoyed it both went to prison. And I won't use their names. But I hate it. It is the least attractive part of this job. I can sell ideas, I can ask for support for others. I have a great deal of difficulty-and my campaign finance people are listening, and they would probably say don't say it-but I have a great deal of difficulty making the close on asking for money. It is the most difficult.

And now we have in our campaign coverage by the reporters, they start to judge whether you are a good candidate, whether you have got good prospects depending on how much money you have got in your account. Read the stories now. They are about how much money did you have this quarter. So the very press that is telling us maybe this is what we ought to do is the very press that is making this part of the horse race, and that is a terrible tragedy. ${ }^{6}$

Speaking at the same hearing, Congressman John Larson (D-CT) echoed these thoughts: "All of my colleagues are principled people who would rather be doing

${ }^{6}$ http://www.gpo.gov/fdsys/pkg/CHRG-111hhrg52711/html/CHRG-111hhrg52711.htm, Accessed March 19, 2015. 
Figure 4.11 - The Rising Costs of Campaigning. Candidates for the U.S. House are forced to raise more money from more donors than ever before.

Average Total Receipts (2010 dollars)

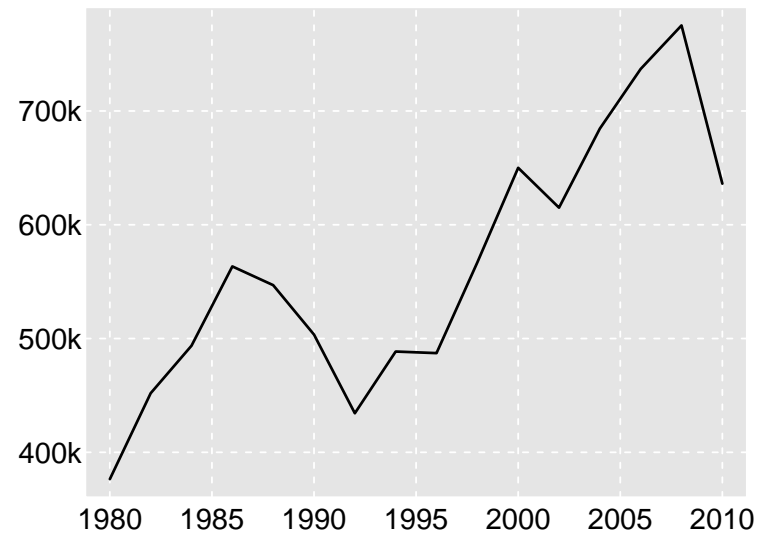

Average Number of Donors

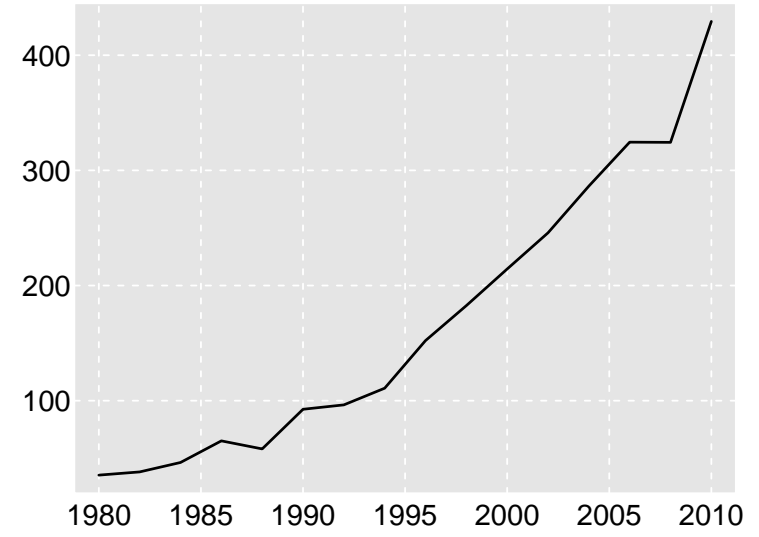

just about anything else, as you bore witness to, than making fundraising calls, attending fundraising breakfasts, lunches, dinners, you name it." Fundraising, these members of Congress say, is an unpleasant but necessary activity - one that is costly to perform but required to win and hold office.

The need to fundraise has grown much more acute in recent decades, to the point that members of Congress are now told to spend most of the day dialing for dollars. David Jolly (R-FL) gave a particularly jarring description of this state of affairs to 60 Minutes: "It is a cult-like boiler room on Capitol Hill where sitting members of Congress, frankly I believe, are compromising the dignity of the office they hold by sitting in these sweatshop phone booths calling people asking them for money. And their only goal is to get $\$ 500$ or $\$ 1,000$ or $\$ 2,000$ out of the person on the other end of the line. It's shameful. It's beneath the dignity of the office that our voters in our communities entrust us to serve." 
Figure 4.11 suggests just how much this cost has risen over time. The left panels shows average total campaign receipts across all U.S. House races by year, in inflation-adjusted 2010 U.S. Dollars, as collated in the DIME dataset. Since 1980, and especially since 1990, candidates have raised more and more money. To keep up, candidates must now raise almost twice as much as they did in 1980. The right panel gives perhaps the clearer window into why this is costly. In isolation, the fact that more money is raised might not mean fundraising is more difficult; perhaps candidates are simply able to get larger amounts of money from the same donors as before. The right panel shows that this is not the case. It plots the average number of donors that candidates raise money from (also from the DIME dataset). Candidates are seeking donations from more and more donors over time. In 2010, candidates received donations from almost exactly 4 times as many donors as in 1990, on average.

There are probably many reasons fundraising needs have grown so rapidly. The changing media landscape necessitates more and more ad buys at higher prices in order to communicate to voters. Technical innovations, both in terms of studying what types of strategies attract voters and in targeting specific voters with ads, have probably raised the returns to campaign spending, creating more upward pressure on fundraising. These needs have risen even more sharply in the last several years after the Citizens United decision. In the same 60 Minutes interview, Reid Ribble (R-WI) explains: "...some of this is the result of Citizens United, the Supreme Court decision that opened up really corporate dollars into the system. And so, if you want to have your own voice, if you want your voice to be heard as opposed to some outside group speaking for you, you better-you better do your job and raise enough money that you can." 
As we have already seen, costs like these deter moderate people from running for office. Candidates, themselves, echo this view. David Jolly, himself a relatively moderate Republican, told 60 Minutes: "At the end of the day, if you tell me that the only way to be a United States senator is to raise $\$ 100$ million in Florida, then I'm not the next United States senator from the state of Florida. And that's OK. It's a shame for the system, but it's fine for me."

Viable candidates for the U.S. House are raising more money from more donors than ever before. Members of Congress spend most of their waking hours dialing for dollars. Would-be candidates are aware of the situation, and there is no doubt that a good many choose not to run for office because of it.

\subsubsection{Increasing Media Scrutiny of Candidates}

Fundraising is not the only cost of running for office, either. As Lungren's quote above alluded to, media coverage of congressional campaigns seems to have changed, in its content and its tenor, over the very same time period that polarization has been growing in U.S. legislatures.

Bai (2014) offers a striking account of this change through the lens of a single event: the Gary Hart scandal of 1987. The book's subtitle-The Week Politics Went Tabloid - summarizes its argument. Exploring Gary Hart's media-fueled fall from grace, Bai argues that the media has changed the way it covers political actors in the U.S., focusing more and more on personal details that may or may not be relevant for evaluating the quality of candidates. Gary Hart's alleged affair with Donna Rice, which precipitated the end of his presidential campaign, was, according to Bai, among the first personal, "tabloid" scandals of American 
political officials - the first of many. Bai writes: "Hart's humiliation had been the first in a seemingly endless parade of exaggerated scandals and public floggings, the harbinger of an age when the threat of instant destruction would mute any thoughtful debate, and when even the perception of some personal imperfection could obliterate, or at least eclipse, whatever else had accumulated in the public record."

Hart himself, in his speech announcing the end of his campaign, worried about the changing role of the media in politics: "We're all going to have to seriously question the system for selecting our national leaders, that reduces the press of this nation to hunters and presidential candidates to being hunted, that has reporters in bushes, false and inaccurate stories printed, photographers peeking in our windows, swarms of helicopters hovering over our roof, and my very strong wife close to tears because she can't even get in her own house at night without being harassed." 7 Though speaking about running for president, his sentiments extend readily to the coverage that candidates for other offices, such as the U.S. House, receive in smaller doses but with similar tenor.

Potential candidates, themselves, appear to be very aware of the toll the media can take on those who enter the poitical arena. Lawless and Fox (2005), interviewing potential candidates, quotes a California attorney who says: "The intrusion into one's privacy that comes with a campaign is such that one would have to be insane to run for office" (126). Sabato (1991) makes an early and clear version of this argument:

\footnotetext{
${ }^{7}$ http://articles.latimes.com/1987-05-09/news/mn-4818_1_proud-man/2, Accessed March 25, 2015.
} 
The second troubling consequence of modern media coverage for the political system has to do with the recruitment of candidates and public servants. Simply put, the price of power has been raised dramatically, far too high for many outstanding potential officeholders...American society today is losing the services of many exceptionally talented individuals who would make outstanding contributions to the commonwealth, but who understandably will not subject themselves and their loved ones to abusive, intrusive press coverage (210211, as quoted in Sutter (2006)).

Sutter (2006) formalizes this logic, showing how "privacy costs" from running for office can affect the set of people willing to become candidates. As the paper concludes, "The proliferation of frenzies and expansion of the range of personal issues subject to scrutiny raises the expected cost to good people of running for public office (38)." Though the paper focuses on a broader concept of candidate "quality" and not ideology, the argument can readily extend to moderate vs. less moderate candidates, as in the theoretical discussion from the previous chapter of this book.

It is difficult to offer hard, quantitative evidence for the claim that the media is making running for office harder. But at the very least, experience suggests that the claim is true. The 24-hour news cycle, manufactured scandals to fill air-time, and the expansion of social media have all lent a circus atmosphere to our elections. Astonishing amounts of time are devoted to absolutely inane details of candidates' lives. This apparent hunger to convert political coverage into entertainment does not come without costs. Whether or not such coverage expands the knowledge of citizens who would not otherwise engage in politics (Baum 2002; Prior 2003), it surely makes people think twice before running for office. Although changing the way the media covers politics seems difficult, and 
maybe impossible, we should acknowledge the likelihood that it is preventing good people from becoming candidates for our legislatures.

\subsection{The Falling Benefits of Holding Office}

Over the same time period that fundraising needs and media coverage have made running for office harder, holding office has become less attractive in a variety of ways. Here, I focus on two: the declining pay for members of the House, and changes to the organization of the legislature that have left rank-and-file members worse off.

\subsubsection{Declining Pay for U.S. House Members}

Holding office conveys many benefits. Office-holders have the chance to influence policy, to bring issues to the attention of government and voters, and enjoy a degree of prestige both locally and, in some cases, nationally. Separate from these various opportunities, legislators also receive monetary compensation for their efforts. Though pay is far from the only benefit of office - and wouldbe candidates are likely to hold many other motives for seeking office - it is an obvious first variable to examine in considering how the benefits of holding office have changed over time. In this section, I examine legislator salaries, and I show that they have declined steeply, in real terms, over time. On this dimension, the benefits of holding office have indeed fallen in recent decades.

In performing this analysis, I will focus only on the salaries members of Congress receive. I do not include other sources of income that pre-date their legislative careers, since those are separate from the benefits of office, and I do not 
examine monetary benefits accruing to legislators after they leave office - though these may be considerable. Studying British politics, for example, Eggers and Hainmueller (2009) use a regression discontinuity design comparing people who barely make it into office to those who barely do not make it into office to show that MPs accrue significant extra wealth through holding office. Building on this research design, Palmer and Schneer (2015) show that U.S. legislators become more likely than comparable non-legislators to hold corporate board memberships, which pay generous salaries. Corporate boards are doubtless only one of many ways members of Congress can extract value from their political careers after leaving office. These outside options increase the total benefits of office and, very conceivably, are an input into any would-be candidate's decision to run for office. Nevertheless, salary is an immediate and relevant input into this decision, too, and we can learn much by studying it. In addition, by examining changes in salary, we can make inferences about the candidate supply that will not be affected by these unobservable benefits so long as they have not changed in the opposite direction of salaries over time.

To examine how U.S. House members are paid, I collected data on the salaries of members of Congress from the Congressional Research Service. Though there are a few positions within the House that get paid more (e.g., Speaker), the vast majority of members receive the same, fixed salary. To see how legislator pay has changed over time, I use data from the CPI to correct for inflation, reporting all salaries in terms of 2011 U.S. Dollars.

Figure 4.12 plots U.S. House member salaries over time. As we see, legislator salaries have declined sharply in real terms since the 1970s. In 1969, members of the U.S. House were paid $\$ 42,500$ - or about $\$ 260,000$ in today's dollars. Today, 


\section{Figure 4.12 - U.S. House Salaries Over Time, Adjusted}

for Inflation. In real terms, members of the US. House are paid $33 \%$ less today than in 1969 .

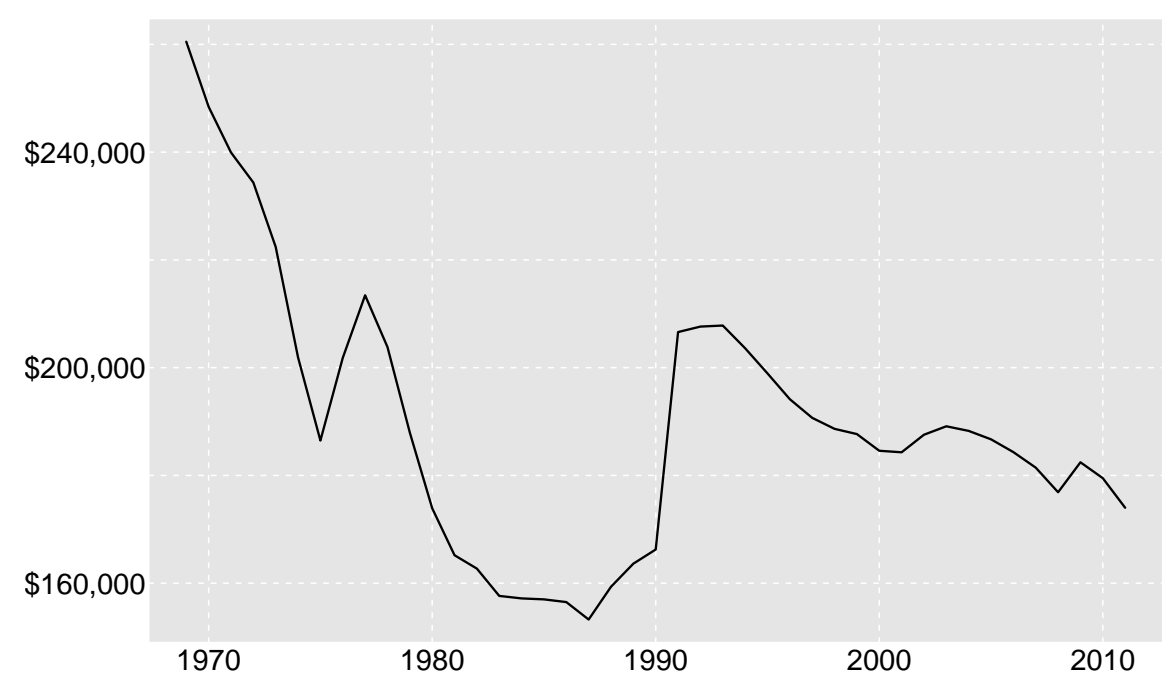

members are paid $\$ 174,000$. Though this amount is nominally higher than that in 1969, it constitutes a decrease of roughly one third (33\%) in real terms due to inflation. This is a large decrease. Members of Congress are simply not compensated in the manner that they used to be.

The reasons for this decrease in real pay are beyond the scope of this study, but we can speculate. Congressional salaries are nominally set to adjust annually based on wages to other fields, but members of Congress seem to be often pressured to reject these increases. This pressure seems to have increased over time - indeed, in 2012 Congress passed legislation freezing congressional salaries. For more information on the process, see Brudnick (2014).

Whatever the reason, legislator salaries are significantly lower today than they were in the 1960s and 1970s. This drop constitutes a meaningful decrease in the benefits of holding office. Although there are many other benefits of holding office - some of which I discuss below-salaries in office are an important and 
necessary component of how we compensate citizens for holding office. When legislator salaries are higher, all else equal, more people, and different types of people, will be willing to run.

Scholarly discussions with potential candidates support this view. Though focused primarily on the gender gap in seeking political office, Lawless and Fox (2005) presents a bevy of data on the calculations of potential candidates, who are "forced to deal with the financial tradeoffs involved in holding elective office" (133). The authors detail a conversation with a Kentucky attorney who has considered running for office but concludes: "My job allows me a lot of comfort. If I ran, I'd have to take off a great deal of time and that would put too big a dent in my pocket" (133). Salary is clearly one of the important inputs into whether would-be candidates run for office or stay out and maintain their current jobs.

One probable result of the lessened salaries for legislators is that, by and large, only wealthy people will run for office (the fact that wealthy people can fund their own campaigns is a separate factor that also encourages them to run). An article entitled "Why is Congress a Millionaires Club?", 8 for example, documents the high wealth of members of Congress compared to the public. The article reads:

As a congressional candidate, "every waking minute of every day is devoted to that campaign," said Doug Heye, a former spokesman for the Republican National Committee. "It requires an extraordinary amount of time, and it becomes difficult for a lot of people if you have a full-time job...When you've got a mortgage to pay and college tuition and braces to pay for, those kinds of day-to-day, real-life expenses come before putting six months into a campaign."

It is likely that very wealthy people are running for office precisely because they enjoy doing so - their wealth permits them to undertake activities for what might

${ }_{8}^{8}$ http://www.cbsnews.com/news/why-is-congress-a-millionaires-club/, Accessed April $7,2015$. 
be called recreational purposes. People who enjoy holding office are likely to be those with stronger and more ideological views. Were salaries higher - a counterfactual scenario I consider in the "Policy Implications" chapter-people who view politics as an important and valuable job, rather than as an idle activity of the rich and ideological, might become more willing to run.

The decreasing salaries of legislators also mean that the opportunity costs of running for office are higher than ever. Fiorina (1994) made a novel argument about opportunity costs and the decision to serve in the legislature. Focusing on state legislatures, the paper argues that the professionalization of legislatures advantaged Democrats because Republican candidates tended to be drawn from higher-paying occupations. When the legislature becomes more professionalized, these higher-earning individuals can less afford to make legislating a full-time job since they have to give up their lucrative jobs in order to do so.

The present argument is quite similar in spirit. When salaries in other, nonpolitical fields are higher, high-skilled people will face increased costs of entering politics because they must forego these other career opportunities. Those willing to run for office, regardless of whether they are of higher or lower "quality," will be those more willing to forego these other opportunities - likely people who hold more extreme ideological views and value the chance to hold office, and/or fear what will happen if they don't hold office, more. 


\subsubsection{Erosion of the Committee System and Diminishing Chances to Influence Policy}

A substantial potential benefit of holding office is the chance to influence policy. Historically, members of the U.S. House wielded control over policy in large part by serving on committees relevant to their districts (Gilligan and Krehbiel 1987; Krehbiel 1990; Londregan and Snyder 1994; Shepsle 1978). In the early decades of the post-war U.S. House, committees were thought to possess considerable power, allowing committee members to push specific policies in their preferred directions and to block policy changes in their committee's jurisdiction that they did not like. The most powerful were the committee chairs, highly coveted positions assigned purely on the basis of seniority. The seniority system offered a simple career ladder to members of Congress; the longer they stayed in office, the more power they would accrue, and the more chances they would have to influence policy (among other privileges). For a moderate potential candidate, this system would seemingly be quite appealing; the moderate's heightened ability to gain repeated reelections would make her likely, if she so desired, to ascend to a position of considerable power.

Starting in the early 1970s, though, majority-party Democrats pushed through a series of reforms stripping the committee system of power and strengthening the office of the Speaker. In one of the most detailed accounts of the reforms, Rohde (1991) describes the numerous ways the Democratic party went about strengthening the party leadership. The Democratic caucus removed the absolute right of the Speaker to choose committee chairs, subjecting assignments to an up-or-down vote and eroding the seniority system as a result. Within the same time period, 
the caucus gave the Speaker new powers; the power to refer bills to multiple committees, for example, further shifted power from committees to party leadership, preventing as it did a single committee from obstructing the Speaker's agenda. These changes, Rohde argues, ensured that the Democratic party - and not set of senior committee chairs - would determine legislative policy.

Hall and Shepsle (2014) argues that strengthening the leadership must come at a cost. The agenda power that the Democrats - and later, in the early 1990s, the majority-party Republicans - gave to their leadership came from senior (often Southern) committee chairs. The Democratic reforms of the 1970s sounded the death knell for powerful committees, signaling, as Rohde (1991) and others have argued, the end of committee government and the beginning of government by party leadership.

This dramatic change in how members of Congress legislate would not go unnoticed by potential candidates. While in the past the powerful committee system assured potential moderate candidates of a chance to possess influence, the party-led legislature offers no such thing. With a powerful majority-party leader, members are more like "foot-soldiers" than individual crafters of policy. The bulk of legislation-including all significant bills - no longer run the route from committee to conference committee to passage. Instead, party leaders coordinate on amendments, "ping-ponging" bills between the chambers and striking bargains at the party level. Though there is no doubt room for individual influence (for example, the "Cornhusker Kickback"), it is far less than in the previous era of strong committees.

Putting forth exactly such an argument, Thomsen (2014: 789) writes that, because "Party leaders who set the legislative agenda are now ideologues them- 
selves...it would be difficult for moderates to advance their desired policies or obtain a leadership position in Congress." Thomsen (2016) builds on this argument, showing further evidence that the candidate pool has polarized in part because serving in the modern U.S. House is increasingly a poor fit for ideological moderates.

\subsection{Decreasing the Costs of Running for Office}

Based on the descriptive analyses presented earlier, there are many possible ways to change the costs of running for office. These interventions could focus on the media, on the way campaigns are run, or on the opportunity costs related to professions outside the legislature (for example, making it easier to hold another job while serving in office). I focus on what is both one of the most salient costs and, also, the most feasible to alter: the way campaigns are run.

\subsubsection{Campaign Finance Reform to Limit Time Spent Fundraising}

As I have argued, candidates are forced to devote a huge amount of time - time which they do not enjoy - fundraising. Throughout the book, I have already furnished a number of colorful quotes that reflect just how much most members of Congress detest fundraising. Yet they all do it, and do it a lot. How can this be?

The situation is much like that with steroids in professional baseball. Suppose (as is almost certainly true) that steroids are bad for your health but make you a better baseball player. Like elections, performance in baseball is relative; your 
success depends not just on some absolute benchmark of quality but on doing better than your opponents. Realizing the need to outperform, any individual player might think about doing steroids to get an edge, but might prefer not to do them if he knew that no one else was going to do them, either. Therein lies the rub. So long as a completely credible detection and punishment system does not exist, players will feel compelled to do steroids because of their belief that other players are doing them, too.

The dynamic in politics is the same. Any given candidate might prefer to spend less time fundraising. But each candidate sees that other candidates are fundraising more, and more, and more, forcing their opponents to respond in kind. People cannot dial back their efforts so long as they believe that their opponents won't do likewise. Foreseeing this vicious cycle, moderate would-be candidates may choose not to run in the first place.

The solution to this "race to the bottom" is the same as in baseball: a powerful reform that credibly promises to all candidates that no one can out-raise the other beyond a certain point. Like rigorous steroid testing, campaign finance reform can reassure candidates that they don't need to spend four hours a day fundraising because neither they, nor their opponents, are allowed to. Implementing such an idea is extremely difficult, though. Even putting aside issues of constitutional law for the moment, limiting fundraising in the right way is tricky. To see this, we can again return to the laboratory of the U.S. states. The states employ a dazzling variety of campaign finance laws. The two most directly relevant for our purposes are the public funding of elections and low limits on the size of campaign contributions. 
Hall (2014) studies the effects of public funding programs in the U.S. states. Three states have passed these programs relatively recently - Arizona, Connecticut, and Maine - and two more, Minnesota and Wisconsin, passed them in the 1970s. Though the precise details vary in important ways across states, the basic idea in all five is that candidates can apply for and, once they meet some minimal fundraising requirements, can receive public funding in lieu of private fundraising. Ideally, public funding removes significant fundraising burdens from candidates, making the electoral process easier and encouraging more people to run for office.

The effects of public funding, however, have not been as expected. Although, as Hall (2014) shows, electoral competition has increased in states that implemented public funding programs, the programs have also markedly increased legislative polarization. Why is this?

In order to qualify for public funding, candidates must first raise small (usually $\$ 5$ ) donations from a fixed number of individual donors. This seemingly small barrier alters the donor landscape in important ways. Without public funding, candidates raise significant amounts of money from interest groups. With public funding, these groups no longer participate in campaign finance in the same way (although they can still donate to candidates who opt out of public funding). The result is that elections become much more dominated by individual donors, and we know from a large body of scholarship that individual donors support more ideologically extreme candidates than do interest group donors (see for example Bonica 2014).

The nuanced effects of public funding programs point to the deeper difficulties of encouraging more moderate candidates through campaign finance reform. 
Put simply, most reforms have many unintended consequences. It is difficult to create a reform that isolates only a single factor-like the difficulty of running for office. Another, similar reform exhibits this same issue well. Just as some states have experimented with public funding, many others have experimented with limiting the size of individual and interest-group contributions, respectively. Barber (2015) studies the effects of these limits, and the results point to the same underlying phenomenon. In places where individuals can donate more, legislators are more extreme; in places where groups can contribute more, legislators are more moderate.

Barber's results do suggest that limiting individual contributions strictly may reduce polarization. However, it is impossible to know if this has anything to do with changing the costs of running for office, or if it simply reflects that, when individuals can't contribute much, the types of candidates who benefit from individual contributions suffer. In addition, before recommending such a tact, we might worry about other effects it could have. Leaving only interest groups to contribute, for example, would certainly raise suspicions of corruption. Campaign finance also likely enhances voter engagement and voter information (through candidate advertising, etc.), so the losses may far exceed the gain of more moderate representation. These are tradeoffs that would be difficult to resolve even if we had any certainty of the effects of such reforms on all the various outcomes we care about.

The reform that might more directly solve the race-to-the-bottom problem is a limit on campaign spending, itself, rather than on contributions. If candidates are only allowed to spend a certain amount, there is no reason for them to raise 
more than that amount. Although this would be the most logical, it is a nonstarter in the U.S., where such limits are unconstitutional for the time being.

Fouirnaies (2016) studies the effects of such limits by taking advantage of historical changes to spending limits in constituencies in the U.K. These changes, Fouirnaies shows, noticeably changed campaigns and election outcomes. When constituencies quasi-randomly had higher limits on candidate spending, incumbents did better and elections became more partisan. Although Fouirnaies has no direct measure of ideology, fewer elections are contested by multiple parties when spending limits rise. This suggests, as I have argued, that higher spending limits make campaigning more difficult and deter many would-be candidates, particularly moderate ones.

The view of campaign finance reform I've discussed is unusual because it has said nothing about issues of corruption and bias that may arise from the extreme fundraising needs of candidates. Most rhetoric surrounding campaign finance - much of it beyond breathless - is not about the difficulties of raising money but about the corruption that may come along with the contributions. If candidates want donations, and donors want favors, the unrestricted flow of cash from donors to candidates may be worrisome for reasons having nothing to do with the burdens the system places on candidates.

The potential corrupting influence of campaign finance is well beyond the scope of this book. It suffices for now to point out that these would only justify campaign finance reform all the more. At the same time that limiting candidates' fundraising activities could make being a candidate a better job, thus encouraging more moderates to become candidates, it could also restrict the supposed corruption that is endemic within our campaign finance system. However, I do 
not want to lean on this additional justification because evidence for its veracity is extremely limited.

\subsubsection{Informing Voters}

Separate from raising the benefits of offices themselves, the expected benefits of office increase with the probability of winning election. Policies that make it easier for more moderate candidates to win office might therefore encourage moderates to run for office. One mechanism that might increase the probability that moderate candidates win election is voter information. Snyder and Stromberg (2010) presents possibly the most comprehensive evidence for this link. The paper establishes that voters are more informed about U.S. House candidates in districts where media congruence is higher - i.e., voters are better informed in places where their newspapers largely cover their local news (as opposed to, say, a nearby city located outside their congressional district). Having shown this informational link, the paper then shows how this information affects both voter and legislator behavior. Among other things, legislators are shown to take more moderate positions - and be rewarded for these positions - in more informed districts.

Hall (2015) uses the measure from Snyder and Stromberg (2010) to show that the penalty to nominating extremists is larger - roughly three times as large - in the most informed (i.e., most congruent) district than in the least informed one. More moderate candidates thus seem to do especially well in general elections where the voters are more informed about the candidates. Though candidates may be better off in the general election, in deciding whether to run for office they must first consider the primary election cycle. Primary voters, on average, seem 
Figure 4.13 - Centrism and Primary Vote Share Across

Media Information. Moderates are disadvantaged in low information districts, but this disadvantage is erased in higherinformation districts.

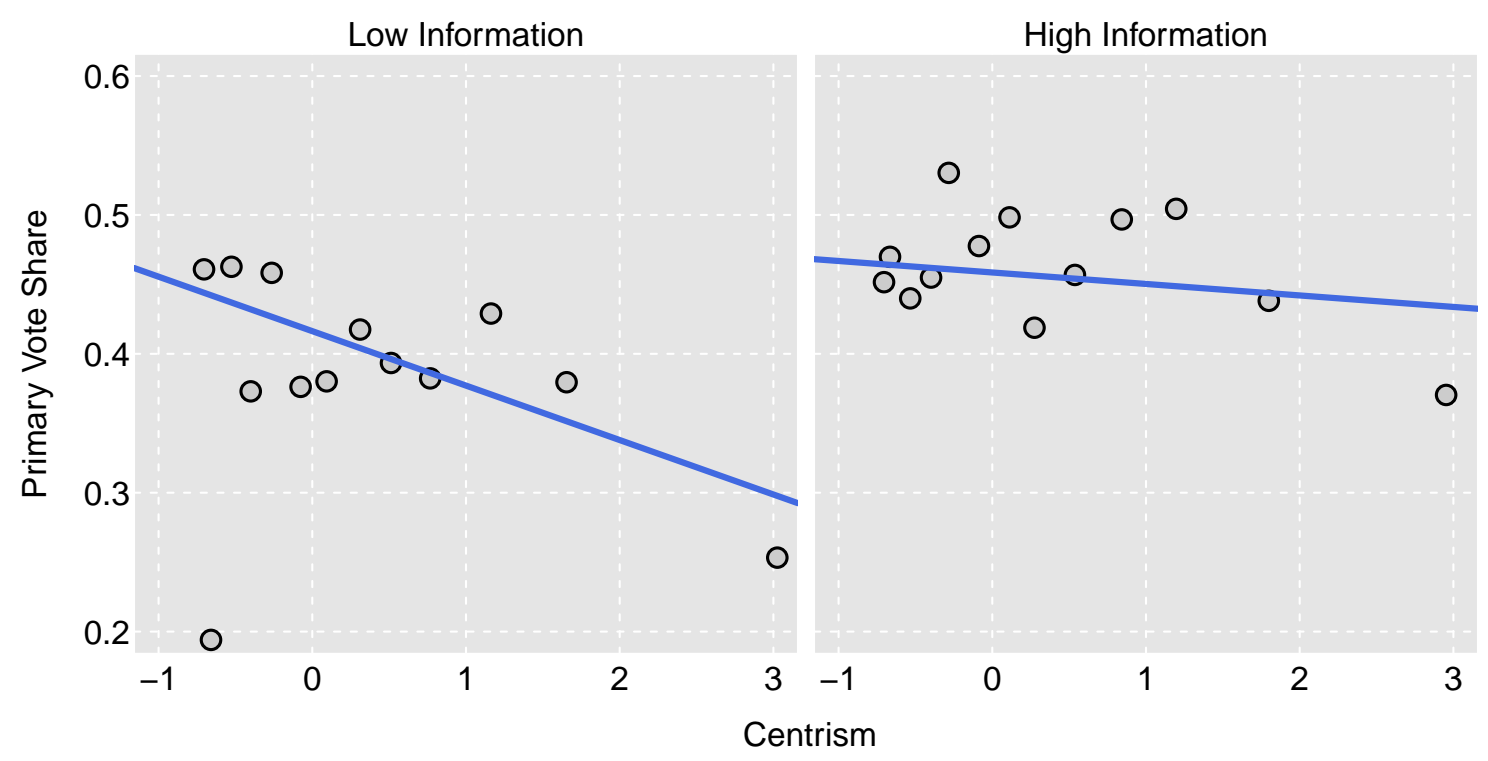

to prefer more ideologically extreme candidates (Brady, Han, and Pope 2007; Hall and Snyder 2014). To increase the expected benefits of office and induce more moderate candidates to run, then, the probability of winning both the primary and the general must increase. Do primary voters behave differently in districts with more media information?

To answer this question, I examine the association between candidate ideology and success in primary elections across levels of media information. Using the measure of media congruence from Snyder and Stromberg (2010), I look at two types of districts: those I call "Low Information," and those I call "High Information." Specifically, I re-scale the congruence measure to run from 0 , in the least informed district, to 1 , in the most informed district. Low Information dis- 
tricts are those where this rescaled measure is at or below 0.25; High Information districts are those where this rescaled measure is at or above 0.75 .

Following Hall and Snyder (2014), I measure candidates in primaries as more or less moderate based on their "relative centrism"; that is, on how close or far away they are, ideologically, from the most extreme candidate in the race. The higher this centrism variable is, the more moderate the candidate, in general. More detailed formal results are available in the Appendix to this chapter.

Figure 4.13 presents the results. The left panel plots the association between centrism and vote share in low-information primaries - that is, in primary elections where media congruence is low so that voters receive relatively little media coverage of their primaries. Here, we see a strong and negative association; more moderate candidates do markedly worse than do more extreme candidates in these elections.

In the right panel, we see that this relationship completely flattens out. In high information primaries - primaries where media congruence is high so that voters receive more media information about their primaries - there is no observable relationship between centrism and primary vote share. While extremists are advantaged when information is low, they are no better off than moderates in primaries where information levels are high.

More informed voters thus appear both to advantage more moderate candidates in the general election and, if not advantage moderates in the primary, at least no longer penalize them. The effect of information on elections - as best as we can measure it - thus is to increase the electoral fortunes of moderates at both stages of the electoral process. Taken together, the results thus suggest that, if voters were more informed on the whole, the reward to being a more moder- 
ate candidate would be higher - and, as a result, would-be moderate candidates would be more likely to run in the first place.

\section{Summary}

This chapter has presented the practical fruits of the theoretical labor from earlier in the book. Thinking about "who runs?" offers new insights into how the design of our electoral system affects the candidates whom voters are compelled to chose from among at the ballot box. The theoretical framework that I introduced in Chapter 3, and the accompanying empirical evidence for its validity that I presented in this chapter, suggest that re-valuing political office - enhancing the values of holding office and decreasing the costs of running for office - could encourage more moderate candidates to run for office.

In this chapter, I've shown some evidence that this claim is true, and I've used the logical framework to argue for a variety of specific reforms that could help depolarize our legislatures. Raising legislator salaries is the most straightforward reform that I have discussed, and it is the one I am able to study in depth, empirically. Looking at salary reforms in state legislatures, I documented how legislator pay-raises induce more moderates to run for office in subsequent elections.

Though the evidence is certainly interesting, I expressed caution in extending this reform, alone, to the federal level. Increasing the size of the prize while leaving all other factors unchanged might, if the prize grows large enough, create an excess of electoral competition which, in turn, could actually deter some people from running for office. Whether this would happen or not is difficult to predict. 
Nevertheless, it would seem safer to grow the prize by raising salaries while simultaneously enacting reforms that prevent elections from becoming increasingly costly in response.

Separately, I have also presented evidence that information - measured here by media congruence - raises the probability that more moderate candidates win both the primary and general election, and thus increases the expected benefits of office. Informing voters, too, should encourage a more moderate candidate supply.

In parallel, I have also argued that we can reduce the costs of running for office by using campaign finance reform to commit candidates to expending less effort on fundraising. Fundraising is, in part, a "race to the bottom" in which candidates are forced to exert more and more effort fundraising because their opponents are, too. Reforms targeted at limiting this effort are likely to make running for office less costly, regardless of any other effects they might also have on money in politics. Again, the possible effects of this type of reform on the candidate supply must be weighed, too, against its other effects. If candidates help inform voters through their fundraising, then limiting this activity might lead to a less informed electorate.

The ideas in this chapter are only a preliminary look at possible policy reforms related to who we get to run for office; they are far from actionable policy ideas. However, they hopefully help make clear how the logic of the book's argument and theoretical framework can be applied to the current U.S. electoral context. There are a variety of ways we can think about altering the costs and benefits of running for office, and they are likely to induce differing sets of people to run for office. 


\section{Appendix}

\section{State Legislators Running for the House}

Early in the chapter, I showed that state legislators are more likely to run for the House when they can do so without giving up their seat. Now, I confirm this relationship more formally. Specifically, I estimate equations of the form

$$
\text { Run For House }_{i t}=\beta_{0}+\beta_{1} \text { Give Up Seat }_{i t}+X_{i t}+\epsilon_{i t} \text {, }
$$

where Run For House $i$ is an indicator variable for whether state legislator $i$ chooses to run for the U.S. House in the election at time $t$. The variable Give Up Seat ${ }_{i t}$ is an indicator variable for whether state legislator $i$ has to give up her seat in the state legislature in order to run for the House at time $t$. Finally, $X_{i t}$ stands in for a set of control variables.

The coefficient of interest, $\beta_{1}$, measures how much more or less likely state legislators are to run for the House if they do not have to give up their seat in order to do so-i.e., if it is much less costly to run. Table 4.1 presents the estimated results.

In the first column, I include all of the data and run a simple pooled regression. In any given electoral cycle, state legislators choose to run for the House when they have to give up their seats $1.4 \%$ of the time, as the second row (constant) shows; however, as the first row shows, this probability increases by 1.6 percentage points, to $3 \%$ in total, when they do not have to give up their seats to run. State 
Table 4.1 - Potential Candidates Are More Likely to Run When Costs Are Lower.

\begin{tabular}{lccc}
\hline \hline & Run For House & Run For House & Run For House \\
\hline Seat Not Up & 0.010 & 0.008 & 0.010 \\
& $(0.003)$ & $(0.004)$ & $(0.003)$ \\
Constant (Seat Up) & 0.014 & 0.022 & 0.047 \\
& $(0.001)$ & $(0.011)$ & $(0.018)$ \\
$\mathrm{N}$ & 61,453 & 61,453 & 10,468 \\
\hline Sample & Full & Full & Partial \\
Year Fixed Effects & No & Yes & Yes \\
Candidate Fixed Effects & No & Yes & Yes \\
\hline \hline
\end{tabular}

Robust standard errors clustered by candidate in parentheses.

legislators are more than twice as likely to run for the House when they can do so without risking control their current offices.

In the second column, I add candidate and year fixed effects to perform a difference-in-differences analysis, comparing the change in the propensity to run for the House induced when a state legislator goes from having to give up her seat to run to not having to do so. Again we see the probability of running almost double (from $1.3 \%$ to $2.4 \%$ ). In the final column, I replicate this differencein-differences using only the subset of the data that includes legislators who experience variation in whether they have to give up their seats or not. This sample offers, perhaps, better comparability between those legislators who do not need to risk their seat at any given time and those who do, since they all face both situations at some point in their careers. Again, we see a marked increase in their propensity to run for the House when the cost of doing so is lower.

In the next analysis in the chapter, I then showed that the manner in which legislators responded to the risk of having to give up their seats varied with 
their ideology. In the chapter, I showed this with a simple graph showing that more extreme legislators were more likely to run regardless of ideology, while more moderate legislators were more sensitive to this cost. More formally, I now estimate equations of the form

$$
\begin{array}{r}
\text { Run For House }_{i t}=\beta_{0}+\beta_{1} \text { Give Up Seat }_{i t} \\
+\beta_{2} \text { Give Up Seat }_{i t} \times \text { Extremism }_{i t}+\beta_{3} \text { Extremism }_{i t}+X_{i t}+\epsilon_{i t} .
\end{array}
$$

The coefficient $\beta_{1}$ thus indicates how much more likely moderate legislators (those with Extremism $=0$ ) are to run for the House when they do not have to give up their seat, relative to when they do have to. Extremism is defined using NP Scores as discussed in the body of the chapter. The coefficient $\beta_{2}$, the main quantity of interest, reflects how much less or more sensitive legislators with more extreme roll-call voting records are to the cost of giving up their seat to run for the House. A negative estimate for $\beta_{2}$ would thus indicate that more extreme legislators are less sensitive to the costs of running for office.

Table 4.2 presents the estimated results, focusing on the sample of legislators with variation in the costs of running. ${ }^{9}$ The first column shows the overall results. As the first row shows, moderate state legislators are 1.1 percentage points more likely to run for the House when they don't have to give up their seats than when they do. However, legislators one standard deviation more extreme than the median are half as sensitive, as the second row indicates. A one unit increase in extremist is estimated to decrease the effect of not having to give a state legislature seat by -0.006 - more than half of the 0.011 effect for the

\footnotetext{
${ }^{9}$ Results are extremely similar using the full sample.
} 
Table 4.2 - Moderates Are More Sensitive to Costs Than Are Extremists.

\begin{tabular}{lccc}
\hline \hline & $\begin{array}{c}\text { Both Parties } \\
\text { Run For House }\end{array}$ & $\begin{array}{c}\text { Dem } \\
\text { Run For House }\end{array}$ & $\begin{array}{c}\text { Rep } \\
\text { Run For House }\end{array}$ \\
\hline Seat Not Up & 0.011 & 0.010 & 0.011 \\
& $(0.003)$ & $(0.004)$ & $(0.005)$ \\
Seat Not Up $\times$ Extremism & -0.006 & -0.005 & -0.007 \\
& $(0.003)$ & $(0.004)$ & $(0.006)$ \\
Extremism & 0.001 & -0.003 & 0.003 \\
& $(0.004)$ & $(0.006)$ & $(0.006)$ \\
$\mathrm{N}$ & 10,468 & 5,247 & 5,221 \\
\hline Year Fixed Effects & Yes & Yes & Yes \\
Candidate Fixed Effects & Yes & Yes & Yes \\
\hline \hline
\end{tabular}

Robust standard errors clustered by candidate in parentheses.

median legislator. In addition to being statistically significant, the difference is substantively meaningful and consistent with the theory's prediction.

The second two columns verify the results of the first for each party, separately. No major differences are found between Democrats and Republicans; moderate state legislators in both parties are more sensitive to the costs of running for office than are the more ideologically extreme state legislators. Inevitably, because each of these analyses cuts the sample in half, standard errors are larger. Nevertheless, there does not seem to be any evidence that the relationship between extremism and sensitivity to costs varies by party.

\section{Scare-off of Moderates}

As I discussed in the chapter, the simple raw comparison of candidate pools when there are or are not incumbents could be biased. I now address this issue 
using two more complex empirical designs. In the first, I employ a difference-indifferences design, examining districts that switch the party of their incumbent and looking at the subsequent changes in the ideology of the party's candidate pool. This strategy allows for the inclusion of a large number of observations and is thus most precise from a statistical point of view.

Specifically, I estimate equations of the form

$$
\text { Average Dem Cand Ideology } y_{i p, t+1}=\beta_{1} \text { Dem Win } n_{i p t}+\gamma_{i}+\delta_{t}+\epsilon_{i p, t+1}
$$

where $\gamma_{i}$ and $\delta_{t}$ represent district and year fixed effects, respectively. I estimate this equation separately for Democrats and for Republicans (replacing the word "Dem" with "Rep" in each case in equation 4.3). The quantity of interest is $\beta_{1}$, which measures the effect of Democratic (or Republican) incumbency on the ideology of the subsequent candidate pool for the Democrats (or Republicans) in that district in the next election cycle.

To address concerns that the so-called "parallel trends" assumption of the difference-in-differences design is invalid, I also implement a general-election regression discontinuity design (Lee 2008). In this alternate approach I look at the subsequent Democratic candidate pool after "coin-flip" races in which a district just barely receives a Democrat or Republican incumbent.

For the RD, I estimate equations of the form

$$
\text { Average Cand Ideology } y_{i p, t+1}=\beta_{1} \text { Party } \text { Win }_{i p t}+f\left(V_{i p t}\right)+\epsilon_{i p, t+1} \text {, }
$$


Table 4.3 - Effect of Party Incumbency on Ideological Composition of Out-Party Candidate Pool in Next Election Cycle.

\begin{tabular}{lcccc}
\hline \hline & \multicolumn{3}{c}{$\begin{array}{l}\text { Ideology of Candidate Pool, } t+1 \\
\text { Diff-in-diff }\end{array}$} & \multicolumn{2}{c}{ RD } \\
& Dem & Rep & Dem & Rep \\
\hline \multirow{2}{*}{ Party Incumbency } & 0.17 & -0.17 & 0.32 & -0.11 \\
& $(0.03)$ & $(0.03)$ & $(0.03)$ & $(0.02)$ \\
\multirow{2}{*}{ Intercept } & -0.89 & 0.96 & -0.95 & 0.97 \\
\hline $\mathrm{N}$ & 4338 & 4011 & 4338 & 4011 \\
District Fixed Effects & Yes & Yes & No & No \\
Year Fixed Effects & Yes & Yes & No & No \\
RD Specification & - & - & Cubic & Cubic \\
\hline \hline
\end{tabular}

Last two columns include cubic specification of forcing variable (party's vote share winning margin). Robust standard errors in parentheses.

where $f\left(V_{i p t}\right)$ is a flexible function of the new forcing variable, now defined as the party's vote-share winning margin. The idea in this approach is to compare the Democratic (or Republican) candidate pool after a close election where the Democrats (or Republicans) barely secured incumbency to the same candidate pool after a close election where the Republicans (or Democrats) barely secured incumbency. The difference in the ideology of the candidate pool across these two cases represents the causal effect of party incumbency on the candidate pool's ideology.

Table 4.3 presents the results from both approaches. The first two columns show the difference-in-differences results for the two parties, respectively. In the first column we see that Democratic party incumbency causes approximately a 0.17 point increase in the average candidate ideology in the subsequent primary. Since more negative scores mean more liberal, this increase represents a shift in the moderate direction caused by incumbency. Thus when the Democrats lose the 
seat, their subsequent candidate pool becomes more extreme. The second column, for the Republicans, reveals the same pattern. When the Republicans win the seat, the subsequent candidate pool's average ideology decreases by roughly the same 0.17 points, indicating a shift in the moderate direction. Thus when the Republicans lose the seat, and a Democratic incumbent is in office, the subsequent Republican pool becomes more ideologically extreme.

The final two columns show the estimates from the general-election RD. They are quite similar to the difference-in-differences estimates. In both cases, we again see party incumbency causing the party's candidate pool to become more extreme, indicating a "scare off" of moderate challengers.

\section{Effects of Salaries}

To estimate the causal effects of changes in legislator salaries, I use OLS to estimate difference-in-differences equations of the form

$$
\text { Polarization of Candidate Pool } \text { P }_{i t}=\beta \log \text { Salary }_{i t}+\gamma_{i}+\delta_{t}+\epsilon_{i t} \text {, }
$$

where Polarization of Candidate Pool ${ }_{i t}$ is the CFScore-based measure of candidatepool polarization in state $i$ at time $t$, as described in the body of the chapter. The main explanatory variable is simply the logged legislator salary in state $i$ at time $t$, and $\gamma_{i}$ and $\delta_{t}$ stand in for state and year fixed effects, respectively. Because the treatment is fixed at the state level, all standard errors are clustered at the state level. In order to assess the key identifying assumption of parallel trends, I also re-estimate this equation with the addition of state-specific linear time trends. 
Table 4.4 - Higher Salaries Decrease Polarization of Candidate Pool, U.S. State Legislatures, 1990-2012.

\begin{tabular}{lccc}
\hline \hline & Polarization & Polarization & Polarization \\
\hline Log Salary & -0.039 & -0.032 & -0.035 \\
& $(0.019)$ & $(0.017)$ & $(0.015)$ \\
Log Salary, $t+1$ & & & -0.005 \\
& & & $(0.023)$ \\
Log Salary, $t+2$ & & & -0.037 \\
& & & $(0.065)$ \\
$\mathrm{N}$ & 435 & 435 & 334 \\
\hline Year Fixed Effects & Yes & Yes & Yes \\
State Fixed Effects & Yes & Yes & Yes \\
State Trends & No & Yes & No \\
\hline \hline Robur
\end{tabular}

Robust standard errors clustered by state in parentheses.

Table 4.4 presents the results. The first column reflects the vanilla differencein-differences. As the column shows, a 1\% increase in salary appears to produce roughly a -0.04 decrease in the polarization of the candidate pool. This effect is statistically significant and relatively precise.

The next two columns show evidence in favor of the parallel trends assumption. In the second column, we see that the addition of the state-specific linear trends does not markedly alter the coefficient. It is true that it is no longer statistically significant (barely), but the addition of 50 linear trends obviously reduces power substantially. In the third column, I include two leads of the log salary variable. If there is significant pre-trending, then the inclusion of these variables should remove the coefficient on the main quantity of interest; yet, as we see, this coefficient is almost unchanged. Accordingly, the parallel trends assumption 
Table 4.5 - Higher Salaries Decrease Polarization of Legislature.

\begin{tabular}{lccc}
\hline \hline & Polarization & Polarization & Polarization \\
\hline Log Salary & -0.045 & -0.044 & -0.037 \\
& $(0.032)$ & $(0.018)$ & $(0.035)$ \\
Log Salary, $t+1$ & & & 0.078 \\
& & & $(0.067)$ \\
Log Salary, $t+2$ & & & -0.156 \\
& & 374 & $0.124)$ \\
$\mathrm{N}$ & 374 & & 303 \\
\hline Year Fixed Effects & Yes & Yes & Yes \\
State Fixed Effects & Yes & Yes & Yes \\
State Trends & No & Yes & No \\
\hline \hline Robles
\end{tabular}

Robust standard errors clustered by state in parentheses.

seems plausible. Taken together, we see strong evidence that increasing salaries decrease the polarization of the candidate pool.

Table 4.4 re-estimates the exact same regressions, but now with legislative polarization as the outcome variable. Specifically, the NP-Score dataset provides a measure of the estimated distance between the party's medians in each state legislature. I compute the average of this measure across the two chambers within each state, for each year, and I use this as the outcome variable. As I discussed in the body of the chapter, we see a corresponding decrease in legislative polarization when salaries increase. Although the estimated effect is somewhat imprecise in the first column, it does become statistically significant with the addition of state trends. More importantly, though, the coefficient is quite stable across the three columns. As before, the parallel trends assumption appears to be plausible. 


\section{Effects of Information}

To estimate the effects of media information on primary election outcomes, I re-estimate the simple analysis from Hall and Snyder (2014) which investigates the associational relationship between ideology and electoral success in (among other things) primary elections. I interact candidate ideology with district media congruence to see whether information changes the way primary voters nominate candidates. Specifically, I estimate equations of the form

$$
\begin{aligned}
& \text { Prim Vote Share }_{i p j t}=\beta_{0}+\beta_{1} \text { Centrism }_{i p j t} \\
& \quad+\beta_{2} \text { Centrism }_{i p j t} \times \text { Congruence }_{j t}+\beta_{3} \text { Congruence }_{j t}+X_{j t}+\epsilon_{j t},
\end{aligned}
$$

where Prim Vote Share $_{i j t}$ is the vote share to candidate $i$ in party $p$ in district $j$ at time $t$. The variable Centrism Cpjt $_{\text {is }}$ is the estimated ideological distance between the candidate and her most extreme opponent (i.e., the left-most Democrat in a Democratic primary and the right-most Republican in a Republican one). Higher values for this variable thus denote more moderate candidates. Finally, we interact this variable with Congruence $_{j t}$, which measures the media congruence of district $j$ in year $t$.

Table 4.6 presents the results. The quantity of interest is presented in the second row, representing the interaction between centrism and congruence. Congruence is re-scaled to run from 0 , in the least congruent district, to 1 in the most congruent district. In the second and third columns, I add a set of control variables from Hall and Snyder (2014). Specifically, these controls are: a third-order polynomial in the number of donors a candidate receives money from; a third- 
Table 4.6 - District-level Information and Voting for Primary Candidates. More informed districts support less extreme primary candidates.

\begin{tabular}{llll}
\hline \hline & Vote Share & Vote Share & Vote Share \\
\hline Centrism & -0.04 & -0.05 & -0.04 \\
\multirow{3}{*}{ Centrism × Congruence } & $(0.01)$ & $(0.01)$ & $(0.01)$ \\
& 0.05 & 0.06 & 0.06 \\
Congruence & $(0.02)$ & $(0.02)$ & $(0.02)$ \\
& 0.11 & 0.01 & -0.02 \\
Controls & $(0.03)$ & $(0.03)$ & $(0.03)$ \\
Year Fixed Effects & No & Yes & Yes \\
N & No & No & Yes \\
\hline \hline
\end{tabular}

Standard errors clustered by race in parentheses.

order polynomial in the total amount of money a candidate raises; fixed effects for the number of primary candidates in the race; and the full set of controls from Snyder and Stromberg (2010). Across all specifications, we see that, while centrism is negatively associated with primary vote share in the least informed district - as shown in the first row - the advantage to extremism is completely wiped out in the most informed district. 


\section{Chapter 5}

\section{Conclusion: Good Government from Reflection and Choice}

It has been frequently remarked that it seems to have been reserved to the people of this country, by their conduct and example, to decide the important question, whether societies...are really capable or not of establishing good government from reflection and choice, or whether they are forever destined to depend for their political constitutions on accident and force. If there be any truth in the remark, the crisis at which we are arrived may with propriety be regarded as the era in which that decision is to be made; and a wrong election of the part we shall act may, in this view, deserve to be considered as the general misfortune of mankind.

-Alexander Hamilton, Federalist 1

The nature of the workings of government depends ultimately on the men who run it. The men we elect to office and the circumstances we create that affect their work determine the nature of popular government. Let there be emphasis on those we elect to office.

-V.O. Key, American State Politics: An Introduction

Americans have long debated how we can best structure our government. From the very beginning, it was clear that America's governmental design would be somewhat unique in its explicit recognition that individuals were, at best, 
highly imperfect - that because of what Madison called the "defect of better motives," our government would need to be carefully designed to restrain the personal ambitions and motives of those seeking to serve as our representatives. This philosophy has suffused American political thought. The same skepticism we hear about our politicians today - that they are venal, that they are corrupt, that they serve only themselves, that they will say anything, do anything, to get elected and to make money - is only the echo of similar sentiments, put forward with different words, by America's original voters, thinkers, and pundits.

Given this commonly held attitude, it is surprising that so much political philosophy has debated the structure of our government without more seriously considering whether it would attract the right types of people to run for office in the first place. When in one breath most people would vigorously agree with Madison about the defects in individual's motives, in their next they would also claim that we should expect our candidates to stand for office purely because of the virtue of doing so, and not for monetary reward or personal advancement. How can we on the one hand agree that our government should restrain the inevitably self-interested behavior of citizens while on the other holding out hope that our candidates will somehow, magically, not be self-interested themselves? It is a pernicious and long-lasting contradiction in beliefs that has helped create the impossible situation potential candidates find themselves in today. When we create a job that "you'd have to be crazy" to seek out, we should not be surprised when our legislatures go mad.

Few would deny that the job of legislator is a crazy one today. Even casual exposure to the current campaign finance landscape is enough to create this unalterable impression, to say nothing of the other difficulties of being a candidate 
or an incumbent. Yet the political science literature rarely considers how these costs affect who runs for office, or how who runs for office affects the ideology of our legislatures. Strategic models of elections tend to focus on how voters' preferences are translated into government activity, while the literature on who runs for office mostly focuses on issues of candidate identity, like gender and race. These are important topics in their own right. But who runs for office also matters, as I have shown, for how polarized our legislatures become. If we want less polarized legislatures, we must think more carefully about how to induce moderate people to run for office.

This book started with an idea about how we should "hire" our representatives. Employers in many parts of the economy that require high ability, highly educated workers with specific, advanced skills have long understood the need to attract such individuals by offering lucrative, compelling jobs. It's time we applied the same logic to our legislatures. One reason - if not the main reason - that our candidates seem so dissatisfying is that we have presented them with a job opportunity that few good candidates could possibly be interested in pursuing. But instead of revising our beliefs and reforming this job, we have instead misattributed this failing to all candidates, both real and hypothetical, concluding that our politics are fundamentally broken and, perversely, that we should ask more and more of our legislators while offering them less and less for their efforts. No doubt, few could argue that our current representatives in Congress have done anything to earn a pay raise or to be otherwise rewarded. The mistake is to attribute the activities of our current representatives, elected under our current system, having chosen to run for office knowing full well what a bad deal it was, to the potential activities of future representatives who might instead be induced 
to run by different promises and, as a result, who might themselves be superior legislators.

In the chapters that followed, I laid out the case for why we need to think about the question "Who Wants to Run?" In Chapter 1, we saw that, like potential employees, political candidates arrive on the scene with a host of fixed attributes, including a range of ideological views they are unlikely to change. Even though this may sound obvious to observers of politics, it's actually a subtle and contentious point. At the same time most anyone would agree candidates are each unique in their own ways, many people subscribe to the view that candidates will "say whatever they need to" to win election. A long and rich literature in political science takes this view, too, thinking of candidates as adjusting their platforms based on strategic needs. Although I have no doubt that such adjustments can and do occur - and that thinking in this way has been extremely productive for the study of politics - the evidence I have presented in this book suggests that these adjustments are the exception rather than the rule in America's legislative elections. In most cases, candidates seem to offer the same overall ideological platform for their entire careers. Even in salient situations where we might expect them to change, like when they are challenged in a primary, they tend to stick to their ideological guns. Though candidates may tweak their positions on specific issues, their overall ideological portfolio rarely appears to change.

Just as employers are constrained by the applicant pool, because of this ideological rigidity, voters, too, are constrained by who runs for office. When moderate people do not run for office but extremists do, voters are left to make polarized choices. Of course, this dynamic only constrains voters if they really would prefer to elect more moderate candidates. This, too, is a contentious claim. Although 
a significant body of literature suggests more moderate candidates tend to do better in elections, plenty of scholarship disagrees. In Chapter 2, I did two things to attempt to resolve these debates. First, I explained how studies of the links between candidate ideology and electoral success do not always seek to study the same questions. Some are interested in the "causal effect" of candidate positioning, while others want to understand, more simply, whether elections filter out more extreme candidates and favor more moderate ones. Second, I argued that papers use a variety of different methodological assumptions. Putting this all together, I offered comprehensive new evidence, using a variety of different empirical approaches, that suggests that more moderate candidates really do do better, electorally. This does not mean that a candidate could improve her electoral prospects by moving to the middle - it is not causal evidence about candidate positions - but it means that voters do elect moderate candidates when given the opportunity, on average. It is not a far leap to then suggest that if more moderate candidates were to run for office, they, too, might be welcomed by voters.

Turning to descriptive evidence, we have seen how this dynamic plays out, not only in the U.S. House but in a variety of electoral contexts. The people running for office are becoming more ideologically extreme, forcing voters to choose among more and more extreme options. It is not only that the two parties' candidates are on average taking more extreme positions. Even the most moderate choices voters are offered are systematically farther apart than they used to be. This shift has coincided with the sharp rise in legislative polarization. Indeed, it is possible that an important part of the polarization in our legislatures is the result of the polarized choices voters are given at the ballot box. 
Having diagnosed the symptom of this particular problem, in Chapter 3 I turned to a theoretical argument to try to explain why there have been such fundamental shifts in who runs for office. The theory rests on the idea that candidates of differing ideological positions face different ideological costs and benefits from running. More extreme individuals, I argued, are more averse to letting an opponent in the other party win, and thus are more willing to bear the burdens of being a candidate. This makes electoral equilibria more likely to be ones in which two more extreme people face off against each other, rather than ones in which two relatively moderate people compete. When we make it harder and harder to run for office, or when we make holding office less attractive, then this differential willingness looms larger and larger. Thus, the theory predicts that when the net benefits of running for office decrease - that is, when the costs go up or the benefits of office go down - the set of people running for office will be more extreme.

I stress that this theory does not rely on any psychological mechanism, though such a mechanism might well be plausible. The theory does not suppose that more extreme people enjoy running more, or hold their beliefs more strongly. The predictions are derived purely from the fact that, by virtue of their more extreme positions in the spatial model, their likely opponents are farther from them than they are from a potential moderate candidate. This is the key thing. I do not want to rule out the notion that more extreme people might be "true believers" who are more likely to stand for office, but I have no direct evidence for it, and it is not a claim which is necessary for the theory to hold.

Having presented the theory, in Chapter 4 I then turned to evidence that it offers useful intuition about how our actual elections are proceeding. Looking 
at state legislators, I first showed that potential U.S. House candidates really do consider the costs and benefits of running for office - but, as the theory predicts, more moderate state legislators pay more heed to these calculations, while more extreme state legislators are more likely to run in any event. Moreover, reductions in the expected value of holding office also shift who runs for office, deterring more moderate candidates from running. In particular, when one party "randomly" takes control of a Congressional seat, the other party's candidates who seek that seat in the next election become more extreme, on average.

These tests suggested that the main predictions of the theory held some water. The next logical question was to determine whether it really has become harder to run for office - and/or that holding office has become less attractive - to see if the theory's logic could explain why the candidate pool has become more polarized.

First, using both statistical evidence and also descriptive evidence, I showed that running for office has become increasingly difficult over time. Fundraising demands have increased across the board. Candidates are raising more money and doing it from a larger number of donors. These are demands that require significant effort. Indeed, the parties' own internal documents reveal that candidates are expected to spend more than half a full business day - that is, 4 hours - every day, making phone calls to raise money. There are few, if any, people who enjoy doing this. The candidates' own words about fundraising, words like "loathsome" and "embarrassing," provide a clear window into their feelings.

This burden of fundraising is a somewhat different complaint than many other accounts of money in politics, which focus instead on money's corrupting influence. In this work, I remain agnostic about how donors might distort electoral and legislative behavior. Perhaps campaign spending affects elections and, in 
turn, empowers interest groups who can dangle donations in front of candidates; or perhaps not. Either way, it is clear that we are in an equilibrium where candidates feel obligated to expend tremendous effort fundraising. This effort is per se damaging to the political process, even if money does not corrupt politics. As Secretary of State and former Senator John Kerry (D-MA) put it in his farewell remarks to the Senate:

The unending chase for money, I believe, threatens to steal our democracy itself. I used the wording - and I want to be clear about it-I mean by it not the corruption of individuals but corruption of a system itself that all of us are forced to participate in against our will.

The very fact that candidates are forced to do something they find so unpleasant for so much time ensures that the people who run for office will be of a very particular type.

At the same time that fundraising has become more and more difficult, the media's coverage of politics has changed, too. The 24-hour news cycle, cable news, the internet, Facebook, Twitter, and all their relatives have changed the way candidates are covered. A greater and greater share of political coverage seems to consist of inventing offenses and over-interpreting misstatements. Candidates' personal lives, for better or worse, are more and more a scrutinized component of the media's coverage. The result is unambiguous. Candidates and their families find running for office more difficult and more unpleasant than ever before. This is not to pretend that campaigning used to be easy, before the media's evolution. Even Julius Caesar faced brutal attacks and ridicule when he ran for office in Ancient Rome. But it surely seems that the increasing volume and tenor of media 
coverage prevents many people from running for office. Again, these increasing costs will disproportionately deter more moderate candidates.

As these costs of running for office have risen, holding office has simultaneously become less attractive, with fewer opportunities for individual legislators to make their mark. As the parties have strengthened, the committee system and the careerist incentives that it creates have eroded, leaving members as little more than foot-soldiers for party leadership. It is more difficult than ever to make one's individual mark in the legislature. Naturally, it is hard to separate cause from effect, here. There may be a feedback cycle in which polarization changes the shape of the legislature, which in turn makes the set of people who run for office more polarized, which again further strengthens parties in the legislature. But whatever the initial causal arrow, it seems clear that, now, the legislature is not as attractive a place for candidates as it once was. This, in turn, deters more moderate people from running for office.

Separate from the internal workings of the legislature, I also documented how much less our legislators are being paid, in real dollars, than they used to. This is perhaps the most important point of all, because it leads to the most obvious policy corrective. The less we pay legislators, the fewer moderates will run for office, overall.

We have also seen evidence for how we can reverse these trends. Potential candidates, like potential employees, are sensitive to the value of the job opportunity. And right now, job opportunities in our legislatures are less attractive than ever. Indeed, it is hard to convey in writing just how unpleasant, just how ridiculous, we have made the job of legislator today. We expect our legislators to spend more than half their waking hours calling people they've never met to ask 
for money. We expect them to perpetually run for reelection. We expect them to have perfect, flawless pasts and to enjoy sharing the intimate details of these pasts with us, the American people. We expect them to travel between Washington and home on a weekly basis (though of course we also expect them to spend as little money as possible traveling). We expect them to always be perfect, to always have "charisma," to always be smiling, and to never suggest their job is anything other than a treat and an honor to hold. And we expect them, in many cases, to take a large pay cut in order to do all of these things. And then we expect them to thank us for the job! If we can get over this wrongheaded view about how to treat our legislators, we can make a real difference in who runs for office.

\subsection{Ben Franklin's Dated Views on Legislative Salaries}

Paying our legislators more is a controversial idea. As I discussed in Chapter 4, Americans are in almost universal agreement that legislators should be paid less. There is probably no easier way to whip up voter anger than to accuse legislators of trying to augment their salaries. But this opposition is nothing new. In fact, concerns about paying Americans to serve in government are as old as America's government itself.

In one of his more famous speeches, Benjamin Franklin held forth on the "Dangers of a Salaried Bureaucracy." According to Franklin, paying people to serve in government would ensure that only the greedy, those motivated by money rather 
than duty, would become our officials. Moreover, with a prescient eye towards some of the game theoretic issues I have discussed, Franklin feared that making office financially valuable would induce wasteful and destructive competition among office seekers. "Place before the eyes of such men a post of honor, that shall, at the same time, be a place of profit, and they will move heaven and earth to obtain it," as he wrote. At the same time, Franklin was aware of the possibility that not paying government officials might lead to a deficit of willing office seekers. He dismissed this problem, though, declaring: "I think we shall never be without a sufficient number of wise and good men to undertake and execute well and faithfully the office in question." ${ }^{1}$

We should consider Franklin's own position as he made this declaration. Franklin was fabulously wealthy, and he was participating in a nascent government run exclusively by wealthy, white, male individuals - many of them slaveowners - presiding over an electoral system that required individuals to own property in order to vote. So long as government was to be restricted to people of these means, it might well seem logical not to pay them for their time. This quasi-aristocratic view is long outdated. Most people probably agree that we should encourage the best individuals, regardless of financial means, to serve in office. Would Franklin's argument still apply if considering people not already wealthy enough to work a job for no pay?

The evidence I have put forward suggests that Franklin was wrong. Contrary to his claim, there is a shortage of candidates in many U.S. elections, and the fact that we have made the job of legislator so unattractive - in part because it does

\footnotetext{
${ }^{1}$ Franklin's presumption that these individuals would be men is an additional but unrelated flaw in his reasoning.
} 
not pay as well as other jobs for highly trained professionals - is an important cause of this shortage.

Although I do not mean to imply that America's democracy is truly broken, we are in what might be called a candidate trap. In this trap, the benefits candidate receive for holding office and voters' beliefs about the quality of candidates are self-reinforcing. Candidates are highly ideological and dissatisfying to voters; in turn, voters see no reason to pay legislators well, agreeing with Franklin's logic. Because pay is low, only highly ideological and lower quality individuals, who are more willing to take on the costs of office, choose to run; reinforcing voters' views that legislators are bad and do not deserve to be paid well.

The opposite of this trap would be a world in which legislators are popular. Voters feel that they deserve good compensation and allow them to be paid more. As a result, better candidates run for office, producing good legislators and reinforcing voters' views that legislators deserve good pay. The only way to escape the bad trap is to gather the collective will to change the way our legislatures and our campaigns are organized - not to reward our current incumbents, as I have labored to stress over and over again, but instead to stimulate different kinds of candidates to run in the future.

This is not a big vs. small government debate. Creating a job that people will want to seek out does not mean expanding the scope of government or even meaningfully affecting our budget. Whatever we want our legislators to do in Washington, be it grow, shrink, or maintain government, raise or lower taxes, whether we want them to pursue free trade or protectionism, open immigration or closed borders, interventionist or isolationist foreign policy, we should want them to do it effectively and with competence, with the minimal amount of 
waste and the maximal amount of expertise. We simply cannot achieve this goal when we ask people to seek out a job that seems to be designed primarily for ideologues and pathological liars on both sides of the partisan divide.

\subsection{Designing Institutions to Attract Effective Representatives}

Although this book focuses on polarization, its overall argument is broader than just ideology. The idea that we must design our elections and our legislatures to encourage good types to run for office is a general idea. Although polarization may be among the most pressing issues today, there are many other ways in which the costs of running for office may depress the quality of our candidates.

A historical perspective on who runs for office in the U.S. is one way to see this point. In The Federalist Papers, as Publius grapples with the ideal setup for America's fledgling government, attention inevitably turns, if only briefly, to whom should be permitted to seek a seat in the House of Representatives. The concern of Publius is not a positive one - who could be encouraged to seek office-but rather a negative one: whom we should bar from seeking office. He proposes: "A representative of the United States must be of the age of twentyfive years; must have been seven years a citizen of the United States; must, at the time of his election, be an inhabitant of the State he is to represent; and, during the time of his service, must be in no office under the United States." The reasons to limit those who can run for office seem straightforward, especially in the early days of the 13 states. The founders feared that foreign agents, 
monarchs, or others with questionable motives would seek office only to destroy the new government from within; hence the seven-year citizenship requirement and the residence requirement. The age requirement seems to have been driven by a genuine belief that would-be representatives needed a necessary amount of seasoning before they could reliably serve in office. Besides these questions of eligibility, The Federalist Papers offer almost no direct commentary on the need to encourage people to run for office. To my knowledge, the closest the papers come to discussing the possibility that the structure of government might alter the identities of those will to serve comes in Federalist 53, where Publius writes: "The distance which many of the representatives will be obliged to travel, and the arrangements rendered necessary by that circumstance, might be much more serious objections with fit men to this service, if limited to a single year, than if extended to two years."

This was an important oversight which had consequences for the nature of America's early federal legislatures. Indeed, the unattractiveness of the early office of representative quickly became a noticeable issue in the new Republic.

In his masterful study of the budding Congress of the early 19th century, Young (1966) talks at length of how unattractive jobs in the new legislature were. First, and most simply, few desired to be in Washington, a newly manufactured city bereft of the comforts of more established cities, artificially constructed on swampland far from home. As Young (1966: 41) reports, "Almost no one, it seemed, could find anything flattering to say about the capital in the Jeffersonian years." Indeed, "Washington was an ever-present reminder to the men in power of the low esteem in which power was held" (41).

This disinterest extended to the actual job of legislator, too. Young writes: 
Expressions of enthusiasm for what they did at Washington were as rare as expressions of satisfaction with the place. The thanklessness, the indignity, and the meanness of the political vocation are such recurrent themes of comment in the community record, and the drumfire of self-censure was so constant an accompaniment to the work of governing, as to convey the impression of a community war with itself (51).

Pulling quotations from politicians of the time, Young reports that "to be a politician was to lose one's freedom...it was to lose one's privacy, to be made naked to one's enemies." What is worse, "a political career also meant financial ruin" because "Politics was a vocation pursued at the cost of the 'abandonment of our professions or occupations, and the consequent derangement of our private affairs."'

Much like accounts of current politics, the reward for these sacrifices seemed scant. "As compensation for the personal deprivations that were said to go with membership in the Washington community, satisfaction in work done was felt to offer slight returns. What, the rulers asked themselves, were the rewards for 'passing five months of ceaseless occupation and discomfort' in Washington each year?" Whether because the dysfunction of early Congresses reduced their esteem, or whether the members of Congress themselves produced the dysfunction because of their lowly attributes, the prevailing view was that to be a legislator was to fight a hopeless battle. Sterling quotes one member of Congress who declares that "the ear of this House...is sealed against truth and reason" (55).

There can be no doubt these conditions affected who ran for office. It is not possible to obtain data on the ideological positions of those who ran for office in the early U.S, so no large-scale empirical study can be performed - and even so, it is doubtful that ideology would necessarily have been the dominant different 
between those who ran and those who did not, given the somewhat chaotic nature of ideology and the absence of real parties in the first years of the new nation. Nevertheless, the problem of attracting good political candidates, of one form or another, was a pressing concern even from the first days of America's national legislatures.

There are good reasons to think that the fundamental arguments of this book apply to many other democracies, too. Many of these democracies place greater constraints on who can run for office, on who is likely to win office, and on how much influence individuals can have in the legislature. In the U.K., for example, individual legislators play only a small role in the legislature, which is dominated by the parties. Moreover, while legislators are beholden to a specific constituency, parties can move loyal members to safe districts in a manner akin to ranking members highly on a closed list. Yet, despite these party-centric elements, citizens of the U.K. still worry a great deal about the quality of their representatives. Complaining about Parliament's "political class," Nigel Farage, the controversial leader of the UKIP party, declared that "...this country is now run by a bunch of college kids who have never done a proper day's work in their lives" (as quoted in Allen and Cairney 2015). Whether we agree with Farage's specific complaint or not, it is true that British MPs are not representative of the broader public - a fact that has produced consternation not only among UKIP supporters (Allen and Cairney 2015).

At the end of the day, "who wants to run?" is a question we should ask not just in one particular context, like the U.S., and not with regard to only one particular candidate attribute, like ideology. This is a vague but important point. To refine it into specific goals for future research, we must strive to identify 
which characteristics of candidates we care about. Current literature attempts this, but not always with great success. Things like educational background and occupation - commonly used as proxies for non-ideological candidate "quality" may not be especially closely related to actual quality. But they are among the only things we can easily observe about candidates. To extend the question "who wants to run?" beyond ideology, we will first need to think more clearly about what we, as voters, actually want in a candidate. This is no small task, but it is crucial for moving the political science literature, and especially the American politics literature, beyond its almost singular focus on ideology in elections and legislatures.

\subsection{Who Will Run? Our Future Candidates}

Polarization in America's legislatures is one of the dominant political issues of our time. The wide and growing ideological gulf between Democrats and Republicans, present even when the two parties seek to represent the same set of voters, suggests that the political process is not successfully serving our citizens. More pressingly, this ideological gap seems to have slowed down, if not broken, our legislatures. Appropriations bills are no longer passed on time, if at all. Negotiations over previously trivial matters, like raising the debt ceiling, now break down and produce gridlock - even shutting down the government at times. An act as important as replacing a vacancy on the Supreme Court is now beyond the ability of our legislators.

The Constitution carefully meted out powers to the branches of government, ensuring that the legislature, the judiciary, and the executive all had means to 
check one another's power. As a consequence of this shrewd decision, our system of government is only as strong as our weakest link. No matter how badly the president may want to advance policy, he or she can only do so with the cooperation of the legislature. Right now, our legislatures appear to be incapable of meeting even their most basic purposes. The consequences this failure has for the safety, security, and economic well-being of our society are obvious and dire.

I do not claim to offer any simple fix for a problem this large and intractable. But I do hope to have identified one meaningful part of it. We have many problems in our government, today, and no doubt many are the responsibility of the deep changes wrought on society by economic depression, technological change, and the large and growing income inequality among our citizens. But we also have a serious problem with our legislative candidates. The nature of the job we have created for our legislators, and the requirements we have put around obtaining office, mean that almost no one wants to run for office today-and those who are willing to run are, by and large, ideologically extreme. We have not created a job that moderates want to seek out.

This is not just a short-term problem. Children growing up today are the candidates of tomorrow - except that almost no children are even remotely interested in becoming politicians. In their recent book, Lawless and Fox (2015) report that nearly 9 out of 10 high school students surveyed say that they will never run for office. This is no doubt a massive overestimate of how many will actually run, but even so it conveys how unattractive the job is.

The failure to "kindle ambitions for office," in Schlesinger's words, causes many problems. Some, like our political system's inability to encourage people who are not white men to run for office, have been well documented. But po- 
litical science has largely neglected the link between this ambition problem and ideology. When we make political office unattractive, we don't just miss out on opportunities to elect more diverse and more talented representatives, but, as I have shown in this book, the choices we are presented with become more ideologically extreme. If we want more moderates in office, we need to make them a better job offer. 


\section{Bibliography}

Abadie, Alberto, Alexis Diamond, and Jens Hainmueller. 2010. "Synthetic Control Methods for Comparative Case Studies: Estimating the Effect of Californias Tobacco Control Program." Journal of the American Statistical Association 105(490): 493-505.

Abramitzky, Ran. 2011. "Lessons from the Kibbutz on the Equality-Incentives Trade-off." The Journal of Economic Perspectives 25(1): 185-207.

Abramowitz, Alan I. 2011. The Disappearing Center: Engaged Citizens, Polarization, and American Democracy. New Haven, CT: Yale University Press.

Abrams, Samuel J., and Morris P. Fiorina. 2012. "The Big Sort' That Wasn't: A Skeptical Reexamination." PS: Political Science \& Politics 45(2): 203-210.

Achen, Christopher H., and Larry M. Bartels. 2006. It Feels Like We're Thinking: The Rationalizing Voter and Electoral Democracy. In Annual Meeting of the American Political Science Association, Philadelphia.

Ahler, Douglas J., and David E. Broockman. 2016. "Does Elite Polarization Imply Poor Representation? A New Perspective on the "Disconnect" Between Politicians and Voters." Working Paper.

Aldrich, John H., and David W. Rohde. 2001. "The Logic of Conditional Party Government: Revisiting the Electoral Connection." In Congress Reconsidered. 7 ed. CQ Press, pp. 269-92.

Alesina, Alberto. 1988. "Credibility and Policy Convergence in a Two-Party System with Rational Voters." 78(4): 796-805.

Allen, Peter, and Paul Cairney. 2015. "What Do We Mean When We Talk about the 'Political Class'?" Political Studies Review .

Ansolabehere, Stephen, James M. Snyder, Jr., and Charles Stewart, III. 2001. "Candidate Positioning in US House Elections." American Journal of Political Science 45(1): 136-159.

Ansolabehere, Stephen, John M. de Figueiredo, and James M. Snyder. 2003. "Why is There So Little Money in US Politics?" The Journal of Economic Perspectives 17(1): 105-130. 
Ansolabehere, Stephen, John Mark Hansen, Shigeo Hirano, and James M. Snyder Jr. 2010. "More Democracy: The Direct Primary and Competition in US Elections." Studies in American Political Development 24(2): 190-205.

APSA, Committee Report. 1950. "Toward a More Responsible Two-Party System." American Political Science Review 44(3).

Aranson, Peter H., and Peter C. Ordeshook. 1972. "Spatial Strategy for Sequential Elections." In Probability Models of Collective Decision Making, ed. Richard G. Niemi, and Herbert F. Weisberg. Columbus, OH: Charles E. Merrill.

Bafumi, Joseph, and Michael C. Herron. 2010. "Leapfrog Representation and Extremism: A Study of American Voters and Their Members in Congress." American Political Science Review 104(03): 519-542.

Bai, Matt. 2014. All the Truth is Out: The Week Politics Went Tabloid. New York, NY: Alfred A. Knopf.

Barber, James David. 1965. The Lawmakers: Recruitment and Adaptation to Legislative Life. Yale University Press.

Barber, Michael. 2015. "Ideological Donors, Contribution Limits, and the Polarization of American Legislatures." Journal of Politics 78(1): 296-310.

Barber, Michael J., Brandice Canes-Wrone, and Sharece Thrower. N.d. "Sophisticated Donors: Which Candidates Do Individual Contributors Finance?" American Journal of Political Science. Forthcoming.

Bartels, Larry M. 2003. "Democracy with attitudes." Electoral democracy pp. 4882.

Bartels, Larry M. 2009. Unequal Democracy: The Political Economy of the New Gilded Age. Princeton University Press.

Baum, Matthew A. 2002. "Sex, Lies, and War: How Soft News Brings Foreign Policy to the Inattentive Public." American Political Science Review 96(1): 91-109.

Bawn, Kathleen, Knox Brown, Angela Ocampo, Shawn Patterson, John Ray, and John Zaller. 2015. "Social Choice and Coordination Problems in Open House Primaries." Presented at the American Political Science Association Conference, San Francisco, CA, 2016. 
Besley, Timothy, and Stephen Coate. 1997. "An Economic Model of Representative Democracy." The Quarterly Journal of Economics 112(1): 85-114.

Bishop, Bill. 2009. The big sort: Why the Clustering of Like-Minded America is Tearing Us Apart. Houghton Mifflin Harcourt.

Black, Duncan. 1948. "On the Rationale of Group Decision-Making." The Journal of Political Economy 56(1): 23-34.

Black, Gordon S. 1972. "A Theory of Political Ambition: Career Choices and the Role of Structural Incentives." American Political Science Review 66(1): $144-159$.

Boatright, Robert G. 2013. Getting Primaried: The Changing Politics of Congressional Primary Challenges. University of Michigan Press.

Bonica, Adam. 2013. "Ideology and Interests in the Political Marketplace." American Journal of Political Science 57(2): 294-311.

Bonica, Adam. 2014. "Mapping the Ideological Marketplace." American Journal of Political Science 58(2): 367-386.

Brady, David W., Hahrie Han, and Jeremy C. Pope. 2007. "Primary Elections and Candidate Ideology: Out of Step with the Primary Electorate?" Legislative Studies Quarterly 32(1): 79-105.

Brudnick, Ida A. 2014. "Salaries of Members of Congress: Recent Actions and Historical Tables." Congressional Research Service Report 7-5700.

Burden, Barry C. 2001. "The Polarizing Effects of Congressional Primaries." In Congressional Primaries and Political Representation, ed. Peter F. Galderisi, Marni Ezra, and Michael Lyons. Lanham, MD: Rownman \& Littlefield Publishers Inc pp. 95-115.

Burden, Barry C. 2004. "Candidate Positioning in US Congressional Elections." British Journal of Political Science 34(2): 211-227.

Calonico, Sebastian, Mattias D. Cattaneo, and Rocío Titiunik. 2014. "Robust Nonparametric Confidence Intervals for Regression-Discontinuity Designs." Econometrica 82(6): 2295-2326.

Calvert, Randall L. 1985. "Robustness of the Multidimensional Voting Model: Candidate Motivations, Uncertainty, and Convergence." American Journal of Political Science 29(1): 69-95. 
Campbell, Angus, Philip E. Converse, Warren E. Miller, and Donald E. Stokes. 1960. The American Voter. University of Chicago Press.

Canes-Wrone, Brandice, and Kenneth W. Shotts. 2007. "When Do Elections Encourage Ideological Rigidity?" American Political Science Review 101(2): $273-288$.

Canes-Wrone, Brandice, David W. Brady, and John F. Cogan. 2002. "Out of Step, Out of Office: Electoral Accountability and House Members' Voting." American Political Science Review 96(1): 127-140.

Carnes, Nicholas. 2013. White-collar Government: The Hidden Role of Class in Economic Policy Making. University of Chicago Press.

Carson, Jamie L., Michael H. Crespin, Charles J. Finocchiaro, and David W. Rohde. 2007. "Redistricting and Party Polarization in the U.S. House of Representatives." American Politics Research 35(6): 878-904.

Caughey, Devin M., and Jasjeet S. Sekhon. 2011. "Elections and the Regression Discontinuity Design: Lessons from Close US House Races, 1942-2008." Political Analysis 19(4): 385-408.

Clinton, Joshua D., and Ted Enamorado. 2014. "The National News Media's Effect on Congress: How Fox News Affected Representatives in Congress." Journal of Politics 76(4): 928-943.

Coleman, James S. 1971. "Internal Processes Governing Party Positions in Elections." Public Choice 11: 35-60.

Cox, Gary W., and Jonathan N. Katz. 1996. "Why Did the Incumbency Advantage in US House Elections Grow?" American Journal of Political Science 40(2): 478-497.

Cox, Gary W., and Mathew D. McCubbins. 2007. Legislative Leviathan: Party Government in the House. Cambridge University Press.

DeBacker, Jason Matthew. 2015. "Flip-Flopping: Ideological Adjustment Costs in the United States Senate." Economic Inquiry 53(1): 108-128.

Downs, Anthony. 1957. An Economic Theory of Democracy. New York: Harper and Row.

Eggers, Andrew C., and Jens Hainmueller. 2009. "MPs For Sale? Returns to Office in Postwar British Politics." American Political Science Review 103(4): 513. 
Eilperin, Juliet. 2007. Fight Club Politics: How Partisanship is Poisoning the House of Representatives. Rowman \& Littlefield.

Erikson, Robert S. 1971. "The Electoral Impact of Congressional Roll Call Voting." American Political Science Review 65(4): 1018-1032.

Erikson, Robert S., and Gerald C. Wright. 2000. "Representation of Constituency Ideology in Congress." In Continuity and Change in House Elections, ed. David W. Brady, John F. Cogan, and Morris P. Fiorina. Stanford University Press.

Fearon, James D. 1999. "Electoral Accountability and the Control of Politicians: Selecting Good Types versus Sanctioning Poor Performance." In Democracy, Accountability, and Representation, ed. Bernard Mann, Adam Przeworski, and Susan C. Stokes. Cambridge University Press pp. 55-97.

Feigenbaum, James J., and Andrew B. Hall. 2015. "How Legislators Respond to Localized Economic Shocks: Evidence From Chinese Import Competition." Journal of Politics 77(4): 1012-1030.

Fiorina, Morris P. 1994. "Divided Government in the American States: A Byproduct of Legislative Professionalism?." American Political Science Review 88(2): 304-316.

Fiorina, Morris P., and Samuel J. Abrams. 2009. Disconnect: The Breakdown of Representation in American Politics. University of Oklahoma Press.

Fiorina, Morris P., Samuel A. Abrams, and J eremy C. Pope. 2008. "Polarization in the American Public: Misconceptions and Misreadings." The Journal of Politics 70(4): 556-560.

Fiorina, Morris P., Samuel J. Abrams, and Jeremy C. Pope. 2005. Culture War? The Myth of a Polarized America. New York, NY: Pearson Longman.

Fouirnaies, Alexander. 2016. "What Are the Electoral Consequences of Campaign Spending Limits?" Working Paper.

Fouirnaies, Alexander, and Andrew B. Hall. 2014. "The Financial Incumbency Advantage: Causes and Consequences." Journal of Politics 76(3): 711-724.

Fowler, Anthony, and Andrew B. Hall. 2015. "Searching for Convergence." Working Paper.

Fowler, Anthony, and Andrew B. Hall. N.d. "Long Term Consequences of Election Results." British Journal of Political Science. Forthcoming. 
Fowler, Linda L. 1993. Candidates, Congress, and the American Democracy. University of Michigan Press.

Francia, Peter L., and Paul S. Herrnson. 2001. "Begging for Bucks." Campaigns 86 Elections April: 51-52.

Gentkow, Matthew, Jesse M. Shapiro, and Matt Taddy. 2015. "Measuring Polarization in High-Dimensional Data: Method and Application to Congressional Speech." Working Paper.

Gilligan, Thomas W., and Keith Krehbiel. 1987. "Collective Decisionmaking and Standing Committees: An Informational Rationale for Restrictive Amendment Procedures." Journal of Law, Economics and Organization 3(2): 287-335.

Green, D.P., B. Palmquist, and E. Schickler. 2002. Partisan Hearts and Minds: Political Parties and the Social Identities of Voters. Yale University Press.

Grimmer, Justin. 2013. Representational Style in Congress: What Legislators Say and Why It Matters. Cambridge University Press.

Grimmer, Justin, and Eleanor Neff Powell. 2014. "Money in Exile: Campaign Contributions and Committee Access." Working Paper.

Grimmer, Justin, Eitan Hersh, Brian Feinstein, and Daniel Carpenter. 2012. "Are Close Elections Random?" Presented at the 2012 Annual Meeting of the Midwest Political Science Association. http://stanford.edu/ jgrimmer/CEF.pdf.

Hall, Andrew B. 2014. "How the Public Funding of Elections Increases Candidate Polarization." Working Paper.

Hall, Andrew B. 2015. "What Happens When Extremists Win Primaries?" American Political Science Review 109(1): 18-42.

Hall, Andrew B., and James M. Snyder, Jr. 2014. "Candidate Ideology and Electoral Success." Working Paper.

Hall, Andrew B., and James M. Snyder, Jr. N.d. "How Much of the Incumbency Advantage is Due to Scare-off?" Political Science Research and Methods. Forthcoming.

Hall, Andrew B., and Kenneth A. Shepsle. 2014. "The Changing Value of Seniority in the US House: Conditional Party Government Revised." Journal of Politics 76(1): 98-114. 
Healy, Andrew, and Neil Malhotra. 2009. "Myopic Voters and Natural Disaster Policy." American Political Science Review 103(3): 387-406.

Healy, Andrew J, Neil Malhotra, and Cecilia Hyunjung Mo. 2010. "Irrelevant Events Affect Voters' Evaluations of Government Performance." Proceedings of the National Academy of Sciences 107(29): 12804-12809.

Hill, Seth J., and Chris Tausanovitch. 2016. "Southern Realignment, Party Sorting, and the Polarization of American Primary Electorates, 1958-2012." Working Paper.

Hirano, Shigeo, and James M. Snyder, Jr. 2014. "Primary Elections and the Quality of Elected Officials." Quarterly Journal of Political Science 9(4): 473500 .

Hirano, Shigeo, James M. Snyder, Jr., Stephen Ansolabehere, and John Mark Hansen. 2010. "Primary Elections and Partisan Polarization in the US Congress." Quarterly Journal of Political Science 5(2): 169-191.

Hotelling, Harold. 1929. "Stability in Competition." The Economic Journal 39(153): 41-57.

Jacobs, Lawrence R., and Robert Y. Shapiro. 1997. "Debunking the Pandering Politician Myth." Public Perspective 8(3): 3-5.

Jacobson, Gary C. 1989. "Strategic Politicians and the Dynamics of US House Elections, 1946-86." American Political Science Review 83(3): 773-793.

Joesten, Danielle A., and Walter J. Stone. 2014. "Reassessing Proximity Voting: Expertise, Party, and Choice in Congressional Elections." Journal of Politics 76(3): 740-753.

Key, Jr., V.O. 1966. The Responsible Electorate. Harvard University Press.

Krehbiel, Keith. 1990. "Are Congressional Committees Composed of Preference Outliers?" American Political Science Review 84(1): 149-163.

Lawless, Jennifer L., and Richard L. Fox. 2005. It Takes a Candidate: Why Women Don't Run for Office. Cambridge University Press.

Lawless, Jennifer L., and Richard L. Fox. 2015. Running From Office: Why Young Americans are Turned Off to Politics. Oxford University Press.

Lee, David S. 2008. "Randomized Experiments From Non-Random Selection in US House Elections." Journal of Econometrics 142(2): 675-697. 
Lee, David S., Enrico Moretti, and Matthew J. Butler. 2004. "Do Voters Affect or Elect Policies? Evidence from the US House." The Quarterly Journal of Economics 119(3): 807-859.

Levendusky, Matthew. 2009. The Partisan Sort: How Liberals Became Democrats and Conservatives Became Republicans. University of Chicago Press.

Levitt, Steven D., and Catherine D. Wolfram. 1997. "Decomposing the Sources of Incumbency Advantage in the US House." Legislative Studies Quarterly 22(1): 45-60.

Londregan, John, and James M. Snyder, Jr. 1994. "Comparing Committee and Floor Preferences." Legislative Studies Quarterly 19(2): 233-266.

Maestas, Cherie D., Sarah Fulton, L. Sandy Maisel, and Walter J. Stone. 2006. "When to Risk It? Institutions, Ambitions, and the Decision to Run for the U.S. House." American Political Science Review 100(5): 195-208.

Masket, Seth E, Jonathan Winburn, and Gerald C Wright. 2012. "The Gerrymanderers Are Coming! Legislative Redistricting Won't Affect Competition or Polarization Much, No Matter Who Does It." PS: Political Science 85 Politics 45(1): 39-43.

Mayhew, David R. 1974. Congress: The Electoral Connection. Vol. 26 Yale University Press.

McCarty, Nolan, Jonathan Rodden, Boris Shor, Christopher Tausanovitch, and Chris Warshaw. 2015. "Geography, Uncertainty, and Polarization." Working Paper.

McCarty, Nolan, Keith T. Poole, and Howard Rosenthal. 2009. "Does Gerrymandering Cause Polarization?" American Journal of Political Science 53(3): 666-680.

McCarty, Nolan M., Keith T. Poole, and Howard Rosenthal. 2006. Polarized America: The Dance of Ideology and Unequal Riches. MIT Press Cambridge, MA.

McDermott, Monika L. 1997. "Voting Cues in Low-Information Elections: Candidate Gender as a Social Information Variable in Contemporary United States Elections." American Journal of Political Science 41(1): 270-283.

McGhee, Eric, Seth Masket, Boris Shor, Steven Rogers, and Nolan McCarty. 2014. "A Primary Cause of Partisanship? Nomination Systems and Legislator Ideology." American Journal of Political Science 58(2): 337-351. 
Miller, Warren E., and Donald E. Stokes. 1963. "Constituency Influence in Congress." American Political Science Review 57(1): 45-56.

Osborne, Martin J., and Al Slivinski. 1996. "A Model of Political Competition with Citizen-Candidates." The Quarterly Journal of Economics 111(1): 65-96.

Osborne, Martin J., and Ariel Rubinstein. 1994. A Course in Game Theory. MIT press.

Owen, Guillermo, and Bernard Grofman. 2006. "Two-stage Electoral Competition in Two-Party Contests: Persistent Divergence of Party Positions." Social Choice and Welfare 26(3): 547-569.

Palmer, Maxwell, and Benjamin Schneer. 2015. "Capitol Gains: The Returns to Elected Office from Corporate Board Directorships." Working Paper.

Pildes, Richard H. 2011. "Why the Center Does Not Hold: the Causes of Hyperpolarized Democracy in America." California Law Review pp. 273-333.

Poole, Keith T., and Howard Rosenthal. 2000. Congress: A Political-Economic History of Roll Call Voting. Oxford University Press, USA.

Prior, Markus. 2003. "Any Good News in Soft News? The Impact of Soft News Preference on Political Knowledge." Political Communication 20(2): 149-171.

Rohde, David W. 1991. Parties and Leaders in the Post-Reform House. University of Chicago Press.

Sabato, Larry J. 1991. Feeding Frenzy: How Attack Journalism Has Transformed American Politics. New York: Free Press.

Schlesinger, Joseph A. 1966. Ambition and Politics: Political Careers in the United States. Rand McNally.

Shepsle, Kenneth A. 1978. The Giant Jigsaw Puzzle: Democratic Committee Assignments in the Modern House. University of Chicago Press.

Shor, Boris, and Nolan McCarty. 2011. "The Ideological Mapping of American Legislatures." American Political Science Review 105(3): 530-51.

Snyder, Jason. 2005. "Detecting Manipulation in US House Elections." Unpublished Manuscript, University of California, Los Angeles. http://citeseerx.ist.psu.edu/viewdoc/download?doi=10.1.1.335. $6505 \& r e p=r e p 1 \&$ type $=p d f$. 
Snyder, Jr., James M. 1992. "Long-term Investing in Politicians; or, Give Early, Give Often." Journal of Law 83 Economics 35(1): 15-43.

Snyder, Jr., James M., and David Stromberg. 2010. "Press Coverage and Political Accountability." Journal of Political Economy 118(2): 355-408.

Stone, Walter J., and Elizabeth N. Simas. 2010. "Candidate Valence and Ideological Positions in U.S. House Elections." American Journal of Political Science 54(2): 371-388.

Sulkin, Tracy. 2005. Issue Politics in Congress. Cambridge University Press.

Sutter, Daniel. 2006. "Media scrutiny and the quality of public officials." Public Choice 129(1-2): 25-40.

Tausanovitch, Chris, and Christopher Warshaw. 2015. "Does the Spatial Proximity Between Legislators and Voters Affect Voting Decisions in U.S. House Elections?" Working Paper.

Theriault, Sean M. 2008. Party Polarization in Congress. Cambridge University Press.

Thomsen, Danielle M. 2014. "Ideological Moderates Won't Run: How Party Fit Matters for Partisan Polarization in Congress." The Journal of Politics 76(7): 786-797.

Thomsen, Danielle M. 2016. Opting Out of Congress: Partisan Polarization and the Decline of Moderate Candidates. Cambridge University Press.

Thomsen, Danielle M. N.d. "Why So Few (Republican) Women? Explaining the Partisan Imbalance of Women in the US Congress." Legislative Studies Quarterly. Forthcoming.

Tomz, Michael, and Robert P. Van Houweling. 2015. "Candidate Repositioning." Unpublished Manuscript.

Voorheis, John, Nolan McCarty, and Boris Shor. 2015. "Unequal Incomes, Ideology and Gridlock: How Rising Inequality Increases Political Polarization." Working Paper.

Welch, Susan. 1985. "Are Women More Liberal than Men in the U. S. Congress?" Legislative Studies Quarterly 10(1): 125-134.

Wittman, Donald. 1977. "Candidates with Policy Preferences: A Dynamic Model." Journal of Economic Theory 14(1): 180-189. 
Wittman, Donald. 1983. "Candidate Motivation: A Synthesis of Alternative Theories." American Political Science Review 77(1): 142-157.

Young, James Sterling. 1966. The Washington Community, 1800-1828. Columbia University Press. 